\title{
Bipolar versus monopolar transurethral resection of the prostate for lower urinary tract symptoms secondary to benign prostatic obstruction (Review)
}

Alexander CE, Scullion MMF, Omar MI, Yuan Y, Mamoulakis C, N'Dow JMO, Chen C, Lam TBL

Alexander CE, Scullion MMF, Omar MI, Yuan Y, Mamoulakis C, N'Dow JMO, Chen C, Lam TBL.

Bipolar versus monopolar transurethral resection of the prostate for lower urinary tract symptoms secondary to benign prostatic obstruction.

Cochrane Database of Systematic Reviews 2019, Issue 12. Art. No.: CD009629.

DOI: 10.1002/14651858.CD009629.pub4. 
TABLE OF CONTENTS

HEADER 1

ABSTRACT

PLAIN LANGUAGE SUMMARY ....

SUMMARY OF FINDINGS

BACKGROUND

OBJECTIVES

METHODS

RESULTS

Figure 1.

Figure 2.

Figure 3.

Figure 4.

Figure 5.

Figure 6.

Figure 7.

DISCUSSION

AUTHORS' CONCLUSIONS

ACKNOWLEDGEMENTS

REFERENCES

CHARACTERISTICS OF STUDIES

DATA AND ANALYSES

Analysis 1.1. Comparison 1 BTURP versus MTURP, Outcome 1 Urological symptoms (IPSS at 12 months).

Analysis 1.2. Comparison 1 BTURP versus MTURP, Outcome 2 Bother (HRQoL at 12 months).

Analysis 1.3. Comparison 1 BTURP versus MTURP, Outcome 3 TUR syndrome.

Analysis 1.4. Comparison 1 BTURP versus MTURP, Outcome 4 Urinary incontinence at 12 months.

Analysis 1.5. Comparison 1 BTURP versus MTURP, Outcome 5 Blood transfusion.

Analysis 1.6. Comparison 1 BTURP versus MTURP, Outcome 6 Re-TURP.

Analysis 1.7. Comparison 1 BTURP versus MTURP, Outcome 7 Erectile function (IIEF-5 score at 12 months). 
[Intervention Review]

\section{Bipolar versus monopolar transurethral resection of the prostate for lower urinary tract symptoms secondary to benign prostatic obstruction}

Cameron Edwin Alexander1, Malo MF Scullion¹, Muhammad Imran Omar 1,2, Yuhong Yuan ${ }^{3}$, Charalampos Mamoulakis4, James MO N'Dow 5 , Changhao Chen 6 , Thomas BL Lam¹

${ }^{1}$ Academic Urology Unit, University of Aberdeen, Aberdeen, UK. ${ }^{2}$ European Association of Urology, Arnhem, Netherlands. ${ }^{3}$ Department of Medicine, Division of Gastroenterology, McMaster University, Hamilton, Canada. ${ }^{4}$ Department of Urology, University General Hospital of Heraklion, University of Crete Medical School, Heraklion, Crete, Greece. 5Urology Department, NHS Grampian, Aberdeen Royal Infirmary, Aberdeen, UK. ${ }^{6}$ Department of Urology, Sun Yat-Sen Memorial Hospital, Sun Yat-Sen University, Guangzhou, China

Contact address: Thomas BL Lam, Academic Urology Unit, University of Aberdeen, 2nd Floor, Health Sciences Building, Foresterhill, Aberdeen, AB25 2ZD, UK. thomasbllam@abdn.ac.uk.

Editorial group: Cochrane Urology Group

Publication status and date: New, published in Issue 12, 2019.

Citation: Alexander CE, Scullion MMF, Omar MI, Yuan Y, Mamoulakis C, N'Dow JMO, Chen C, Lam TBL. Bipolar versus monopolar transurethral resection of the prostate for lower urinary tract symptoms secondary to benign prostatic obstruction. Cochrane Database of Systematic Reviews 2019, Issue 12. Art. No.: CD009629. DOI: 10.1002/14651858.CD009629.pub4.

Copyright @ 2019 The Cochrane Collaboration. Published by John Wiley \& Sons, Ltd.

\section{A B S T R A C T}

\section{Background}

Transurethral resection of the prostate (TURP) is a well-established surgical method for treatment of men with lower urinary tract symptoms (LUTS) secondary to benign prostatic obstruction (BPO). This has traditionally been provided as monopolar TURP (MTURP), but morbidity associated with MTURP has led to the introduction of other surgical techniques. In bipolar TURP (BTURP), energy is confined between electrodes at the site of the resectoscope, allowing the use of physiological irrigation medium. There remains uncertainty regarding differences between these surgical methods in terms of patient outcomes.

\section{Objectives}

To compare the effects of bipolar and monopolar TURP.

\section{Search methods}

A comprehensive systematic electronic literature search was carried out up to 19 March 2019 via CENTRAL, MEDLINE, Embase, ClinicalTrials.gov, PubMed, and WHO ICTRP. Handsearching of abstract proceedings of major urological conferences and of reference lists of included trials, systematic reviews, and health technology assessment reports was undertaken to identify other potentially eligible studies. No language restrictions were applied.

\section{Selection criteria}

Randomised controlled trials (RCTs) that compared monopolar and bipolar TURP in men (> 18 years) for management of LUTS secondary to BPO.

\section{Data collection and analysis}

Two independent review authors screened the literature, extracted data, and assessed eligible RCTs for risk of bias. Statistical analyses were undertaken according to the statistical guidelines presented in the Cochrane Handbook for Systematic Reviews of Interventions. The quality of evidence (QoE) was rated according to the GRADE approach. 


\section{Main results}

A total of 59 RCTs with 8924 participants were included. The mean age of included participants ranged from 59.0 to 74.1 years. Mean prostate volume ranged from $39 \mathrm{~mL}$ to $82.6 \mathrm{~mL}$.

\section{Primary outcomes}

BTURP probably results in little to no difference in urological symptoms, as measured by the International Prostate Symptom Score (IPSS) at 12 months on a scale of 0 to 35 , with higher scores reflecting worse symptoms (mean difference (MD) $-0.24,95 \%$ confidence interval (CI) -0.39 to -0.09 ; participants $=2531 ; \mathrm{RCTs}=16 ; \mathrm{I}^{2}=0 \%$; moderate certainty of evidence (CoE), downgraded for study limitations), compared to MTURP.

BTURP probably results in little to no difference in bother, as measured by health-related quality of life (HRQoL) Score at 12 months on a scale of 0 to 6 , with higher scores reflecting greater bother (MD $-0.12,95 \% \mathrm{Cl}-0.25$ to 0.02 ; participants $=2004 ; \mathrm{RCTs}=11 ; I^{2}=53 \% ;$ moderate CoE, downgraded for study limitations), compared to MTURP.

BTURP probably reduces transurethral resection (TUR) syndrome events slightly (risk ratio (RR) $0.17,95 \% \mathrm{Cl} 0.09$ to 0.30 ; participants $=6745 ; \mathrm{RCTs}=44 ; \mathrm{I}^{2}=0 \%$; moderate CoE, downgraded for study limitations), compared to MTURP. This corresponds to 20 fewer TUR syndrome events per 1000 participants ( $95 \% \mathrm{Cl} 22$ fewer to 17 fewer).

\section{Secondary outcomes}

BTURP may carry a similar risk of urinary incontinence at 12 months (RR $0.20,95 \% \mathrm{Cl} 0.01$ to $4.06 ;$ participants $=751 ; \mathrm{RCTs}=4 ; \mathrm{I}^{2}=0 \%$; low CoE, downgraded for study limitations and imprecision), compared to MTURP. This corresponds to four fewer events of urinary incontinence per 1000 participants (95\% Cl five fewer to 16 more).

BTURP probably slightly reduces blood transfusions (RR 0.42, $95 \% \mathrm{Cl} 0.30$ to 0.59 ; participants $=5727 ; \mathrm{RCTs}=38 ; \mathrm{I}^{2}=0 \%$; moderate CoE, downgraded for study limitations), compared to MTURP. This corresponds to 28 fewer events of blood transfusion per 1000 participants (95\% $\mathrm{Cl} 34$ fewer to 20 fewer).

BTURP may result in similar rates of re-TURP (RR 1.02, 95\% Cl 0.44 to 2.40; participants $=652$; RCTs $=6 ; I^{2}=0 \%$; low CoE, downgraded for study limitations and imprecision). This corresponds to one more re-TURP per 1000 participants ( $95 \% \mathrm{Cl} 19$ fewer to 48 more).

Erectile function as measured by the International Index of Erectile Function score (IIEF-5) at 12 months on a scale from 5 to 25 , with higher scores reflecting better erectile function, appears to be similar ( $M D 0.88,95 \% \mathrm{Cl}-0.56$ to $2.32 ; \mathrm{RCTs}=3 ; \mathrm{I}^{2}=68 \%$; moderate CoE, downgraded for study limitations) for the two approaches.

\section{Authors' conclusions}

BTURP and MTURP probably improve urological symptoms, both to a similar degree. BTURP probably reduces both TUR syndrome and postoperative blood transfusion slightly compared to MTURP. The impact of both procedures on erectile function is probably similar. The moderate certainty of evidence available for the primary outcomes of this review suggests that there is no need for further RCTs comparing BTURP and MTURP.

\section{PLAIN LANGUAGE SUMMARY}

\section{Bipolar versus monopolar transurethral resection of the prostate for lower urinary tract symptoms secondary to benign prostatic obstruction}

\section{Review question}

How does surgery using bipolar technology compare with traditional monopolar technology for men with an enlarged prostate causing difficulty with urination?

\section{Background}

People with an enlarged prostate can experience difficulty passing urine. This occurs because the enlarged prostate compresses the urinary tube from which urine leaves the bladder. One option for treatment of this condition is telescopic surgery, which acts to remove prostate tissue and relieve the blockage. This is traditionally performed using a technology called monopolar TURP (short for 'transurethral resection of the prostate'). In recent times, a technique called bipolar TURP has been developed. This approach uses saline instead of other watery fluids and may put men at lower risk for a problem called TUR syndrome, which is a rare but potentially serious complication caused by fluid absorption, but it is unclear how the two procedures compare overall.

\section{How up-to-date is this review?}

The studies included in this review are those that were available via an electronic database search conducted on 19 March 2019.

Bipolar versus monopolar transurethral resection of the prostate for lower urinary tract symptoms secondary to benign prostatic 


\section{Study characteristics}

We searched the medical literature for clinical trials up to 19 March 2019. We found 59 randomised trials that compared BTURP with MTURP. These studies included a total of 8924 patients. The longest period of follow-up for the outcomes of interest was 12 months after treatment.

\section{Key results}

Compared to MTURP, BTURP probably results in similar reduction in urinary symptoms and bother.

It probably slightly reduces both the risk of TUR syndrome and the need for blood transfusion.

Erectile function is probably similar after both procedures, as is the risk of urinary incontinence and the need for a repeat procedure.

\section{Quality of evidence}

The quality of evidence for the outcomes of ability to pass urine, patient bother, TUR syndrome, need for blood transfusion, and erectile function was considered to be moderate. The quality of evidence for the outcomes of urinary leakage after the procedure and need for a repeat procedure was low. 


\section{SUMMARY OF FINDINGS}

Summary of findings for the main comparison. BTURP compared to MTURP for lower urinary tract symptoms secondary to benign prostatic obstruction

\section{BTURP compared to MTURP for lower urinary tract symptoms secondary to benign prostatic obstruction}

Patient or population: men with lower urinary tract symptoms secondary to benign prostatic obstruction

Setting: hospital

Intervention: BTURP

Comparison: MTURP

\begin{tabular}{|c|c|c|c|c|c|}
\hline \multirow[t]{2}{*}{ Outcomes } & \multirow{2}{*}{$\begin{array}{l}\text { № of partici- } \\
\text { pants } \\
\text { (studies) } \\
\text { Follow-up }\end{array}$} & \multirow{2}{*}{$\begin{array}{l}\text { Certainty of } \\
\text { the evidence } \\
\text { (GRADE) }\end{array}$} & \multirow{2}{*}{$\begin{array}{l}\text { Relative ef- } \\
\text { fect } \\
(95 \% \mathrm{Cl})\end{array}$} & \multicolumn{2}{|l|}{ Anticipated absolute effects ${ }^{\star}(95 \% \mathrm{Cl})$} \\
\hline & & & & Risk with MTURP & Risk difference with BTURP \\
\hline $\begin{array}{l}\text { Urological symptoms } \\
\text { (IPSSa at } 12 \text { month- } \\
\mathrm{s}^{a} \text { ) }\end{array}$ & $\begin{array}{l}2531 \\
\text { (16 RCTs) }\end{array}$ & $\begin{array}{l}\oplus \oplus \oplus \ominus \\
\text { MODERATE } b\end{array}$ & - & $\begin{array}{l}\text { Mean urological symptoms (IPSS at } 12 \text { months) } \\
\text { was } 6.4 \\
\text { Weighted mean }=6.4\end{array}$ & $\begin{array}{l}\text { MD } 0.24 \text { lower } \\
\text { ( } 0.39 \text { lower to } 0.09 \text { lower) }\end{array}$ \\
\hline $\begin{array}{l}\text { Bother (HRQoL } C \text { at } 12 \\
\text { months) }\end{array}$ & $\begin{array}{l}2004 \\
\text { (11 RCTs) }\end{array}$ & $\begin{array}{l}\oplus \oplus \oplus \ominus \\
\text { MODERATE } b\end{array}$ & - & $\begin{array}{l}\text { Mean bother (HRQoL at } 12 \text { months) was } 1.7 \\
\text { Weighted mean }=1.7\end{array}$ & $\begin{array}{l}\text { MD } 0.12 \text { lower } \\
\text { ( } 0.25 \text { lower to } 0.02 \text { higher) }\end{array}$ \\
\hline \multirow[t]{2}{*}{ TUR syndrome } & \multirow{2}{*}{$\begin{array}{l}6745 \\
(44 \mathrm{RCTs})\end{array}$} & \multirow{2}{*}{$\begin{array}{l}\oplus \oplus \oplus \odot \\
\text { MODERATE } b\end{array}$} & \multirow{2}{*}{$\begin{array}{l}\text { RR } 0.17 \\
(0.09 \text { to } 0.30)\end{array}$} & Study population & \\
\hline & & & & $\begin{array}{l}24 \text { per } 1000 \\
\text { Weighed mean number of events }=1.8\end{array}$ & $\begin{array}{l}20 \text { fewer per } 1000 \\
\text { (22 fewer to } 17 \text { fewer) }\end{array}$ \\
\hline $\begin{array}{l}\text { Urinary incontinence } \\
\text { at } 12 \text { months }\end{array}$ & $\begin{array}{l}751 \\
\text { (4 RCTs) }\end{array}$ & $\begin{array}{l}\oplus \oplus \odot \ominus \\
\mathrm{LOWb}, \mathrm{d}\end{array}$ & $\begin{array}{l}\text { RR } 0.20 \\
(0.01 \text { to } 4.06)\end{array}$ & $\begin{array}{l}5 \text { per } 1000 \\
\text { Weighted mean number of events }=0.5\end{array}$ & $\begin{array}{l}4 \text { fewer per } 1000 \\
\text { ( } 5 \text { fewer to } 16 \text { more) }\end{array}$ \\
\hline \multirow[t]{2}{*}{ Blood transfusion } & \multirow{2}{*}{$\begin{array}{l}5727 \\
\text { (38 RCTs) }\end{array}$} & \multirow{2}{*}{$\begin{array}{l}\oplus \oplus \oplus \ominus \\
\text { MODERATE } b\end{array}$} & \multirow{2}{*}{$\begin{array}{l}\text { RR } 0.42 \\
\text { ( } 0.30 \text { to } 0.59)\end{array}$} & Study population & \\
\hline & & & & $\begin{array}{l}48 \text { per } 1000 \\
\text { Weighted mean number of events }=3.7\end{array}$ & $\begin{array}{l}28 \text { fewer per } 1000 \\
\text { (34 fewer to } 20 \text { fewer) }\end{array}$ \\
\hline Re-TURP & 652 & $\oplus \oplus \Theta \odot$ & RR 1.02 & Study population & \\
\hline
\end{tabular}




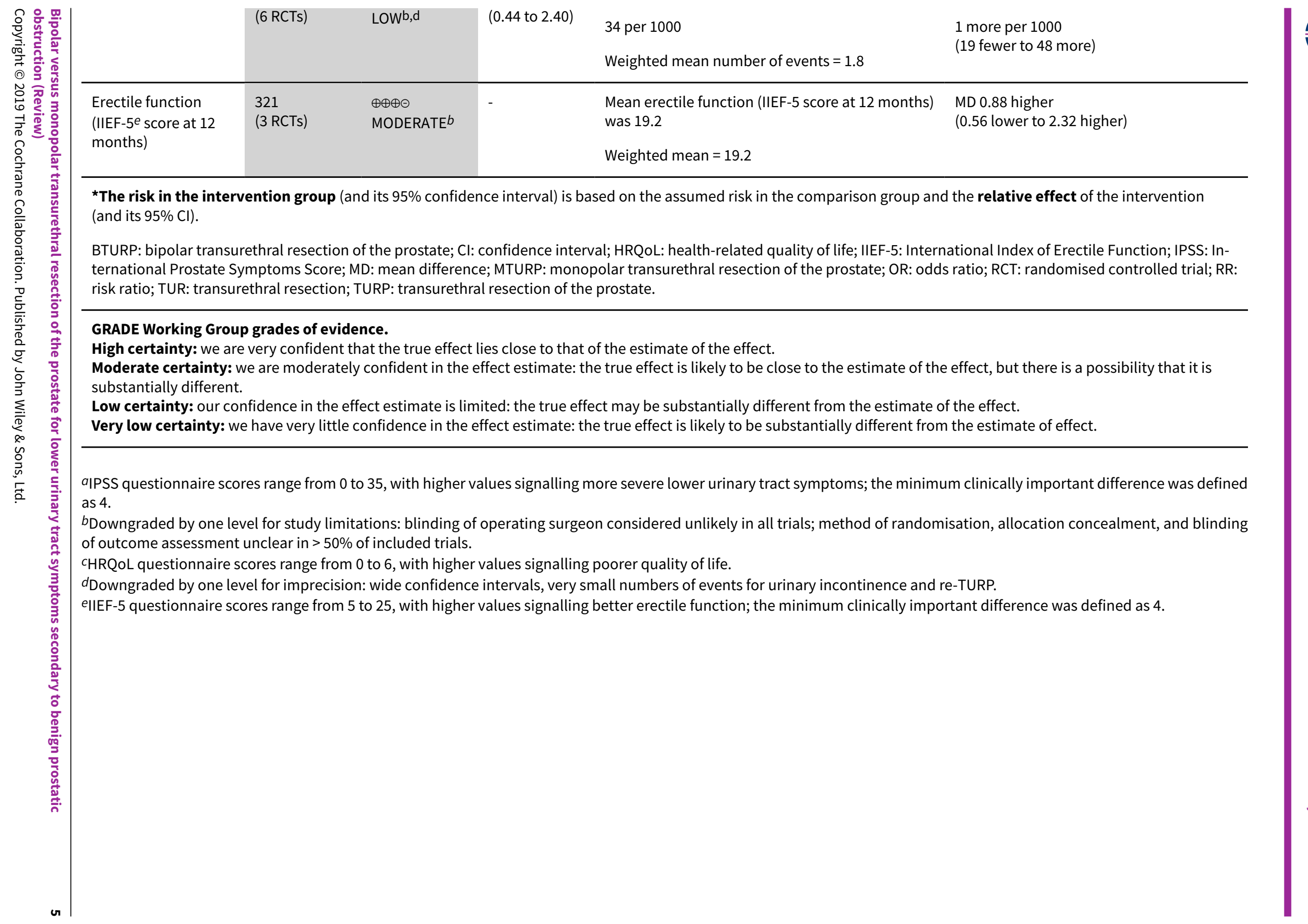




\section{B A C K G R O U N D}

\section{Description of the condition}

Benign prostatic hyperplasia (BPH) is a non-malignant condition that is histologically characterised by the cellular proliferation of stromal and epithelial tissues of the prostate (Isaacs 1989). The increase in size of the prostate, which occurs secondary to BPH, is described as benign prostatic enlargement (BPE) and can cause bladder outlet obstruction (BOO) due to compression of the urethra (Abrams 2002). BPE may be diagnosed as the cause for BOO following complete patient medical history, use of self-completed validated symptom questionnaires and bladder diaries, assessment of postvoid residual urine volume, uroflowmetry, digital rectal examination, or pressure flow studies (Abrams 2009; EAU 2018). BOO due to BPE is also described as benign prostatic obstruction (BPO) and is the most common cause of lower urinary tract symptoms (LUTS) in men (CG97 LUTS: NICE guideline, 2010).

\section{LUTS include:}

- urinary storage symptoms (frequency, nocturia, urgency, incontinence);

- voiding symptoms (weak or intermittent urinary stream, splitting or spraying, hesitancy, straining); and

- postmicturition symptoms (sensation of incomplete emptying, dribbling) (Abrams 2002).

The prevalence and severity of LUTS increase with age. In the Multinational Survey of the Aging Male (MSAM-7), in which 12,815 men in Europe aged 50 to 80 years were surveyed, $31 \%$ reported moderate to severe LUTS, and the prevalence of moderate to severe LUTS increased from $22 \%$ to $45 \%$ when men aged 50 to 59 years were compared with those 70 to 80 years of age, respectively (Rosen 2003; Speakman 2015). LUTS due to BPO have a significant negative impact on men's quality of life (QoL) and daily activities (Agarwal 2014; Kupelian 2006), and their high prevalence means that medical and surgical management carries major economic implications for healthcare providers. The TRIUMPH study (Trans European Research into the Use of Management Policies for LUTS suggestive of BPH in Primary Health Care) reported a mean annual cost of $€ 858$ per patient in 2003 among 5057 European men treated for LUTS due to BPH (van Exel 2006).

\section{Description of the intervention}

For most patients presenting with LUTS secondary to BPO, a trial of medical management with drug therapy is indicated (Lepor 1993). However, use of a surgical intervention may be indicated when the patient wants to avoid taking daily medication, when medical therapy fails to sufficiently alleviate bothersome LUTS, and in certain conditions for which a more aggressive approach than medical therapy is required, including acute/chronic renal insufficien$c y$, refractory urinary retention, recurrent urinary tract infections (UTIs), bladder stones, and gross haematuria believed to occur secondary to BPH (AUA 2018; Mebust 1989). Surgery for BPH represents the 10th most common operation performed across the National Health Service (Kirby 2010).

Transurethral resection of the prostate (TURP) via a monopolar electrosurgery unit (ESU), also known as monopolar TURP (MTURP), is a well-established surgical management option for BPO and is widely considered to be the "gold standard" because of its well-documented favourable long-term outcomes (Reich 2006). The European Association of Urology (EAU) Guidelines state that TURP is the current standard surgical procedure for men with prostate sizes of 30 to $80 \mathrm{~mL}$ and bothersome to severe LUTS secondary to BPO (EAU 2018).

MTURP employs a single active electrode (the loop) at the site of surgery, which transmits energy into the prostatic tissue through the patient's body to the return electrode pad on the skin surface. This circuit requires using a non-conductive hypo-osmolar irrigation medium, such as mannitol, sorbitol, or glycine solution. Excessive absorption of such irrigation fluid into the systemic circulation through the prostatic venous sinuses and the peri-prostatic tissues may rarely lead to life-threatening dilutional hyponatraemia, known as transurethral resection (TUR) syndrome, which is associated with longer resection times and larger prostates (Acuña Lopez 2010; Hahn 1993; Reich 2008).

The distance between electrodes and the need for electrical current to pass through body tissue as seen with MTURP also require use of higher voltages. MTURP therefore occurs at higher temperatures, leading to thermal damage of surrounding tissues and associated complications, including bleeding and clot retention, erectile dysfunction, urinary incontinence, urethral stricture, and bladder neck contracture (Issa 2008). Although MTURP carries a low risk of mortality $(0.1 \%)$, such complications mean that it continues to be associated with a high level of patient morbidity (11.1\%) (Reich 2008). In light of this, researchers have sought to develop a surgical intervention that can offer effective management of BPO with reduced risk of complications. This has involved incorporation of bipolar technology or bipolar transurethral resection of the prostate (BTURP), which represents a technical modification of standard MTURP.

\section{How the intervention might work}

In contrast to MTURP, the bipolar circuit is completed locally with energy confined between an active electrode (resection loop) and a return electrode situated on the resectoscope tip ("true" bipolar), or the sheath ("quasi" systems) (De Sio 2006).

Commercially available bipolar systems were first introduced and assessed in the early 2000 s and include:

- Gyrus Plasmakinetic (ACMI, Southborough, MA, USA) (Symons 2002);

- Vista Coblation/Controlled Tissue Resection (CTR) system (ACMI) (Singh 2005; Wendt-Nordhal 2004);

- AUTOCON II 400 ESU (Karl Storz Endoscope, Tuttlingen, Germany); and

- TURis (Olympus, Tokyo, Japan) (Abascal Junquera 2006; Komura 2015).

During BTURP, energy is transmitted from the active electrode to the surrounding conductive solution. This results in water evaporation, which creates an interface gas layer surrounding the loop that poses resistance to the energy flow. By adding voltage to the gas layer, a highly energised state of matter (the plasma) is formed around the electrode. Whilst this requires high current initially, maintenance of the plasma requires minimal energy, allowing tissue resection to be performed with a lower voltage. Coagulation is achieved by the dissipation of energy as heat within vessel walls, which creates sealing coagulum from blood and tissue and collagen shrinkage (Issa 2008). 
The bipolar circuit allows for use of a conductive and physiological irrigation medium, such as normal saline, and because less tissue resistance is encountered, lower voltages are required (Issa 2008). This has the theoretical advantages of removing the risk of TUR syndrome and allowing TURP to be performed at lower temperatures with reduced thermal damage to surrounding tissues. True bipolar systems, in particular, have the theoretical advantage of negating the passage of electrical current through the urethra and peri-prostatic tissue (Faul 2008; Mamoulakis 2013). The subsequent potential for BTURP to reduce the risk of adverse events, such as bleeding, erectile dysfunction, and urinary incontinence, has been assessed in a large number of randomised controlled trials (RCTs) (Mamoulakis 2009; Omar 2014).

\section{Why it is important to do this review}

In spite of the accumulation of evidence comparing MTURP and BTURP over the last decade, there has been ongoing uncertainty regarding the differences between these two surgical methods in terms of patient outcomes. The most recently undertaken systematic reviews and meta-analyses that have examined this question concluded that although BTURP may be associated with fewer adverse events, including TUR syndrome, clot retention, and blood transfusion, further RCTs are required in light of the methodological limitations and limited follow-up of existing RCTs (Cornu 2015; Mamoulakis 2009; Omar 2014). Current American Urological Association (AUA) guidelines state that clinicians may use a monopolar or bipolar approach to TURP, depending on their expertise with these techniques, and EAU guidelines state that BTURP achieves similar short-, mid-, and long-term results comparable with MTURP, but that BTURP has a more favourable perioperative profile (AUA 2018; EAU 2018).

It was important to undertake this review in light of the significant increase in available evidence examining this research question since the most recently published reviews (Cornu 2015; Mamoulakis 2013; Omar 2014). Previous reviews have not consistently adhered to the methodological standards of Cochrane, including publication of a review protocol, implementation of rigorous search strategy, application of GRADE, and use of patient-focused outcomes.

\section{O B J E C T IVES}

To compare the effects of bipolar and monopolar TURP.

\section{METHODS}

\section{Criteria for considering studies for this review}

\section{Types of studies}

We included only randomised controlled trials (RCTs) because of their ability to provide the most reliable evidence.

\section{Types of participants}

Participants (> 18 years) with lower urinary tract symptoms (LUTS) secondary to benign prostatic obstruction (BPO).

BPO will be defined as bladder outlet obstruction secondary to benign prostatic enlargement (BPE).

\section{Types of interventions}

We investigated the following comparison of intervention versus comparator.

\section{Intervention}

The intervention was bipolar transurethral resection of the prostate (BTURP).

\section{Comparator}

The comparator was monopolar transurethral resection of the prostate (MTURP).

If a trial included multiple arms, we included in the review any arms that met the inclusion criteria.

\section{Minimum duration of intervention and follow-up}

As our review considered single surgical interventions, the minimum duration of the intervention was not applicable in our review. We did not exclude RCTs based on duration of follow-up.

\section{Types of outcome measures}

We did not exclude trials because one or several of our primary or secondary outcome measures were not reported in the publication. When none of our primary or secondary outcomes were reported, we did not include this trial but provided some basic information in an additional table.

\section{Primary outcomes}

- Urological symptoms as measured by the International Prostate Symptom Score (IPSS) questionnaire score at 12 months

- Bother as measured by a health-related quality of life (HRQoL) questionnaire score at 12 months

- Transurethral resection (TUR) syndrome

\section{Secondary outcomes}

- Urinary incontinence at 12 months

- Postoperative blood transfusion

- Incidence of second transurethral resection of the prostate (TURP) (i.e. re-do TURP)

- Erectile function as measured by the International Index of Erectile Function (IIEF-5) questionnaire score at 12 months

Method and timing of outcome measurement

- Urological symptoms were measured by the International Prostate Symptom Score (IPSS) questionnaire at 12 months postoperatively

- Bother was measured by a validated health-related quality of life (HRQoL) questionnaire at 12 months, as defined by the trialists

- Adverse events such as TUR syndrome, blood transfusion, and the need for re-TURP were measured at any time postoperatively

- Urinary incontinence was measured at 12 months, with the definition of urinary incontinence considered to be that used by the trialists 


\section{Search methods for identification of studies}

\section{Electronic searches}

We searched the following sources from inception of each database to the specified date and placed no restrictions on the language of publication nor on the status of the publication. The search strategy was up-to-date as of 19 March 2019.

- The Cochrane Library databases (Cochrane Reviews and other reviews, CENTRAL, and technology assessments) (Appendix 1).

- MEDLINE (Ovid MEDLINE(R) In-Process \& Other Non-Indexed Citations and Ovid MEDLINE(R) 1946 to Present) (Appendix 2); also PubMed (http://www.ncbi.nlm.nih.gov/pubmed) before the end of the review, to capture non-MEDLINE records.

- Embase (OvidSP 1974 to Present) (Appendix 3).

Review authors also performed handsearches of the following trial registers.

- ClinicalTrials.gov (https://clinicaltrials.gov/).

- World Health Organization International Clinical Trials Registry Platform (WHO ICTRP; http://www.who.int/ictrp/en).

\section{Searching other resources}

We used the reference lists of included trials, systematic reviews, meta-analyses, and health technology assessment reports to search for other potentially eligible trials or ancillary publications. In addition, we contacted authors of the included trials to request additional information on the retrieved trials. We also searched the abstract proceedings for major urological conferences, including the European Association of Urology (EAU) (https://urosource.uroweb.org/urosource? page $=1 \&$ search $=\&$ types $=$ abstract $)$ and the American Urological Association (AUA), from 2009 to 2018 (https://www.auanet.org/research/annual-meeting-abstracts).

\section{Data collection and analysis}

\section{Selection of studies}

Two review authors (CEA and MS) independently screened abstracts, titles, or both for records retrieved in the literature searches to determine which trials should be assessed further. We obtained full-text copies of all potentially relevant records. We resolved disagreements through consensus or by recourse to a third review author (MIO). If we were unable to resolve a disagreement, we categorised the trial as a "study awaiting classification" and contacted trial authors for clarification. We prepared an adapted Preferred Reporting Items for Systematic Reviews and Meta-Analyses (PRISMA) flow diagram to show the process of trial selection (Liberati 2009).

\section{Data extraction and management}

For trials that fulfilled our inclusion criteria, two review authors (CEA and MS) independently extracted key participant and intervention characteristics. We reported data on efficacy outcomes and adverse events using standardised data extraction sheets. We resolved disagreements by discussion or, if required, by consultation with a third review author (MIO).

\section{Duplicate and companion publications}

In the event of duplicate publications, companion documents, or multiple reports of a primary trial, we maximised the information yield by collating all available data and using the most complete data set aggregated across all known publications. We listed duplicate publications, companion documents, multiple reports of a primary trial, and trial documents of the included trials (such as trial registry information) as secondary references under the study ID of the included trial. We also listed duplicate publications, companion documents, multiple reports of a trial, and trial documents of excluded trials (such as trial registry information) as secondary references under the study ID of the excluded trial.

\section{Data from clinical trial registers}

When data from included trials were available as study results in clinical trial registers such as ClinicalTrials.gov or similar sources, we made use of this information and extracted data. When a full publication of the trial was available, we collated and critically appraised all available data. If an included trial was marked as a completed study in a clinical trial register but no additional information was available, we added this trial to the Characteristics of studies awaiting classification table.

\section{Assessment of risk of bias in included studies}

Two review authors (CEA and MS) independently assessed the risk of bias of each included trial. We resolved disagreements by consensus or by consultation with a third review author (MIO). When there was disagreement, we consulted the rest of the group and made a judgement based on consensus. When adequate information was not available from trial authors, trial protocols, or both, we contacted trial authors to request missing data on risk of bias items.

We used the Cochrane 'Risk of bias' assessment tool and judged risk of bias criteria as having low, high, or unclear risk (Higgins 2011). We evaluated individual bias items as described in the Cochrane Handbook for Systematic Reviews of Interventions, according to the criteria and associated categorisations contained therein (Higgins 2011).

\section{Random sequence generation (selection bias due to inadequate generation of a randomised sequence) - assessment at trial level}

For included trials, we described the method used to generate the allocation sequence to allow an assessment of whether it should produce comparable groups.

- Low risk of bias: trial authors achieved sequence generation using computer-generated random numbers or a random numbers table. Drawing lots, tossing a coin, shuffling cards or envelopes, and throwing dice were adequate if this was performed by an independent person who was not otherwise involved in the trial. We considered use of the minimisation technique as equivalent to being random.

- Unclear risk of bias: information about the sequence generation process was insufficient.

- High risk of bias: the sequence generation method was non-random or quasi-random (e.g. sequence generated by odd or even date of birth, sequence generated by some rule based on date (or day) of admission, sequence generated by some rule based on hospital or clinic record number, allocation by judgement of the clinician, allocation by preference of the participant, allocation based on results of a laboratory test or a series of tests, allocation by availability of the intervention).

Bipolar versus monopolar transurethral resection of the prostate for lower urinary tract symptoms secondary to benign prostatic 
Allocation concealment (selection bias due to inadequate concealment of allocation before assignment) - assessment at trial level

For included trials, we described the method used to conceal allocation to interventions before assignment and assessed whether intervention allocation could have been foreseen in advance of or during recruitment, or could have changed after assignment.

- Low risk of bias: trial authors used central allocation (including telephone, interactive voice recorder, or web-based and pharmacy-controlled randomisation), sequentially numbered drug containers of identical appearance, or sequentially numbered opaque sealed envelopes.

- Unclear risk of bias: information about allocation concealment was insufficient.

- High risk of bias: trial authors used an open random allocation schedule (e.g. a list of random numbers), assignment envelopes without appropriate safeguards, alternation or rotation, date of birth, case record numbers, or any other explicitly unconcealed procedure.

We also evaluated trial baseline data to incorporate assessment of baseline imbalance into the risk of bias judgement for selection bias (Corbett 2014). Chance imbalances may also affect judgements on the risk of attrition bias. In the case of unadjusted analyses, we distinguished between studies rated as low risk of bias on the basis of randomisation methods and baseline similarity or baseline similarity alone (Corbett 2014).

\section{Blinding of participants and study personnel (performance bias due to knowledge of allocated interventions by participants and personnel during the trial) - assessment at outcome level}

We evaluated the risk of detection bias for all outcomes collectively, as it was considered that all study outcomes in our review were equally susceptible to performance bias. We have noted if outcomes were self-reported, investigator-assessed, or adjudicated outcome measures.

- Low risk of bias: blinding of participants and key study personnel is ensured, and it is unlikely that the blinding could have been broken; there was no blinding or incomplete blinding, but we judge that the outcome is unlikely to have been influenced by lack of blinding.

- Unclear risk of bias: information about blinding of participants and study personnel is insufficient; the trial does not address this outcome.

- High risk of bias: there was no blinding or incomplete blinding, and the outcome is likely to have been influenced by lack of blinding; blinding of trial participants and key personnel was attempted, but it is likely that the blinding could have been broken, and the outcome is likely to be influenced by lack of blinding.

\section{Blinding of outcome assessment (detection bias due to knowledge of allocated interventions by outcome assessors) - assessment at outcome level}

We evaluated the risk of detection bias separately for subjective, patient-reported outcomes (urological symptoms, bother, erectile function at 12 months) and for objective, investigator-assessed outcomes (incidence of TUR syndrome, blood transfusion, re-TURP, and urinary incontinence at 12 months).

- Low risk of bias: blinding of outcome assessment is ensured, and it is unlikely that the blinding could have been broken; there was no blinding of outcome assessment, but we judge that the outcome measurement was unlikely to have been influenced by lack of blinding.

- Unclear risk of bias: information about the blinding of outcome assessors is insufficient; the trial did not address this outcome.

- High risk of bias: there was no blinding of outcome assessment, and the outcome measurement is likely to have been influenced by lack of blinding; there was blinding of outcome assessment, but it is likely that the blinding could have been broken, and the outcome measurement is likely to be influenced by lack of blinding.

Incomplete outcome data (attrition bias due to quantity, nature, or handling of incomplete outcome data) - assessment at outcome level

We evaluated the risk of attrition bias separately for immediate postoperative outcomes (TUR syndrome, blood transfusion) and long-term outcomes, including those reported at 12 months (urological symptoms, bother, erectile function and urinary incontinence at 12 months, need for re-TURP).

We stated whether the trial reported attrition and exclusions and the number of participants included in the analysis at each stage (compared with the number of randomised participants per intervention/comparator groups). We also noted whether the trial reported the reasons for attrition or exclusion, and whether missing data were balanced across groups or were related to outcomes. We will consider the implications of missing outcome data per outcome such as high dropout rates (e.g. > 15\%) or disparate attrition rates (e.g. difference $\geq 10 \%$ between trial arms).

- Low risk of bias: no outcome data are missing; reasons for missing outcome data are unlikely to be related to true outcomes (for survival data, censoring was unlikely to introduce bias); missing outcome data were balanced in numbers across intervention groups, with similar reasons for missing data across groups; for dichotomous outcome data, the proportion of missing outcomes compared with observed event risk is not enough to have a clinically relevant impact on the intervention effect estimate; for continuous outcome data, plausible effect size (mean difference or standardised mean difference) among missing outcomes is not enough to have a clinically relevant impact on observed effect size; appropriate methods, such as multiple imputation, were used to handle missing data.

- Unclear risk of bias: information is insufficient to assess whether missing data in combination with the method used to handle missing data were likely to induce bias; the trial did not address this outcome.

- High risk of bias: the reason for missing outcome data is likely to be related to the true outcome, with imbalance in numbers or reasons for missing data across intervention groups; for dichotomous outcome data, the proportion of missing outcomes compared with observed event risk is enough to induce clinically relevant bias in intervention effect estimates; for continuous outcome data, plausible effect size (mean difference or standardised mean difference) among missing outcomes is enough

Bipolar versus monopolar transurethral resection of the prostate for lower urinary tract symptoms secondary to benign prostatic 
to induce clinically relevant bias in observed effect size; 'astreated' or similar analysis was done with substantial departure of the intervention received from that assigned at randomisation; application of simple imputation is potentially inappropriate.

\section{Selective reporting (reporting bias due to selective outcome reporting) - assessment at trial level}

We prepared a 'Risk of bias' graph and a 'Risk of bias' summary figure.

We distinguished between self-reported, investigator-assessed, and adjudicated outcome measures.

We considered the following outcomes as self-reported: urological symptoms, bother, erectile function at 12 months as reported by participants.

We considered the following outcomes as investigator-assessed: TUR syndrome, blood transfusion, urinary Incontinence at 12 months, re-TURP.

\section{Summary assessment of risk of bias}

\section{Risk of bias for a trial across outcomes}

Some risk of bias domains such as selection bias (sequence generation and allocation sequence concealment) affect the risk of bias across all outcome measures in a trial. In any trials with high risk of selection bias, all endpoints investigated in the associated trial were marked as high risk.

\section{Risk of bias for an outcome within a trial and across domains}

We assessed the risk of bias for an outcome measure by including all entries relevant to that outcome (i.e. both trial-level entries and outcome-specific entries). We considered low risk of bias to denote low risk of bias for all key domains, unclear risk to denote unclear risk of bias for one or more key domains, and high risk to denote high risk of bias for one or more key domains.

\section{Risk of bias for an outcome across trials and across domains}

These are our main summary assessments that are incorporated into our judgements about the quality of evidence in the 'Summary of finding' tables. We defined outcomes as having low risk of bias when most information comes from trials at low risk of bias, unclear risk when most information comes from trials at low or unclear risk of bias, and high risk when a sufficient proportion of information comes from trials at high risk of bias.

\section{Measures of treatment effect}

When at least two included trials are available for a comparison and a given outcome, we have expressed dichotomous data as a risk ratio (RR) or an odds ratio (OR) with $95 \%$ confidence interval (Cl). For continuous outcomes measured on the same scale (e.g. weight loss in kilograms), we estimated the intervention effect using the mean difference with $95 \% \mathrm{Cl}$. For continuous outcomes measuring the same underlying concept but using different measurement scales, we calculated the standardised mean difference (SMD).

For outcomes of urological symptoms as measured by IPSS at 12 months and erectile function as measured by IIEF- 5 score, the minimum clinically important difference (MCID) was considered to be
4. For other primary and secondary outcomes, the MCID was considered to be arbitrary or too subjective to define.

\section{Unit of analysis issues}

This review took into account the level at which randomisation occurred such as cross-over trials, cluster-randomised controlled trials, and multiple observations for the same outcome. When more than one comparison from the same trial was eligible for inclusion in the same meta-analysis, we combined groups to create a single pair-wise comparison. This review does not include any trials with cross-over or cluster design.

\section{Dealing with missing data}

When possible, we contacted authors of the included trials with the aim of obtaining missing data.

We carefully evaluated important numerical data such as screened, randomly assigned participants, as well as intention-to-treat and as-treated and per-protocol populations. When required, we investigated attrition rates (e.g. dropouts, losses to follow-up, withdrawals) and critically appraised issues concerning missing data and use of imputation methods (e.g. last observation carried forward).

For trials where the standard deviation of the outcome is not available at follow-up or cannot be re-created, we standardised by using the average of the pooled baseline standard deviation from trials in which this information was reported.

When included trials did not report means and standard deviations (SDs) for outcomes, and we did not receive the needed information from trial authors, we aimed to input these values by estimating mean and variance from median, range, and size of the sample ( $\mathrm{Ho}-$ zo 2005).

\section{Assessment of heterogeneity}

We identified heterogeneity (inconsistency) by visually inspecting the forest plots and by using a standard $\mathrm{Chi}^{2}$ test with a significance level of $\alpha=0.1$. In view of the low power of this test, we also considered the $I^{2}$ statistic, which quantifies inconsistency across trials to assess the impact of heterogeneity on the meta-analysis (Higgins 2003), noting that an $I^{2}$ statistic $\geq 75 \%$ indicates a considerable level of heterogeneity (Higgins 2011).

When there was evidence of heterogeneity, we attempted to determine possible reasons for this by examining individual trial and subgroup characteristics.

\section{Assessment of reporting biases}

For those outcomes for which more than 10 trials are included, we used funnel plots to assess small-trial effects. Several explanations may account for funnel plot asymmetry, including true heterogeneity of effect with respect to trial size, poor methodological design (and hence bias of small trials), and publication bias. Therefore these results require careful interpretation (Egger 1997; Sterne 2011).

\section{Data synthesis}

We undertook meta-analysis only if participants, interventions, comparisons, and outcomes were judged to be sufficiently similar to ensure an answer that is clinically meaningful. Unless we found 
good evidence of homogenous effects across trials, we primarily used a random-effects model to summarise low risk of bias data. In addition, we performed statistical analyses according to the statistical guidelines presented in the Cochrane Handbook for Systematic Reviews of Interventions (Higgins 2011).

\section{Quality of evidence and 'Summary of findings' table}

We presented the overall certainty of evidence for each outcome according to the Grading of Recommendations Assessment, Development and Evaluation (GRADE) approach, which takes into account issues related not only to internal validity (risk of bias, inconsistency, imprecision, publication bias) but also to external validity, such as directness of results (Guyatt 2008; Guyatt 2011a; Guyatt 2011b; Guyatt 2011c; Guyatt 2011d; Guyatt 2011e; Guyatt 2011f; Guyatt 2011g; Guyatt 2011h). Two review authors (CEA and MIO) independently rated the certainty of evidence for each outcome. We presented a summary of the evidence in Summary of findings for the main comparison. This provides key information about the best estimate of the magnitude of effect, in relative terms and as absolute differences, for each relevant comparison of alternative management strategies, numbers of participants and trials addressing each important outcome, and rating of overall confidence in effect estimates for each outcome. We created Summary of findings for the main comparison based on the methods described in the Cochrane Handbook for Systematic Reviews of Interventions by using the table editor in Review Manager (RevMan) (Higgins 2011). We used the GRADEpro Guideline Development Tool (GDT) software to help with standardisation of Summary of findings for the main comparison. We justified all decisions to downgrade the certainty of evidence by using footnotes, and we provided comments to aid the reader's understanding of the Cochrane Review when necessary.

We presented Summary of findings for the main comparison to report the following outcomes, listed according to priority.

- Urological symptoms as measured by the International Prostate Symptom Score (IPSS) questionnaire at 12 months.

- Bother as measured by a health-related quality of life (HRQoL) questionnaire at 12 months.

- Transurethral resection (TUR) syndrome.

- Postoperative blood transfusion.

- Postoperative urinary incontinence at 12 months.
- Incidence of second TURP (i.e. re-do TURP).

- Erectile function at 12 months as measured by IIEF-5.

\section{Subgroup analysis and investigation of heterogeneity}

We expected the following characteristics to introduce clinical heterogeneity, and we planned on carrying out the following subgroup analyses including investigations of interactions.

- Prostate volume: large versus small prostate volume, with specific categories for these to be defined by the primary authors.

- Patient age: older versus younger patients, with specific categories for these to be defined by the primary authors.

In light of the anticipated heterogeneity of thresholds for specific categories of prostate volume and patient age, we did not apply our own specific values.

\section{Sensitivity analysis}

We undertook sensitivity analyses to explore the influence of the following factors (when applicable) on effect sizes by restricting analysis to the following.

- Taking into account risk of bias, as specified in the Assessment of risk of bias in included studies section.

- Very long or large trials, to establish the extent to which they dominate the overall results.

\section{RES U L T S}

\section{Description of studies}

\section{Results of the search}

We identified 1249 records through an electronic database search. We identified 40 records through handsearching of other sources. After removing 432 duplicates, we screened the titles and abstracts of 857 records, and we excluded 647 records. We screened 210 fulltext records and excluded 81 records that did not meet the inclusion criteria. We included a total of 59 RCTs (129 records). We did not identify studies awaiting classification nor ongoing RCTs. The flow of literature through the assessment process is shown in the PRISMA flowchart (Figure 1). Baseline characteristics of the included studies are detailed in Table 1. 
Figure 1. Flow diagram.

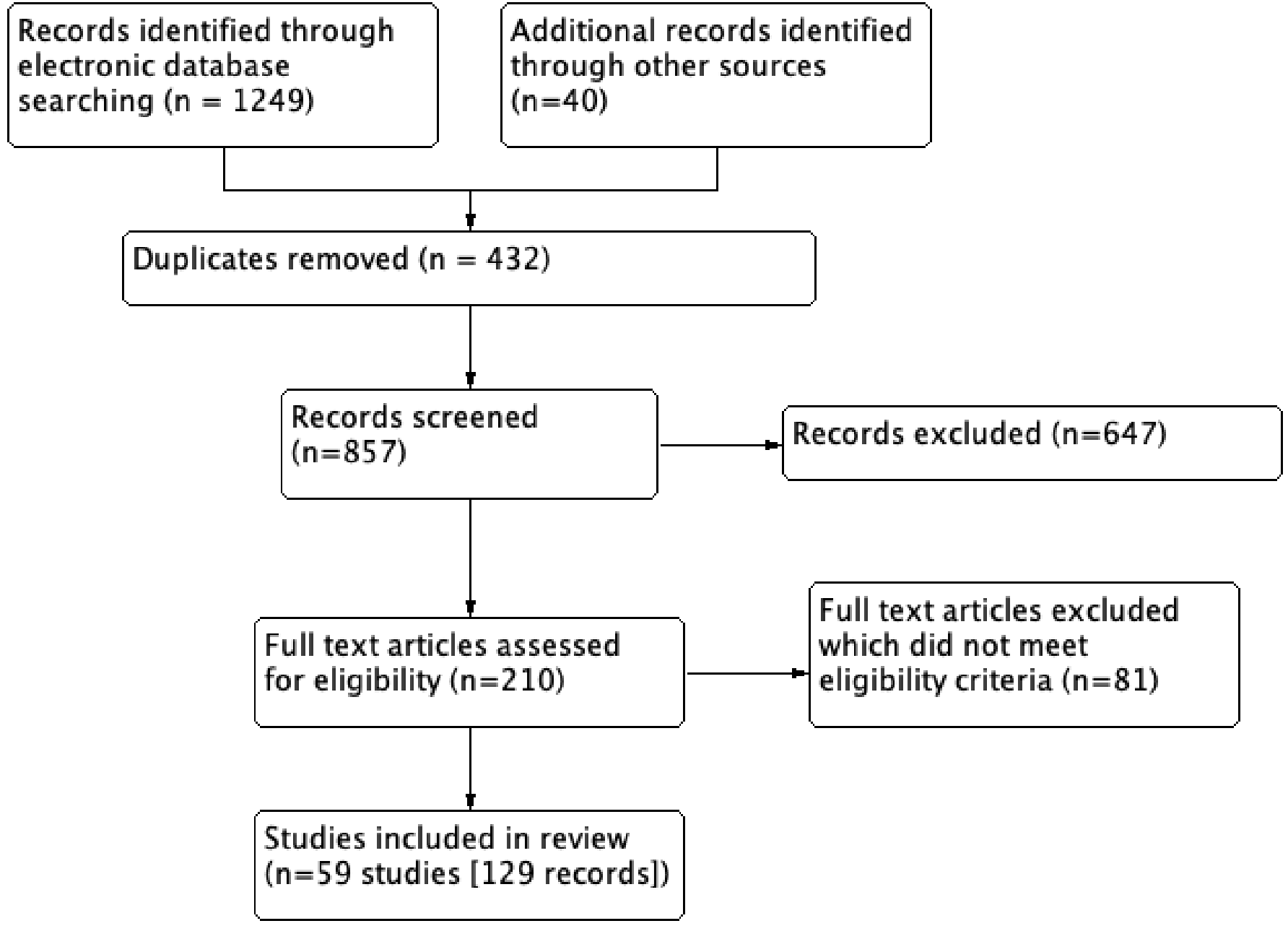

\section{Included studies}

Details of included studies are presented in the Characteristics of included studies table.

\section{Source of data}

Of the 59 included RCTs, seven were published in Chinese (He 2010; Mei 2010; Qian 2014; Wang 2007; Wu 2005; Xin 2009; Xue 2008), one in Korean (Kim 2006), one in German (Rose 2007), one in French (Ghozzi 2014), one in Spanish (Rojo 2018), and the other 48 in English.

Of the 59 included RCTs, full-text publications were available for 46 RCTs, and only abstract proceedings were identified for the 13 remaining RCTs (Bahadzor 2006; Bertolotto 2007; Choi 2006; D'Elia 2004; Eaton 2004; Egui Rojo 2017; Goh 2009; Kadyan 2014; Nasution 2017; Shaik 2017; Symons 2002; Terrone 2006; Xin 2007).

\section{Study design and settings}

All studies were RCTs that compared BTURP to MTURP. Four studies were multi-institutional (Bertolotto 2007; Choi 2006; Mamoulakis 2013; Méndez-Probst 2011), and 55 were single-institution trials. The included studies were performed between 2002 and 2016. The follow-up duration varied from only the immediate postoperative period to 48 months - De Sio 2006 - and 60 months postoperatively - Xie 2012.

\section{Participants}

The included trials enrolled participants aged $>18$ years with lower urinary tract symptoms (LUTS) secondary to benign prostatic obstruction (BPO). BPO was to be defined as bladder outlet obstruction secondary to benign prostatic enlargement (BPE). We included 8924 randomised participants. Of these, 6745 contributed data to the primary and secondary outcomes. The mean age of included participants ranged from 59.0 (BTURP) and 61.0 (MTURP) - De Sio 2006 - to 74.1 (BTURP) and 73.8 (MTURP) - Wu 2005. The mean prostate volume ranged from $39 \mathrm{~mL}$ (BTURP and MTURP) - Egui Rojo 2017 - to $82.4 \mathrm{~mL}$ (BTURP) and 82.6 mL (MTURP) - Bhansali 2009.

\section{Intervention and comparator}

A total of 50 studies reported the specific BTURP technology used in their intervention group, as described in the 'Description of interventions' table (Table 2). In all, 31 studies used Gyrus Plasmakinetic (ACMI, Southborough, MA, USA), 14 used TURis (Olympus, Tokyo, Japan), four used the Vista Coblation/Controlled Tissue Resection (CTR) system (ACMI), and one used AUTOCON II 400 ESU (Karl Storz Endoscope, Tuttlingen, Germany). A total of 46 studies reported the specific irrigation fluid that was used with MTURP, as detailed in the

Bipolar versus monopolar transurethral resection of the prostate for lower urinary tract symptoms secondary to benign prostatic 
'Description of interventions' table (Table 2); 24 used glycine; seven used mannitol; three used mannitol/ethanol; three used mannitol/sorbitol; three used sterile distilled water; two used glucose solution; one used Urion liquid; and one multi-centre trial varied irrigation fluid by centre (glycine, sorbitol, mannitol/sorbitol, water).

\section{Outcomes}

The number of studies that reported each of the respective primary and secondary outcomes is described in Summary of findings for the main comparison. Urological symptoms as measured by IPSS at 12 months were reported by 16 studies. Bother as reported by HRQoL at 12 months was reported by 11 studies. The incidence of TUR syndrome was reported by 44 studies; the incidence of postoperative urinary incontinence at 12 months by four studies; the incidence of postoperative blood transfusion by 38 studies; and the incidence of re-TURP by six studies. Erectile function as measured by IIEF- 5 score at 12 months was reported by three RCTs.

\section{Funding sources and conflicts of interest}

Four studies reported sources of funding. Chen 2010 reported support from Shanghai Shenkang Hospital Development Centre and Science and Technology Fund of Shanghai Jiao Tong University School of Medicine, Mamoulakis 2013 from Karl Storz Endoscope, Méndez-Probst 2011 from Olympus and ACMI, and Singhania 2010 from BYL Nair Hospital.

\section{Excluded studies}

We excluded a total of 81 studies ( 83 records) on full-text screening as they did not meet inclusion criteria. Details of the excluded studies are presented in the Characteristics of excluded studies table.

\section{Risk of bias in included studies}

A summary of risk of bias judgements for the included studies is presented in the 'Risk of bias' graph (Figure 2) and in the 'Risk of bias' summary (Figure 3 ) (Characteristics of included studies).

Figure 2. Risk of bias graph: review authors' judgements about each risk of bias item presented as percentages across all included studies.

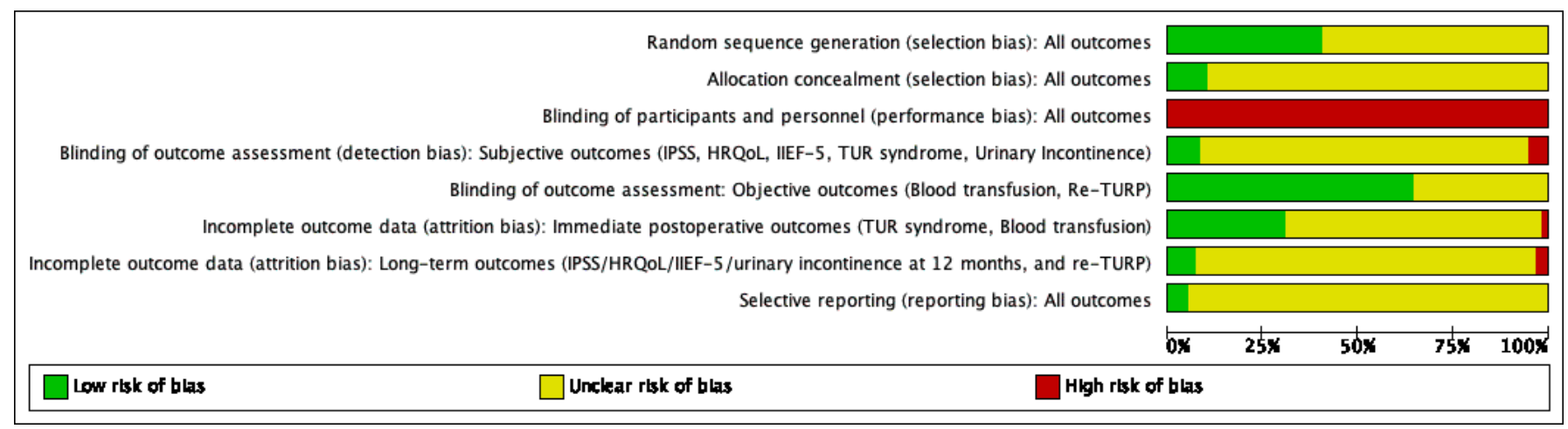


Figure 3. Risk of bias summary: review authors' judgements about each risk of bias item for each included study.

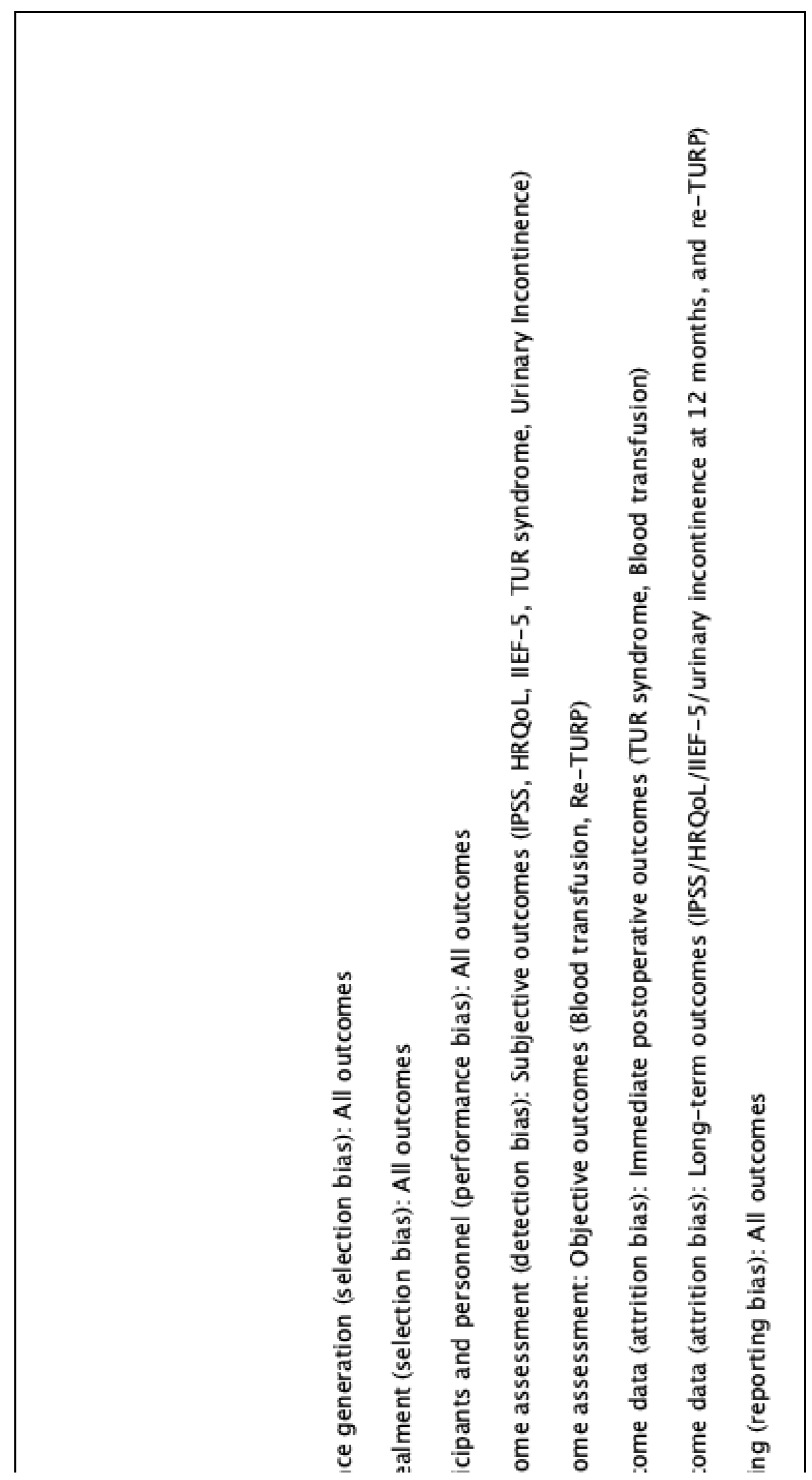

Bipolar versus monopolar transurethral resection of the prostate for lower urinary tract symptoms secondary to benign prostatic 
Figure 3. (Continued)

\begin{tabular}{|c|c|c|c|c|c|c|c|c|}
\hline & 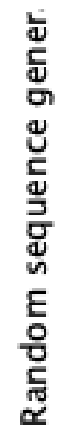 & 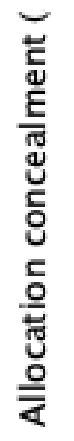 & 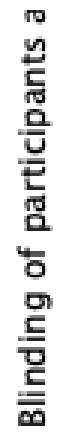 & 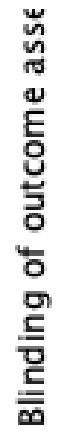 & 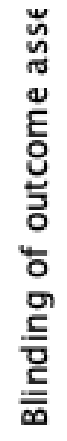 & 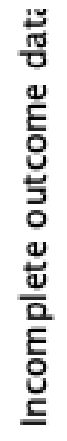 & 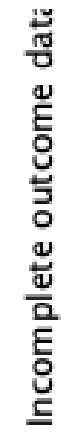 & 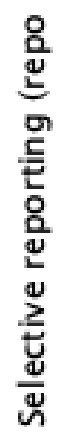 \\
\hline Abascal Junquera 2006 & $?$ & $?$ & & $?$ & + & $?$ & $?$ & $?$ \\
\hline Acuña Lopez 2010 & $?$ & $?$ & & $?$ & + & $?$ & $?$ & $?$ \\
\hline Ahmad 2016 & $?$ & $?$ & & $?$ & + & + & $?$ & $?$ \\
\hline Akçaydz 2006 & $?$ & $?$ & & $?$ & + & $?$ & $?$ & $?$ \\
\hline Akman 2013 & ? & ? & & ? & + & ? & ? & $?$ \\
\hline At-Rawashdah 2017 & + & $?$ & & ? & + & ? & + & $?$ \\
\hline Bahadzor 2006 & ? & ? & & ? & ? & $?$ & $?$ & $?$ \\
\hline Bertolotto 2007 & ? & $?$ & & $?$ & $?$ & $?$ & $?$ & $?$ \\
\hline Bhantsall 2009 & + & $?$ & & + & $?$ & $?$ & $?$ & $?$ \\
\hline Chen 2009 & ? & $?$ & & ? & + & ? & $?$ & $?$ \\
\hline Chen 2010 & + & $?$ & & & + & $?$ & $?$ & $?$ \\
\hline Chol 2006 & $?$ & $?$ & & ? & ? & ? & $?$ & ? \\
\hline D'Ella 2004 & ? & $?$ & & ? & ? & ? & ? & ? \\
\hline Demlrdag 2016 & ? & ? & & $?$ & + & & & ? \\
\hline De Slo 2006 & + & ? & & $?$ & + & ? & $?$ & $?$ \\
\hline Eaton 2004 & $?$ & $?$ & & ? & $?$ & $?$ & ? & $?$ \\
\hline Egul Rojo 2017 & ? & $?$ & & ? & $?$ & $?$ & $?$ & ? \\
\hline E-Assmy $201 B$ & + & $?$ & & $?$ & ? & ? & $?$ & + \\
\hline Erturhan 2007 & ? & $?$ & & ? & + & ? & $?$ & $?$ \\
\hline Fagerström 2011 & + & $?$ & & $?$ & + & $?$ & $?$ & $?$ \\
\hline
\end{tabular}

Bipolar versus monopolar transurethral resection of the prostate for lower urinary tract symptoms secondary to benign prostatic 
Figure 3. (Continued)

\begin{tabular}{|c|c|c|c|c|c|c|c|}
\hline Erturhan 2007 & $?$ & $?$ & $?$ & + & $?$ & $?$ & $?$ \\
\hline Fagerström 2011 & + & $?$ & $?$ & + & $?$ & $?$ & $?$ \\
\hline Geavlete 2011 & + & $?$ & + & + & $?$ & $?$ & $?$ \\
\hline Ghozzl 2014 & $?$ & $?$ & $?$ & + & + & + & $?$ \\
\hline Glullanelli 2013 & $?$ & $?$ & $?$ & + & $?$ & $?$ & $?$ \\
\hline Goh 2009 & $?$ & $?$ & $?$ & $?$ & $?$ & $?$ & $?$ \\
\hline He 2010 & $?$ & $?$ & $?$ & 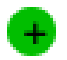 & $?$ & $?$ & $?$ \\
\hline Ho 2007 & + & $?$ & $?$ & + & + & $?$ & $?$ \\
\hline Huang 2012 & + & + & $?$ & $?$ & $?$ & $?$ & $?$ \\
\hline lorl 200B & + & $?$ & $?$ & + & $?$ & $?$ & $?$ \\
\hline Kadyan 2014 & $?$ & $?$ & $?$ & $?$ & $?$ & $?$ & $?$ \\
\hline KIm 2006 & $?$ & $?$ & ? & + & ? & $?$ & $?$ \\
\hline Komura 2015 & + & $?$ & + & + & + & $?$ & + \\
\hline Kong 2009 & + & + & $?$ & + & $?$ & $?$ & $?$ \\
\hline Kumar 2013 & + & $?$ & ? & + & + & $?$ & $?$ \\
\hline Un 2006 & + & + & $?$ & $?$ & $?$ & + & $?$ \\
\hline Mamoulakes 2013 & + & + & + & + & + & $?$ & + \\
\hline Mel 2010 & $?$ & $?$ & $?$ & + & + & $?$ & $?$ \\
\hline Wendez-Probst 2011 & $?$ & $?$ & $?$ & + & $?$ & $?$ & $?$ \\
\hline Mkhielsen 2007 & + & $?$ & 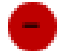 & + & $?$ & $?$ & $?$ \\
\hline Nasution 2017 & $?$ & $?$ & ? & ? & $?$ & $?$ & $?$ \\
\hline Nuhog̈lu 2006 & $?$ & $?$ & ? & + & + & $?$ & $?$ \\
\hline Patankar 2006 & + & + & + & + & + & $?$ & ? \\
\hline Qlan 2014 & + & ? & $?$ & $?$ & $?$ & $?$ & ? \\
\hline Rojo 201B & + & ? & $?$ & ? & ? & $?$ & 7 \\
\hline
\end{tabular}

Bipolar versus monopolar transurethral resection of the prostate for lower urinary tract symptoms secondary to benign prostatic 
Figure 3. (Continued)

\begin{tabular}{|c|c|c|c|c|c|c|c|}
\hline Qlan 2014 & + & $?$ & $?$ & $?$ & $?$ & $?$ & $?$ \\
\hline Rojo 201B & + & $?$ & $?$ & $?$ & $?$ & $?$ & $?$ \\
\hline Rose 2007 & $?$ & $?$ & $?$ & $?$ & + & $?$ & $?$ \\
\hline Secklner 2006 & $?$ & $?$ & $?$ & + & + & $?$ & $?$ \\
\hline Shalk 2017 & $?$ & $?$ & $?$ & $?$ & $?$ & $?$ & $?$ \\
\hline Singh 2005 & + & $?$ & $?$ & + & $?$ & $?$ & $?$ \\
\hline Singhanla 2010 & + & $?$ & $?$ & + & $?$ & $?$ & $?$ \\
\hline Stuckl 2014 & + & $?$ & $?$ & + & $?$ & - & $?$ \\
\hline Symons 2002 & $?$ & $?$ & $?$ & $?$ & $?$ & $?$ & $?$ \\
\hline Terrone 2006 & $?$ & $?$ & $?$ & $?$ & $?$ & $?$ & $?$ \\
\hline Wang 2007 & $?$ & $?$ & $?$ & $?$ & + & $?$ & $?$ \\
\hline Wu 2005 & $?$ & $?$ & $?$ & + & + & $?$ & $?$ \\
\hline$X \mid=2012$ & + & + & & + & + & 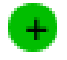 & $?$ \\
\hline$X \ln 2007$ & $?$ & $?$ & $?$ & $?$ & + & $?$ & $?$ \\
\hline$X \ln 2009$ & $?$ & $?$ & $?$ & + & + & $?$ & $?$ \\
\hline$x \in 200 B$ & $?$ & $?$ & $?$ & + & + & $?$ & $?$ \\
\hline Yang 2004 & $?$ & $?$ & $?$ & + & $?$ & $?$ & $?$ \\
\hline Yousef 2010 & + & $?$ & $?$ & + & + & $?$ & $?$ \\
\hline
\end{tabular}




\section{Allocation}

\section{Random sequence generation}

The sequence generation for participation allocation was adequate in 24 studies and was rated at low risk of bias. In the remaining trials, the method of sequence generation was unclear or was not specified (Figure 2, Figure 3).

\section{Allocation concealment}

Six studies had adequate allocation concealment and were rated to be at low risk of bias. In the remaining trials, treatment allocation was unclear (Figure 2, Figure 3).

\section{Blinding}

\section{Blinding of participants and personnel}

All studies were considered to be at high risk of bias, as it was considered unlikely that any of the operating surgeon(s) of included studies were blinded. No studies reported blinding of operating surgeon(s) to the interventions (Figure 2, Figure 3).

\section{Blinding of outcome assessment}

Subjective outcomes (urological symptoms at 12 months, bother at 12 months, erectile function at 12 months, urinary incontinence at 12 months, TUR syndrome)

Five studies reported adequate blinding of outcome assessment and were rated at low risk of bias; three studies reported that blinding of outcome assessment was not undertaken and were rated at high risk of bias; and the remaining studies did not report blinding of outcome assessment and did not report the objective outcomes of interest; these were rated at unclear risk (Figure 2, Figure 3).

\section{Objective outcomes (blood transfusion and re-TURP)}

A total of 38 studies were rated at low risk of bias, and the remaining studies were rated at unclear risk, as they did not report the objective outcomes of interest (Figure 2, Figure 3).

\section{Incomplete outcome data}

\section{Immediate postoperative outcomes (blood transfusion, TUR syndrome)}

In all, 18 studies were rated at low risk of bias for these outcomes. One study was rated at high risk of bias due to loss to follow-up or missing data resulting in significant differential loss to follow-up between trial arms (Demirdag 2016). In the other studies, risk of bias due to incomplete outcome data was unclear (Figure 2, Figure 3).

\section{Long-term outcomes (urological symptoms at 12 months, bother at 12 months, erectile function at 12 months, urinary incontinence, re-TURP)}

Four studies were rated at low risk of bias for these outcomes. Two studies were rated at high risk of bias due to significant loss to follow-up (Demirdag 2016; Stucki 2014). The other studies were considered to be at unclear risk of bias (Figure 2, Figure 3).

\section{Selective reporting}

We identified published protocols for three included studies and rated the risk of reporting bias for these studies as low (El-Assmy 2018; Komura 2015; Mamoulakis 2013). We judged the risk of selective reporting bias as unclear for the remaining studies, with no identifiable published protocols available (Figure 2, Figure 3).

\section{Other potential sources of bias}

No other potential sources of bias were assessed.

\section{Effects of interventions}

See: Summary of findings for the main comparison BTURP compared to MTURP for lower urinary tract symptoms secondary to benign prostatic obstruction

A summary of results for the comparison of BTURP versus MTURP for LUTS due to BPO is provided in Summary of findings for the main comparison.

\section{BTURP versus MTURP}

\section{Primary outcomes}

Urological symptoms as measured by IPSS at 12 months

BTURP probably results in similar improvements in urological symptoms, as measured by the International Prostate Symptom Score (IPSS) at 12 months (mean difference (MD) -0.24, 95\% confidence interval $(\mathrm{Cl})-0.39$ to -0.09 ; participants $=2531 ; \mathrm{RCTs}=16 ; \mathrm{I}^{2}$ $=0 \%$ ), compared to MTURP (Analysis 1.1$)$. The MD of $-0.24(95 \% \mathrm{Cl}$ -0.39 to -0.09 ) was less than the predefined minimum clinically important difference for IPSS of 4 .

We rated the certainty of evidence as moderate, downgrading by one level for study limitations, including concerns over selection bias (method of randomisation and allocation concealment was unclear in $>50 \%$ of included RCTs), performance bias (blinding of operating surgeons was considered unlikely in all trials), detection bias (blinding of outcomes assessment was unclear in $>50 \%$ of included RCTs), and reporting bias (selective reporting was unclear in $>50 \%$ of included RCTs) (Summary of findings for the main comparison; Figure 4). 
Figure 4. Funnel plot of comparison: 1 BTURP versus MTURP, outcome: 1.1 Urological symptoms (IPSS at 12 months).

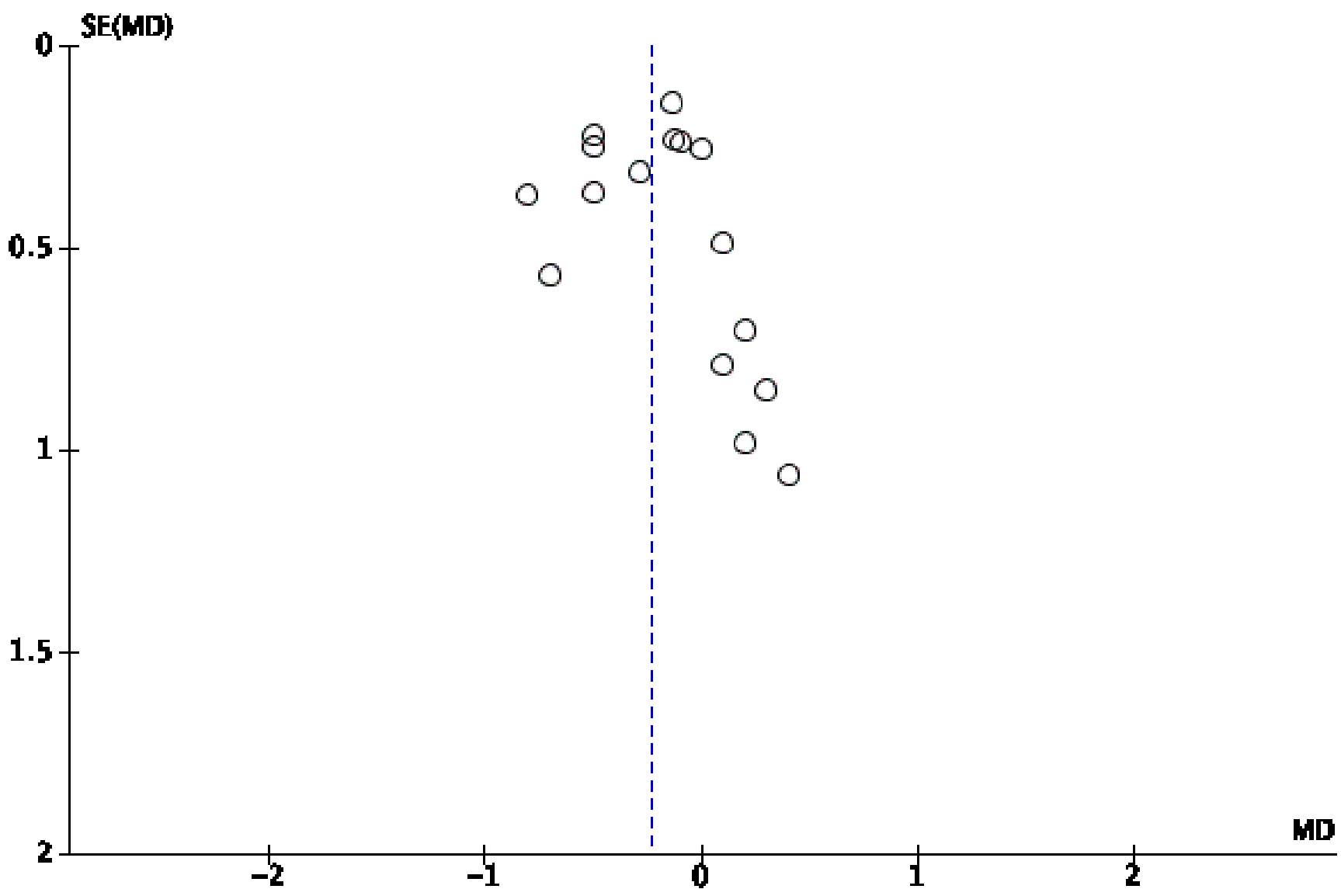

\section{Bother as measured by HRQoL score at 12 months}

BTURP probably results in similar improvements in bother, as measured by health-related quality of life (HRQoL) scores at 12 months (MD -0.12, 95\% Cl -0.25 to 0.02; participants = 2004; RCTs $=11 ; \mathrm{I}^{2}=$ $53 \%$ ), compared to MTURP (Analysis 1.2).

We rated the certainty of evidence as moderate, downgrading by one level for study limitations, including concerns over selection bias (method of randomisation and allocation concealment was unclear in $>50 \%$ of included RCTs), performance bias (blinding of operating surgeons was considered unlikely in all trials), detection bias (blinding of outcome assessment was unclear in $>50 \%$ of included RCTs), and reporting bias (selective reporting was unclear in $>50 \%$ of included RCTs) (Summary of findings for the main comparison; Figure 5). 
Figure 5. Funnel plot of comparison: 1 B-TURP versus M-TURP, outcome: 1.2 Bother (HRQoL at 12 months).

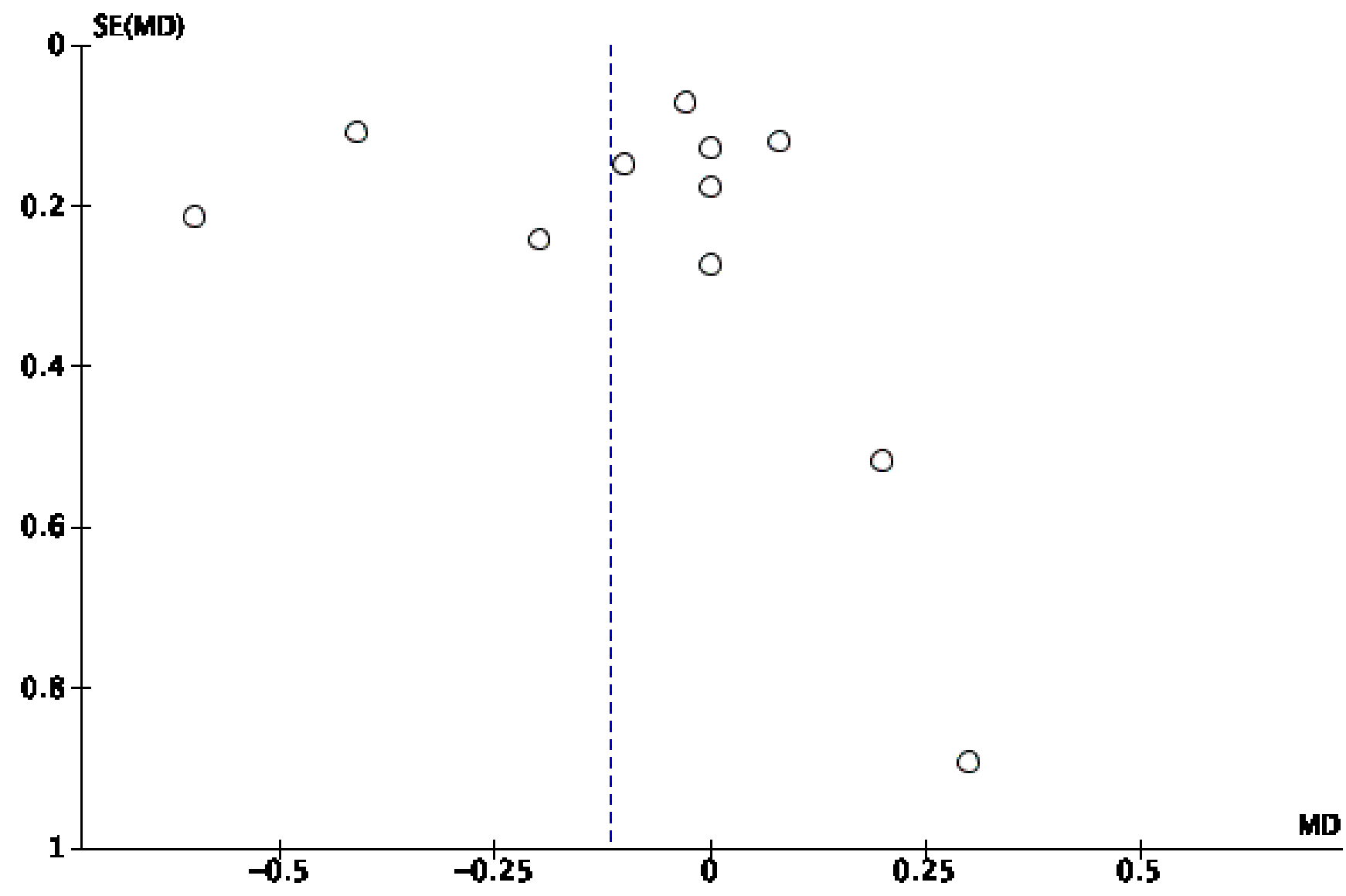

\section{TUR syndrome}

BTURP probably slightly reduces TUR syndrome events (risk ratio (RR) $0.17,95 \% \mathrm{Cl} 0.09$ to 0.30 ; participants $=6745$; $\mathrm{RCTs}=44 ; \mathrm{I}^{2}=0 \%$ ) compared to MTURP. This corresponds to 20 fewer TUR syndrome events per 1000 participants $(95 \% \mathrm{Cl} 22$ fewer to 17 fewer; Analysis 1.3).
We rated the certainty of evidence as moderate, downgrading by one level for study limitations, including concerns over selection bias (method of randomisation and allocation concealment was unclear in $>50 \%$ of included RCTs), performance bias (blinding of operating surgeons was considered unlikely in all trials), and reporting bias (selective reporting was unclear in $>50 \%$ of included RCTs) (Summary of findings for the main comparison; Figure 6). 
Figure 6. Funnel plot of comparison: 1 B-TURP versus M-TURP, outcome: 1.3 TUR syndrome.

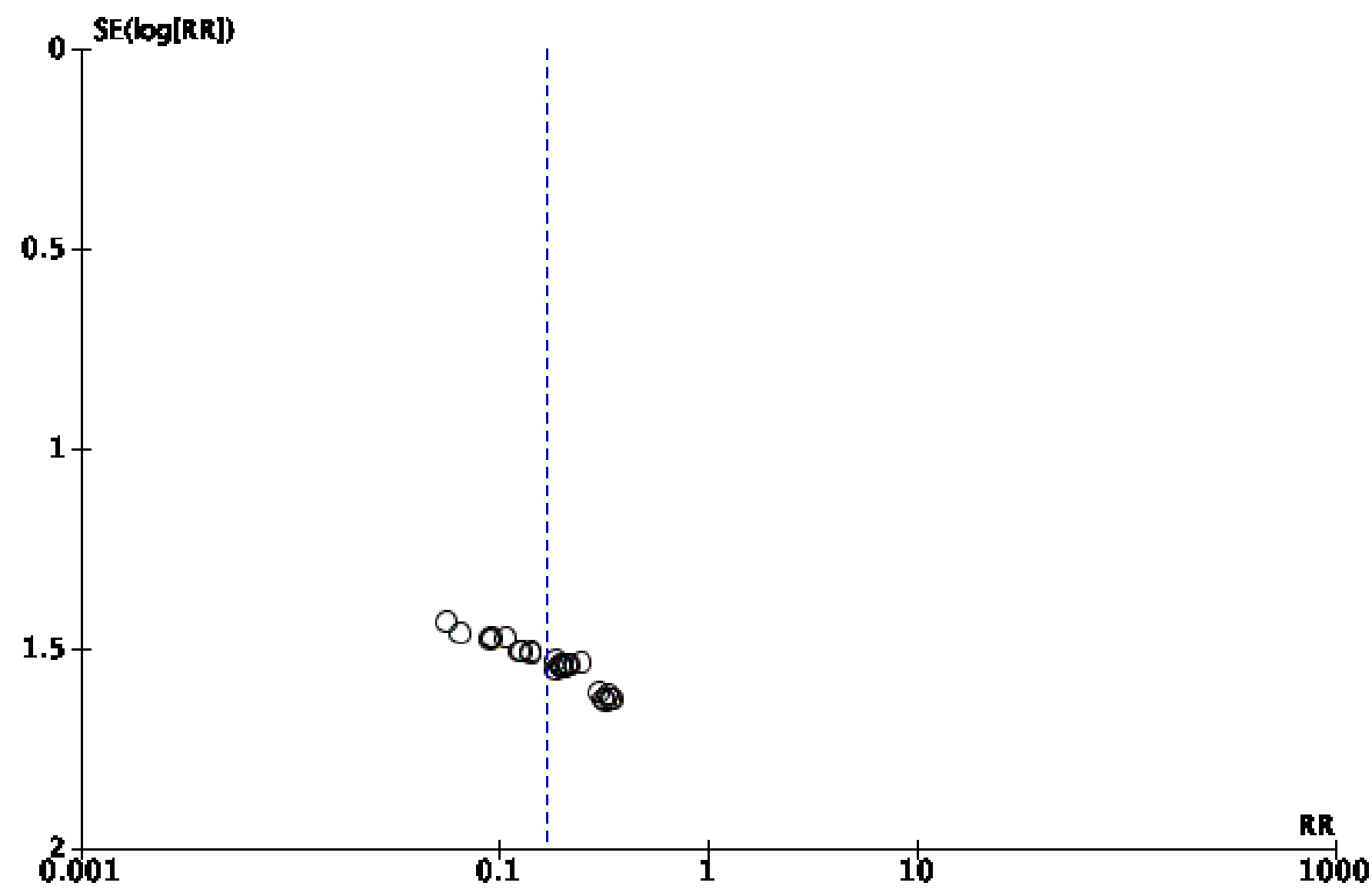

\section{Secondary outcomes}

\section{Urinary incontinence at 12 months}

BTURP may result in similar rates of urinary incontinence at 12 months (RR $0.20,95 \% \mathrm{Cl} 0.01$ to 4.06; participants $=751$; RCTs $=4$ ) compared to MTURP. This corresponds to four fewer events of urinary incontinence per 1000 participants ( $95 \% \mathrm{Cl} 5$ fewer to 16 more) (Analysis 1.4).

We rated the certainty of evidence as low, downgrading by one level for study limitations, with concerns over selection bias (method of randomisation and allocation concealment was unclear in $>50 \%$ of included RCTs), performance bias (blinding of operating surgeons was considered unlikely in all trials), detection bias (blinding of outcome assessment was unclear in $>50 \%$ of included RCTs), and reporting bias (selective reporting was unclear in $>50 \%$ of included $\mathrm{RCTs}$ ), as well as by one level for imprecision (wide confidence in- tervals and small numbers of events; Summary of findings for the main comparison).

\section{Blood transfusion}

BTURP probably slightly reduces blood transfusions (RR 0.42, 95\% $\mathrm{Cl} 0.30$ to 0.59 ; participants $=5727$; RCTs $=38 ; \mathrm{I}^{2}=0 \%$ ) compared to MTURP. This corresponds to 28 fewer blood transfusions per 1000 participants (95\% Cl 34 fewer to 20 fewer; Analysis 1.5).

We rated the certainty of evidence as moderate, downgrading by one level for study limitations, including concerns over selection bias (method of randomisation and allocation concealment was unclear in $>50 \%$ of included RCTs), performance bias (blinding of operating surgeons was considered unlikely in all trials), and reporting bias (selective reporting was unclear in $>50 \%$ of included RCTs) (Summary of findings for the main comparison; Figure 7). 
Figure 7. Funnel plot of comparison: 1 BTURP versus MTURP, outcome: 1.5 Blood transfusion.

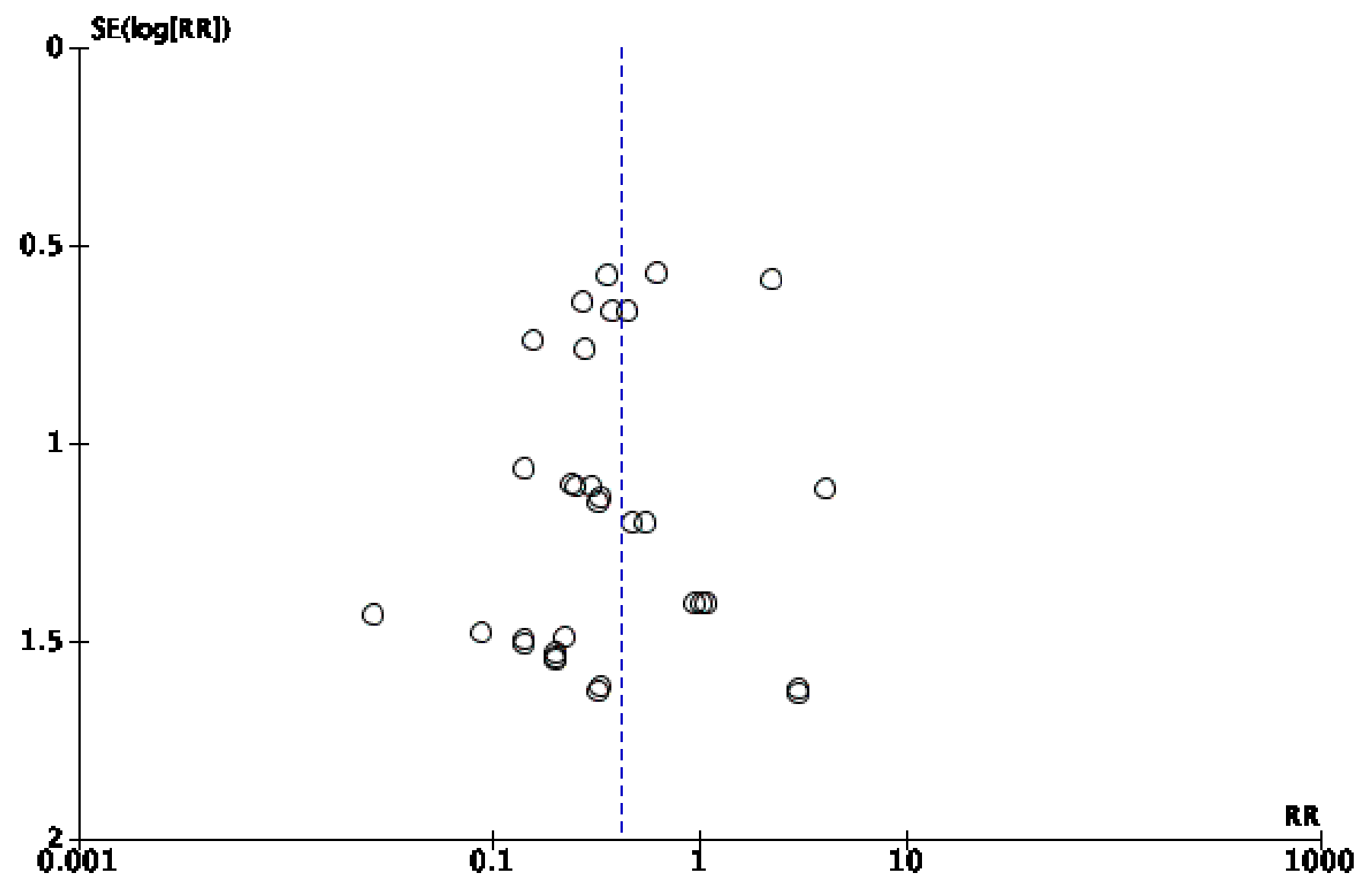

\section{Re-TURP}

BTURP may result in similar rates of re-TURP ( $R R 1.02,95 \% \mathrm{Cl} 0.44$ to 2.40; participants $\left.=652 ; \mathrm{RCTs}=6 ;\left.\right|^{2}=0 \%\right)$ compared to MTURP. This corresponds to one more event of re-TURP per 1000 participants (95\% $\mathrm{Cl} 19$ fewer to 48 more) (Analysis 1.6).

We rated the certainty of evidence as low, downgrading by one level for imprecision (wide confidence intervals and small numbers of events) and by one level for study limitations, with concerns over selection bias (method of allocation concealment was unclear in $>50 \%$ of included RCTs), performance bias (blinding of operating surgeons was considered unlikely in all trials), and reporting bias (selective reporting was unclear in $>50 \%$ of included RCTs) (Summary of findings for the main comparison).

\section{Erectile function as measured by IIEF-5 score at 12 months}

BTURP probably results in similar erectile function as measured by the International Index of Erectile Function score (IIEF-5) at 12 months (MD $0.88,95 \% \mathrm{Cl}-0.56$ to $2.32 ; \mathrm{RCTs}=3 ; \mathrm{I}^{2}=68 \%$ ) compared to MTURP (Analysis 1.7). The MD of 0.88 ( $95 \% \mathrm{Cl}-0.56$ to 2.32 ) was less than the predefined minimum clinically important difference of 4 for IIEF-5 at 12 months.

We rated the certainty of evidence as moderate, downgrading by one level for study limitations, including concerns over selection bias (method of allocation concealment was unclear in $>50 \%$ of included RCTs), performance bias (blinding of operating surgeons was considered unlikely in all trials), and reporting bias (selective reporting was unclear in $>50 \%$ of included RCTs) (Summary of findings for the main comparison).

\section{Subgroup analysis}

\section{Prostate volume}

Of the included RCTs, Kumar 2013 was the only study to include specific subgroup analyses by prostate volume. Researchers defined small prostates as $>20 \mathrm{~mL}$ to $<50 \mathrm{~mL}$ and large prostates as 50 to $80 \mathrm{~mL}$. They compared monopolar TURP, bipolar TURP, and photoselective vaporisation of the prostate (PVP) by prostate volume and observed no significant difference in effect for urological symptoms (IPSS at 12 months), bother (HRQoL at 12 months), TUR syndrome, or erectile function (IIEF-5 at 12 months). They did, however observe a significant difference in effect for blood transfusion in men with large prostates. The number of events of postoperative blood transfusion in men with large prostates who had undergone MTURP was six $(n=31)$ compared to one blood transfusion for $\operatorname{BTURP}(n=27)$ and no blood transfusions for $\operatorname{PVP}(n=31)(P=0.009)$.

\section{Patient age}

We did not identify any analysis or data within the included RCTs that would allow for subgroup analysis by patient age.

Bipolar versus monopolar transurethral resection of the prostate for lower urinary tract symptoms secondary to benign prostatic 


\section{Sensitivity analysis}

In light of the judged high risk of attrition bias seen in Demirdag 2016, with 37 patients excluded due to loss to follow-up or missing data and the significant differential loss to follow-up (23/59 participants lost to follow-up for BTURP vs 14/59 for MTURP), we performed sensitivity analysis while excluding this study from the meta-analysis for outcomes assessed. The exclusion of Demirdag 2016 from the meta-analysis did not result in any significant change in effect size that would impact the overall conclusions of the analysis; for blood transfusion, effect size changed from RR $0.42(95 \% \mathrm{Cl}$ 0.30 to 0.59 ) (study included) to RR 0.40 ( $95 \% \mathrm{Cl} 0.28$ to 0.57 ) (study excluded), and for TUR syndrome, effect size and $95 \% \mathrm{Cls}$ remained identical (RR $0.17,95 \% \mathrm{Cl} 0.09$ to 0.30 ), regardless of its inclusion or exclusion from the meta-analysis.

In light of the size of the largest included RCT (Al-Rawashdah 2017), with 497 included participants, we performed sensitivity analysis while excluding this study from the meta-analysis for outcomes assessed. The exclusion of Al-Rawashdah 2017 from the meta-analyses did not result in any significant change in effect size that would impact the overall conclusions of the analysis; for urological symptoms (IPSS at 12 months), effect size changed from MD -0.24 (95\% $\mathrm{Cl}-0.39$ to -0.09$)$ (study included) to MD- $0.28(95 \% \mathrm{Cl}-0.45$ to -0.10$)$ (study excluded); for bother (HRQoL at 12 months), effect size changed from MD $-0.12(95 \% \mathrm{Cl}-0.25$ to 0.02$)$ (study included) to $-0.13(95 \% \mathrm{Cl}-0.30$ to 0.03 ) (study excluded); for TUR syndrome, effect size changed from RR 0.17 ( $95 \% \mathrm{Cl} 0.09$ to 0.30$)$ (study included) to RR 0.18 ( $95 \% \mathrm{Cl} 0.10$ to 0.32 ) (study excluded); and for blood transfusion, effect size changed from RR $0.42(95 \% \mathrm{Cl} 0.30$ to 0.59$)$ (study included) to RR 0.43 ( $95 \% \mathrm{Cl} 0.30$ to 0.60 ) (study excluded).

\section{DISCUSSION}

\section{Summary of main results}

Bilateral transurethral resection of the prostate (BTURP) and monopolar transurethral resection of the prostate (MTURP) probably result in similar improvement in urological symptoms and bother. BTURP probably slightly reduces transurethral resection (TUR) syndrome and postoperative blood transfusion compared to MTURP. BTURP and MTURP probably do not differ in terms of erectile function. The moderate certainty of evidence available for urological symptoms, bother, TUR syndrome, blood transfusion, and erectile function suggests that there is no need for further randomised controlled trials (RCTs) comparing BTURP and MTURP for these outcomes. Observed differences between BTURP and MTURP for International Prostate Symptoms Score (IPSS) and International Index of Erectile Function (IIEF-5) score at 12 months were less than the predefined minimum clinically important differences for these outcomes and therefore are unlikely to be of clinical relevance to patients or care providers.

BTURP and MTURP may also have similar effects on postoperative urinary incontinence and the need for re-TURP, but low-certainty evidence for these outcomes means that they deserve further study in the form of prospective RCTs that incorporate standardised and clinically meaningful definitions, as well as sufficient duration of follow-up.

\section{Overall completeness and applicability of evidence}

We believe that evidence is generalisable in addressing the question of how BTURP compares with MTURP for men with lower uri- nary tract symptoms (LUTS) due to benign prostatic obstruction (BPO). All studies recruited men with significant LUTS secondary to $\mathrm{BPO}$ requiring surgery, although some heterogeneity is evident in terms of prostate size and patient age.

In terms of the index intervention of BTURP, significant clinical heterogeneity is apparent in terms of the different types of BTURP used. Data were insufficient for sensitivity or subgroup analysis on how the different types of BTURP compared to each other. All studies compared BTURP versus the control intervention of MTURP, which was glycine-based in most studies. For outcomes, we noted heterogeneity of outcome measurement and reporting, with some studies not specifying how outcomes were measured. In particular, the primary outcome of TUR syndrome was inconsistently defined, with some studies failing to provide a clear definition. Accordingly, the incidence of TUR syndrome varied across studies. It should be noted that $20 \%$ of participants who developed TUR syndrome were derived from a single study (Yousef 2010). The higher incidence of TUR syndrome in some selected trials may be due to learning curve effects, different hospital settings and hospital protocols, or large size of the prostate as in the Yousef 2010 RCT. In that study, the average resection weight of the prostate was significantly higher than that in other included RCTs, at a mean (standard deviation (SD)) of 82.5 grams (15.5) (BTURP) and 89.2 grams (18.3) (MTURP). This large resection weight should be considered in the context of more widespread urological practice. Furthermore, it is possible that inconsistencies in the definition/method of measuring the presence of TUR syndrome across different RCTs could explain the different rates reported. Nevertheless, the evidence overall appears to be sufficiently complete for us to present conclusions regarding the clinical effectiveness of BTURP compared with MTURP, in terms of reducing TUR syndrome.

\section{Quality of the evidence}

The certainty of evidence (GRADE) was moderate for the primary outcomes of urological symptoms, bother, and TUR syndrome, and for the secondary outcomes of blood transfusion and erectile function. Certainty of evidence for these outcomes was downgraded by one level due to methodological limitations, including concerns regarding selection bias (method of randomisation and allocation concealment was unclear in $>50 \%$ of included RCTs), performance bias (blinding of operating surgeons was considered unlikely in all trials), detection bias (blinding of outcomes assessment for subjective outcomes was unclear in $>50 \%$ of included RCTs), and reporting bias (selective reporting was unclear in $>50 \%$ of included RCTs). Certainty of evidence (GRADE) was low for the secondary outcomes of urinary incontinence and re-TURP and was downgraded by one level for imprecision (small numbers of events and wide confidence intervals) and by one level for methodological limitations, with concerns regarding selection bias (method of allocation concealment was unclear in $>50 \%$ of included RCTs), performance bias (blinding of operating surgeons was considered unlikely in all trials), and reporting bias (selective reporting was unclear in $>50 \%$ of included RCTs).

Another potential source of bias is clinical heterogeneity across subgroups of interventions. For instance, BTURP represents a diverse range of interventions, with differences in equipment, magnitude of energy, and techniques. The various bipolar systems represent distinct technological advancements based on different electrophysiological principles regarding current flow. The various bipolar systems (Vista Coblation/Controlled Tissue Resection (CTR)

Bipolar versus monopolar transurethral resection of the prostate for lower urinary tract symptoms secondary to benign prostatic 
system (ACMI, Southborough, MA, USA); Gyrus (ACMI); TURis (Olympus, Tokyo, Japan); S(a)line Resectoscope (Richard Wolf $\mathrm{GmbH}$, Knittlingen, Germany); Tekno Tom (Tekno-Medical, Tuttlingen, Germany); and AUTOCON II 400 ESU (Karl Storz Endoscope, Tuttlingen, Germany)) share a common feature, namely, the ability to perform in normal saline (Issa 2008; Rassweiler 2007). However, some are considered "quasi-" rather than "true" bipolar systems because they do not meet the definition that requires both electrodes be attached to a single port (International Electrotechnical Commission 1998; www.iec.ch). Therefore, each system follows distinct electrophysiological principles regarding current flow due to the different configuration-arrangement of the active and neutral electrodes (mainly the position and shape of the latter) at the resectoscope, which may result in significant clinical effects (Faul 2008). Consequently, efficacy and principally safety should be cautiously and separately evaluated for each system (Faul 2008). In this systematic review, subgroup analyses were not performed to check for differences among the three systems evaluated in RCTs, as in previous meta-analyses (CG97 LUTS: NICE guideline, 2010; Cornu 2015; Mamoulakis 2009a), which may have introduced bias.

\section{Potential biases in the review process}

In spite of our stringent inclusion criteria and comprehensive search strategy, it is possible that not all eligible RCTs were included in the databases searched. For some older reports of RCTs, useable data were limited and contacting study authors was challenging. To reduce the risk of bias, we carefully performed the method described in the Cochrane Handbook for Systematic Reviews of Interventions (Higgins 2011). There was no deviation from the original protocol, but this was updated when required to meet updated Cochrane requirements.

One author of this review (CM) was directly involved in a large international multi-centre RCT comparing BTURP versus MTURP that is included in the present review (Mamoulakis 2013), as well as in the first focused meta-analysis published in the field (Mamoulakis 2009a). To minimise bias, the risk of bias assessment of all RCTs including Mamoulakis 2013 and GRADE certainty of evidence assessments were performed by other review authors, who were not involved in the RCTs nor in the pivotal meta-analysis (CA, MS and CA, MS, MO, respectively). On the other hand, some authors of this review (CA, MO, CM, J N'D, TL) were directly involved in a previously published similar meta-analysis in the field (Omar 2014). In this meta-analysis, the same seven outcomes were considered critical to clinical decision-making and therefore were selected for GRADE assessment in evaluating the certainty of evidence, which may have resulted in bias.

For the 11 studies not published in English (Ghozzi 2014; He 2010; Kim 2006; Mei 2010; Qian 2014; Rojo 2018; Rose 2007; Wang 2007; Wu 2005; Xin 2009; Xue 2008), study authors were able to identify other suitably trained individuals who could offer translation to allow assessment of eligibility for inclusion, data extraction, and risk of bias. To identify all potentially eligible studies, a comprehensive electronic search was undertaken in concordance with guidance provided in the Cochrane Handbook for Systematic Reviews of Interventions (Higgins 2011), along with handsearching of trial registers including ClinicalTrials.gov (https://clinicaltrials.gov/) and the World Health Organization International Clinical Trials Registry Platform (WHO ICTRP; http://www.who.int/ictrp/en) and major urological conference proceedings.
Last but not least, the number of studies was insufficient to generate funnel plots per comparison for three out of the seven outcomes of this review (i.e. urinary incontinence at 12 months, erectile dysfunction at 12 months, and repeat TURP). Consequently, risk of reporting bias cannot be ruled out.

\section{Agreements and disagreements with other studies or reviews}

We identified the following relevant systematic reviews.

- An early systematic review compared the effectiveness and safety of ablative methods (including BTURP) against MTURP for treating patients with LUTS secondary to BPO (Lourenco 2008); it included six RCTs (De Sio 2006; Kim 2006; Nuhoğlu 2006; Seckiner 2006; Singh 2005; Tefekli 2005). These are all included in the present review, with the exception of Tefekli 2005, which was excluded as it examined the use of a hybrid bipolar technique utilising vaporisation as well as resection. Urological symptoms as measured by IPSS was the primary outcome; others included maximum urinary flow rate $\left(\mathrm{Q}_{\max }\right)$, duration of operation, length of hospital stay, reoperation, and adverse events. It was concluded that data were too few to provide precise estimates, and that statistically significant differences could not be detected. Duration of the operation was the only exception, favouring BTURP, which bore significant heterogeneity and was of doubtful clinical or economic importance (Lourenco 2008).

- A subsequent focused meta-analysis - Mamoulakis 2009a - included 16 RCTs (Abascal Junquera 2006; Akçayöz 2006; Bhansali 2009; De Sio 2006; Erturhan 2007; Ho 2007; Iori 2008; Kim 2006; Lin 2006; Michielsen 2007; Nuhoğlu 2006; Patankar 2006; Rose 2007; Seckiner 2006; Singh 2005; Yang 2004), all of which are also included in the present review. Review authors concluded that no clinically relevant differences exist in short-term (up to 12 months) effectiveness (urological symptoms as measured by IPSS, bother as measured by HRQoL score, and $\mathrm{Q}_{\text {max }}$ ); no differences exist in operation duration and incidence of acute urine retention after postoperative catheter removal; and no differences exist in short-term urethral stricture/bladder neck contracture rates, but that BTURP is preferable due to a more favourable perioperative safety profile (elimination of TUR syndrome, lower incidence of clot retention, lower incidence of blood transfusion - achieved with the Gyrus system (ACMI Southborough, MA, USA) - and shorter irrigation, catheterisation, and possibly hospitalisation times). Data on the TURis system (Olympus, Tokyo, Japan) were not mature at that time to permit safe conclusions. That meta-analysis did not consider the incidence of urinary incontinence or erectile dysfunction, nor did it implement the GRADE system. However, it was noted that the quality of RCTs was relatively poor, and that limited follow-up might result in under-reporting of complications such as urethral stricture/bladder neck contracture rates.

- Two subsequent meta-analyses - Ahyai 2010; Burke 2010 - that included nine RCTs (De Sio 2006; Ho 2007; lori 2008; Michielsen 2007; Nuhoğlu 2006; Patankar 2006; Seckiner 2006; Singh 2005; Yang 2004) and 12 RCTs (Abascal Junquera 2006; De Sio 2006; Erturhan 2007; Ho 2007; lori 2008; Lin 2006; Michielsen 2007; Nuhoğlu 2006; Patankar 2006; Seckiner 2006; Singh 2005; Yang 2004), respectively, out of the 16 RCTs included in the abovementioned pivotal meta-analysis did not provide any additional information (Mamoulakis 2009a). 
- A subsequent focused meta-analysis of high quality was conducted by some of the authors of the present review (Omar 2014). This meta-analysis included 24 RCTs (Abascal Junquera 2006; Akçayöz 2006; Bhansali 2009; Chen 2009; De Sio 2006; Erturhan 2007; Fagerström 2011; Geavlete 2011; Ho 2007; Iori 2008; Kim 2006; Kong 2009; Lin 2006; Mamoulakis 2013; Méndez-Probst 2011; Michielsen 2007; Nuhoğlu 2006; Patankar 2006; Rose 2007; Seckiner 2006; Singh 2005; Singhania 2010; Yang 2004; Yousef 2010), all of which are also included in the present review. Review authors concluded that no clinically relevant differences exist in short-term (up to 12 months) effectiveness (urological symptoms as measured by IPSS, bother as measured by HRQoL score, and $\mathrm{Q}_{\max }$ ), no differences exist in the short-term incidence of adverse events (acute urine retention after postoperative catheter removal, urinary incontinence, urethral strictures, urinary tract infections, and need for reoperation), and results on erectile dysfunction are inconclusive, but that BTURP is preferable due to a more favourable safety profile (lower incidence of TUR syndrome, lower incidence of blood transfusion, and lower incidence of clot retention).

- One of the major strengths of this meta-analysis is that GRADE was applied for the first time for evaluating the certainty of evidence. The same seven outcomes as in the present review were selected. Application of GRADE showed evidence for assessed outcomes to be of moderate certainty, except for HRQoL score and erectile function (low certainty of evidence). Several major methodological limitations were identified in the included RCTs, the vast majority of which had short-term follow-up. Review authors stressed that these results should be interpreted with caution, and that larger, well-designed RCTs that adhere to the recommendations set out in the Consolidated Standards Of Reporting Trials (CONSORT) statement are needed, which include clinically important outcome measures.

- A subsequent meta-analysis - Cornu 2015 - included 23 RCTs (Akman 2013; Bhansali 2009; Chen 2010; De Sio 2006; Erturhan 2007; Fagerström 2011; Geavlete 2011; Giulianelli 2013; Ho 2007; Huang 2012; Iori 2008; Kim 2006; Kong 2009; Mamoulakis 2013; Méndez-Probst 2011; Michielsen 2007; Nuhoğlu 2006; Patankar 2006; Seckiner 2006; Singh 2005; Singhania 2010; Xie 2012; Yang 2004), all of which are also included in the present review. Review authors concluded that no clinically relevant differences exist in short-term (up to 12 months) effectiveness (urological symptoms as measured by IPSS, bother as measured by HRQoL score, and $\mathrm{Q}_{\max }$ ), catheterisation, and hospitalisation times; that no differences exist in operation duration, in the incidence of urinary tract infections, or in the short-term incidence of urethral strictures/bladder neck contractures, incontinence, and need for reoperation; and that results on erectile dysfunction are inconclusive, but BTURP is preferable due to a more favourable safety profile (elimination of TUR syndrome, lower incidence of blood transfusions, lower incidence of clot retention, lower incidence of acute urine retention after postoperative catheter removal, lower incidence of need for immediate reoperation). Neither the risk of bias tool nor GRADE was implemented in this meta-analysis.

Compared to all relevant previous meta-analyses, our present systematic review and meta-analysis represents the largest body of evidence by far, including 59 RCTs. One of the major strengths of the present meta-analysis is that the strict methods described in the
Cochrane Handbook for Systematic Reviews of Interventions - Higgins 2011 - were used and GRADE was applied in evaluating the certainty of evidence. There was no deviation from the original protocol, but this was updated when required to meet updated Cochrane requirements. Despite the fact that a limited number of outcomes were addressed compared to previous meta-analyses, results are in general agreement: no clinically relevant differences exist in shortterm (up to 12 months) effectiveness (urological symptoms as measured by IPSS, bother as measured by HRQoL score); and no differences exist in the short-term incidence of adverse events (urinary incontinence, need for re-TURP, erectile function); but BTURP may be preferable due to a more favourable perioperative safety profile (lower incidence of TUR syndrome, lower blood transfusion rates).

\section{AUTHORS' CONCLUSIONS}

\section{Implications for practice}

The lack of clinically important differences in urological symptoms and bother at 12 months when MTURP and BTURP are compared suggests that these surgical interventions can offer comparable clinical effectiveness in the management of LUTS secondary to BPO. This remains true for several other important short-term adverse events, including urinary incontinence, need for re-TURP, and erectile function. This has important implications for surgeons and patients for whom these surgical interventions are considered in the surgical management of BPO.

The ability of BTURP to potentially reduce TUR syndrome events and the need for blood transfusion suggest that it offers a favourable perioperative safety profile compared to MTURP. These benefits have potential implications in reducing morbidity and mortality associated with surgical treatment of BPO, especially in light of a reported incidence of TUR syndrome of up to $2.1 \%$ in some series (Reich 2008). This may allow for longer resection times and resection of larger prostates without risk of TUR syndrome. The allowance for longer resections may also permit further time to ensure sufficient coagulation time to secure haemostasis, thereby reducing risks of bleeding. These features may be particularly beneficial for urologists in training. However, it should be borne in mind that bipolar technology does not prevent fluid absorption (Rassweiler 2007; Starkman 2007), which may still result in fluid overload.

\section{Implications for research}

The low certainty of evidence for how BTURP and MTURP compare in terms of urinary incontinence and need for re-TURP means that these outcomes deserve further study in the form of prospective RCTs that incorporate clinically meaningful definitions and sufficient duration of follow-up (e.g. at 12 months). The potentially attenuated benefits of BTURP in patients with larger prostates, compared to MTURP, deserve further study, with potential implications for TUR syndrome and blood transfusion events. In addition, it remains unknown whether there are any differences in clinical effectiveness among the different types of BTURP as a technology, in terms of equipment, energy, and techniques, as well as the relative cost-effectiveness of BTURP technology compared to MTURP. 


\section{ACK N OWLEDGEMENTS}

We thank Professor Philipp Dahm, Co-ordinating Editor, Cochrane Urology, for advice and guidance provided with regards to Cochrane Review methods.
We are grateful to the following individuals for their kind efforts in assisting with study translation, assessment of eligibility, and data extraction for foreign language articles: Lena Lantsova, Euan Fisher, Christopher Carroll, Sergio Fdez-Pello Montes, Jae Hung, and Professor Phillipp Dahm. 


\section{R E F E R E N C E S}

\section{References to studies included in this review}

\section{Abascal Junquera 2006 \{published data only\}}

* Abascal Junquera JM, Cecchini Rosell L, Salvador Lacambra C, Martos Calvo R, Celma Domenech A, Morote Robles J. Bipolar versus monopolar transurethral resection of the prostate: perioperative analysis of the results. Actas Urologicas Españolas 2006;30(7):661-6. [PUBMED: 17058610]

\section{Acuña Lopez 2010 \{published data only\}}

* Acuña-López JA, Hernández-Torres AU, Gómez-

Guerra LS, Martínez-Montelongo R, Lozano-Salinas JF. Bipolar versus monopolar transurethral resection of the prostate: intraoperative and postoperative result analysis. Revista Mexicana de Urología 2010;70(3):146-51. [http:// revistamexicanadeurologia.com/Revistas/2010/English/MayJun/Bipolar\%20versus\%20monopolar.pdf]

\section{Ahmad 2016 \{published data only\}}

* Ahmad M, Khan H, Aminullah, Masood I, Masood W, Malik A. Comparison of bipolar and monopolar cautery use in TURP for treatment of enlarged prostate. Journal of Ayub Medical College Abbottabad 2016;28(4):758-61.

\section{Akçayöz 2006 \{published data only\}}

*Akçayöz M, Kaygisiz O, Akdemir O, Aki FT, Adsan O, Cetinkaya M. Comparison of transurethral resection and plasmakinetic transurethral resection applications with regard to fluid absorption amounts in benign prostate hyperplasia. Urologia Internationalis 2006;77(2):143-7. [PUBMED: 16888420]

\section{Akman 2013 \{published data only\}}

* Akman T, Binbay M, Tekinarslan E, Tepeler A, Akcay M, Ozgor F, Ugurlu M, Muslumanoglu A. Effects of bipolar and monopolar transurethral resection of the prostate on urinary and erectile function: a prospective randomized comparative study. British Journal of Urology International 2013;111(1):129-36. [PUBMED: 22672229]

Akman T, Binbay M, Tekinarslan E, Tepeler A, Akçay M, Özgör F, et al. Effects of bipolar and monopolar transurethral resection of the prostate on urinary and erectile functions: a prospective randomized comparative study. Journal of Endourology 2012;26(Suppl 1):A269-270.

\section{Al-Rawashdah 2017 \{published data only\}}

* Al-Rawashdah SF, Pastore AL, Salhi YA, Fuschi A, Petrozza V, Maurizi A, et al. Prospective randomized study comparing monopolar with bipolar transurethral resection of the prostate in benign prostatic obstruction: 36 -month outcomes. World Journal of Urology 2017;35(10):1595-601.

Palleschi G, Pastore AL, Al Salhi Y, Fuschi A, Velotti G, Leto A, et al. Prospective randomized study comparing monopolar with bipolar transurethral resection of prostate on a large cohort of patients with benign prostatic obstruction: long term outcomes. Journal of Urology. Conference: 112th Annual Meeting of American Urological Association, AUA 2017. United States. 197 (4 Suppl 1) (pp e448), 2017. [Conference Abstract] April 2017:197:e448.
Pastore AL, Palleschi G, Al Rawashdah S, Fuschi A, Velotti G, Leto $A$, et al. Prospective randomized study comparing monopolar with bipolar transurethral resection of prostate on a large cohort of patients with benign prostatic obstruction: long term outcomes. European Urology, Supplements. Conference: 32nd Annual European Association of Urology Congress, EAU 2017. United Kingdom. 16 (3) (pp e517-e518), 2017. [Conference Abstract] March 2017;16(3):e517-e518.

Pastore AL, Palleschi G, Illiano E, Constantini E, Al Rawshdah S, Al Salji Y, et al. Prospective randomized study comparing monopolar with bipolar transurethral resection of prostate in benign prostatic obstruction: long term outcomes. Neurourology and Urodynamics. Conference: 47th Annual Meeting of the International Conference Society, ICS 2017. Italy. 36 (pp S476-S477), 2017. [Conference Abstract] July 2017;36:S476-S477.

\section{Bahadzor 2006 \{published data only\}}

* Bahadzor B, Fadzli I, Nazri J, Zulkifli Z, Taufik M. Prospective randomized clinical trial comparing the use of plasmakinetic resection of prostate versus conventional transurethral resection of prostate In the treatment of benign prostatic hyperplasia. International Journal of Urology 2006;13(Suppl.1):A21-2.

\section{Bertolotto 2007 \{published data only\}}

* Bertolotto F, Naselli A, Vigliercio G, Raggio M, Puppo P. Prospective randomized study confronting monopolar versus bipolar TURP. 6 months follow up outcome. European Urology Supplements 2007;6(2):137.

Bertolotto F, Raggio M, Vigliercio G, Germinale F, Introini C. Monopolar vs. bipolar TUR: results of a randomised prospective study. European Urology Supplements 2006;5(2):311.

\section{Bhansali 2009 \{published data only\}}

* Bhansali M, Patankar S, Dobhada S, Khaladkar S. Management of large (>60 g) prostate gland: PlasmaKinetic Superpulse (bipolar) versus conventional (monopolar) transurethral resection of the prostate. Journal of Endourology 2009;23(1):141-5. [PUBMED: 19178175]

\section{Chen 2009 \{published data only\}}

* Chen Q, Zhang L, Liu YJ, Lu JD, Wang GM. Bipolar transurethral resection in saline system versus traditional monopolar resection system in treating large-volume benign prostatic hyperplasia. Urologia Internationalis 2009;83(1):55-9. [PUBMED: 19641360]

\section{Chen 2010 \{published data only\}}

* Chen Q, Zhang L, Fan QL, Zhou J, Peng YB, Wang Z. Bipolar transurethral resection in saline vs traditional monopolar resection of the prostate: results of a randomized trial with a 2-year follow-up. British Journal of Urology International 2010;106(9):1339-43. [PUBMED: 20477825]

\section{Choi 2006 \{published data only\}}

${ }^{*}$ Choi SH, Lee JH, Seo JH, Yoon CJ, Moon KH, Park YI, Cho SR. The comparison of PK tissue management system TURP with

Bipolar versus monopolar transurethral resection of the prostate for lower urinary tract symptoms secondary to benign prostatic 
conventional monopolar TURP. European Urology Supplements 2006;5(2):271.

\section{D'Elia 2004 \{published data only\}}

* D'Elia G, Mastrangeli B. A randomized prospective trial of bipolar versus standard monopolar transurethral resection of the prostate. European Urology Supplements 2004;3(2):235.

\section{Demirdag 2016 \{published data only\}}

* Demirdag C, Citgez S, Tunc B, Simsekoglu F, Can G, Onal B. The clinical effect of bipolar and monopolar transurethral resection of the prostate more than 60 milliliters. Urology 2016;98:132-7.

\section{De Sio 2006 \{published data only\}}

Autorino R, Damiano R, Di Lorenzo G, Quarto G, Perdonà S, D'Armiento M, et al. Four-year outcome of a prospective randomised trial comparing bipolar plasmakinetic and monopolar transurethral resection of the prostate. European Urology 2009;55(4):922-9. [PUBMED: 19185975]

Autorino R, De Sio M, D'Armiento M. Bipolar plasmakinetic technology for the treatment of symptomatic benign prostatic hyperplasia: evidence beyond marketing hype?. British Journal of Urology International 2007a;100(5):983-5. [PUBMED: 17578467]

Autorino R, De Sio M, Quarto G, Giugliano F, Mordente S, Neri F, et al. Bipolar plasmakinetic vs standard trans-urethral resection of the prostate: long term follow-up from a single institution. Journal of Endourology 2007;21(Suppl 1):A97.

De Sio M, Autorino R, Quarto G, Cosentino L, Pane U, Mordente S, et al. Gyrus ${ }^{\mathrm{TM}}$ bipolar versus standard monopolar transurethral resection of the prostate: a randomized prospective trial. Journal of Endourology 2005;19(Suppl 1):A43.

* De Sio M, Autorino R, Quarto G, Damiano R, Perdonà S, di Lorenzo G, Mordente S, D'Armiento M. Gyrus bipolar versus standard monopolar transurethral resection of the prostate: a randomized prospective trial. Urology 2006;67(1):69-72. [PUBMED: 16413335]

Kaplan SA. Four-year outcome of a prospective randomised trial comparing bipolar plasmakinetic and monopolar transurethral resection of the prostate. Editorial comment. Journal of Urology 2010;183(5):1936.

Rassweiler J. Editorial comment on: Four-year outcome of a prospective randomised trial comparing bipolar plasmakinetic and monopolar transurethral resection of the prostate. European Urology 2009;55(4):929-30. [PUBMED: 19185978]

Seitz M, Gratzke C. Editorial comment on: Four-year outcome of a prospective randomised trial comparing bipolar plasmakinetic and monopolar transurethral resection of the prostate. European Urology 2009;55(4):930-1. [PUBMED: 19185980]

\section{Eaton 2004 \{published data only\}}

* Eaton A, Francis R, Duncan N, De Silva B. A randomized prospective study comparing the performance of the $4 \mathrm{~mm}$ plasma kinetic loop against standard monopolar TURP in prostates 4-=100 gm size. European Urology Supplements 2004;3(2):145.

Eaton AC, Duncan NH. Gyrus plasmakinetic bipolar loop resection compared to conventional monopolar TURP in prostates $>40$ gms. Journal of Endourology 2003;17(7):A8.

Egui Rojo 2017 \{published data only\}

* Egui Rojo MA, Redon Galvez L, Alvarez Ardura M, Otaola Arca H, Paez Borda A. Monopolar versus bipolar transurethral resection of the prostate: evaluation of the impact on sexual function. Journal of Sexual Medicine 2017;14:e107-e197.

\section{El-Assmy 2018 \{published data only\}}

*El-Assmy A, ElShal AM, Mekkawy R, El-Kappany H, Ibrahiem EHI. Erectile and ejaculatory function changes following bipolar versus monopolar transurethral resection of the prostate: a prospective randomized study. International Urology and Nephrology 2018;50(9):1569-76.

\section{Erturhan 2007 \{published data only\}}

* Erturhan S, Erbagci A, Seckiner I, Yagci F, Ustun A. Plasmakinetic resection of the prostate versus standard transurethral resection of the prostate: a prospective randomized trial with 1-year follow-up. Prostate Cancer and Prostatic Diseases 2007;10(1):97-100. [PUBMED: 16926854 ]

\section{Fagerström 2011 \{published data only\}}

Fagerström T, Nyman CR, Hahn RG. Bipolar transurethral resection of the prostate causes less bleeding than the monopolar technique: a single-centre randomized trial of 202 patients. British Journal of Urology International 2010;105(11):1560-4. [PUBMED: 19912211]

* Fagerström T, Nyman CR, Hahn RG. Complications and clinical outcome 18 months after bipolar and monopolar transurethral resection of the prostate. Journal of Endourology 2011;25(6):1043-9. [PUBMED: 21568691]

\section{Geavlete 2011 \{published data only\}}

* Geavlete B, Georgescu D, Multescu R, Stanescu F, Jecu M, Geavlete P. Bipolar plasma vaporization vs monopolar and bipolar TURP - A prospective, randomized, long-term comparison. Urology 2011;78(4):930-5. [PUBMED: 21802121]

Geavlete B, Multescu R, Georgescu D, Stanescu F, Jecu M, Moldoveanu C, et al. Three-year prospective, randomized comparison of the bipolar plasma vaporization of the prostate, monopolar and bipolar resection in medium size BPH patients. European Urology Supplements 2013;12(4):e1276.

Geavlete B, Multescu R, Georgescu D, Stanescu F, Jecu M, Moldoveanu C, et al. Three-year prospective, randomized comparison of the bipolar plasma vaporization of the prostate, monopolar and bipolar resection in medium size BPH patients. Journal of Urology 2013;189(Suppl 4):e806-7.

Geavlete B, Multescu R, Georgescu D, Stanescu F, Moldoveanu C, Jecu M, et al. Bipolar plasma vaporization versus monopolar and bipolar resection - Which is "the better choice" in cases of average size BPH?. European Urology Supplements 2012a;11(4):99. 
Geavlete B, Multescu R, Moldoveanu C, Jecu M, Georgescu D, Geavlete P. Bipolar plasma vaporization versus monopolar and bipolar resection - Which is "the better choice" in cases of average size BPH?. Journal of Endourology 2012;26:A46.

Geavlete B, Multescu R, Stanescu F, Georgescu D, Jecu M, Geavlete P. Bipolar plasma vaporization versus monopolar and bipolar TURP - Results of a prospective, randomized, long-term comparison. Journal of Urology 2011;185(4):e907-8.

Geavlete B, Multescu R, Stanescu F, Georgescu D, Jecu M, Geavlete P. Bipolar plasma vaporization versus monopolar and bipolar TURP - results of a prospective, randomized, long term comparison. European Urology Supplements 2011a;10(2):61-2.

Geavlete B, Multescu R, Stanescu F, Georgescu D, Jecu M, Geavlete P. Bipolar plasma vaporization versus monopolar and bipolar TURP: results of a prospective, randomized, long-term comparison. Urology 2011c;78(Suppl 3A):S13.

Geavlete B, Multescu R, Stanescu F, Georgescu D, Jecu M, Moldoveanu C, Geavlete P. Bipolar plasma vaporization versus monopolar and bipolar TURP: results of a prospective, randomized, long term comparison. Journal of Endourology 2011b;25(S1):A138.

Geavlete B, Multescu R, Stanescu F, Georgescu D, Jecu M, Moldoveanu C, et al. A prospective, long term, randomized comparison of the bipolar plasma vaporization of the prostate, monopolar and bipolar resection in cases of average size prostates. Journal of Urology 2012;187(Suppl 4):e798.

\section{Ghozzi 2014 \{published data only\}}

* Ghozzi S, Ghorbel J, Ben Ali M, Dridi M, Maarouf J, Khiari R, et al. Bipolar versus monopolar transurethral resection of the prostate: a prospective randomized study [Article in French]. Progrès en Urologie 2014;24(2):121-6. [PUBMED: 24485082]

Khiari R, Ben Rais N, Rebai H, Mansouri O, Zwari MB, Cherif M, et al. Bipolar resection versus standard transurethral resection of the prostate: a prospective randomized study with 2-year follow-up. 3rd International Meeting Challenges in Endourology \& Functional Urology, Paris. 2013. [http://www.challengesendourology.com/2013/posters/PP-06.pdf]

Oussama M, Ghorbel J, Hedi R, Zouari M, Kilani T, Maaroufi J, et al. Bipolar resection versus standard transurethral resection of the prostate: a prospective randomized study with 2-year follow-up. European Urology Supplemnets 2013;12(1):e520.

\section{Giulianelli 2013 \{published data only\}}

* Giulianelli R, Albanesi L, Attisani F, Gentile BC, Vincenti G, Pisanti F, et al. Comparative randomized study on the efficaciousness of endoscopic bipolar prostate resection versus monopolar resection technique. 3 year follow-up. Archivio Italiano di Urologia e Andrologia 2013;85(2):86-91. [PUBMED: 23820656]

Giulianelli R, Gentile BC, Bmnori S, Vincent G, Akpan Patrick G. The comparative randomized study on the efficaciousness of endoscopic Gyrus prostate resection versus traditional. European Urology Supplements 2005;4(3):148.

\section{Goh 2009 \{published data only\}}

Goh M, Gulur DM, Aning J, Okeke A, Gilbert H, Kinder R, et al. Bipolar versus monopolar transurethral Resection of the prostate (TURP) for benign prostatic obstruction: a randomised prospective trial comparing treatment efficacy and the incidence of transurethral resection (TUR) syndrome. Journal of Urology 2010;183:e739. [EMBASE: 225347]

* Goh MHC, Gulur DM, Okeke AA, Gilbert HW, Kinder RB, Timoney AG. Bipolar versus monopolar transurethral resection of the prostate for benign prostatic obstruction: a randomised prospective trial with one year follow up. British Journal of Urology International 2009;103(Suppl 4):17.

Gulur DM, Goh MHC, Anning JJ, Okeke AA, Gilbert HW, Kinder RB, et al. Comparison between bipolar versus monopolar transurethral resection of the prostate: a randomized prospective trial. European Urology Supplements 2010;9(2):279.

Gulur DM, Goh MHC, Okeke AA, Gilbert HW, Kinder RB, Timoney AG. A randomised controlled trial of the incidence of TUR syndrome in bipolar versus monopolar transurethral resection of the prostate for benign prostatic obstruction. British Journal of Urology International 2009;103(Suppl 4):16-7.

Gulur DM, Goh MHC, Okeke AA, Gilbert HW, Kinder RB, Timoney AG. Transurethral resection of the prostate for benign prostatic obstruction: a comparison of the Olympus bipolar and monopolar resectoscopes from the operation surgeon's perspective. British Journal of Urology International 2010a;106(Suppl 1):21-2.

\section{He 2010 \{published data only\}}

* He JW, Xie J, Chen GY, Guan DH, LIN YW. Therapeutic efficacy of bipolar plasmakinetic resection compared with transurethral resection on benign prostate hyperplasia [Article in Chinese]. Chinese Journal of Endourology (electronic version) 2010;4(4):302-4.

\section{Ho 2007 \{published data only\}}

Hakenberg OW. Editorial comment on: A prospective randomized study comparing monopolar and bipolar transurethral resection of prostate using transurethral resection in saline (TURIS) system. European Urology 2007;52(2):523. [PUBMED: 17416452]

Ho H, Yip S, Foo KT, Cheng C. A prospective randomized controlled trial comparing bipolar transurethral resection in saline (TURIS) system and conventional monopolar transurethral resection of prostate in men with benign prostate hyperplasia: a 1 year's clinical efficacy and safety. Journal of Endourology 2005;19(Suppl 1):A47.

Ho H, Yip S, Lim K, Foo K, Cheng C. A prospective randomized controlled trial comparing bipolar transurethral resection in saline (TURIS) system and conventional monopolar transurethral resection of prostate in men with benign prostate hyperplasia: a 1 year's clinical efficacy and safety. The Journal of Urology 2006;175(4):461.

Ho H, Yip S, Lim KB, Foo KT, Cheng C. A prospective randomized controlled trial comparing bipolar transurethral resection 
in saline (TURIS) system and conventional monopolar transurethral resection of prostate in men with benign prostate hyperplasia: 1 years's clinical efficacy and safety. European Urology Supplements 2006;5(2):308.

* Ho HS, Yip SK, Lim KB, Fook S, Foo KT, Cheng CW. A prospective randomized study comparing monopolar and bipolar transurethral resection of prostate using transurethral resection in saline (TURIS) system. European Urology 2007;52(2):517-22. [PUBMED: 17416453]

Reich O. Editorial comment on: A prospective randomized study comparing monopolar and bipolar transurethral resection of prostate using transurethral resection in saline (TURIS) system. European Urology 2007;52(2):523-4. [PUBMED: 17416451]

\section{Huang 2012 \{published data only\}}

Degirmenci T, Kozacioglu Z. Re: Huang et al: Bipolar transurethral resection of the prostate causes deeper coagulation depth and less bleeding than monopolar transurethral prostatectomy (Urology 2012;80:1116-20). Urology 2013;81(2):471-2. [PUBMED: 23374838]

* Huang X, Wang L, Wang XH, Shi HB, Zhang XJ, Yu ZY. Bipolar transurethral resection of the prostate causes deeper coagulation depth and less bleeding than monopolar transurethral prostatectomy. Urology 2012;80(5):1116-20. [PUBMED: 22990062]

Mamoulakis C, Ubbink DT, Sofras F, N'Dow JM, de la Rosette JJ. Re: Huang et al: Bipolar transurethral resection of the prostate causes deeper coagulation depth and less bleeding than monopolar transurethral prostatectomy (Urology 2012;80:1116-20). Urology 2013d;81(5):1113-5. [PUBMED: 23608435]

Mandal S, Singh V, Sankhwar S. Re: Huang et al: Bipolar transurethral resection of the prostate causes deeper coagulation depth and less bleeding than monopolar transurethral prostatectomy (Urology 2012;80:1116-20). Urology 2013;81(2):468. [PUBMED: 23374832]

\section{Iori 2008 \{published data only\}}

Autorino R, De Sio M. Re: Iori F, Franco G, Leonardo C, et al. Bipolar transurethral resection of the prostate: clinical and urodynamic evaluation (Urology 2008;71:252-5). Urology 2008;72(2):462-3. [PUBMED: 18561987]

DeNunzio C, Leonardo C. Re: lori et al: Bipolar transurethral resection of the prostate: clinical and urodynamic evaluation. (Urology 2008;71:252-5). Urology 2008;72(5):1188-9. [PUBMED: 18984146]

* Iori F, Franco G, Leonardo C, Laurenti C, Tubaro A, D-Amico F, et al. Bipolar transurethral resection of prostate: clinical and urodynamic evaluation. Urology 2008;71(2):252-5. [PUBMED: 18308095]

\section{Kadyan 2014 \{published data only\}}

* Kadyan B, Kankalia SP, Sabale VP, Satav V, Bhirud P, Garg S. A prospective randomized study comparing safety and efficacy of bipolar resection versus standard transurethral resection of prostate. Indian Journal of Urology 2014;30:s155. [EMBASE: 71491390]

Kim 2006 \{published data only\}

* Kim JY, Moon KH, Yoon CJ, Park TC. Bipolar transurethral resection of the prostate: a comparative study with monopolar transurethral resection [Article in Korean]. Korean Journal of Urology 2006;47(5):493-7.

\section{Komura 2015 \{published data only\}}

Komura K, Inamoto T, Takai T, Uchimoto T, Saito K, Tanda N, et al. Could transurethral resection of the prostate using the TURis system take over conventional monopolar transurethral resection of the prostate? A randomized controlled trial and midterm results. Urology 2014;84(2):405-11. [PUBMED: 24958486]

* Komura K, Inamoto T, Takai T, Uchimoto T, Saito K, Tanda N, et al. Incidence of urethral stricture after bipolar transurethral resection of the prostate using TURis: results from a randomized trial. BJU International 2015;115(4):644-52. [PUBMED: 24909399]

\section{Kong 2009 \{published data only\}}

* Kong CH, Ibrahim MF, Zainuddin ZM. A prospective, randomized clinical trial comparing bipolar plasma kinetic resection of the prostate versus conventional monopolar transurethral resection of the prostate in the treatment of benign prostatic hyperplasia. Annals of Saudi Medicine 2009;29(6):429-32. [PUBMED: 19847078]

\section{Kumar 2013 \{published data only\}}

${ }^{*}$ Kumar A, Vasudeva P, Kumar N, Nanda B, Jha SK, Mohanty N. A prospective randomized comparative study of monopolar and bipolar transurethral resection of the prostate and photoselective vaporization of the prostate in patients who present with benign prostatic obstruction: a single center experience. Journal of Endourology 2013;27(10):1245-53. [PUBMED: 23746047]

Kumar N, Kumar A, Vasudeva P, Nanda B, Kumar R, Jha SK. Monopolar TURP vs. bipolar TURP vs. photoselective vaporization prostate: prospective randomized comparison in patient with lower urinary tract symptom secondary to benign prostatic obstruction. Indian Journal of Urology 2014;30:s46. [EMBASE: 71490887]

Kumar N, Vasudeva P, Kumar A, Singh H. Prospective randomized comparison of monopolar TURP, bipolar TURP and photoselective vaporization of the prostate in patients with benign prostatic obstruction. LUTS 2018;10:17-20.

\section{Lin 2006 \{published data only\}}

* Lin MS, Wu JC, Hsieh HL, Lin TC, Chen CC, Lin E. Comparison between monopolar and bipolar TURP in treating benign prostatic hyperplasia: 1-year report. Mid-Taiwan Journal of Medicine 2006;11:143-8.

\section{Mamoulakis 2013 \{published data only\}}

Bachmann A, Muir GH, Wyler SF, Rieken M. Surgical benign prostatic hyperplasia trials: the future is now!. European Urology 2013;63(4):677-9. [PUBMED: 23158588]

Bipolar versus monopolar transurethral resection of the prostate for lower urinary tract symptoms secondary to benign prostatic 
Cetti RJ, Hicks JA, Venn SN, Carter PG, Britton JP. Results from an international multi-centre double-blind randomized controlled trial on the perioperative efficacy and safety of bipolar vs monopolar transurethral resection of the prostate. British Journal of Urology International 2012;109(11):E38; author reply E38-40. [PUBMED: 22564326]

Hindley R. Bipolar vs monopolar transurethral resection of the prostate: evaluation of impact on overall sexual function in an international randomized controlled setting. British Journal of Urology International 2013;112(1):7-9. [PUBMED: 23759006]

Ho CC, Eng HS, Das S. Results from an international multi-centre double-blind randomized controlled trial on the perioperative efficacy and safety of bipolar vs monopolar transurethral resection of the prostate. British Journal of Urology International 2012;109(7):E22; author reply E22-4. [PUBMED: 22414177]

Kaplan SA. Re: Bipolar vs monopolar transurethral resection of the prostate: evaluation of the impact on overall sexual function in an international randomized controlled trial setting. Editorial comment. Journal of Urology 2014;191(6):1826-7.

* Mamoulakis C, Schulze M, Skolarikos A, Alivizatos G, Scarpa RM, Rassweiler JJ, et al. Midterm results from an international multi-centre randomised controlled trial comparing bipolar with monopolar transurethral resection of the prostate. European Urology 2013;63(4):667-76. [PUBMED: 23102675]

Mamoulakis C, Schulze M, Skolarikos A, Alivizatos G, Scarpa RM, Rassweiler JJ, et al. Reply from Authors re: Bachmann A, Muir GH, Wyler SF, Rieken M. Surgical benign prostatic hyperplasia trials: the future is now! European Urology 2013;63:677-9. Best Available Evidence in 2012 on Bipolar Versus Monopolar Transurethral Resection of the Prostate for Benign Prostatic Obstruction: It's About Time to Decide!. European Urology 2013a;63(4):679-80.

Mamoulakis C, Schulze M, Skolarikos A, Alivizatos G, Scarpa RM, Rassweiler JJ, et al. Results from an international multi-centre double-blind randomized controlled trial on the perioperative efficacy and safety of bipolar vs monopolar transurethral resection of the prostate. Reply. British Journal of Urology International 2012a;109(11):E38-40.

Mamoulakis C, Schulze M, Skolarikos A, Alivizatos G, Scarpa RM, Rassweiler JJ, et al. Travel-associated extended spectrum betalactamase-producing Escherichia coli bloodstream infection following transrectal ultrasound-guided prostate biopsy. Reply. British Journal of Urology 2012b;109(7):E21-4.

Mamoulakis C, Skolarikos A, Schulze M, Scoffone C, Rassweiler J, Alivizatos $\mathrm{G}$, et al. Bipolar vs monopolar TURP: impact on the overall sexual function and midterm safety-efficacy results of an international multi-centre randomized controlled trial. European Urology Supplements 2013b;12(1):e521.

Mamoulakis C, Skolarikos A, Schulze M, Scoffone CM, Rassweiler JJ, Alivizatos G, et al. Bipolar vs monopolar transurethral resection of the prostate: evaluation of the impact on overall sexual function in an international randomized controlled trial setting. British Journal of Urology International 2013c;112(1):109-20. [PUBMED: 23490008]

Mamoulakis C, Skolarikos A, Schulze M, Scoffone CM, Rassweiler JJ, Alivizatos G, et al. Results from an international multi-centre double-blind randomized controlled trial on the perioperative efficacy and safety of bipolar vs monopolar transurethral resection of the prostate. British Journal of Urology International 2012;109(2):240-8. [PUBMED: 21557796]

Mamoulakis C, Skolarikos A, Schulze M, Scoffone M, Rassweiler J, Alivizatos G, et al. Results from a randomized double-blind controlled trial on perioperative efficacy and safety of bipolar versus monopolar transurethral resection of the prostate. European Urology Supplements 2011;10(2):62.

Rioja Zuazu J, Mamoulakis C, Skolarikos A, Alivizatos G, Schulze M, Rassweiler J, et al. Bipolar versus monopolar transurethral resection of the prostate: results of an international multicenter blinded randomized clinical trial. European Urology Supplements 2009;8(4):266.

Schulze M, Mamoulakis C, Rioja J, Skolarikos A, Rassweiler J, Alivizatios $\mathrm{G}$, et al. Preliminary results from an international multicenter blinded randomized clinical trial comparing bipolar with monopolar transurethral resection of the prostate. Journal of Urology 2009;181(4 Suppl):699.

Skolarikos A, Rassweiler J, de la Rosette JJ, Alivizatos G, Scoffone C, Scarpa RM, et al. Safety and efficacy of bipolar versus monopolar transurethral resection of the prostate in patients with large prostates or severe lower urinary tract symptoms: post hoc analysis of a European multicenter randomised controlled trial. Journal of Urology 2016;195(3):677-84.

\section{Mei 2010 \{published data only\}}

* Mei HB, Wang F, Chang JP, Zhang ZL, Shi M, Ye SB, et al. Comparison of clinical effect of transurethral resection and bipolar plasma kinetic resection of benign prostatic hyperplasia [Article in Chinese]. Chinese Journal of Endourology (electronic version) 2010;4(3):1-5.

\section{Méndez-Probst 2011 \{published data only\}}

Hueber PA, Al-Asker A, Zorn KC. Monopolar vs. bipolar TURP: assessing their clinical advantages. Canadian Urological Association Journal 2011;5(6):390-1. [PUBMED: 22154631]

* Méndez-Probst CE, Nott L, Pautler SE, Razvi H. A multi-centre single-blind randomized controlled trial comparing bipolar and monopolar transurethral resection of the prostate. Canadian Urological Association Journal 2011;5(6):385-9. [PUBMED: 22154630]

\section{Michielsen 2007 \{published data only\}}

Alexander C, Omar MI. Re: Urethral strictures and bipolar transurethral resection in saline of the prostate: fact or fiction? (From: Michielsen DP, Coomans D. Journal of Endourology 2010;24:1333-7). Journal of Endourology 2013 Feb 21 [Epub ahead of print];30(7):832. [PUBMED: 23272942]

Ho H, Lim KB. Re: Bipolar transurethral resection in saline - an alternative surgical treatment for bladder outlet obstruction?

Bipolar versus monopolar transurethral resection of the prostate for lower urinary tract symptoms secondary to benign prostatic 
Michielsen DP, Debacker T, De Boe B, Van Lersberghe C, Kaufman L, Braeckman JG, et al. Journal of Urology 2007;178:2035-9. Journal of Urology 2008;179(6):2482-3; author reply 2483. [PUBMED: 18436257 ]

Michielsen DP, Coomans D. Urethral strictures and bipolar transurethral resection in saline of the prostate: fact or fiction?. Journal of Endourology 2010;24(8):1333-7. [PUBMED: 20583960]

Michielsen DP, Coomans D, Braeckman JG, Umbrain V. Bipolar transurethral resection in saline: the solution to avoid hyponatraemia and transurethral resection syndrome. Scandinavian Journal of Urology and Nephrology 2010b;44(4):228-35. [PUBMED: 20345336]

* Michielsen DP, Debacker T, De Boe V, Van Lersberghe C, Kaufman L, Braeckman JG, et al. Bipolar transurethral resection in saline - an alternative surgical treatment for bladder outlet obstruction?. Journal of Urology 2007;178(5):2035-9. [PUBMED: 17869297]

\section{Nasution 2017 \{published data only\}}

Nasution P, Nur Budaya T, Duarsa G, Prasetyawan W, Laksono K, Wijaya $\mathrm{C}$, et al. Comparative study of monopolar versus bipolar transurethral resection of the prostate versus thulium laser vaporesection of the prostate (ThuVaRP) in patients with benign prostatic hyperplasia and urinary retention: randomized multicenter study. Journal of Clinical Urology. Conference: 2017 Annual Scientific Meeting of the British Association of Urological Surgeons, BAUS 2017. United Kingdom. June 2017; Vol. 10 (2 Suppl 1):69.

\section{Nuhoğlu 2006 \{published data only\}}

* Nuhoğlu B, Ayyildiz A, Karagüzel E, Cebeci O, Germiyanoğlu C. Plasmakinetic prostate resection in the treatment of benign prostate hyperplasia: results of 1-year follow up. International Journal of Urology 2006;13(1):21-4. [PUBMED: 16448427]

\section{Patankar 2006 \{published data only\}}

Patankar S. Comparison between plasmakinetic resection of prostate and monopolar TURP: a prospective randomized trial with 5-year follow-up. Journal of Urology 2012;187(4 Suppl 1):e878-9.

* Patankar S, Jamkar A, Dobhada S, Gorde V. PlasmaKinetic Superpulse transurethral resection versus conventional transurethral resection of prostate. Journal of Endourology 2006;20(3):215-9. [PUBMED: 16548733]

Patankar S, Rasal D, Shah R, Oza N. Comparison between plasmakinetic resection of prostate and monopolar TURP: a prospective randomized trial with 5-year follow-up. Urology 2011;78(Suppl 3A):S13-4.

Patankar SB, Dobhada SH. Superpulse bipolar prostate resection $\mathrm{V} / \mathrm{s}$ conventional TURP: a randomized prospective trial with 3 months follow up - an Indian experience. Journal of Endourology 2004;18(Suppl 1):A77.

Qian 2014 \{published data only\}

* Qian P, Li Mingtao. Study of transurethral bipolar plasma kinetic resection operation for treatment of benign prostatic hyperplasia patients and its effect on sexual function. Chinese Journal of Andrology 2014;28(6):52-4.

Rojo 2018 \{published data only\}

* Rojo MAE, Galvez LR, Ardura MA, Arca HO, Borda AP. Comparison of monopolar versus bipolar transurethral resection of the prostate: evaluation of the impact on sexual function. Andrologia 2018;212:1-7.

Rose 2007 \{published data only\}

* Rose A, Suttor S, Goebell PJ, Rossi R, Rübben H. Transurethral resection of bladder tumors and prostate enlargement in physiological saline solution (TURIS). A prospective study. Urologe A 2007;46(9):1148-50. [PUBMED: 17619851]

\section{Seckiner 2006 \{published data only\}}

* Seckiner I, Yesilli C, Akduman B, Altan K, Mungan NA. A prospective randomized study for comparing bipolar plasmakinetic resection of the prostate with standard TURP. Urologia Internationalis 2006;76(2):139-43. [PUBMED: 16493215]

Seckiner I, Yesilli C, Akduman B, Altan K, Mungan NA. TURP vs plasmakinetic resection of the prostate: results of a prospective randomized study. European Urology Supplements 2005;4(3):148.

\section{Shaik 2017 \{published data only\}}

* Shaik JA, Devraj R, Vidyasager, Ram Reddy CH. Bipolar versus monopolar transurethral resection of the prostate for benign prostatic obstruction: a randomized prospective study. Indian Journal of Urology 2017;33:(Suppl 1).

Singh 2005 \{published data only\}

* Singh H, Desai MR, Shrivastav P, Vani K. Bipolar versus monopolar transurethral resection of prostate: randomized controlled study. Journal of Endourology 2005;19(3):333-8. [PUBMED: 15865523]

\section{Singhania 2010 \{published data only\}}

* Singhania P, Nandini D, Sarita F, Hemant P, Hemalata I. Transurethral resection of prostate: a comparison of standard monopolar versus bipolar saline resection. International Brazilian Journal of Urology 2010;36(2):183-9. [PUBMED: 20450503]

\section{Stucki 2014 \{published data only\}}

* Stucki P, Marini L, Mattei A, Xafis K, Boldini M, Danuser H. Bipolar versus monopolar transurethral resection of the prostate: a prospective randomized trial focusing on bleeding complications. Journal of Urology 2014 Nov 20;193(4):pii: S0022-5347(14)04936-2. doi: 10.1016/j.juro.2014.08.137. [Epub ahead of print]. [PUBMED: 25464004]

Stucki P, Mattei A, Marini L, Xafis K, Danuser H. Bipolar versus monopolar transurethral resection of the prostate: a prospective randomized trial focusing on bleeding complications. Journal of Urology 2013;189(Suppl 4):e817.

\section{Symons 2002 \{published data only\}}

* Symons S, Browning A, Chahal R. A comparative study of the Gyrus plasmakinetic electrosurgical system versus conventional loop electroresection (TURP) for the treatment of bladder

Bipolar versus monopolar transurethral resection of the prostate for lower urinary tract symptoms secondary to benign prostatic 
outflow obstruction - six month data. European Urology Supplements 2002;1(1):169.

\section{Terrone 2006 \{published data only\}}

Poggio M, Scoffone C, Cecilia C, Scarpa RM. Bipolar versus monopolar TURP: a randomized study. Journal of Endourology 2006;20(Suppl 1):A87.

* Terrone C, Scoffone C, Cracco C, Poggio M, Tarabuzzi R, Morra I, et al. Bipolar versus monopolar TURP: a randomized study. European Urology Supplements 2006;5(2):235.

\section{Wang 2007 \{published data only\}}

* Wang D, Lu J, Xia S, Zhu J, Sun X, Zhang Q, Wen W. A comparative study of transurethral plasma kinetic resection versus transurethral resection of the prostate for benign prostatic hyperplasia [Article in Chinese]. Journal of Clinical Urology 2007;22(7):520-2

Wu 2005 \{published data only\}

* Wu WJ, Wang XH, Wang HP, Zou WB, Liang XY, Cai ZG, et al. Therapeutic efficacy of bipolar plasmakinetic technique compared with transurethral resection on benign prostate hyperplasia. National Medical Journal of China 2005;85(47):3365-7.

\section{Xie 2012 \{published data only\}}

${ }^{*}$ Xie CY, Zhu GB, Wang XH, Liu XB. Five-year follow-up results of a randomized controlled trial comparing bipolar plasmakinetic and monopolar transurethral resection of the prostate. Yonsei Medical Journal 2012;53(4):734-41. [PUBMED: 22665339]

\section{Xin 2007 \{published data only\}}

${ }^{*}$ Xin G, Xingqiao W, Jianguang Q, Yubin C. A prospective randomized study comparing gyrus bipolar and standard monopolar transurethral resection of the prostate. Journal of Endourology 2007;21(Suppl 1):A102.

Xin 2009 \{published data only\}

* Xin L, Zhu J, Yao B. Transurethral prostate ion bipolar electrosurgical excision efficacy. Medical Journal of Communications 2009;23(6):685-7.

\section{Xue 2008 \{published data only\}}

* Xue S, Ma HQ, Ge JP, Wei W, Zhou WQ, Zhou SG, et al. A comparative study of two different surgical procedures for benign prostatic hyperplasia [Article in Chinese]. Journal of Postgraduate Medicine 2008;21(3):283-6.

\section{Yang 2004 \{published data only\}}

* Yang S, Lin WC, Chang HK, Hsu JM, Lin WR, Chow YC, et al. Gyrus plasmasect: is it better than monopolar transurethral resection of prostate?. Urologia Internationalis 2004;73(3):258-61. [PUBMED: 15539847]

\section{Yousef 2010 \{published data only\}}

* Yousef AA, Suliman GA, Elashry OM, Elsharaby MD, Elgamasy Ael-N. A randomized comparison between three types of irrigating fluids during transurethral resection in benign prostatic hyperplasia. BioMed Central Anesthesiology 2010 May 28;10(7):doi:10.1186/1471-2253-10-7. [PUBMED: 20509864]

\section{References to studies excluded from this review}

Demir 2015 \{published data only\}

* Demir A, Karadag MA, Cecen K, Uslu M, Arslan OE. Monopolar versus plasmakinetic energy effect on prostatic tissue damage in terms of PSA levels: a prospective randomised trial. Urologia Internationalis 2015;95:265-8.

\section{El Saied Hafez 2013 \{published data only\}}

* El Saied Hafez MH, El Din Abd El Hamid MH, Abd El Raouf S, Soaida SM, Marie MM. Bipolar versus monopolar transurethral prostate resection: comparison of hemodynamic and biochemical changes. Egyptian Journal of Anaesthesiology 2014;30(1):47-52. [EMBASE: 2014067679]

Engeler 2010 \{published data only\}

* Engeler DS, Schwab C, Neyer M, Grün T, Reissigl A, Schmid HP. Bipolar versus monopolar TURP: a prospective controlled study at two urology centers. Prostate Cancer and Prostatic Diseases 2010;13(3):285-91. [PUBMED: 20142841]

Fung 2005 \{published data only\}

* Fung BT, Li SK, Yu CF, Lau BE, Hou SS. Prospective randomized controlled trial comparing plasmakinetic vaporesection and conventional transurethral resection of the prostate. Asian Journal of Surgery 2005;28(1):24-8. [PUBMED: 15691793]

Inzuna 2017 \{published data only\}

Inzunza G, Rada G, Majerson A. Bipolar or monopolar transurethral resection for benign prostatic hyperplasia? [Review]. Medwave 2018;18(1):e7134.

\section{Kwon 2011 \{published data only\}}

* Kwon JS, Lee JW, Lee SW, Choi HY, Moon HS. Comparison of effectiveness of monopolar and bipolar transurethral resection of the prostate and open prostatectomy in large benign prostatic hyperplasia. Korean Journal of Urology 2011;52(4):269-73. [PUBMED: 21556214]

\section{Liangyu 2006 \{published data only\}}

* Liangyu X, Dirong C, Xiaogang L, Jianye D. A comparative study on erectile dysfunction after transurethral plasma kinetic resection of prostate or TURP for BPH [Article in Chinese]. Chinese Journal of Andrology 2006;20(11):34-6.

Lv 2012 \{published data only\}

* Lv L, Wang L, Fan M, Ju W, Pang Z, Zhu Z, et al. Two-year outcome of high-risk benign prostate hyperplasia patients treated with transurethral prostate resection by plasmakinetic or conventional procedure. Urology 2012;80(2):389-94. [PUBMED: 22698467]

Rodriguez AR. Editorial comment. Urology 2012;80(2):394-5; author reply 395. [PUBMED: 22698468]

\section{Michielsen 2010b \{published data only\}}

* Michielsen DP, Coomans D, Peeters I, Braeckman JG. Conventional monopolar resection or bipolar resection in saline for the management of large (>60 g) benign prostatic hyperplasia: an evaluation of morbidity. Minimally Invasive 
Therapy and Allied Technologies 2010;19(4):207-13. [PUBMED: 20642387]

\section{Michielsen 2011 \{published data only\}}

* Michielsen DP, Coomans D, Van Lersberghe C, Braeckman JG. Comparison of the haemostatic properties of conventional monopolar and bipolar transurethral resection of the prostate in patients on oral anticoagulants. Archives of Medical Science 2011;7(5):856-63. [PUBMED: 22291832]

\section{Muslumanoglu 2012 \{published data only\}}

Muslumanoglu AY, Yuruk E, Binbay M, Akman T. Transurethral resection of prostate with plasmakinetic energy: 100 months results of a prospective randomized trial. British Journal of Urology International 2012;10(4):546-9. [PUBMED: 22115409]

Muslumanoglu AY, Yuruk E, Binbay M, Akman T. Transurethral resection of prostate with plasmakinetic energy: 100 months results of a prospective randomized trial. European Urology Supplements 2011;10(9):583.

\section{Neyer 2011 \{published data only\}}

Neyer M, Engeler D, Schwab C, Pointner J, Grun T, Schmid HP, et al. A prospective controlled study comparing bipolar versus monopolar transurethral resection of the prostate. Journal of Urology 2010;183(4):e738-9.

Neyer M, Reissigl A, Schwab C, Bachmayer C, Abt D, Schmid HP, Engeler D. A prospective controlled study comparing bipolar versus monopolar transurethral resection of the prostate: longterm outcome. European Urology Supplements 2011;10(2):62.

* Neyer M, Reissigl A, Schwab C, Pointner J, Abt D, Bachmayer C, et al. Bipolar versus monopolar transurethral resection of the prostate: results of a comparative, prospective bicenter study - perioperative outcome and long-term efficacy. Urologia Internationalis 2013;90(1):62-7. [PUBMED: 23147406]

\section{Tefekli 2005 \{published data only\}}

Ho H, Yip S, Foo KT. Re: A hybrid technique using bipolar energy in transurethral prostate surgery: a prospective, randomized comparison. Journal of Urology 2006a;175(5):1965; author reply 1965-6. [PUBMED: 16600811]

* Tefekli A, Muslumanoglu AY, Baykal M, Binbay M, Tas A, Altunrende $F$. A hybrid technique using bipolar energy in transurethral prostate surgery: a prospective, randomized comparison. Journal of Urology 2005;174(4 Pt 1):1339-43. [PUBMED: 16145415]

\section{Treharne 2018 \{published data only\}}

Treharne C, Crowe L, Booth D, Ihara Z. Economic value of the transurethral resection in saline system for treatment of benign prostatic hyperplasia in England and Wales: systematic review, meta-analysis, and cost-consequence model. European Urology Focus 2018;4(2):270-9.

\section{Valdivia Uría 2005 \{published data only\}}

* Valdivia Uría JG, Regojo Zapata O, Sánchez Zalabardo JM, Elizalde Benito A, Navarro Gil J, Hijazo Conejos I. Transurethral resection with saline solution: a technological achievement not yet assimilated by the urological community [Article in
Spanish]. Archivos Españoles de Urología 2005;58(4):335-45. [PUBMED: 15989098]

\section{Vasudeva 2019 \{published data only\}}

Vasudeva P, Kumar N, Kumar A, Kumar G, Patel M, Gupta P. Impact of monopolar TURP, bipolar TURP and photoselective vaporization of prostate for enlarged prostate on erectile function. Luts 2019;11(1):24-9.

\section{Yoon 2006 \{published data only\}}

* Yoon CJ, Kim JY, Moon KH, Jung HC, Park TC. Transurethral resection of the prostate with a bipolar tissue management system compared to conventional monopolar resectoscope: one-year outcome. Yonsei Medical Journal 2005;47(5):715-20. [PUBMED: 17066516]

\section{Zhang 2013 \{published data only\}}

* Zhang HM, Zheng JH, Xu YF, Peng B, Yan Y, Gao QR. Improvement of erectile function in patients with benign prostatic hyperplasia undergoing transurethral plasmakinetic resection of the prostate. International Journal of Urology 2013;20(7):724-8. [PUBMED: 23305506]

\section{Additional references}

\section{Abrams 2002}

Abrams $P$, et al. The standardisation of terminology of lower urinary tract function: report from the Standardisation Sub-committee of the International Continence Society. Neurourology and Urodynamics 2002;21(2):167-78.

\section{Abrams 2009}

Abrams P, Chapple C, Khoury S, Roehrborn C, de la Rosette J. Evaluation and treatment of lower urinary tract symptoms in older men. Journal of Urology 2009;181(4):1779-87. [PUBMED: 19233402]

\section{Agarwal 2014}

Agarwal A, et al. What is the most bothersome lower urinary tract symptom? Individual and population-level perspectives for both men and women. European Urology 2014;65(6):1211-7.

\section{Ahyai 2010}

Ahyai SA, Gilling P, Kaplan SA, Kuntz RM, Madersbacher S, Montorsi F, et al. Meta-analysis of functional outcomes and complications following transurethral procedures for lower urinary tract symptoms resulting from benign prostatic enlargement. European Urology 2010;58(3):384-97. [PUBMED: 20825758]

\section{AUA 2018}

Foster HE, Barry MJ, Gandh MCi, Kaplan SA, Kohler T, Lerner LB, et al. Surgical management of lower urinary tract symptoms attributed to benign prostatic hyperplasia (2018). American Urological Association Guidelines Retrieved from http:// www.auanet.org/guidelines/surgical-management-of-lowerurinary-tract-symptoms-attributed-to-benign-prostatichyperplasia-(2018);(accessed June 2018):612-9. 


\section{Burke 2010}

Burke N, Whelan JP, Goeree L, Hopkins RB, Campbell K, Goeree R, et al. Systematic review and meta-analysis of transurethral resection of the prostate versus minimally invasive procedures for the treatment of benign prostatic obstruction. Urology 2010;75(5):1015-22. [PUBMED: 19854492]

\section{CG97 LUTS: NICE guideline, 2010}

Lower Urinary Tract Symptoms: Full Guideline [CG97]. London: National Institute for Health and Clinical Excellence, 2010.

\section{Corbett 2014}

Corbett MS, Higgins JPT, Woolacott NF. Assessing baseline imbalance in randomised trials: implications for the Cochrane risk of bias tool. Research Synthesis Methods 2015;5:79-85.

\section{Cornu 2015}

Cornu JN, Ahyai S, Bachmann A, de la Rosette J, Gilling P, Gratzke C, et al. A systematic review and meta-analysis of functional outcomes and complications following transurethral procedures for lower urinary tract symptoms resulting from benign prostatic obstruction: an update. European Urology 2015;67(6):1066-96. [PUBMED: 24972732]

\section{EAU 2018}

Gravas S, Cornu JN, Drake MJ, Gacci M, Gratzke C, Herrmann TRW, et al. Treatment of non-neurogenic male LUTS. European Association of Urology Guidelines 2018; Vol. Retreived from http://uroweb.org/guideline/treatment-of-nonneurogenic-male-luts/, issue accessed June 2018.

\section{Egger 1997}

Egger M, Davey Smith G, Schneider M, Minder C. Bias in metaanalysis detected by a simple, graphical test. British Medical Journal 1997;315(7109):629-34. [PUBMED: 9310563]

\section{Faul 2008}

Faul P, Schlenker B, Gratzke C, Stief CG, Reich O, Hahn RG. Clinical and technical aspects of bipolar transurethral prostate resection. Scandinavian Journal of Urology and Nephrology 2008;42(4):318-23. [PUBMED: 18622807]

\section{Guyatt 2008}

Guyatt GH, Oxman AD, Kunz R, Vist GE, Falck-Ytter Y, Schünemann HJ, GRADE Working Group. What is "quality of evidence" and why is it important to clinicians?. British Medical Journal 2008;336(7651):995-8. [PUBMED: 18456631]

\section{Guyatt 2011a}

Guyatt G, Oxman AD, Akl EA, Kunz R, Vist G, Brozek J, et al. GRADE guidelines: 1. Introduction - GRADE evidence profiles and summary of findings tables. Journal of Clinical Epidemiology 2011;64(4):383-94. [PUBMED: 21195583]

\section{Guyatt 2011b}

Guyatt GH, Oxman AD, Kunz R, Atkins D, Brozek J, Vist G, et al. GRADE guidelines: 2 . Framing the question and deciding on important outcomes. Journal of Clinical Epidemiology 2011;64(4):395-400. [PUBMED: 21194891]

\section{Guyatt 2011c}

Guyatt GH, Oxman AD, Vist G, Kunz R, Brozek J, Alonso-Coello P, et al. GRADE guidelines: 4. Rating the quality of evidence study limitations (risk of bias). Journal of Clinical Epidemiology 2011;64(4):407-15. [PUBMED: 21247734]

\section{Guyatt 2011d}

Guyatt GH, Oxman AD, Montori V, Vist G, Kunz R, Brozek J, et al. GRADE guidelines: 5 . Rating the quality of evidence - publication bias. Journal of Clinical Epidemiology 2011;64(12):1277-82. [PUBMED: 21802904]

\section{Guyatt 2011e}

Guyatt G, Oxman AD, Kunz R, Brozek J, Alonso-Coello P, Rind $D$, et al. GRADE guidelines 6 . Rating the quality of evidence - imprecision. Journal of Clinical Epidemiology 2011;64(12):1283-93. [PUBMED: 21839614]

\section{Guyatt $2011 f$}

Guyatt GH, Oxman AD, Kunz R, Woodcock J, Brozek J, Helfand M, et al. GRADE guidelines: 7. Rating the quality of evidence - inconsistency. Journal of Clinical Epidemiology 2011;64(12):1294-302. [PUBMED: 21803546]

\section{Guyatt 2011g}

Guyatt GH, Oxman AD, Kunz R, Woodcock J, Brozek J, Helfand M, et al. GRADE guidelines: 8 . Rating the quality of evidence - indirectness. Journal of Clinical Epidemiology 2011;64(12):1303-10. [PUBMED: 21802903]

\section{Guyatt 2011h}

Guyatt GH, Oxman AD, Sultan S, Glasziou P, Akl EA, AlonsoCoello P, et al. GRADE guidelines: 9. Rating up the quality of evidence. Journal of Clinical Epidemiology 2011;64(12):1311-6. [PUBMED: 21802902]

\section{Hahn 1993}

Hahn RG. Ethanol monitoring of extravascular absorption of irrigation fluid. British Journal of Urology 1993;72:766-9.

\section{Higgins 2003}

Higgins JP, Thompson SG, Deeks JJ, Altman DG. Measuring inconsistency in meta-analyses. British Medical Journal 2003;327(7414):557-60. [PUBMED: 12958120]

\section{Higgins 2011}

Higgins JPT, Green S (editors). Cochrane Handbook for Systematic Reviews of Interventions. Version 5.1.0 (updated March 2011). The Cochrane Collaboration, 2011. Available from www.handbook.cochrane.org.

\section{Hozo 2005}

Hozo SP, Djulbegovic B, Hozo I. Estimating the mean and variance from the median, range, and the size of a sample. BMC Medical Research Methodology 2005;5(13):doi: https:// doi.org/10.1186/1471-2288-5-13.

\section{Isaacs 1989}

Isaacs JT, Coffey DS. Etiology and disease process of benign prostatic hyperplasia. Prostate Suppl 1989;2:33-50. 


\section{Issa 2008}

Issa MM. Technological advances in transurethral resection of the prostate: bipolar versus monopolar TURP. Journal of Endourology 2008;22(8):1587-95. [PUBMED: 18721041]

\section{Kirby 2010}

Kirby RS, Kirby M, Fitzpatrick JM. Benign prostatic hyperplasia: counting the cost of its management. British Journal of Urology International 2010;105(7):901-2. [PUBMED: 20356323]

\section{Kupelian 2006}

Kupelian V, et al. Prevalence of lower urinary tract symptoms and effect on quality of life in a racially and ethnically diverse random sample: the Boston Area Community Health (BACH) Survey. Archives of Internal Medicine 2006;166(21):2381-7.

\section{Lepor 1993}

Lepor $\mathrm{H}$. The role of alpha blockage in the treatment of BPH. In: Lepor H, Lawson R editor(s). Prostatic Diseases. Philadelphia: WB Saunders, 1993:170-81.

\section{Liberati 2009}

Liberati A, Altman DG, Tetzlaff J, Mulrow C, Gotzsche PC, Ioannidis JPA, et al. The PRISMA statement for reporting systematic reviews and meta-analyses of studies that evaluate health care interventions: explanation and elaboration. PLOS Med 2009;6(7):doi: https://doi.org/10.1136/bmj.b2700.

\section{Lourenco 2008}

Lourenco T, Pickard R, Vale L, Grant A, Fraser C, MacLennan G, et al. Alternative approaches to endoscopic ablation for benign enlargement of the prostate: systematic review of randomised controlled trials. British Medical Journal 2008;337:a449. [PUBMED: 18595932]

\section{Mamoulakis 2009}

Mamoulakis C, Trompetter M, de la Rosette J. Bipolar transurethral resection of the prostate: the 'golden standard' reclaims its leading position. Current Opinion in Urology 2009;19(1):26-32. [PUBMED: 19057207]

\section{Mamoulakis 2009a}

Mamoulakis C, Ubbink DT, de la Rosette JJ. Bipolar versus monopolar transurethral resection of the prostate: a systematic review and meta-analysis of randomized controlled trials. European Urology 2009;56(5):798-809. [PUBMED: 19595501]

\section{Mamoulakis 2010}

Mamoulakis C, de la Rosette JJ, Ubbink DT. Re: Burke et al: Systematic review and meta-analysis of transurethral resection of the prostate versus minimally invasive procedures for the treatment of benign prostatic obstruction (Urology 2010;75:1015-22). Urology 2010; Vol. 75, issue 5:1235-6; author reply 1236-7. [PUBMED: 20451750]

\section{Mebust 1989}

Mebust WK, Holtgrewe HL, Cockett ATK, et al. Transurethral prostatectomy: immediate and postoperative complications. A cooperative study of thirteen participating institutions evaluating 3,885 patients. Journal of Urology 1989;141:243-7.

\section{Omar 2014}

Omar MI, Lam TBL, Cameron A, Graham J, Mamoulakis C, Imamura M, et al. Systematic review and meta-analysis of the clinical effectiveness of bipolar compared to monopolar transurethral resection of the prostate. British Journal of Urology International 2014;113(1):24-35. [PUBMED: 24053602]

\section{Rassweiler 2007}

Rassweiler J, Schulze M, Stock C, Teber D, De La Rosette J. Bipolar transurethral resection of the prostate - technical modifications and early clinical experience. Minimally Invasive Therapy and Allied Technologies 2007;16(1):11-21. [PUBMED: 17365673]

\section{Reich 2006}

Reich O, Gratzke C, Stief CG. Techniques and long-term results of surgical procedures for BPH. European Urology 2006;49(6):970-8; discussion 978. [PUBMED: 16481092]

\section{Reich 2008}

Reich O, Gratzke C, Bachmann A, Seitz M, Schlenker B, Hermanek $P$, et al. Morbidity, mortality and early outcome of transurethral resection of the prostate: a prospective multicenter evaluation of 10,654 patients. Journal of Urology 2008;180(1):246-9. [PUBMED: 18499179]

\section{Rosen 2003}

Rosen R, Altwein J, Boyle P, et al. Lower urinary tract symptoms and male sexual dysfunction: the multinational survey of the aging male (MSAM-7). European Urology 2003;44:637-49.

\section{Speakman 2015}

Speakman M, Kirby R, Doyle S, Ioannou C. Burden of male lower urinary tract symptoms (LUTS) suggestive of benign prostatic hyperplasia (BPH) - focus on the UK. BJU International 2015;115:508-19.

\section{Starkman 2007}

Starkman JS, Santucci RA. Comparison of bipolar transurethral resection of the prostate with standard transurethral prostatectomy: shorter stay, earlier catheter removal and fewer complications. British Journal of Urology International 2005;95(1):69-71. [PUBMED: 15638897]

\section{Sterne 2011}

Sterne JAC, Sutton AJ, Ionnadis JPA, Terrin N, Jones DR, et al. Recommendations for examining and interpreting funnel plot asymmetry in meta-analyses of randomised controlled trials. BMJ 2011;342:doi: https://doi.org/10.1136/bmj.d4002.

\section{van Exel 2006}

van Exel NJ, Koopmanschap MA, McDonnel J, Chapple CR, Berges R, Rutten FF. Medical consumption and costs during a one-year follow-up of patients with LUTS suggestive of BPH in six European countries: report of the TRIUMPH study. European Urology 2006;49:92-102.

\section{Wendt-Nordhal 2004}

Wendt-Nordahl G, Hacker A, Reich O, Djaven B, Alken P, Michel MS. The Vista system: a new bipolar resection device 
for endourological procedures: comparison with conventional resectoscope. European Urology 2004;46:586-90.

\section{References to other published versions of this review}

Mamoulakis 2014

Mamoulakis C, Sofras F, de la Rosette J, Omar MI, Lam TBL, N'Dow JMO, Ubbink DT. Bipolar versus monopolar transurethral

\section{CHARACTERISTICS OF STUDIES}

Characteristics of included studies [ordered by study ID]

Abascal Junquera 2006

Methods - Study type: single-centre randomised controlled trial (1:1)

- Setting: Spain resection of the prostate for lower urinary tract symptoms secondary to benign prostatic obstruction. Cochrane Database of Systematic Reviews 2014.

* Indicates the major publication for the study

- Total participants enrolled: $45 ;(A)=24,(B)=21$

- Inclusion criteria: clinical diagnosis of symptomatic BPH with USS prostate volume between 30 and 70 grams

- Exclusion criteria: anticoagulant therapy, neurogenic bladder, de-obstructive surgery for prostate adenocarcinoma or suspected adenocarcinoma, indwelling bladder catheter

\section{Baseline characteristics:}

No significant differences between arms reported

Age, years (SD): $(A)=69.5(9.5),(B)=67.3(9.2)$

Mean preoperative prostate volume, grams (SD): $(A)=39.5(9.8),(B)=42.5(11.6)$

Preoperative catheterisation state: not reported

Interventions

- Intervention A: bipolar TURP (Olympus SurgMaster)

- Intervention B: monopolar TURP (Storz, irrigation fluid = glycine)

Outcomes

\section{Primary outcomes:}

IPSS (12 months): not reported

HRQoL (12 months): not reported

TUR syndrome: $(A)=0(n=24),(B)=0(n=21)$

\section{Secondary outcomes:}

Blood transfusion: $(A)=0(n=24),(B)=0(n=21)$

Urinary incontinence (12 months): not reported

Erectile dysfunction (IIEF-5) (12 months): not reported

Need for repeat TURP (i.e. re-TURP): not reported

\section{Other reported outcomes: \\ Acute urinary retention \\ Mean duration of resection time \\ Mean duration of catheterisation \\ Mean duration of hospital stay}

Bipolar versus monopolar transurethral resection of the prostate for lower urinary tract symptoms secondary to benign prostatic 
Abascal Junquera 2006 (Continued)

Mean duration of irrigation

Mean reduction in serum sodium

Mean reduction in haematocrit

\begin{tabular}{ll}
\hline Source of funding None reported \\
\hline Notes
\end{tabular}

\section{Risk of bias}

\begin{tabular}{lll}
\hline Bias & Authors' judgement & Support for judgement \\
\hline $\begin{array}{lll}\text { Random sequence gener- } \\
\text { ation (selection bias): All } \\
\text { outcomes }\end{array}$ & Unclear risk & Not reported \\
\hline
\end{tabular}

\begin{tabular}{lll}
\hline $\begin{array}{l}\text { Allocation concealment } \\
\text { (selection bias): All out- } \\
\text { comes }\end{array}$ & Unclear risk & Not reported \\
\hline $\begin{array}{l}\text { Blinding of participants } \\
\text { and personnel (perfor- } \\
\text { mance bias): All outcomes }\end{array}$ & High risk & $\begin{array}{l}\text { Not reported but considered unlikely that operating surgeons were blinded to } \\
\text { interventions }\end{array}$ \\
\hline
\end{tabular}

Blinding of outcome as-
sessment (detection bias):
Subjective outcomes
(IPSS, HRQoL, IIEF-5, TUR
syndrome, Urinary Inconti-
nence)

\begin{tabular}{|c|c|c|}
\hline $\begin{array}{l}\text { Blinding of outcome as- } \\
\text { sessment: Objective out- }\end{array}$ & Low risk & $\begin{array}{l}\text { These objective outcomes are not likely affected by blinding of outcome as- } \\
\text { sessment }\end{array}$ \\
\hline
\end{tabular}
comes (Blood transfusion, Re-TURP)

Unclear risk Not reported

\begin{tabular}{|c|c|c|}
\hline $\begin{array}{l}\text { Incomplete outcome da- } \\
\text { ta (attrition bias): Imme- } \\
\text { diate postoperative out- } \\
\text { comes (TUR syndrome, } \\
\text { Blood transfusion) }\end{array}$ & Unclear risk & $\begin{array}{l}\text { This study does not explicitly report on attrition, exclusion of participants from } \\
\text { analyses, or the presence of incomplete outcome data }\end{array}$ \\
\hline
\end{tabular}

\begin{tabular}{|c|c|c|}
\hline $\begin{array}{l}\text { Incomplete outcome data } \\
\text { (attrition bias): Long-term } \\
\text { outcomes (IPSS/HRQoL/ } \\
\text { IIEF-5/urinary inconti- } \\
\text { nence at } 12 \text { months, and } \\
\text { re-TURP) }\end{array}$ & Unclear risk & These outcomes were not assessed by this trial \\
\hline $\begin{array}{l}\text { Selective reporting (re- } \\
\text { porting bias): All outcomes }\end{array}$ & Unclear risk & $\begin{array}{l}\text { RCT protocol could not be identified to allow for full judgement on selective } \\
\text { reporting }\end{array}$ \\
\hline
\end{tabular}

Methods $\quad$ Study type: single-centre randomised controlled trial (1:1)




\section{- Setting: Mexico}
Participants
- Total participants enrolled: $30 ;(A)=15,(B)=15$
- Inclusion criteria: diagnosis of BPH, presenting with ultrasound prostate volume between 20 and 80 $\mathrm{mL}$
- Exclusion criteria: anticoagulant therapy with neurogenic bladder suspected or diagnosed prostate adenocarcinoma

\section{Baseline characteristics:}

No significant differences between arms reported

Age, years: $(A)=68.1,(B)=67.4$

Mean preoperative prostate volume, grams (SD): $(A)=49.6(17.1),(B)=58.8(14.6)$

Preoperative catheterisation state: not reported

- Intervention B: monopolar TURP; monopolar resector, irrigation fluid = glycine

\section{Outcomes}

\section{Primary outcomes:}

IPSS (12 months): not reported

HRQoL (12 months): not reported

TUR syndrome: $(A)=0(n=15),(B)=0(n=15)$

\section{Secondary outcomes:}

Blood transfusion: $(A)=0(n=15),(B)=0(n=15)$

Urinary incontinence (12 months): not reported

Erectile dysfunction (IIEF-5) (12 months): not reported

Need for repeat TURP (i.e. re-TURP): not reported

\section{Other reported outcomes:}

Clot retention

Acute urinary retention

Mean duration of resection

Mean duration of catheterisation

Mean duration of hospital stay

Mean duration of irrigation

Mean decrease in serum sodium

$\%$ change in haematocrit

Incidence of postoperative clot evacuation

Trial also provided subjective assessment of cutting capacity, intraoperative visibility, degree of fragment adherence to blade, bleeding during cutting 
Acuña Lopez 2010 (Continued)

Notes

\section{Risk of bias}

\begin{tabular}{lll}
\hline Bias & Authors' judgement & Support for judgement \\
\hline $\begin{array}{lll}\text { Random sequence gener- } \\
\begin{array}{l}\text { ation (selection bias): All } \\
\text { outcomes }\end{array}\end{array}$ & Unclear risk & Not reported \\
\hline
\end{tabular}

Allocation concealment Unclear risk Not reported
(selection bias): All out-
comes

\begin{tabular}{|c|c|c|}
\hline $\begin{array}{l}\text { Blinding of participants } \\
\text { and personnel (perfor- } \\
\text { mance bias): All outcomes }\end{array}$ & High risk & $\begin{array}{l}\text { Not reported but considered unlikely that operating surgeons were blinded to } \\
\text { interventions }\end{array}$ \\
\hline
\end{tabular}

Blinding of outcome as- $\quad$ Unclear risk $\quad$ Not reported
sessment (detection bias):
Subjective outcomes
(IPSS, HRQoL, IIEF-5, TUR
syndrome, Urinary Inconti-
nence)

\begin{tabular}{ll}
\hline $\begin{array}{l}\text { Blinding of outcome as- } \\
\text { sessment: Objective out- } \\
\text { comes (Blood transfusion, }\end{array}$ & Low risk \\
Re-TURP) & $\begin{array}{l}\text { These objective outcomes are not likely affected by blinding of outcome as- } \\
\text { sessment }\end{array}$ \\
\hline
\end{tabular}

Incomplete outcome da- Unclear risk This study does not explicitly report on attrition, exclusion of participants from ta (attrition bias): Imme- analyses, or the presence of incomplete outcome data

diate postoperative out-

comes (TUR syndrome,

Blood transfusion)

\begin{tabular}{|c|c|c|}
\hline $\begin{array}{l}\text { Incomplete outcome data } \\
\text { (attrition bias): Long-term } \\
\text { outcomes (IPSS/HRQoL/ } \\
\text { IIEF-5/urinary inconti- } \\
\text { nence at } 12 \text { months, and } \\
\text { re-TURP) }\end{array}$ & Unclear risk & These outcomes were not assessed by this trial \\
\hline $\begin{array}{l}\text { Selective reporting (re- } \\
\text { porting bias): All outcomes }\end{array}$ & Unclear risk & $\begin{array}{l}\text { RCT protocol could not be identified to allow for full judgement on selective } \\
\text { reporting }\end{array}$ \\
\hline
\end{tabular}

\section{Ahmad 2016}

\begin{tabular}{ll}
\hline Methods & Study type: single-centre randomised controlled trial $(1: 1)$ \\
& Setting: Pakistan \\
\hline Participants & Total participants enrolled: $220 ;(A)=110,(B)=110$ \\
& Inclusion criteria: symptomatic enlarged prostate based on IPSS \\
& Exclusion criteria: bladder stone, urethral stricture, previous prostatic surgery, neurogenic bladder, \\
& any urological malignancy
\end{tabular}

Bipolar versus monopolar transurethral resection of the prostate for lower urinary tract symptoms secondary to benign prostatic 
Ahmad 2016 (Continued)

\section{Baseline characteristics:}

Mean age, years (SD): $(A)=69.5(10.93), n=110,(B)=69.1(11.72), n=110$

Mean preoperative prostate volume, $\mathrm{mL}(\mathrm{SD}):(\mathrm{A})=50.4(26.34), \mathrm{n}=110,(\mathrm{~B})=48.9(18.6), \mathrm{n}=110$

Preoperative catheterisation state: not reported

$\begin{array}{ll}\text { Interventions } & \text { Intervention A: bipolar TURP (specific technology not reported) } \\ & \text { - Intervention B: monopolar TURP (specific technology not reported, irrigation fluid = glycine } 1.5 \% \text { ) }\end{array}$

Outcomes

Primary outcomes:

IPSS at 12 months: not reported

HRQoL at 12 months: not reported

TUR syndrome: $(A)=0(n=110),(B)=0(n=110)$

\section{Secondary outcomes:}

Blood transfusion: $(A)=1(n=110),(B)=0(n=110)$

Urinary incontinence at 12 months: not reported

IIEF-5 at 12 months: not reported

Need for re-TURP: not reported

\section{Other reported outcomes:}

$\mathrm{Q}_{\max }(\mathrm{mL} / \mathrm{s})$

Duration of resection (minutes)

Amount of tissue resected (grams)

Hospital stay (days)

Duration of catheterisation (days)

Source of funding Not reported

\section{Notes}

\section{Risk of bias}

\begin{tabular}{lll}
\hline Bias & Authors' judgement & Support for judgement \\
\hline $\begin{array}{l}\text { Random sequence gener- } \\
\text { ation (selection bias): All } \\
\text { outcomes }\end{array}$ & Unclear risk & Not reported \\
\hline $\begin{array}{l}\text { Allocation concealment } \\
\text { (selection bias): All out- } \\
\text { comes }\end{array}$ & Unclear risk & Not reported \\
\hline $\begin{array}{l}\text { Blinding of participants } \\
\text { and personnel (perfor- } \\
\text { mance bias): All outcomes }\end{array}$ & High risk & Not reported but considered unlikely that operating surgeons were blinded to \\
\hline $\begin{array}{l}\text { Blinding of outcome as- } \\
\text { sessment (detection bias): }\end{array}$ & Unclear risk & Not reported \\
\hline
\end{tabular}

Bipolar versus monopolar transurethral resection of the prostate for lower urinary tract symptoms secondary to benign prostatic 
Ahmad 2016 (Continued)

Subjective outcomes

(IPSS, HRQoL, IIEF-5, TUR

syndrome, Urinary Inconti-

nence)

\begin{tabular}{|c|c|c|}
\hline $\begin{array}{l}\text { Blinding of outcome as- } \\
\text { sessment: Objective out- }\end{array}$ & Low risk & $\begin{array}{l}\text { Not reported but these objective outcomes are not likely affected by blinding } \\
\text { of outcome assessment }\end{array}$ \\
\hline
\end{tabular}
comes (Blood transfusion, Re-TURP)

$\begin{array}{ll}\begin{array}{l}\text { Incomplete outcome da- } \\ \text { ta (attrition bias): Imme- } \\ \text { diate postoperative out- }\end{array} & \begin{array}{l}\text { This study reports that all participants }(\mathrm{n}=220) \text { were included in the analyses } \\ \text { fomes (TUR syndrome, } \\ \text { flood transfusion) }\end{array}\end{array}$

Incomplete outcome data Unclear risk These outcomes were not assessed by this trial

(attrition bias): Long-term

outcomes (IPSS/HRQoL/

IIEF-5/urinary inconti-

nence at 12 months, and re-TURP)

$\begin{array}{ll}\begin{array}{l}\text { Selective reporting (re- } \\ \text { porting bias): All outcomes }\end{array} & \text { Unclear risk }\end{array} \begin{aligned} & \text { RCT protocol could not be identified to allow for full judgement on selective } \\ & \text { reporting }\end{aligned}$

\section{Akman 2013}

$\begin{array}{ll}\text { Methods } & \text { - Study type: single-centre randomised controlled trial }(1: 1) \\ & \text { - Setting: Turkey }\end{array}$

- Setting: Turkey

\section{Participants}

- Total participants enrolled: $286 ;(A)=143,(B)=143$

- Inclusion criteria: moderate or severe LUTS (IPSS > 16) with failed medical therapy (at least 2 weeks), recurrent urinary retention, able to give fully informed consent

- Exclusion criteria: neurogenic bladder dysfunction, previous prostatic or urethral surgery, prostate cancer, bladder calculus, bladder tumour and coagulopathy, suspicion of prostate cancer (abnormal DRE findings, higher serum PSA levels), urethral stricture

\section{Baseline characteristics:}

No significant differences between arms reported

Mean age, years $(S D):(A)=67.4(9.3),(B)=67.7(7.7)$

Mean preoperative prostate volume, $\mathrm{mL}(\mathrm{SD}):(\mathrm{A})=59.7$ (24.9), $(\mathrm{B})=55.9(23.9)$

Preoperative catheterisation state: not reported

$\begin{array}{ll}\text { Interventions } & \text { Intervention A: bipolar TURP (Olympus UES } 40 \text { SurgMasterSystem) } \\ \text { - Intervention B: monopolar TURP (Martine ME } 411 \text { Electrosurgical Generator, irrigation fluid = glycine) }\end{array}$

Outcomes

\section{Primary outcomes:}

IPSS (12 months): mean IPSS (SD) (12 months): $(A)=10.3(3.0)(n=127),(B)=10.8(2.9)(n=130)$

HRQoL (12 months): not reported

TUR syndrome: $(A)=0(n=143),(B)=2(n=143)$

Bipolar versus monopolar transurethral resection of the prostate for lower urinary tract symptoms secondary to benign prostatic obstruction (Review)

Copyright $\odot 2019$ The Cochrane Collaboration. Published by John Wiley \& Sons, Ltd. 
Akman 2013 (Continued)

\section{Secondary outcomes:}

Blood transfusion: $(A)=3(n=143),(B)=8(n=143)$

Urinary incontinence (12 months): $(A)=0(n=127),(B)=0(n=130)$

Erectile dysfunction (IIEF-5) (12 months): results represented only in graphical format with no specific data reported

Need for repeat TURP (i.e. re-TURP): $(A)=6(n=34),(B)=4(n=33)$ (2012 BJUI paper)

\section{Other reported outcomes:}

$\mathrm{Q}_{\max }$

Clot retention

Urethral stricture

Bladder neck contracture

Operation duration

Catheterisation duration

Hospitalisation duration

Postoperative haemoglobin drop

Postoperative serum sodium drop

Source of funding None reported

Notes

\section{Risk of bias}

\begin{tabular}{lll}
\hline Bias & Authors' judgement & Support for judgement \\
\hline $\begin{array}{l}\text { Random sequence gener- } \\
\text { ation (selection bias): All } \\
\text { outcomes }\end{array}$ & Unclear risk & Not reported \\
\hline $\begin{array}{l}\text { Allocation concealment } \\
\text { (selection bias): All out- } \\
\text { comes }\end{array}$ & Unclear risk & Not reported \\
\hline $\begin{array}{l}\text { Blinding of participants } \\
\text { and personnel (perfor- } \\
\text { mance bias): All outcomes }\end{array}$ & High risk & $\begin{array}{l}\text { Not reported but considered unlikely that operating surgeons were blinded to } \\
\text { interventions }\end{array}$ \\
\hline
\end{tabular}

\begin{tabular}{|c|c|c|}
\hline $\begin{array}{l}\text { Blinding of outcome as- } \\
\text { sessment (detection bias): } \\
\text { Subjective outcomes } \\
\text { (IPSS, HRQoL, IIEF-5, TUR } \\
\text { syndrome, Urinary Inconti- } \\
\text { nence) }\end{array}$ & Unclear risk & Not reported \\
\hline
\end{tabular}

$\begin{array}{ll}\text { Blinding of outcome as- } & \text { Low risk } \\ \text { sessment: Objective out- } & \text { Not reported but these objective outcomes are not likely affected by blinding } \\ \text { of outcome assessment }\end{array}$
comes (Blood transfusion, Re-TURP) 
Akman 2013 (Continued)

Incomplete outcome data (attrition bias): Immediate postoperative outcomes (TUR syndrome, Blood transfusion)
Unclear risk This study does not explicitly report on attrition, exclusion of participants from analyses, or the presence of incomplete outcome data for these outcomes
Incomplete outcome data (attrition bias): Long-term outcomes (IPSS/HRQoL/ IIEF-5/urinary incontinence at 12 months, and re-TURP)
Unclear risk

Study states: "in the monopolar TURP group 130/143 (90.1\%) were followed for at least one year, and in the bipolar TURP group, 127/143 were followed for the same period"

This study provides specific reasons for all patient dropouts and losses to follow-up for these outcomes. It is considered unclear how such incomplete outcome data would impact observed differences in reported outcomes

\begin{tabular}{lll}
$\begin{array}{l}\text { Selective reporting (re- } \\
\text { porting bias): All outcomes }\end{array}$ & Unclear risk & $\begin{array}{l}\text { RCT protocol could not be identified to allow for full judgement on selective } \\
\text { reporting }\end{array}$ \\
\hline
\end{tabular}

\section{Akçayöz 2006}

$\begin{array}{ll}\text { Methods } & \text { Study type: single-centre randomised controlled trial (1:1) } \\ \text { - Setting: Turkey }\end{array}$

Participants Total participants enrolled: $42 ;(A)=21,(B)=21$

- Inclusion criteria: clinical BPH

- Exclusion criteria: suspicion of prostatic adenocarcinoma, urethral stricture, bladder stones, neurological disorders, respiratory problems, previous prostatic urethral or bladder surgery

\section{Baseline characteristics:}

No statistically significant differences between arms reported

Mean age, years (SD): $(A)=67(7),(B)=66(9)$

Mean preoperative prostate volume, $\mathrm{mL}(\mathrm{SD})$ : $(\mathrm{A})=40(13),(B)=47(15)$

Preoperative catheterisation state: not reported

$\begin{array}{ll}\text { Interventions } & \text { Intervention A: bipolar TURP (Gyrus Plasmakinetic) } \\ & \text { - Intervention B: monopolar TURP, irrigation fluid }=1.5 \% \text { glycine }\end{array}$

Outcomes

\section{Primary outcomes:}

IPSS (12 months): not reported

HRQoL (12 months): not reported

TUR syndrome: $(A)=0(n=21),(B)=0(n=21)$

\section{Secondary outcomes:}

Blood transfusion: $(A)=0(n=21),(B)=0(n=21)$

Urinary incontinence (12 months): not reported

Erectile dysfunction (IIEF-5) (12 months): not reported

Need for repeat TURP (i.e. re-TURP): not reported

\section{Other reported outcomes:}


Akçayöz 2006 (Continued)

Operation time

Resected prostate weight

Postoperative serum sodium

Intraoperative fluid absorption

\begin{tabular}{ll}
\hline Source of funding None reported \\
\hline Notes
\end{tabular}

\section{Risk of bias}

\begin{tabular}{lll}
\hline Bias & Authors' judgement & Support for judgement \\
\hline $\begin{array}{lll}\text { Random sequence gener- } \\
\text { ation (selection bias): All }\end{array}$ & Unclear risk & Not reported \\
outcomes & & \\
\hline
\end{tabular}

Allocation concealment $\quad$ Unclear risk Not reported
(selection bias): All out-
comes

\begin{tabular}{|c|c|c|}
\hline $\begin{array}{l}\text { Blinding of participants } \\
\text { and personnel (perfor- } \\
\text { mance bias): All outcomes }\end{array}$ & High risk & $\begin{array}{l}\text { Not reported but considered unlikely that operating surgeons were blinded to } \\
\text { interventions }\end{array}$ \\
\hline
\end{tabular}

\begin{tabular}{|c|c|c|}
\hline $\begin{array}{l}\text { Blinding of outcome as- } \\
\text { sessment (detection bias): } \\
\text { Subjective outcomes } \\
\text { (IPSS, HRQoL, IIEF-5, TUR } \\
\text { syndrome, Urinary Inconti- } \\
\text { nence) }\end{array}$ & Unclear risk & Not reported \\
\hline $\begin{array}{l}\text { Blinding of outcome as- } \\
\text { sessment: Objective out- } \\
\text { comes (Blood transfusion, } \\
\text { Re-TURP) }\end{array}$ & Low risk & $\begin{array}{l}\text { Not reported but these objective outcomes are not likely affected by blinding } \\
\text { of outcome assessment }\end{array}$ \\
\hline $\begin{array}{l}\text { Incomplete outcome da- } \\
\text { ta (attrition bias): Imme- } \\
\text { diate postoperative out- } \\
\text { comes (TUR syndrome, } \\
\text { Blood transfusion) }\end{array}$ & Unclear risk & $\begin{array}{l}\text { This study does not explicitly report on attrition, exclusion of participants from } \\
\text { analyses, or the presence of incomplete outcome data for these outcomes }\end{array}$ \\
\hline $\begin{array}{l}\text { Incomplete outcome data } \\
\text { (attrition bias): Long-term } \\
\text { outcomes (IPSS/HRQoL/ } \\
\text { IIEF-5/urinary inconti- } \\
\text { nence at } 12 \text { months, and } \\
\text { re-TURP) }\end{array}$ & Unclear risk & These outcomes were not assessed by this trial \\
\hline $\begin{array}{l}\text { Selective reporting (re- } \\
\text { porting bias): All outcomes }\end{array}$ & Unclear risk & $\mathrm{RCT}$ protocol not available to allow for full decision on selective reporting \\
\hline
\end{tabular}


Al-Rawashdah 2017

\begin{tabular}{ll}
\hline Methods & Study type: single-centre randomised controlled trial $(1: 1)$ \\
& Setting: Italy \\
\hline Participants & Total participants enrolled: $497 ;(A)=246,(B)=251$ \\
- Inclusion criteria: $B P H$ scheduled to undergo TURP \\
- Exclusion criteria: bleeding disorders, prostate cancer, neurogenic bladder, previous urethral or pro- \\
$\quad$ static surgery \\
Baseline characteristics: \\
Mean age, years (SD): $(A)=67.7(0.6)(n=246),(B)=67.0(0.7)(n=251)$ \\
Mean preoperative prostate volume, $m L(S D):(A)=53.95(0.16),(B)=54.11(0.17)$ \\
Preoperative catheterisation state: $n o t$ reported
\end{tabular}

Interventions

- Intervention A: bipolar TURP (specific technology = Gyrus PK Super-Pulse Olympus)

- Intervention B: monopolar TURP (specific technology = Karl Storz and ERBE Generator, irrigation fluid = sorbitol/mannitol irrigation fluid)

\section{Outcomes}

\section{Primary outcomes:}

IPSS at 12 months: $(A)=7.75(0.10)(n=251),(B)=7.89(0.10)(n=246)$

HRQoL at 12 months: $(A)=0.81(0.05)(n=251),(B)=0.84(0.05)(n=246)$

TUR syndrome: $(A)=0(n=251),(B)=7(n=246)$

\section{Secondary outcomes:}

Blood transfusion: $(A)=0(n=251),(B)=5(n=246)$

Urinary incontinence at 12 months: not reported

IIEF-5 at 12 months: not reported

Need for re-TURP: not reported

\section{Other reported outcomes:}

$\mathrm{Q}_{\max }$

PVR

Operative time

PSA level drop

Length of hospitalisation

Time of catheterisation

Urinary retention

Postoperative haemoglobin drop

Postoperative sodium drop

Urethral stricture

Bladder neck contracture

Source of funding None


Al-Rawashdah 2017 (Continued)

Notes

\section{Risk of bias}

\begin{tabular}{lll}
\hline Bias & Authors' judgement & Support for judgement \\
\hline $\begin{array}{l}\text { Random sequence gener- } \\
\begin{array}{l}\text { ation (selection bias): All } \\
\text { outcomes }\end{array}\end{array}$ & Low risk & "All 497 patients..enrolled in this study were computer randomized (simple \\
& & randomization 1:1)" \\
\hline
\end{tabular}

\begin{tabular}{|c|c|c|}
\hline $\begin{array}{l}\text { Allocation concealment } \\
\text { (selection bias): All out- } \\
\text { comes }\end{array}$ & Unclear risk & Specific method used to conceal allocation sequence not reported \\
\hline $\begin{array}{l}\text { Blinding of participants } \\
\text { and personnel (perfor- } \\
\text { mance bias): All outcomes }\end{array}$ & High risk & Not reported but considered unlikely that operating surgeons were blinded \\
\hline $\begin{array}{l}\text { Blinding of outcome as- } \\
\text { sessment (detection bias): } \\
\text { Subjective outcomes } \\
\text { (IPSS, HRQoL, IIEF-5, TUR } \\
\text { syndrome, Urinary Inconti- } \\
\text { nence) }\end{array}$ & Unclear risk & Not reported \\
\hline $\begin{array}{l}\text { Blinding of outcome as- } \\
\text { sessment: Objective out- } \\
\text { comes (Blood transfusion, } \\
\text { Re-TURP) }\end{array}$ & Low risk & $\begin{array}{l}\text { Not reported but objective outcomes unlikely to be affected by blinding of out- } \\
\text { come assessment }\end{array}$ \\
\hline $\begin{array}{l}\text { Incomplete outcome da- } \\
\text { ta (attrition bias): Imme- } \\
\text { diate postoperative out- } \\
\text { comes (TUR syndrome, } \\
\text { Blood transfusion) }\end{array}$ & Unclear risk & $\begin{array}{l}\text { This study does not explicitly report on attrition, exclusion of participants from } \\
\text { analyses, or the presence of incomplete outcome data for these outcomes } \\
\text { specifically }\end{array}$ \\
\hline
\end{tabular}

\begin{tabular}{|c|c|c|}
\hline $\begin{array}{l}\text { Incomplete outcome data } \\
\text { (attrition bias): Long-term } \\
\text { outcomes (IPSS/HRQoL/ } \\
\text { IIEF-5/urinary inconti- } \\
\text { nence at } 12 \text { months, and } \\
\text { re-TURP) }\end{array}$ & Low risk & $\begin{array}{l}\text { Study states: "all patients completed the follow-up visits at } 3,12,24 \text {, and } 36 \\
\text { months" }\end{array}$ \\
\hline $\begin{array}{l}\text { Selective reporting (re- } \\
\text { porting bias): All outcomes }\end{array}$ & Unclear risk & RCT protocol could not be identified for full judgement on selective reporting \\
\hline
\end{tabular}

\section{Bahadzor 2006}

\begin{tabular}{ll}
\hline Methods & Study type: single-centre randomised controlled trial (1:1); conference abstract only available for \\
data extraction \\
- Setting: Malaysia
\end{tabular}

Participants

- Total number enrolled: $103 ;(A)=52,(B)=51$

- Included: benign prostatic hyperplasia (BPH)

- Exclusion criteria: not reported

- Age: not reported

Bipolar versus monopolar transurethral resection of the prostate for lower urinary tract symptoms secondary to benign prostatic obstruction (Review)

Copyright $\odot 2019$ The Cochrane Collaboration. Published by John Wiley \& Sons, Ltd. 
Bahadzor 2006 (Continued)

- Baseline characteristics: not reported

\begin{tabular}{ll}
\hline Interventions & Intervention A: bipolar TURP (Plasma Kinetic Resection of Prostate) \\
& - Intervention B: monopolar TURP, irrigation fluid = not reported \\
\hline
\end{tabular}

Outcomes

\section{Primary outcomes:}

IPSS (12 months): not reported

HRQoL (12 months): not reported

TUR syndrome: not reported

\section{Secondary outcomes:}

Blood transfusion: not reported

Urinary incontinence (12 months): not reported

Erectile dysfunction (IIEF-5) (12 months): not reported

Need for repeat TURP (i.e. re-TURP): not reported

\section{Other reported outcomes:}

Acute urinary retention

Abstract states that data recorded for mean operative time, haemoglobin drop, serum sodium level, duration of catheterisation, hospital stay, IPSS, QoL, and PVR at 1 month but no specific data reported in abstract

\begin{tabular}{ll}
\hline Source of funding & None reported \\
\hline Notes & This is a conference abstract with limited information \\
\hline
\end{tabular}

\section{Risk of bias}

\begin{tabular}{lll}
\hline Bias & Authors' judgement & Support for judgement \\
\hline $\begin{array}{ll}\text { Random sequence gener- } \\
\text { ation (selection bias): All }\end{array}$ & Unclear risk & Not reported \\
outcomes & \\
\hline
\end{tabular}

Allocation concealment $\quad$ Unclear risk $\quad$ Not reported
(selection bias): All out-
comes

\begin{tabular}{lll}
\hline $\begin{array}{l}\text { Blinding of participants } \\
\text { and personnel (perfor- } \\
\text { mance bias): All outcomes }\end{array}$ & High risk & Not reported but considered unlikely that operating surgeons were blinded \\
\hline $\begin{array}{l}\text { Blinding of outcome as- } \\
\text { sessment (detection bias): }\end{array}$ & Unclear risk & Not reported \\
$\begin{array}{l}\text { Subjective outcomes } \\
\text { (IPSS, HRQoL, IIEF-5, TUR } \\
\text { syndrome, Urinary Inconti- } \\
\text { nence) }\end{array}$ & \\
\hline
\end{tabular}

Blinding of outcome as-
sessment: Objective out- $\quad$ These outcomes were not reported by this trial


Bahadzor 2006 (Continued) comes (Blood transfusion, Re-TURP)

\begin{tabular}{|c|c|c|}
\hline $\begin{array}{l}\text { Incomplete outcome da- } \\
\text { ta (attrition bias): Imme- } \\
\text { diate postoperative out- } \\
\text { comes (TUR syndrome, } \\
\text { Blood transfusion) }\end{array}$ & Unclear risk & These outcomes were not reported \\
\hline $\begin{array}{l}\text { Incomplete outcome data } \\
\text { (attrition bias): Long-term } \\
\text { outcomes (IPSS/HRQoL/ } \\
\text { IIEF-5/urinary inconti- } \\
\text { nence at } 12 \text { months, and } \\
\text { re-TURP) }\end{array}$ & Unclear risk & These outcomes were not reported \\
\hline $\begin{array}{l}\text { Selective reporting (re- } \\
\text { porting bias): All outcomes }\end{array}$ & Unclear risk & RCT protocol not available to allow for full judgement \\
\hline
\end{tabular}

\section{Bertolotto 2007}

Methods - Study type: multi-centre (3-centre) randomised controlled trial (1:1); only published abstract available for data extraction

- Setting: Italy

\section{Participants}

- Total number enrolled: $100 ;(A)=52,(B)=48$

- Inclusion criteria: candidates for surgery for obstructive symptoms, prostate estimated volume $<100$ $\mathrm{mL}, \mathrm{Q}_{\max } \leq 15 \mathrm{~mL} / \mathrm{s}, \mathrm{IPSS} \geq 13$, PSA $\leq 4 \mathrm{ng} / \mathrm{L}$

- Exclusion criteria: not reported

Baseline characteristics: reported only for overall cohort and not individual arms

Age, years:not reported for both arms (median age overall $=71$ )

\begin{tabular}{ll}
\hline Interventions & Intervention A: bipolar TURP (TURis; Olympus Surgmaster) \\
& - Intervention B: monopolar TURP, irrigation fluid = glycine
\end{tabular}

Outcomes

\section{Primary outcomes:}

IPSS (12 months): not reported

HRQoL (12 months): not reported

TUR syndrome: $(A)=0(n=52),(B)=0(n=48)$

\section{Secondary outcomes:}

Blood transfusion: not reported

Urinary incontinence (12 months): not reported

Erectile dysfunction (IIEF-5) (12 months): not reported

Need for repeat TURP (i.e. re-TURP): not reported

\section{Other reported outcomes:}

Urethral stricture 
Bertolotto 2007 (Continued)

Bladder neck contracture

Operation duration

$\mathrm{Q}_{\max }$ at 6 months

IPSS at 6 months

\begin{tabular}{ll}
\hline Source of funding & None reported \\
\hline Notes & $\begin{array}{l}\text { This is a conference abstract with limited information. Patient population identical to that reported in a } \\
\text { previously published abstract by the same authors (Bertolotto 2006) }\end{array}$
\end{tabular}

\section{Risk of bias}

\begin{tabular}{lll}
\hline Bias & Authors' judgement & Support for judgement \\
\hline $\begin{array}{l}\text { Random sequence gener- } \\
\text { ation (selection bias): All } \\
\text { outcomes }\end{array}$ & Unclear risk & Not reported \\
\hline $\begin{array}{l}\text { Allocation concealment } \\
\text { (selection bias): All out- } \\
\text { comes }\end{array}$ & Unclear risk & Not reported \\
\hline
\end{tabular}

Blinding of participants $\quad$ High risk Not reported but considered unlikely that operating surgeons were blinded
$\begin{aligned} & \text { and personnel (perfor- } \\ & \text { mance bias): All outcomes }\end{aligned}$

Blinding of outcome as-
sessment (detection bias):
Subjective outcomes
(IPSS, HRQoL, IIEF-5, TUR
syndrome, Urinary Inconti-
nence)

Unclear risk Not reported

Blinding of outcome as- Unclear risk These outcomes were not assessed by this trial
sessment: Objective out-
comes (Blood transfusion,
Re-TURP)

\begin{tabular}{|c|c|c|}
\hline $\begin{array}{l}\text { Incomplete outcome da- } \\
\text { ta (attrition bias): Imme- } \\
\text { diate postoperative out- } \\
\text { comes (TUR syndrome, } \\
\text { Blood transfusion) }\end{array}$ & Unclear risk & $\begin{array}{l}\text { This study does not explicitly report on attrition, exclusion of participants from } \\
\text { analyses, or the presence of incomplete outcome data for these outcomes } \\
\text { specifically }\end{array}$ \\
\hline $\begin{array}{l}\text { Incomplete outcome data } \\
\text { (attrition bias): Long-term } \\
\text { outcomes (IPSS/HRQoL/ } \\
\text { IIEF-5/urinary inconti- } \\
\text { nence at } 12 \text { months, and } \\
\text { re-TURP) }\end{array}$ & Unclear risk & These outcomes were not reported \\
\hline $\begin{array}{l}\text { Selective reporting (re- } \\
\text { porting bias): All outcomes }\end{array}$ & Unclear risk & RCT protocol not available to allow for full judgement \\
\hline
\end{tabular}


Bhansali 2009

\begin{tabular}{ll}
\hline Methods & Study type: single-centre randomised controlled trial $(1: 1)$ \\
& Setting: India
\end{tabular}

\section{Baseline characteristics:}

No significant differences between groups for reported characteristics

Age: not reported

Mean preoperative prostate gland size, grams (SD): $(A)=82.38(17.965),(B)=82.61(19.157)$

Preoperative catheterisation state: not reported

\begin{tabular}{ll}
\hline Interventions & Intervention A: bipolar TURP (Plasmakinetic Superpulse System - 24 Gyrus) \\
& - Intervention B: monopolar TURP (ValleyLab, irrigation fluid = glycine)
\end{tabular}

Outcomes Primary outcomes:

IPSS (12 months): not reported specifically, only AUA scores

HRQoL (12 months): not reported

TUR syndrome: $(A)=0(n=34),(B)=4(n=33)$

\section{Secondary outcomes:}

Blood transfusion: not reported

Urinary incontinence (12 months): not reported

Erectile dysfunction (IIEF-5) (12 months): not reported

Need for repeat TURP (i.e. re-TURP): not reported

\section{Other reported outcomes:}

$\mathrm{Q}_{\max }(3,9,12$ months)

Urethral stricture

Bladder neck contracture

Mean blood loss $(\mathrm{mL})$

Hospitalisation duration

Catheterisation duration

\begin{tabular}{ll}
\hline Source of funding & Study states "no financial conflict of interest" but does not report funding for study specifically \\
\hline Notes & Study authors contacted regarding absence of specific data on postoperative AUASS and QoL scores \\
\hline Risk of bias & \\
\hline
\end{tabular}

Bipolar versus monopolar transurethral resection of the prostate for lower urinary tract symptoms secondary to benign prostatic 
Bhansali 2009 (Continued)

\begin{tabular}{lll} 
Bias & Authors' judgement & Support for judgement \\
\hline $\begin{array}{l}\text { Random sequence gener- } \\
\text { ation (selection bias): All }\end{array}$ & Low risk & Study states: "patients were randomised 1:1 using envelopes into two groups" \\
outcomes & &
\end{tabular}

\begin{tabular}{|c|c|c|}
\hline $\begin{array}{l}\text { Allocation concealment } \\
\text { (selection bias): All out- } \\
\text { comes }\end{array}$ & Unclear risk & $\begin{array}{l}\text { Unclear whether the envelopes were sequentially numbered, opaque, and } \\
\text { sealed }\end{array}$ \\
\hline
\end{tabular}

\begin{tabular}{|c|c|c|}
\hline $\begin{array}{l}\text { Blinding of participants } \\
\text { and personnel (perfor- } \\
\text { mance bias): All outcomes }\end{array}$ & High risk & $\begin{array}{l}\text { Participants were blinded but considered unlikely that operating surgeons } \\
\text { were blinded }\end{array}$ \\
\hline
\end{tabular}

\begin{tabular}{|c|c|c|}
\hline $\begin{array}{l}\text { Blinding of outcome as- } \\
\text { sessment (detection bias): } \\
\text { Subjective outcomes } \\
\text { (IPSS, HRQoL, IIEF-5, TUR } \\
\text { syndrome, Urinary Inconti- } \\
\text { nence) }\end{array}$ & Low risk & $\begin{array}{l}\text { "In the study, participants were blinded regarding the treatment modality they } \\
\text { were receiving, as were the staff members who had done the outcome assess- } \\
\text { ment of the patient's treatment, including decision to remove the catheter in } \\
\text { post-operative period" }\end{array}$ \\
\hline $\begin{array}{l}\text { Blinding of outcome as- } \\
\text { sessment: Objective out- } \\
\text { comes (Blood transfusion, } \\
\text { Re-TURP) }\end{array}$ & Unclear risk & These outcomes were not reported by this trial \\
\hline $\begin{array}{l}\text { Incomplete outcome da- } \\
\text { ta (attrition bias): Imme- } \\
\text { diate postoperative out- } \\
\text { comes (TUR syndrome, } \\
\text { Blood transfusion) }\end{array}$ & Unclear risk & $\begin{array}{l}\text { This study does not explicitly report on attrition, exclusion of participants from } \\
\text { analyses, or the presence of incomplete outcome data for these outcomes } \\
\text { specifically }\end{array}$ \\
\hline
\end{tabular}

Incomplete outcome data Unclear risk These outcomes were not reported by the trial

(attrition bias): Long-term

outcomes (IPSS/HRQoL/

IIEF-5/urinary inconti-

nence at 12 months, and re-TURP)

\begin{tabular}{|c|c|c|}
\hline $\begin{array}{l}\text { Selective reporting (re- } \\
\text { porting bias): All outcomes }\end{array}$ & Unclear risk & $\begin{array}{l}\text { RCT protocol could not be identified to allow for full assessment of selective } \\
\text { reporting. However, no outcome data on the incidence of blood transfusion or } \\
\text { QoL were reported even though the study reports capturing these data else- } \\
\text { where in the manuscript }\end{array}$ \\
\hline
\end{tabular}

Chen 2009

\begin{tabular}{ll}
\hline Methods & Study type: single-centre randomised controlled trial $(1: 1)$ \\
& - Setting: China \\
\hline Participants & Total participants enrolled: $40 ;(\mathrm{A})=21,(\mathrm{~B})=19$ \\
- Inclusion criteria: older than 55 years and fit for anaesthesia, symptomatic $\mathrm{BPH}$, prostate volume $>$ \\
& $50 \mathrm{~mL}, \mathrm{IPSS} \geq 18, \mathrm{Q}_{\max }<15 \mathrm{~mL} / \mathrm{s}$, failed medical therapy with alpha blockers or 5 -alpha reductase \\
& inhibitors \\
- Exclusion criteria: suspected prostate cancer, bladder calculus, neurogenic bladder, previous \\
prostate surgery, previous urethral stricture
\end{tabular}


Chen 2009 (Continued)

\section{Baseline characteristics:}

No significant differences between arms reported

Mean age, years (SD): $(A)=72.6(6.5),(B)=71.8(6.3)$

Mean preoperative prostate volume, $\mathrm{mL}(\mathrm{SD}):(\mathrm{A})=78.4(16.4),(\mathrm{B})=76.8$ (17.5)

Preoperative catheterisation state: not reported

\begin{tabular}{ll}
\hline Interventions & Intervention A: bipolar TURP (TURIS, Olympus) \\
& - Intervention B: monopolar TURP (Olympus, irrigation fluid = mannitol $4 \%$ )
\end{tabular}

\begin{tabular}{|c|c|c|}
\hline \multirow[t]{18}{*}{ Outcomes } & \multirow{2}{*}{\multicolumn{2}{|c|}{$\begin{array}{l}\text { Primary outcomes: } \\
\text { IPSS (12 months): not reported }\end{array}$}} \\
\hline & & \\
\hline & \multicolumn{2}{|c|}{ HRQoL (12 months): not reported } \\
\hline & \multicolumn{2}{|c|}{ TUR syndrome: $(A)=0(n=21),(B)=1(n=19)$} \\
\hline & \multicolumn{2}{|l|}{ Secondary outcomes: } \\
\hline & \multicolumn{2}{|c|}{ Blood transfusion: $(A)=1(n=21),(B)=3(n=19)$} \\
\hline & \multicolumn{2}{|c|}{ Urinary Incontinence (12 months): not reported } \\
\hline & \multicolumn{2}{|c|}{ Erectile dysfunction (IIEF-5) (12 months): not reported } \\
\hline & \multicolumn{2}{|c|}{ Need for repeat TURP (i.e. re-TURP): not reported } \\
\hline & \multicolumn{2}{|c|}{ Other reported outcomes: } \\
\hline & \multicolumn{2}{|c|}{ IPSS at 3 months and 6 months } \\
\hline & \multicolumn{2}{|c|}{$\mathrm{Q}_{\max }$ at 3 months and 6 months } \\
\hline & \multicolumn{2}{|l|}{ Acute urinary retention } \\
\hline & \multicolumn{2}{|l|}{ Duration of operation } \\
\hline & \multicolumn{2}{|c|}{ Duration of catheterisation } \\
\hline & \multicolumn{2}{|c|}{ Duration of hospital stay } \\
\hline & \multicolumn{2}{|c|}{ Decrease in postop serum sodium } \\
\hline & \multicolumn{2}{|c|}{ Decrease in postop haemoglobin } \\
\hline Source of funding & \multicolumn{2}{|l|}{ None reported } \\
\hline Notes & \multicolumn{2}{|c|}{$\begin{array}{l}\text { This RCT is based on a different population than a subsequent publication by the authors (Chen 2010) - } \\
\text { this has been confirmed by study authors }\end{array}$} \\
\hline \multicolumn{3}{|l|}{ Risk of bias } \\
\hline Bias & Authors' judgement & Support for judgement \\
\hline $\begin{array}{l}\text { Random sequence gener- } \\
\text { ation (selection bias): All } \\
\text { outcomes }\end{array}$ & Unclear risk & Not reported \\
\hline
\end{tabular}




\section{Chen 2009 (Continued)}

Allocation concealment Unclear risk Not reported
(selection bias): All out-

comes

\begin{tabular}{|c|c|c|}
\hline $\begin{array}{l}\text { Blinding of participants } \\
\text { and personnel (perfor- } \\
\text { mance bias): All outcomes }\end{array}$ & High risk & $\begin{array}{l}\text { "In our study, patients were blinded to the operation equipment, but not to } \\
\text { surgeons" }\end{array}$ \\
\hline
\end{tabular}

\begin{tabular}{|c|c|c|}
\hline $\begin{array}{l}\text { Blinding of outcome as- } \\
\text { sessment (detection bias): } \\
\text { Subjective outcomes } \\
\text { (IPSS, HRQoL, IIEF-5, TUR } \\
\text { syndrome, Urinary Inconti- } \\
\text { nence) }\end{array}$ & Unclear risk & $\begin{array}{l}\text { Not reported for outcome assessors, but patients were blinded as per above: } \\
\text { "in our study, patients were blinded to the operation equipment, but not to } \\
\text { surgeons" }\end{array}$ \\
\hline
\end{tabular}

Blinding of outcome as- Low risk Not reported but objective outcomes unlikely to have been affected
sessment: Objective out-
comes (Blood transfusion,
Re-TURP)

\begin{tabular}{|c|c|c|}
\hline $\begin{array}{l}\text { Incomplete outcome da- } \\
\text { ta (attrition bias): Imme- } \\
\text { diate postoperative out- }\end{array}$ & Unclear risk & $\begin{array}{l}\text { This study does not explicitly report on attrition, exclusion of participants from } \\
\text { analyses, or the presence of incomplete outcome data for these outcomes } \\
\text { specifically }\end{array}$ \\
\hline
\end{tabular}
comes (TUR syndrome, Blood transfusion)

\begin{tabular}{|c|c|c|}
\hline $\begin{array}{l}\text { Incomplete outcome data } \\
\text { (attrition bias): Long-term } \\
\text { outcomes (IPSS/HRQoL/ } \\
\text { IIEF-5/urinary inconti- } \\
\text { nence at } 12 \text { months, and } \\
\text { re-TURP) }\end{array}$ & Unclear risk & These outcomes were not reported by the trial \\
\hline $\begin{array}{l}\text { Selective reporting (re- } \\
\text { porting bias): All outcomes }\end{array}$ & Unclear risk & $\begin{array}{l}\text { RCT protocol not available to allow for full assessment of selective reporting } \\
\text { However, study seems to suggest that data on complications such as urinary } \\
\text { incontinence were recorded, but no data were reported within the manuscript }\end{array}$ \\
\hline
\end{tabular}

Chen 2010

\begin{tabular}{ll}
\hline Methods & Study type: single-centre randomised controlled trial $(1: 1)$ \\
& Setting: China \\
\hline Participants & Total number enrolled: $100 ;(A)=50,(B)=50$ \\
- Inclusion criteria: failure of medical therapy, all indications for surgical treatment of $B P H$ \\
- Exclusion criteria: severe pulmonary disease, allergic response to alcohol, prostate cancer, bladder \\
calculus, neurogenic bladder dysfunction, previous prostate surgery, urethral stricture, coagulopathy
\end{tabular}

\section{Baseline characteristics:}

No significant differences between groups reported

Mean age, years (SD): $(A)=69.7(7.6),(B)=71.2(6.3)$

Mean preoperative prostate volume, $\mathrm{mL}(\mathrm{SD}):(\mathrm{A})=60.2(18.7),(\mathrm{B})=59.1$ (17.3)

Preoperative catheterisation state: not reported

Bipolar versus monopolar transurethral resection of the prostate for lower urinary tract symptoms secondary to benign prostatic 
Chen 2010 (Continued)

Interventions

- Intervention A: bipolar TURP; TURis Olympus SurgMasterSystem

- Intervention B: monopolar TURP; irrigation fluid = 4\% mannitol, $1 \%$ ethanol

Outcomes

Primary outcomes:

IPSS (12 months): $(A)=4.2(2.6)(n=50),(B)=4.1(2.3)(n=50)$

HRQoL (12 months): not reported

TUR syndrome: $(A)=0(n=50),(B)=0(n=50)$

\section{Secondary outcomes:}

Blood transfusion: $(A)=1(n=50),(B)=3(n=50)$

Urinary incontinence (12 months): $(A)=0(n=50),(B)=2(n=50)$

Erectile dysfunction (IIEF-5) (12 months), mean IIEF-5 (SD): (A) = $19.5(6.1)(n=24),(B)=19.3(4.0)(n=$ 28)

Need for repeat TURP (i.e. re-TURP): not reported

\section{Other reported outcomes:}

IPSS at 6, 24 months

$\mathrm{Q}_{\max }$ at 6,12 , and 24 months

IIEF-5 at 6 and 24 months

Urethral stricture

Bladder neck contracture

Acute urinary retention

Duration of operation

Mean operation duration

Mean resected weight

Mean serum sodium decrease

Mean $\mathrm{Hb}$ decrease

Frequency of retrograde ejaculation Shanghai JiaoTong University School of Medicine"

\section{Risk of bias}

\section{Bias}

Authors' judgement Support for judgement

Random sequence generation (selection bias): All

Low risk outcomes
"The stratified permuted randomization algorithm was performed to implement the randomisation" 


\section{Chen 2010 (Continued)}

Allocation concealment (selection bias): All out-

Specific method used to conceal allocation sequence not reported

\begin{tabular}{lll}
\hline $\begin{array}{l}\text { Blinding of participants } \\
\text { and personnel (perfor- } \\
\text { mance bias): All outcomes }\end{array}$ & High risk & $\begin{array}{l}\text { Study states: "only patients were blinded to the different treatments while the } \\
\text { surgeons and supervisors were not" }\end{array}$ \\
\hline $\begin{array}{l}\text { Blinding of outcome as- } \\
\text { sessment (detection bias): }\end{array}$ & High risk & $\begin{array}{l}\text { Study states: "only patients were blinded to the different treatments while the } \\
\text { surgeons and supervisors were not" }\end{array}$ \\
$\begin{array}{l}\text { Subjective outcomes } \\
\text { (IPSS, HRQoL, IIEF-5, TUR } \\
\text { syndrome, Urinary Inconti- }\end{array}$ & \\
nence)
\end{tabular}

\section{Blinding of outcome as- Low risk} sessment: Objective outcomes (Blood transfusion, Re-TURP)
These objective outcomes are unlikely to have been affected by blinding of outcome assessment

\begin{tabular}{|c|c|c|}
\hline $\begin{array}{l}\text { Incomplete outcome da- } \\
\text { ta (attrition bias): Imme- } \\
\text { diate postoperative out- }\end{array}$ & Unclear risk & $\begin{array}{l}\text { This study does not explicitly report on attrition, exclusion of participants from } \\
\text { analyses, or the presence of incomplete outcome data for these outcomes } \\
\text { specifically }\end{array}$ \\
\hline
\end{tabular}
comes (TUR syndrome, Blood transfusion)

\begin{tabular}{|c|c|c|}
\hline $\begin{array}{l}\text { Incomplete outcome data } \\
\text { (attrition bias): Long-term } \\
\text { outcomes (IPSS/HRQoL/ } \\
\text { IIEF-5/urinary inconti- } \\
\text { nence at } 12 \text { months, and } \\
\text { re-TURP) }\end{array}$ & Unclear risk & $\begin{array}{l}\text { Study states: "all } 100 \text { patients completed the two year follow-up", but unclear } \\
\text { if this also applies to the } 12 \text {-month time point }\end{array}$ \\
\hline
\end{tabular}

\begin{tabular}{l}
$\begin{array}{l}\text { Selective reporting (re- } \\
\text { porting bias): All outcomes }\end{array}$ \\
\hline
\end{tabular}

Choi 2006

\begin{tabular}{ll}
\hline Methods & Study type: multi-centre randomised controlled trial; only published abstract available for data ex- \\
& traction. Note number of involved centres not reported in abstract \\
& - Setting: South Korea \\
\hline Participants & Total number enrolled: 200; number of patients in each arm of the trial not reported \\
- Inclusion criteria: “BPH patients" \\
- Exclusion criteria: not reported \\
Baseline characteristics: not reported \\
\hline Interventions \\
- Intervention A: bipolar TURP; Plasma Kinetic (PK) Tissue Management System (Gyrus) \\
\hline
\end{tabular}

Outcomes Primary outcomes:

IPSS (12 months): not reported

HRQoL (12 months): not reported 
Choi 2006 (Continued)

TUR syndrome: not reported

\section{Secondary outcomes:}

Blood transfusion: not reported

Urinary Incontinence (12 months): not reported (no time of follow-up provided for urinary incontinence data)

Erectile dysfunction (IIEF-5) (12 months): not reported

Need for repeat TURP (i.e. re-TURP): not reported

\section{Other reported outcomes:}

Acute urinary retention

Postoperative drop in serum sodium

Postoperative drop in haemoglobin

Abstract states data collected for resected tissue amount, operative time, changes in haemoglobin, hospital stay, duration of catheter, IPSS, $\mathrm{Q}_{\max }$, but no specific data provided

\begin{tabular}{lll}
\hline Source of funding & None reported \\
\hline Notes & This is a conference abstract with limited information \\
\hline Risk of bias & \\
\hline Bias & Authors' judgement & Support for judgement \\
\hline $\begin{array}{l}\text { Random sequence gener- } \\
\text { ation (selection bias): All } \\
\text { outcomes }\end{array}$ & Unclear risk & Not reported \\
\hline $\begin{array}{l}\text { Allocation concealment } \\
\text { (selection bias): All out- } \\
\text { comes }\end{array}$ & Unclear risk & Not reported \\
\hline
\end{tabular}

Blinding of participants

High risk

Not reported but considered unlikely that operating surgeons were blinded

and personnel (perfor-

mance bias): All outcomes

Blinding of outcome as-
sessment (detection bias):
Subjective outcomes
(IPSS, HRQoL, IIEF-5, TUR
syndrome, Urinary Inconti-
nence)

Blinding of outcome assessment: Objective out-

Incomplete outcome da- Unclear risk $\quad$ These outcomes were not reported by this trial
ta (attrition bias): Imme-
diate postoperative out-
comes (TUR syndrome,
Blood transfusion)


Choi 2006 (Continued)
Incomplete outcome data
Unclear risk
These outcomes were not reported by this trial
(attrition bias): Long-term

outcomes (IPSS/HRQoL/

IIEF-5/urinary inconti-

nence at 12 months, and re-TURP)

$\begin{aligned} & \text { Selective reporting (re- } \\ & \text { porting bias): All outcomes }\end{aligned}$
Unclear risk RCT protocol not available to allow for full assessment of selective reporting

\section{D'Elia 2004}

\begin{tabular}{ll}
\hline Methods & Study type: single-centre randomised controlled trial $(1: 1)$ \\
- Setting: Italy
\end{tabular}

\begin{tabular}{ll}
\hline Participants & Total participants enrolled: $85 ;(A)=43,(B)=42$ \\
- Inclusion criteria: not reported \\
- Exclusion criteria: not reported \\
- Baseline characteristics: no specific data reported
\end{tabular}

\begin{tabular}{ll}
\hline Interventions & Intervention A: bipolar TURP (Gyrus) \\
& - Intervention B: monopolar TURP (irrigation fluid = not reported)
\end{tabular}

\begin{tabular}{ll}
\hline Outcomes & Primary outcomes: \\
IPSS (12 months): not reported \\
HRQoL (12 months): not reported \\
TUR syndrome: not reported \\
Secondary outcomes: \\
Blood transfusion: not reported \\
Urinary incontinence (12 months): not reported \\
Erectile dysfunction (IIEF-5) (12 months): not reported \\
Need for repeat TURP (i.e. re-TURP): not reported
\end{tabular}

\section{Other reported outcomes:}

Catheterisation time

Hospitalisation time

Abstract states data collected on operative time, resected weight, blood loss and irrigation fluid absorption, IPSS, peak flow rates, and postvoid residual volumes, but no specific data provided

\begin{tabular}{ll}
\hline Source of funding & None reported \\
\hline Notes & This is a conference abstract with limited information \\
\hline Risk of bias & Authors' judgement Support for judgement \\
\hline Bias & Sul \\
\hline
\end{tabular}

Bipolar versus monopolar transurethral resection of the prostate for lower urinary tract symptoms secondary to benign prostatic 
D'Elia 2004 (Continued)

Random sequence gener- Unclear risk Not reported
ation (selection bias): All
outcomes

Allocation concealment $\quad$ Unclear risk $\quad$ Not reported
(selection bias): All out-
comes

\begin{tabular}{lll}
\hline $\begin{array}{l}\text { Blinding of participants } \\
\text { and personnel (perfor- } \\
\text { mance bias): All outcomes }\end{array}$ & High risk & Not reported but considered unlikely that operating surgeon(s) blinded \\
\hline Blinding of outcome as- & Unclear risk & Not reported \\
sessment (detection bias): & \\
Subjective outcomes & \\
$\begin{array}{l}\text { (IPSS, HRQoL, IIEF-5, TUR } \\
\text { syndrome, Urinary Inconti- } \\
\text { nence) }\end{array}$ & \\
\hline
\end{tabular}

Blinding of outcome as- Unclear risk These outcomes were not reported by the trial
sessment: Objective outcomes (Blood transfusion, Re-TURP)

\begin{tabular}{|c|c|c|}
\hline $\begin{array}{l}\text { Incomplete outcome da- } \\
\text { ta (attrition bias): Imme- } \\
\text { diate postoperative out- } \\
\text { comes (TUR syndrome, } \\
\text { Blood transfusion) }\end{array}$ & Unclear risk & These outcomes were not reported by the trial \\
\hline $\begin{array}{l}\text { Incomplete outcome data } \\
\text { (attrition bias): Long-term } \\
\text { outcomes (IPSS/HRQoL/ } \\
\text { IIEF-5/urinary inconti- } \\
\text { nence at } 12 \text { months, and } \\
\text { re-TURP) }\end{array}$ & Unclear risk & These outcomes were not reported by the trial \\
\hline $\begin{array}{l}\text { Selective reporting (re- } \\
\text { porting bias): All outcomes }\end{array}$ & Unclear risk & $\begin{array}{l}\text { RCT protocol not available to allow for full judgement; however abstract states } \\
\text { that data were collected on operative time, resected weight, blood loss, irriga- } \\
\text { tion fluid absorption, IPSS, peak flow rates, and postvoid residual volumes, but } \\
\text { no specific data outcome data were provided }\end{array}$ \\
\hline
\end{tabular}

De Sio 2006

\begin{tabular}{ll}
\hline Methods & Study type: single-centre randomised controlled trial $(1: 1)$ \\
& Setting: Italy \\
\hline Participants & Total participants enrolled: $70 ;(A)=35,(B)=35$ \\
- Inclusion criteria: symptomatic $B P H$, age $>50$ years, good performance status, acute urinary reten- \\
tion if catheter removal failed after therapy with alpha-blockers or chronic urinary retention unre- \\
sponsive to medical treatment, IPSS $\geq 18$, maximal flow rate $\left(Q_{\max }\right)<15 \mathrm{~mL} / \mathrm{s}$ \\
- Exclusion criteria: prostate volume $<30 \mathrm{~cm}^{3}$, documented or suspected prostate cancer, neurogenic \\
bladder, bladder stone or diverticula, urethral stricture, maximal bladder capacity $>500 \mathrm{~mL}$
\end{tabular}

\section{Baseline characteristics:}


De Sio 2006 (Continued)

No significant differences between arms reported

Mean age, years (SD): $(A)=59(5.9),(B)=61(5.9)$

Mean preoperative prostate volume, $\mathrm{cm}^{3}(\mathrm{SD}):(\mathrm{A})=51.6(3.9),(\mathrm{B})=47.5(5.1)$

Preoperative catheterisation status: not reported

$\begin{array}{ll}\text { Interventions } & \text { Intervention A: bipolar TURP (Gyrus Plasmakinetic System) } \\ & \text { - Intervention B: monopolar TURP (ValleyLab Force FX); irrigation fluid = not reported }\end{array}$

Outcomes

Primary outcomes:

IPSS (12 months): $(A)=3.9(n=35),(B)=3.8(n=35)$

HRQoL (12 months): $(A)=1.0(n=35),(B)=0.8(n=35)$

TUR syndrome: $(A)=0(n=35),(B)=0(n=35)$

\section{Secondary outcomes:}

Blood transfusion: $(A)=1(n=35),(B)=0(n=35)$

Urinary incontinence (12 months): not reported

Erectile dysfunction (IIEF-5) (12 months): not reported

Need for repeat TURP (i.e. re-TURP): $(A)=1(n=32),(B)=1(n=31)$

\section{Other reported outcomes:}

IPSS at 3, 6, and $>12$ months

HRQoL at 24/36/48 months

$\mathrm{Q}_{\text {nax }}(\mathrm{mL} / \mathrm{s})(12$ months)

Urethral stricture

Bladder neck contracture (48 months)

Mean duration of operation (minutes)

Mean decrease in postoperative haemoglobin

Mean decrease in postoperative sodium

Mean duration of catheterisation

Mean duration of hospital stay

Clot retention

Acute urinary retention

Death

Study reports that no financial support was received

Notes

Patient population identical to that reported in 2 abstracts (De Sio 2005; Autorino 2007) and another paper (Autorino 2009) published by the same authors

Four relevant commentaries have been detected and taken into account for potential inclusion of additional information (Autrorino 2007a; Kaplan 2010; Rassweiler 2009; Seitz 2009) 
De Sio 2006 (Continued)

Risk of bias

\begin{tabular}{lll}
\hline Bias & Authors' judgement & Support for judgement \\
\hline $\begin{array}{l}\text { Random sequence gener- } \\
\text { ation (selection bias): All } \\
\text { outcomes }\end{array}$ & Low risk & $\begin{array}{l}\text { Study states: "randomisation was performed using a stratified permuted ran- } \\
\text { domisation algorithm" }\end{array}$ \\
\hline
\end{tabular}

Allocation concealment Unclear risk Specific method of allocation concealment not reported
(selection bias): All out-
comes

Blinding of participants $\quad$ High risk $\quad$ Not reported but considered unlikely that operating surgeon(s) blinded
$\begin{aligned} & \text { and personnel (perfor- } \\ & \text { mance bias): All outcomes }\end{aligned}$

\begin{tabular}{|c|c|c|}
\hline $\begin{array}{l}\text { Blinding of outcome as- } \\
\text { sessment (detection bias): } \\
\text { Subjective outcomes } \\
\text { (IPSS, HRQoL, IIEF-5, TUR } \\
\text { syndrome, Urinary Inconti- } \\
\text { nence) }\end{array}$ & Unclear risk & $\begin{array}{l}\text { Study states: "outcome assessors were blinded to treatments patients had re- } \\
\text { ceived" (Autorino 2009). However, not reported explicitly if patients involved } \\
\text { in recording self-assessed outcomes were blinded }\end{array}$ \\
\hline
\end{tabular}

Blinding of outcome as- Low risk sessment: Objective outThese objective outcomes are unlikely to have been affected by blinding of outcome assessment comes (Blood transfusion, Re-TURP)

\begin{abstract}
Incomplete outcome data (attrition bias): Immediate postoperative outcomes (TUR syndrome, Blood transfusion)
\end{abstract}

Unclear risk

\begin{abstract}
Study accounts for all patients in analyses: "ninety percent of the patients completed the 4-yr assessments: 32 (of 35) in the PK group and 31 (of 35) in the standard TURP group. There was no statistically significant difference in the number of dropouts in the two groups $(p=0.2)$. Reasons for dropout were the following: refused follow-up ( 3 patients), moved away ( 2 patients), and death from other causes (2 patients)" (Autorino 2009)
\end{abstract}

Impact of incomplete outcome data on reported differences in outcomes between intervention arms considered unclear

\begin{tabular}{|c|c|c|}
\hline $\begin{array}{l}\text { Incomplete outcome data } \\
\text { (attrition bias): Long-term } \\
\text { outcomes (IPSS/HRQoL/ } \\
\text { IIEF-5/urinary inconti- } \\
\text { nence at } 12 \text { months, and } \\
\text { re-TURP) }\end{array}$ & Unclear risk & $\begin{array}{l}\text { Study accounts for all patients in analyses: "ninety percent of the patients } \\
\text { completed the 4-yr assessments: } 32 \text { (of } 35 \text { ) in the PK group and } 31 \text { (of } 35 \text { ) in the } \\
\text { standard TURP group. There was no statistically significant difference in the } \\
\text { number of dropouts in the two groups ( } p=0.2 \text { ). Reasons for dropout were the } \\
\text { following: refused follow-up ( } 3 \text { patients), moved away ( } 2 \text { patients), and death } \\
\text { from other causes ( } 2 \text { patients)" (Autorino 2009) }\end{array}$ \\
\hline & & $\begin{array}{l}\text { Impact of incomplete outcome data on reported differences in outcomes be- } \\
\text { tween intervention arms considered unclear }\end{array}$ \\
\hline $\begin{array}{l}\text { Selective reporting (re- } \\
\text { porting bias): All outcomes }\end{array}$ & Unclear risk & $\begin{array}{l}\text { RCT protocol could not be identified to allow for full judgement of selective re- } \\
\text { porting }\end{array}$ \\
\hline
\end{tabular}

\section{Demirdag 2016}

\begin{tabular}{ll}
\hline Methods & - Study type: single-centre randomised controlled trial (1:1) \\
& - Setting: Turkey
\end{tabular}

Participants $\quad$ Total participants enrolled: $118 ;(A)=59,(B)=59$

Bipolar versus monopolar transurethral resection of the prostate for lower urinary tract symptoms secondary to benign prostatic obstruction (Review)

Copyright $\odot 2019$ The Cochrane Collaboration. Published by John Wiley \& Sons, Ltd. 
- Inclusion criteria: prostate glands larger than $60 \mathrm{~mL}$, moderate to severe lower urinary tract symptoms and significant postmicturition residual (PMR) urine volume $(>100 \mathrm{~mL})$ in spite of medical treatment with alpha blockers and 5-alpha reductase inhibitors

- Exclusion criteria: history or suspicion of prostate cancer, bladder stone, neurogenic bladder, previous prostatic surgery, previous urethral stricture

\section{Baseline characteristics:}

Mean age, years (SD): $(A)=65(9.0), n=36,(B)=66.87(10.1), n=45$

Mean preoperative prostate volume, $\mathrm{mL}(\mathrm{SD})$ : $(\mathrm{A})=71.8$ (12.93), $\mathrm{n}=36,(\mathrm{~B})=73.9(14.13), \mathrm{n}=45$

Preoperative catheterisation state: not reported

Interventions

- Intervention A: bipolar TURP (Olympus Gyrus PK SuperPulse Generator)

- Intervention B: monopolar TURP (ValleyLab Force FX Electrocautery, irrigation fluid = glycine 5\%)

Outcomes

\section{Primary outcomes:}

IPSS (12 months): not reported at 12 months

HRQoL (12 months): not reported at 12 months

TUR syndrome: $(A)=0(n=36),(B)=2(n=45)$

\section{Secondary outcomes:}

Blood transfusion: $(A)=4(n=36),(B)=8(n=45)$

Urinary incontinence (12 months): not reported

Erectile dysfunction (IIEF-5) (12 months): not reported at 12 months

Need for repeat TURP (i.e. re-TURP): not reported

\section{Other reported outcomes:}

Operation duration

Postoperative haemoglobin

Postoperative sodium

Catheterisation time

Clot retention

Postoperative IIEF-5 (not explicitly at 12 months)

\begin{tabular}{lll}
\hline Source of funding & None reported \\
\hline Notes & \\
\hline Risk of bias & Authors' judgement & Support for judgement \\
\hline Bias & Unclear risk & $\begin{array}{l}\text { Study states: "randomised into MTURP or BTURP arms via software program } \\
\text { with a 1:1 ratio"; limited detail reported regarding specific randomisation se- } \\
\text { quence }\end{array}$ \\
\hline $\begin{array}{l}\text { Random sequence gener- } \\
\begin{array}{l}\text { ation (selection bias): All } \\
\text { outcomes }\end{array}\end{array}$ &
\end{tabular}

Bipolar versus monopolar transurethral resection of the prostate for lower urinary tract symptoms secondary to benign prostatic 
Demirdag 2016 (Continued)

Allocation concealment Unclear risk Specific method of allocation concealment not reported (selection bias): All outcomes

\begin{tabular}{lll}
$\begin{array}{l}\text { Blinding of participants } \\
\text { and personnel (perfor- } \\
\text { mance bias): All outcomes }\end{array}$ & High risk & Not reported but considered unlikely that operating surgeon(s) blinded \\
\hline $\begin{array}{l}\text { Blinding of outcome as- } \\
\text { sessment (detection bias): }\end{array}$ & Unclear risk & Not reported \\
Subjective outcomes & \\
(IPSS, HRQoL, IIEF-5, TUR & \\
syndrome, Urinary Inconti- & \\
nence) &
\end{tabular}

Blinding of outcome as- Low risk Not reported but objective outcomes unlikely to be affected
sessment: Objective out-
comes (Blood transfusion,
Re-TURP)

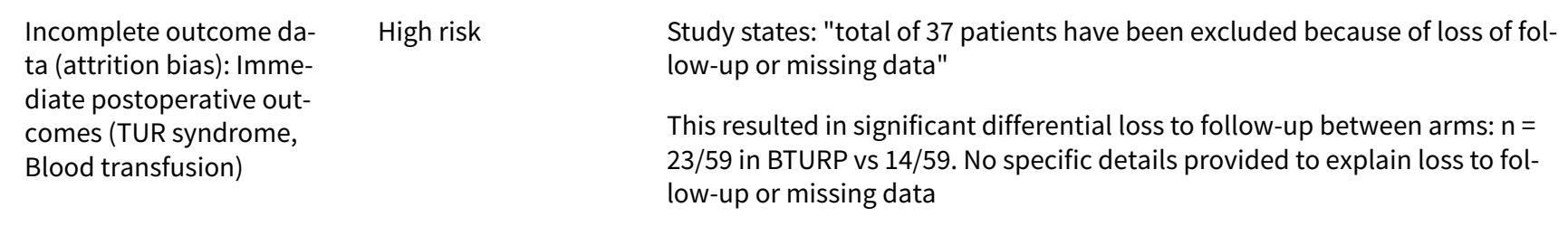

\begin{tabular}{|c|c|c|}
\hline $\begin{array}{l}\text { Incomplete outcome data } \\
\text { (attrition bias): Long-term }\end{array}$ & High risk & $\begin{array}{l}\text { Study states: "total of } 37 \text { patients have been excluded because of loss of fol- } \\
\text { low-up or missing data" }\end{array}$ \\
\hline $\begin{array}{l}\text { nence at } 12 \text { months, and } \\
\text { re-TURP) }\end{array}$ & & $\begin{array}{l}\text { This resulted in significant differential loss to follow-up between arms: } n= \\
23 / 59 \text { in BTURP vs } 14 / 59 \text {. No specific details provided to explain loss to fol- } \\
\text { low-up or missing data }\end{array}$ \\
\hline
\end{tabular}

\begin{tabular}{l}
$\begin{array}{l}\text { Selective reporting (re- } \\
\text { porting bias): All outcomes }\end{array} \quad$ Unclear risk $\quad$ No RCT protocol available to allow for full judgement on selective reporting \\
\hline
\end{tabular}

\section{Eaton 2004}

$\begin{array}{ll}\text { Methods } & \text { Study type: single-centre randomised controlled trial (1:1); only published abstract available for data } \\ & \text { extraction } \\ \text { - Setting: United Kingdom }\end{array}$

\begin{tabular}{ll}
\hline Participants & Total participants enrolled: $100 ;(A)=50,(B)=50$ \\
- Inclusion criteria: urodynamically obstructed men \\
- Exclusion criteria: not reported \\
Baseline characteristics: \\
All were ASA $1 / 2$ \\
Preoperative catheterisation, $\mathrm{n:}(\mathrm{A})=15,(\mathrm{~B})=15$ \\
- Intervention A: bipolar TURP; technology reported as both Plasmakinetic and Karl Storz (unclear if \\
both Gyrus and Karl Storz instruments were used) \\
- Intervention B: monopolar TURP; irrigation fluid = glycine
\end{tabular}


Eaton 2004 (Continued)

Outcomes

\section{Primary outcomes:}

IPSS (12 months): not reported

HRQoL (12 months): not reported

TUR syndrome: not reported

\section{Secondary outcomes:}

Blood transfusion: not reported

Urinary Incontinence (12 months): not reported

Erectile dysfunction (IIEF-5) (12 months): not reported

Need for repeat TURP (i.e. re-TURP): not reported

\section{Other reported outcomes:}

Urethral stricture

Bladder neck contracture

UTI

Bladder neck contracture

Acute urinary retention

Mean duration of catheterisation

Mean duration of hospital stay

Secondary haemorrhage requiring re-admission

PVR change

\begin{tabular}{lll}
\hline Source of funding & None reported \\
\hline Notes & This is a conference abstract with limited information \\
\hline Risk of bias & \\
\hline Bias & Authors' judgement & Support for judgement \\
\hline $\begin{array}{l}\text { Random sequence gener- } \\
\text { ation (selection bias): All } \\
\text { outcomes }\end{array}$ & Unclear risk & Not reported \\
\hline $\begin{array}{l}\text { Allocation concealment } \\
\text { (selection bias): All out- } \\
\text { comes }\end{array}$ & Unclear risk & Not reported \\
\hline
\end{tabular}


Eaton 2004 (Continued) syndrome, Urinary Incontinence)

Blinding of outcome as- Unclear risk These outcomes were not reported by the trial
sessment: Objective out-
comes (Blood transfusion,
Re-TURP)

Incomplete outcome da- Unclear risk These outcomes were not reported by the trial
ta (attrition bias): Imme-
diate postoperative out-
comes (TUR syndrome,
Blood transfusion)

\begin{tabular}{|c|c|c|}
\hline $\begin{array}{l}\text { Incomplete outcome data } \\
\text { (attrition bias): Long-term } \\
\text { outcomes (IPSS/HRQoL/ } \\
\text { IIEF-5/urinary inconti- } \\
\text { nence at } 12 \text { months, and } \\
\text { re-TURP) }\end{array}$ & Unclear risk & These outcomes were not reported by the trial \\
\hline $\begin{array}{l}\text { Selective reporting (re- } \\
\text { porting bias): All outcomes }\end{array}$ & Unclear risk & $\begin{array}{l}\text { RCT protocol not available to allow for full assessment on selective reporting. } \\
\text { However, study states that IPSS at } 12 \text { months was recorded, but no specific } \\
\text { outcome data provided - abstract only with no full manuscript identified }\end{array}$ \\
\hline
\end{tabular}

Egui Rojo 2017

$\begin{array}{ll}\text { Methods } & \text { Study type: single-centre randomised controlled trial (1:1) } \\ \text { - Setting: Spain }\end{array}$

- Total participants enrolled: $77 ;(A)=35,(B)=42$
- Inclusion criteria: not reported
- Exclusion criteria: not reported
Baseline characteristics:
Mean age, years (SD): not reported for individual arms, for both arms: 66 (50 to 82$)$
Mean preoperative prostate volume, $\mathrm{mL}(\mathrm{SD})$ : not reported for individual arms, for both arms: 39 (10 to
$69)$
Preoperative catheterisation state: not reported

Interventions Intervention A: bipolar TURP (specific technology = not reported)

Intervention B: monopolar TURP (specific technology = not reported, irrigation fluid = not reported)

Outcomes

\author{
Primary outcomes: \\ IPSS at 12 months: not reported \\ HRQoL at 12 months: not reported \\ TUR syndrome: not reported
}

Secondary outcomes:

Blood transfusion: not reported 
Egui Rojo 2017 (Continued)

Urinary incontinence at 12 months: not reported

IIEF-5 at 12 months: not reported

Need for re-TURP: not reported

Other reported outcomes:

Retrograde ejaculation

IPSS at IIEF- 5 at 1 and 3 months

\begin{tabular}{ll}
\hline Source of funding & None reported \\
\hline Notes & Only abstract available
\end{tabular}

\section{Risk of bias}

\begin{tabular}{lll}
\hline Bias & Authors' judgement & Support for judgement \\
\hline $\begin{array}{l}\text { Random sequence gener- } \\
\text { ation (selection bias): All } \\
\text { outcomes }\end{array}$ & Unclear risk & Not reported \\
\hline $\begin{array}{l}\text { Allocation concealment } \\
\text { (selection bias): All out- } \\
\text { comes }\end{array}$ & Unclear risk & Not reported \\
\hline
\end{tabular}

\begin{tabular}{l}
$\begin{array}{l}\text { Blinding of participants } \\
\text { and personnel (perfor- } \\
\text { mance bias): All outcomes }\end{array}$ \\
\hline
\end{tabular}

Blinding of outcome as- $\quad$ Unclear risk These outcomes were not reported by this trial
sessment (detection bias):
Subjective outcomes
(IPSS, HRQoL, IIEF-5, TUR
syndrome, Urinary Inconti-
nence)

Blinding of outcome as- Unclear risk These outcomes were not reported by this trial
sessment: Objective out-
comes (Blood transfusion,
Re-TURP)

Incomplete outcome da- Unclear risk These outcomes were not reported by this trial
ta (attrition bias): Imme-
diate postoperative out-
comes (TUR syndrome,
Blood transfusion)

\begin{tabular}{|c|c|c|}
\hline $\begin{array}{l}\text { Incomplete outcome data } \\
\text { (attrition bias): Long-term } \\
\text { outcomes (IPSS/HRQoL/ } \\
\text { IIEF-5/urinary inconti- } \\
\text { nence at } 12 \text { months, and } \\
\text { re-TURP) }\end{array}$ & Unclear risk & These outcomes were not reported by this trial \\
\hline $\begin{array}{l}\text { Selective reporting (re- } \\
\text { porting bias): All outcomes }\end{array}$ & Unclear risk & RCT protocol not available to allow for full assessment of selective reporting \\
\hline
\end{tabular}


El-Assmy 2018

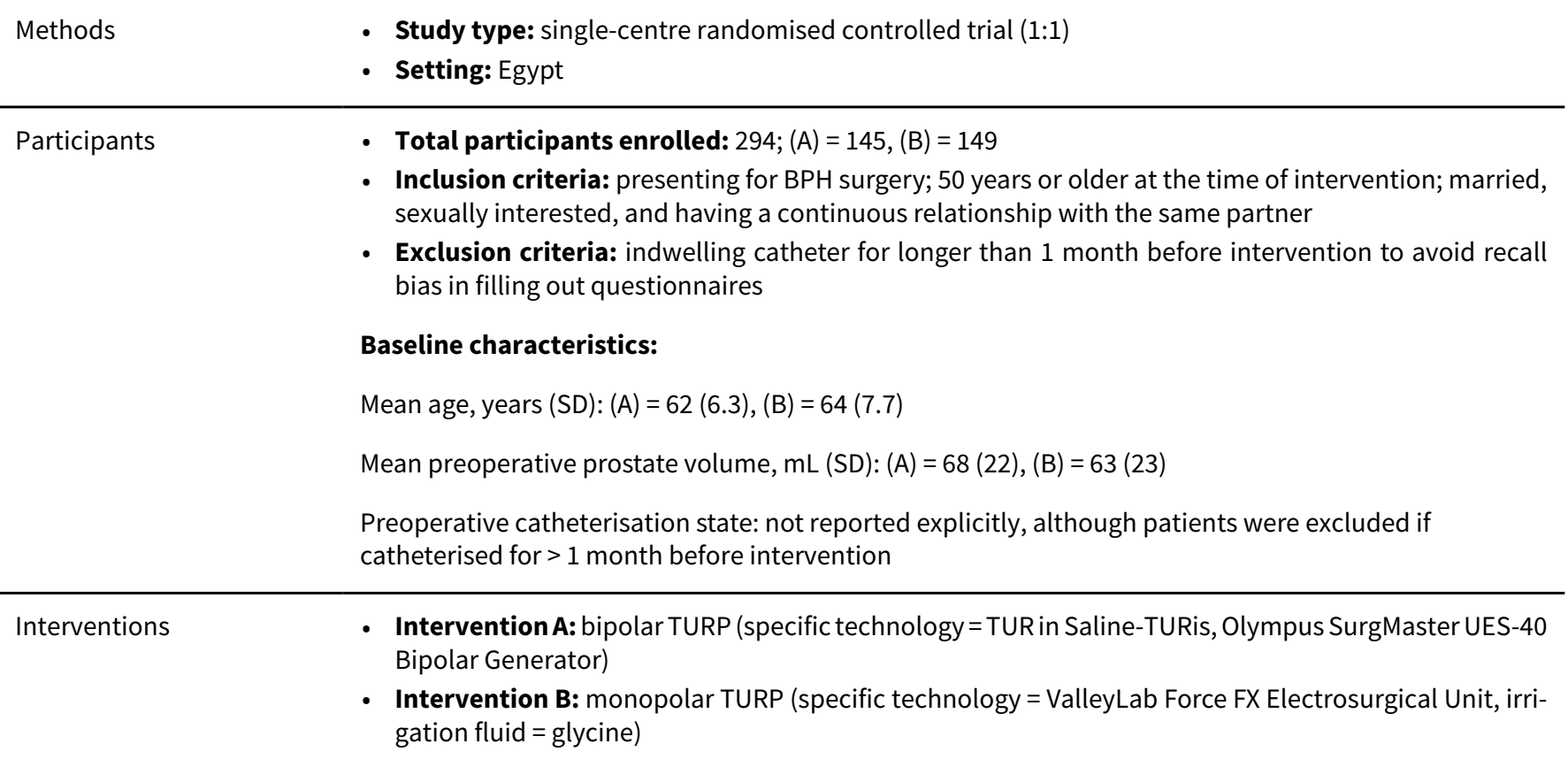

\section{Outcomes}

\section{Primary outcomes:}

IPSS at 12 months: appears to be reported but data not clearly attributable to 1 arm of the trial HRQoL at 12 months: appears to be reported but data not clearly attributable to 1 arm of the trial TUR syndrome: not reported

\section{Secondary outcomes:}

Blood transfusion: not reported

Urinary incontinence at 12 months: not reported

IIEF-5 at 12 months: not reported

Need for re-TURP: not reported

\section{Other reported outcomes:}

IIEF-5 (erectile function) scores

Orgasmic function

Mean operation time

Mean resection weight

Capsular perforation

Mean catheter time

Intercourse satisfaction

Ejaculatory function (Ej-MSHQ score) 
El-Assmy 2018 (Continued)

Notes

\section{Risk of bias}

\begin{tabular}{lll}
\hline Bias & Authors' judgement & Support for judgement \\
\hline $\begin{array}{l}\text { Random sequence gener- } \\
\text { ation (selection bias): All } \\
\text { outcomes }\end{array}$ & Low risk & $\begin{array}{l}\text { Study states: "randomization process was carried out using a computer based } \\
\text { software in a 1:1 ratio" }\end{array}$ \\
\hline
\end{tabular}

\begin{tabular}{lll}
\hline $\begin{array}{l}\text { Allocation concealment } \\
\text { (selection bias): All out- } \\
\text { comes }\end{array}$ & Unclear risk & Method of allocation concealment not reported specifically \\
\hline $\begin{array}{l}\text { Blinding of participants } \\
\text { and personnel (perfor- } \\
\text { mance bias): All outcomes }\end{array}$ & High risk & $\begin{array}{l}\text { Not reported but considered unlikely that operating surgeon(s) were blinded. } \\
\text { Study reports blinding of patients }\end{array}$
\end{tabular}

\begin{tabular}{|c|c|c|}
\hline $\begin{array}{l}\text { Blinding of outcome as- } \\
\text { sessment (detection bias): }\end{array}$ & Unclear risk & $\begin{array}{l}\text { Reported data for IPSS and QoL could not be attributed to } 1 \text { individual arm of } \\
\text { the trial; therefore judgement cannot clearly be made }\end{array}$ \\
\hline
\end{tabular}
the trial; therefore judgement cannot clearly be made

(IPSS, HRQOL, IIEF-5, TUR

syndrome, Urinary Incontinence)

\begin{tabular}{|c|c|c|}
\hline $\begin{array}{l}\text { Blinding of outcome as- } \\
\text { sessment: Objective out- } \\
\text { comes (Blood transfusion, } \\
\text { Re-TURP) }\end{array}$ & Unclear risk & These outcomes were not reported \\
\hline $\begin{array}{l}\text { Incomplete outcome da- } \\
\text { ta (attrition bias): Imme- } \\
\text { diate postoperative out- } \\
\text { comes (TUR syndrome, } \\
\text { Blood transfusion) }\end{array}$ & Unclear risk & These outcomes were not reported \\
\hline $\begin{array}{l}\text { Incomplete outcome data } \\
\text { (attrition bias): Long-term } \\
\text { outcomes (IPSS/HRQoL/ } \\
\text { IIEF-5/urinary inconti- } \\
\text { nence at } 12 \text { months, and } \\
\text { re-TURP) }\end{array}$ & Unclear risk & $\begin{array}{l}\text { Reported data for IPSS and QoL could not be attributed to } 1 \text { individual arm of } \\
\text { the trial; therefore judgement cannot clearly be made }\end{array}$ \\
\hline $\begin{array}{l}\text { Selective reporting (re- } \\
\text { porting bias): All outcomes }\end{array}$ & Low risk & $\begin{array}{l}\text { This study was registered with ClinicalTrials.gov (NCT01810068), with no clear } \\
\text { discrepancies between outcomes in protocol and reported study }\end{array}$ \\
\hline
\end{tabular}

\section{Erturhan 2007}

\begin{tabular}{ll}
\hline Methods & Study type: single-centre randomised controlled trial $(1: 1)$ \\
& Setting: Turkey \\
\hline Participants & Total number enrolled: $240 ;(\mathrm{A})=120,(\mathrm{~B})=120$ \\
& Inclusion criteria: BPE with moderate or severe LUTS (IPSS $\geq 18)$, significant postvoid residual volume \\
& $(>50 \mathrm{~mL})$ \\
- & Exclusion criteria: documented/suspected prostate cancer, previous prostatic surgery, urethral stric- \\
& ture, neurogenic bladder disorder
\end{tabular}

Bipolar versus monopolar transurethral resection of the prostate for lower urinary tract symptoms secondary to benign prostatic 
Erturhan 2007 (Continued)

\section{Baseline characteristics:}

Unclear if significant differences between arms at baseline (no P values provided)

Mean age, years (range): $(A)=68.5(52$ to 90$),(B)=67.4(68$ to 74$)$

Mean prostate volume, $\mathrm{mL}(\mathrm{SD}):(\mathrm{A})=43(9),(B)=42(11)$

Preoperative catheterisation state: not reported

\begin{tabular}{ll}
\hline Interventions & Intervention A: bipolar TURP (Gyrus Plasmakinetic Resection, Medicalm UK) \\
& - Intervention B: monopolar TURP (ValleyLab Force EX, glycine 5\%)
\end{tabular}

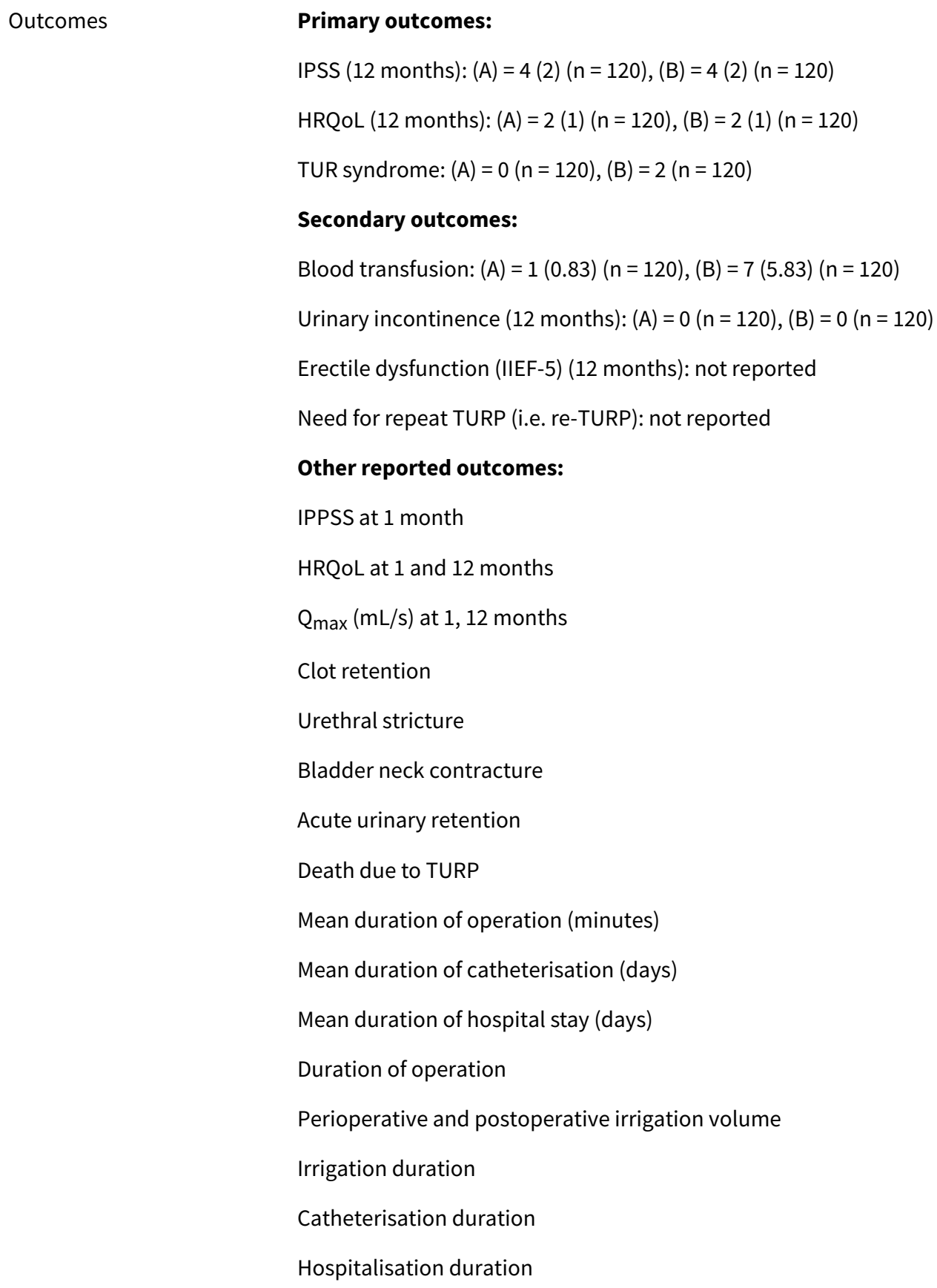


Erturhan 2007 (Continued)

Notes

\section{Risk of bias}

\begin{tabular}{lll}
\hline Bias & Authors' judgement & Support for judgement \\
\hline $\begin{array}{lll}\text { Random sequence gener- } \\
\text { ation (selection bias): All }\end{array}$ & Unclear risk & Not reported \\
outcomes & & \\
\hline
\end{tabular}

Allocation concealment Unclear risk Not reported
(selection bias): All out-
comes

Blinding of participants High risk Not reported but considered unlikely that operating surgeon(s) were blinded
and personnel (perfor-
mance bias): All outcomes

\begin{tabular}{|c|c|c|}
\hline $\begin{array}{l}\text { Blinding of outcome as- } \\
\text { sessment (detection bias): } \\
\text { Subjective outcomes } \\
\text { (IPSS, HRQoL, IIEF-5, TUR } \\
\text { syndrome, Urinary Inconti- } \\
\text { nence) }\end{array}$ & Unclear risk & Not reported \\
\hline $\begin{array}{l}\text { Blinding of outcome as- } \\
\text { sessment: Objective out- } \\
\text { comes (Blood transfusion, } \\
\text { Re-TURP) }\end{array}$ & Low risk & Not reported but objective outcomes unlikely to be affected \\
\hline $\begin{array}{l}\text { Incomplete outcome da- } \\
\text { ta (attrition bias): Imme- } \\
\text { diate postoperative out- } \\
\text { comes (TUR syndrome, } \\
\text { Blood transfusion) }\end{array}$ & Unclear risk & $\begin{array}{l}\text { This study does not explicitly report on attrition, exclusion of participants from } \\
\text { analyses, or the presence of incomplete outcome data for these outcomes } \\
\text { specifically }\end{array}$ \\
\hline $\begin{array}{l}\text { Incomplete outcome data } \\
\text { (attrition bias): Long-term } \\
\text { outcomes (IPSS/HRQoL/ } \\
\text { IIEF-5/urinary inconti- } \\
\text { nence at } 12 \text { months, and } \\
\text { re-TURP) }\end{array}$ & Unclear risk & $\begin{array}{l}\text { This study does not explicitly report on attrition, exclusion of participants from } \\
\text { analyses, or the presence of incomplete outcome data for these outcomes } \\
\text { specifically }\end{array}$ \\
\hline $\begin{array}{l}\text { Selective reporting (re- } \\
\text { porting bias): All outcomes }\end{array}$ & Unclear risk & $\begin{array}{l}\text { RCT protocol could not be identified to allow for full assessment of selective } \\
\text { reporting. However, no data were reported for erectile dysfunction outcomes } \\
\text { although this is described in the methods section as captured data }\end{array}$ \\
\hline
\end{tabular}

\section{Fagerström 2011}

$\begin{array}{ll}\text { Methods } & \text { - Study type: randomised controlled trial (ratio of randomisation not reported) } \\ \text { - Setting: Sweden }\end{array}$

Participants

- Total number enrolled: not specifically reported: $185 ;(A)=98,(B)=87$

- Inclusion criteria: symptomatic BPH requiring surgery due to failed medical therapy or urinary retention, TRUS estimated prostatic volume 30 to $100 \mathrm{~mL}$ 
- Exclusion criteria: evident prostate or bladder cancer, core biopsy of prostate within 3 months before scheduled surgery, neurogenic bladder dysfunction, urethral stricture

\section{Baseline characteristics:}

Not all characteristics comparable at baseline: MTURP patients significantly older $(P=0.007)$

Mean age, years (SD): $(A)=69.5(7.2),(B)=72.7(8.4)$

Mean preoperative prostate volume, $\mathrm{mL}(\mathrm{SD}) ;(\mathrm{A})=55.6(18.2),(\mathrm{B})=58.2(17.6)$

Preoperative catheterisation state: $(A)=33,(B)=34$

$\begin{array}{ll}\text { Interventions } & \text { Intervention A: bipolar TURP (Olympus TURis, Tokyo, Japan) } \\ & \text { - Intervention B: monopolar TURP (irrigation fluid = mannitol } 3 \% \text { and ethanol } 1 \% \text { ) }\end{array}$

Outcomes Primary outcomes:

IPSS (3, 6, 12, > 12 months): no specific data available - graphical format only

HRQoL (validated questionnaire): not reported

TUR syndrome: $(A)=0(n=98),(B)=3(n=87)$

\section{Secondary outcomes:}

Blood transfusion: $(A)=4(n=98),(B)=10(n=87)$

Urinary incontinence 12 months: not reported

IIEF-5 at 12 months: not reported

Need for re-TURP: $(A)=0(n=98),(B)=3(n=87)$

\section{Other reported outcomes:}

Urethral stricture

Bladder neck contracture

UTI

Acute urinary retention

Mean duration of operation

Mean $\mathrm{Hb}$ decrease (\%)

Mean duration of catheterisation (hours)

Mean duration of hospital stay (hours)

Re-admission rate

Source of funding None reported

\section{Notes}

\section{Risk of bias}

Bias Authors' judgement Support for judgement


Fagerström 2011 (Continued)

Random sequence gener- Low risk Study states: "202 patients were allocated, using a random numbers table, to ation (selection bias): All either TURP using a bipolar system or conventional monopolar technique" outcomes

\begin{tabular}{lll}
\hline $\begin{array}{l}\text { Allocation concealment } \\
\text { (selection bias): All out- }\end{array}$ & Unclear risk & Method of allocation concealment not reported specifically \\
comes & & \\
\hline $\begin{array}{l}\text { Blinding of participants } \\
\text { and personnel (perfor- } \\
\text { mance bias): All outcomes }\end{array}$ & High risk & Not reported but considered unlikely that operating surgeon(s) was blinded \\
\hline $\begin{array}{l}\text { Blinding of outcome as- } \\
\text { sessment (detection bias): }\end{array}$ & Unclear risk & \\
$\begin{array}{l}\text { Subjective outcomes } \\
\text { (IPSS, HRQoL, IIEF-5, TUR } \\
\text { syndrome, Urinary Inconti- } \\
\text { nence) }\end{array}$ & \\
\end{tabular}

Blinding of outcome as- Low risk Not reported but objective outcomes unlikely to be affected sessment: Objective outcomes (Blood transfusion, Re-TURP)

\begin{tabular}{|c|c|}
\hline $\begin{array}{l}\text { Incomplete outcome da- } \\
\text { ta (attrition bias): Imme- } \\
\text { diate postoperative out- } \\
\text { comes (TUR syndrome, } \\
\text { Blood transfusion) }\end{array}$ & Unclear risk \\
\hline $\begin{array}{l}\text { Incomplete outcome data } \\
\text { (attrition bias): Long-term } \\
\text { outcomes (IPSS/HRQoL/ } \\
\text { IIEF-5/urinary inconti- } \\
\text { nence at } 12 \text { months, and } \\
\text { re-TURP) }\end{array}$ & Unclear risk \\
\hline
\end{tabular}

The number of patients that underwent analysis in each arm is not clearly reported to allow for this assessment

Selective reporting (re- Unclear risk porting bias): All outcomes

The number of patients that underwent analysis in each arm is not clearly reported to allow for this assessment

Geavlete 2011

$\begin{array}{ll}\text { Methods } & \text { Study type: single-centre randomised controlled trial (1:1:1) } \\ \text { - Setting: Romania }\end{array}$

Participants

- Total number enrolled: $340 ;(A)=170,(B)=170$

- Inclusion criteria: BPH and severe LUTS; inclusion criteria consisted of $\mathrm{Q}_{\max }<10 \mathrm{~mL} / \mathrm{s}, \mathrm{IPSS}>19$, prostate volume between 30 and $80 \mathrm{~mL}$

- Exclusion criteria: severe comorbidities, previous prostate surgery, history of prostate cancer, abnormal DRE, increased PSA

\section{Baseline characteristics:}

No statistically significant differences between arms reported

Age: not reported

Bipolar versus monopolar transurethral resection of the prostate for lower urinary tract symptoms secondary to benign prostatic 
Preoperative catheterisation state: not reported

\begin{tabular}{ll}
\hline Interventions & Intervention A: bipolar TURP (TURis Olympus SurgMaster, saline) \\
& - Intervention B: MTURP (sterile water for irrigation) \\
& - Intervention C: Plasmakinetic Vaporisation of the Prostate (no data collected)
\end{tabular}

Outcomes

Primary outcomes:

IPSS (12 months): $(A)=7.5(2$ to 15$)(n=170),(B)=8.0(3$ to 16$)(n=170)$

HRQoL (12 months): not reported

TUR syndrome: $(A)=0(n=170),(B)=3(n=170)$

\section{Secondary outcomes:}

Blood transfusion: $(A)=3(n=170),(B)=11(n=170)$

Urinary incontinence (12 months): data not reported explicitly at 12 months

Erectile dysfunction (IIEF-5) (12 months): not reported

Need for repeat TURP (i.e. re-TURP): incidence of re-TURP not reported explicitly, only overall re-treatment rates

\section{Other reported outcomes:}

IPSS at 1, 3, 6, 18 months

$\mathrm{Q}_{\max }$

Clot retention

Urinary incontinence (unclear timing of assessment)

Urethral stricture

Bladder neck contracture

UTI

Acute urinary retention

Mean duration of operation (minutes)

Mean duration of catheterisation period (hours)

Mean duration of hospital stay (days)

Mean haemoglobin drop $(\mathrm{g} / \mathrm{dL})$

Capsular perforation rate

Rehospitalisation rate

Source of funding None reported

Notes

\section{Risk of bias}

Bias Authors' judgement Support for judgement

Bipolar versus monopolar transurethral resection of the prostate for lower urinary tract symptoms secondary to benign prostatic 
Geavlete 2011 (Continued)

Random sequence gener- Low risk Study states: "randomised by means of sealed envelopes" ation (selection bias): All outcomes

\begin{tabular}{|c|c|c|}
\hline $\begin{array}{l}\text { Allocation concealment } \\
\text { (selection bias): All out- }\end{array}$ & Unclear risk & $\begin{array}{l}\text { Unclear whether the sealed envelopes were sequentially numbered and } \\
\text { opaque }\end{array}$ \\
\hline
\end{tabular}

\section{Blinding of participants} and personnel (perfor-

Blinding of outcome as-
sessment (detection bias):
Subjective outcomes
(IPSS, HRQoL, IIEF-5, TUR
syndrome, Urinary Inconti-
nence)

\section{Study states: "during follow-up, both patients as well as the urologists per-} forming the investigations were unaware of treatment modality"

Blinding of outcome as- Low risk
sessment: Objective out-
comes (Blood transfusion,
Re-TURP)

\section{Incomplete outcome da-} ta (attrition bias): Immediate postoperative outcomes (TUR syndrome, Blood transfusion)
Study states: "during follow-up, both patients as well as the urologists performing the investigations were unaware of treatment modality"
Unclear risk This study does not explicitly report on attrition, exclusion of participants from analyses, or the presence of incomplete outcome data for these outcomes specifically

\author{
Incomplete outcome data Unclear risk \\ (attrition bias): Long-term \\ outcomes (IPSS/HRQoL/ \\ IIEF-5/urinary inconti- \\ nence at 12 months, and \\ re-TURP)
}

This study does not explicitly report on attrition, exclusion of participants from analyses, or the presence of incomplete outcome data for these outcomes specifically

\begin{tabular}{ll}
\hline Methods & Study type: prospective randomised controlled trial \\
& - Setting: hospital, France \\
\hline Participants & Total number enrolled: $60 ;(\mathrm{A})=31,(\mathrm{~B})=29$ \\
& Inclusion criteria: benign prostatic hyperplasia, age over 50 years, PSA $<4 \mathrm{ng} / \mathrm{mL}$, no suspicious find- \\
& ing on DRE \\
- Exclusion criteria: documented prostate cancer, bladder tumour, urethral stricture, bladder stone, \\
neurogenic bladder, previous TURP
\end{tabular}

\section{Baseline characteristics:}

No statistically significant differences between arms reported

Mean age, years $(S D):(A)=70.25(7.23),(B)=68.71(7.63)$ 
Ghozzi 2014 (Continued)

Mean preoperative prostate volume, $\mathrm{mL}(\mathrm{SD})$ : $(\mathrm{A})=49.5(6.33),(\mathrm{B})=49.5$ (5.48)

Preoperative catheterisation state: not reported

Interventions

- Intervention A: bipolar TURP using 0.9\% saline irrigation. 27 Fr OLYMPUS Active Bipolar Resectoscope utilising TURis technology

- Intervention B: monopolar TURP (1.5\% glycine irrigation). 27 Fr OLYMPUS Active Monopolar Resectoscope

\begin{tabular}{|c|c|}
\hline \multirow[t]{21}{*}{ Outcomes } & Primary outcomes: \\
\hline & IPSS (12 months) (SD): (A) \\
\hline & HRQoL (12 months): not r \\
\hline & TUR syndrome: $(A)=0(n$ \\
\hline & Secondary outcomes: \\
\hline & Blood transfusion: $(\mathrm{A})=1$ \\
\hline & Urinary incontinence (12 \\
\hline & Erectile dysfunction (IIEF \\
\hline & Need for repeat TURP (i.e \\
\hline & Other reported outcom \\
\hline & Operation duration \\
\hline & Resected tissue amount \\
\hline & Serum sodium change \\
\hline & Haemoglobin change \\
\hline & Haematocrit change \\
\hline & $\mathrm{Q}_{\max }$ change \\
\hline & Irrigation duration \\
\hline & Catheterisation duration \\
\hline & Hospitalisation duration \\
\hline & Urethral stricture rate \\
\hline & Bladdder contracture \\
\hline
\end{tabular}

Source of funding None reported

Notes

\section{Risk of bias}

\section{Bias}

Random sequence generation (selection bias): All outcomes 
Ghozzi 2014 (Continued)
Allocation concealment
Unclear risk
Not reported (selection bias): All out- comes

\begin{tabular}{lll}
\hline $\begin{array}{l}\text { Blinding of participants } \\
\text { and personnel (perfor- } \\
\text { mance bias): All outcomes }\end{array}$ & High risk & Not reported, but considered unlikely that operating surgeon(s) were blinded \\
\hline $\begin{array}{l}\text { Blinding of outcome as- } \\
\text { sessment (detection bias): }\end{array}$ & Unclear risk & Not reported \\
Subjective outcomes & \\
(IPSS, HRQoL, IIEF-5, TUR & \\
syndrome, Urinary Inconti- & \\
nence) &
\end{tabular}

Blinding of outcome as- Low risk Not reported but objective outcomes unlikely to have been affected
sessment: Objective out-
comes (Blood transfusion,
Re-TURP)

\begin{tabular}{|c|c|c|}
\hline $\begin{array}{l}\text { Incomplete outcome da- } \\
\text { ta (attrition bias): Imme- }\end{array}$ & Low risk & $\begin{array}{l}\text { All participants in bipolar }(n=31 / 31) \text { and monopolar }(29 / 29) \text { arms appear to be } \\
\text { accounted for in analyses }\end{array}$ \\
\hline
\end{tabular}

diate postoperative outaccounted for in analyses

comes (TUR syndrome, Blood transfusion)

\begin{tabular}{|c|c|c|}
\hline $\begin{array}{l}\text { Incomplete outcome data } \\
\text { (attrition bias): Long-term } \\
\text { outcomes (IPSS/HRQoL/ } \\
\text { IIEF-5/urinary inconti- } \\
\text { nence at } 12 \text { months, and } \\
\text { re-TURP) }\end{array}$ & Low risk & $\begin{array}{l}\text { All participants in bipolar }(n=31 / 31) \text { and monopolar }(29 / 29) \text { arms appear to be } \\
\text { accounted for in analyses }\end{array}$ \\
\hline $\begin{array}{l}\text { Selective reporting (re- } \\
\text { porting bias): All outcomes }\end{array}$ & Unclear risk & No RCT protocol available to allow for full assessment of selective reporting \\
\hline
\end{tabular}

Giulianelli 2013

\begin{tabular}{ll}
\hline Methods & Study type: single-centre randomised controlled trial $(1: 1)$ \\
& - Setting: Italy \\
\hline Participants & Total number enrolled: $160 ;(\mathrm{A})=80,(\mathrm{~B})=80$ \\
& - Inclusion criteria: LUTS of BPH \\
- Exclusion criteria: documented or suspected prostate surgery, renal impairment, associated hy- \\
dronephrosis and urethral stricture
\end{tabular}

\section{Baseline characteristics:}

No significant differences between arms reported

Mean age, years (SD): $(A)=62.5(6.9),(B)=64.18(7.2)$

Mean prostate volume, $\mathrm{mL}(\mathrm{SD}):(\mathrm{A})=47.8(14.6),(B)=50(9.8)$

Interventions

- Intervention A: bipolar TURP; Gyrus Plasmakinetic (PKTURP)

- Intervention B: monopolar TURP; irrigation fluid = mannitol/sorbitol solution

Bipolar versus monopolar transurethral resection of the prostate for lower urinary tract symptoms secondary to benign prostatic 76 obstruction (Review)

Copyright @ 2019 The Cochrane Collaboration. Published by John Wiley \& Sons, Ltd. 
Giulianelli 2013 (Continued)

Outcomes

\section{Primary outcomes:}

IPSS (12 months): $(A)=4.5(n=80),(B)=5.3(n=80)$

HRQoL (12 months): $(A)=0.9(n=80),(B)=1.5(n=80)$

TUR syndrome: $(A)=0(n=80),(B)=2(n=80)$

\section{Secondary outcomes:}

Blood transfusion: $(A)=0(n=80),(B)=3(n=80)$

Urinary incontinence (12 months): $(A)=0(n=79),(B)=0(n=75)$

Erectile dysfunction (IIEF-5) (12 months): $(A)=24(n=80),(B)=22(n=80)$

Need for repeat TURP (i.e. re-TURP): not reported

\section{Other reported outcomes:}

IPSS at $1,3,6,18,24,30,36$ months

HRQoL at 1, 3, 6, 18, 24, 30, 36 months

$\mathrm{Q}_{\max }$

Clot retention

IIEF-5 at 1, 3, 6, 18, 24, 30, 36 months

Bladder neck contracture

UTI

Re-treatment rate (not explicitly re-TURP)

Acute urinary retention

Median duration of operation (minutes)

Median duration of catheterisation (hours)

Median duration of hospital stay (hours)

\section{Risk of bias}

\begin{tabular}{lll}
\hline Bias & Authors' judgement & Support for judgement \\
\hline $\begin{array}{l}\text { Random sequence gener- } \\
\text { ation (selection bias): All } \\
\text { outcomes }\end{array}$ & Unclear risk & Specific method of randomisation not clearly reported \\
\hline $\begin{array}{l}\text { Allocation concealment } \\
\text { (selection bias): All out- } \\
\text { comes }\end{array}$ & Unclear risk & Specific method of allocation concealment not clearly reported \\
\hline $\begin{array}{l}\text { Blinding of participants } \\
\text { and personnel (perfor- } \\
\text { mance bias): All outcomes }\end{array}$ & High risk & Not reported but considered unlikely that operating surgeon(s) were blinded \\
\hline
\end{tabular}

Bipolar versus monopolar transurethral resection of the prostate for lower urinary tract symptoms secondary to benign prostatic 
Giulianelli 2013 (Continued)
Blinding of outcome as-
Unclear risk
Not reported
sessment (detection bias):
Subjective outcomes
(IPSS, HRQOL, IIEF-5, TUR
syndrome, Urinary Inconti- nence)

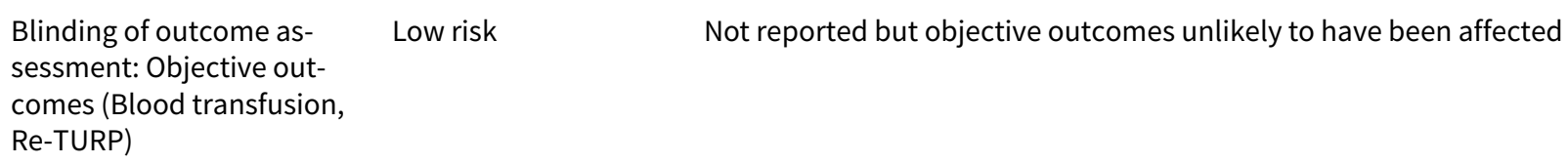

Incomplete outcome data (attrition bias): Immediate postoperative outcomes (TUR syndrome, Blood transfusion)
Unclear risk

This study does not explicitly report on attrition, exclusion of participants from analyses, or the presence of incomplete outcome data for these outcomes specifically
Incomplete outcome data (attrition bias): Long-term outcomes (IPSS/HRQoL/ IIEF-5/urinary incontinence at 12 months, and re-TURP)
Unclear risk

Study states: "one year after TURP, 154 patients ( 75 in the monopolar and 79 in the bipolar group) were assessed for urinary continence and number of retreatments"

This suggests that 6 patients were lost to follow-up with no reported reason for loss to follow-up. Impact of incomplete outcome data on reported differences in outcomes between intervention arms considered unclear

$\begin{array}{lll}\begin{array}{l}\text { Selective reporting (re- } \\ \text { porting bias): All outcomes }\end{array} & \text { Unclear risk } & \text { RCT protocol not available to allow for full assessment }\end{array}$

Goh 2009

\begin{tabular}{|c|c|}
\hline Methods & $\begin{array}{l}\text { - Study type: single-centre randomised controlled trial (1:1) } \\
\text { - Setting: United Kingdom }\end{array}$ \\
\hline Participants & $\begin{array}{l}\text { Total participants enrolled: } 210 ;(A)=110,(B)=100 \\
\text { - Inclusion criteria: not reported } \\
\text { - Exclusion criteria: not reported } \\
\text { Baseline characteristics: } \\
\text { No significant differences between arms reported } \\
\text { Mean age, years (SD): }(A)=72,(B)=73 \\
\text { Mean preoperative prostate volume, } \mathrm{mL}:(A)=68.9,(B)=69.8 \\
\text { Preoperative catheterisation state: } \text { not reported }\end{array}$ \\
\hline Interventions & $\begin{array}{l}\text { - Intervention A: bipolar TURP; Olympus SurgMaster TURis, irrigation fluid = saline } \\
\text { - Intervention B: monopolar TURP (glycine), irrigation fluid = glycine }\end{array}$ \\
\hline Outcomes & $\begin{array}{l}\text { Primary outcomes: } \\
\text { IPSS (12 months): } \text { not reported } \\
\text { HRQoL (12 months): not reported } \\
\text { TUR syndrome: }(A)=0(n=110),(B)=3(n=100)\end{array}$ \\
\hline
\end{tabular}

Bipolar versus monopolar transurethral resection of the prostate for lower urinary tract symptoms secondary to benign prostatic 
Goh 2009 (Continued)

\section{Secondary outcomes:}

Blood transfusion: not reported

Urinary Incontinence (12 months): not reported

Erectile dysfunction (IIEF-5) (12 months): not reported

Need for repeat TURP (i.e. re-TURP): not reported

\section{Other reported outcomes:}

Mean duration of resection (minutes)

Mean postoperative sodium

Capsular perforation rate

Comparison of resectoscopes in terms of 15 parameters scored by the operating surgeon on a scale of 1 to 10 , with higher scores indicating better performance

$\begin{array}{ll}\text { Source of funding } & \text { None reported } \\ \text { Notes } & \text { This is a conference abstract with limited information. Data for many outcomes are reported as } \\ \text { significant or not significant without numerical values. Protocol is available at http://www.isrct- } \\ \text { n.com/ISRCTN49628875?q=bipolar\%20AND\%20prostate\%20AND\%20Goh\&filters=\&sort=\&offset=1\&to- } \\ \text { talResults=1\&page=1\&pageSize=10\&searchType=basic-search } \\ \text { "A comparison between the use of transurethral resection of the prostate (TURP) with bipolar cutting } \\ \text { loop diathermy for the treatment of benign prostatic hypertrophy (Goh; Southmead Hospital, Bristol, } \\ \text { UK)" }\end{array}$

\section{Risk of bias}

\begin{tabular}{|c|c|c|}
\hline Bias & Authors' judgement & Support for judgement \\
\hline $\begin{array}{l}\text { Random sequence gener- } \\
\text { ation (selection bias): All } \\
\text { outcomes }\end{array}$ & Unclear risk & Not reported \\
\hline $\begin{array}{l}\text { Allocation concealment } \\
\text { (selection bias): All out- } \\
\text { comes }\end{array}$ & Unclear risk & Not reported \\
\hline $\begin{array}{l}\text { Blinding of participants } \\
\text { and personnel (perfor- } \\
\text { mance bias): All outcomes }\end{array}$ & High risk & Not reported but considered unlikely that operating surgeon(s) were blinded \\
\hline $\begin{array}{l}\text { Blinding of outcome as- } \\
\text { sessment (detection bias): } \\
\text { Subjective outcomes } \\
\text { (IPSS, HRQoL, IIEF-5, TUR } \\
\text { syndrome, Urinary Inconti- } \\
\text { nence) }\end{array}$ & Unclear risk & Not reported \\
\hline $\begin{array}{l}\text { Blinding of outcome as- } \\
\text { sessment: Objective out- } \\
\text { comes (Blood transfusion, } \\
\text { Re-TURP) }\end{array}$ & Unclear risk & These outcomes were not reported by this study \\
\hline
\end{tabular}

Bipolar versus monopolar transurethral resection of the prostate for lower urinary tract symptoms secondary to benign prostatic 


\section{Goh 2009 (Continued)}

Incomplete outcome data (attrition bias): Immediate postoperative outcomes (TUR syndrome, Blood transfusion)
Unclear risk This study does not explicitly report on attrition, exclusion of participants from analyses, or the presence of incomplete outcome data for these outcomes specifically

Incomplete outcome data (attrition bias): Long-term outcomes (IPSS/HRQoL/ IIEF-5/urinary incontinence at 12 months, and re-TURP)

\section{Selective reporting (re- Unclear risk} porting bias): All outcomes
RCT protocol not available to allow for full assessment. However, abstract states that IPSS was recorded at 12 months, but these data are not reported, and it does not appear that they have been published

He 2010

$\begin{array}{ll}\text { Methods } & \text { - Study type: single-centre randomised controlled trial }(1: 1) \\ \text { - Setting: China }\end{array}$

Participants

- Total participants enrolled: $300 ;(A)=150,(B)=150$

- Inclusion criteria: symptomatic BPH that required surgery owing to urinary retention or failed medical therapy

- Exclusion criteria: severe medical disease, previous prostatic or urethral surgery, prostate cancer, acontractile detrusor

\section{Baseline characteristics:}

No significant differences between arms reported

Mean age, years (SD): $(A)=72.5(4.0),(B)=71.9(3.1)$

Mean preoperative prostate volume, $\mathrm{mL}(\mathrm{SD})$ : $(\mathrm{A})=45.0(5.5),(B)=46.1(6.3)$

Preoperative catheterisation state: not reported

Interventions

Outcomes

- Intervention A: bipolar TURP (Gyrus Transurethral Bipolar Electrosurgical System)

- Intervention B: monopolar TURP (Wolf 26 F Storz Electrosurgical Generator), irrigation fluid = 5\% mannitol

\section{Primary outcomes:}

IPSS (12 months): not reported

HRQoL (12 months): not reported

TUR syndrome: $(A)=0(n=142),(B)=5(n=139)$

\section{Secondary outcomes:}

Blood transfusion: $(A)=1(n=142),(B)=3(n=139)$

Urinary incontinence (12 months): not reported (only data at 3 months available)

Erectile dysfunction (IIEF-5) (12 months): not reported

Need for repeat TURP (i.e. re-TURP): Not reported

Bipolar versus monopolar transurethral resection of the prostate for lower urinary tract symptoms secondary to benign prostatic 80 obstruction (Review)

Copyright @ 2019 The Cochrane Collaboration. Published by John Wiley \& Sons, Ltd. 
He 2010 (Continued)

\section{Other reported outcomes:}

IPSS at 3 months, no specific data available for 6 and 12 months

Mean QoL at 3 months

$\mathrm{Q}_{\max }(\mathrm{mL} / \mathrm{s})$

Clot retention

Incontinence (3 months)

Urethral stricture

Bladder neck contracture

Duration of operation (minutes)

Duration of catheterisation (days)

Duration of hospital stay (days)

Change in postoperative serum sodium ( $\mathrm{Na}+)$

None reported

\section{Notes}

\section{Risk of bias}

\begin{tabular}{lll}
\hline Bias & Authors' judgement & Support for judgement \\
\hline $\begin{array}{l}\text { Random sequence gener- } \\
\text { ation (selection bias): All }\end{array}$ & Unclear risk & Not reported \\
outcomes & & \\
\hline
\end{tabular}

Allocation concealment $\quad$ Unclear risk $\quad$ Not reported
(selection bias): All out-
comes

\begin{tabular}{lll}
$\begin{array}{l}\text { Blinding of participants } \\
\text { and personnel (perfor- } \\
\text { mance bias): All outcomes }\end{array}$ & High risk & Not reported but considered unlikely that operating surgeon(s) were blinded \\
\hline $\begin{array}{l}\text { Blinding of outcome as- } \\
\text { sessment (detection bias): }\end{array}$ & Unclear risk & Not reported \\
$\begin{array}{l}\text { Subjective outcomes } \\
\text { (IPSS, HRQoL, IIEF-5, TUR } \\
\text { syndrome, Urinary Inconti- } \\
\text { nence) }\end{array}$ &
\end{tabular}

Blinding of outcome as- Low risk Not reported but objective outcomes unlikely to be affected
sessment: Objective out-
comes (Blood transfusion,
Re-TURP)

\begin{tabular}{ll}
$\begin{array}{l}\text { Incomplete outcome da- } \\
\text { ta (attrition bias): Imme- } \\
\text { diate postoperative out- } \\
\begin{array}{l}\text { comes (TUR syndrome, } \\
\text { Blood transfusion) }\end{array}\end{array}$ & $\begin{array}{l}\text { All participants in bipolar }(\mathrm{n}=142 / 142) \text { and monopolar (139/139) arms appear } \\
\text { to be accounted for in analyses, with no reported loss to follow-up for these } \\
\text { outcomes }\end{array}$ \\
\hline
\end{tabular}




\section{He 2010 (Continued)}

Incomplete outcome data (attrition bias): Long-term outcomes (IPSS/HRQoL/ IIEF-5/urinary incontinence at 12 months, and re-TURP)

$\begin{aligned} & \text { Selective reporting (re- } \\ & \text { porting bias): All outcomes }\end{aligned}$
Unclear risk

\section{Ho 2007}

$\begin{array}{ll}\text { Methods } & \text { - Study type: single-centre randomised controlled trial }(1: 1) \\ & \text { - Setting: Singapore }\end{array}$

- Setting: Singapore

\section{Participants}

- Total number enrolled: $100 ;(A)=48,(B)=52$

- Inclusion criteria: > 50 years, fit for anaesthesia, failed medical therapy with alpha-blockers or 5-alpha reductase inhibitors, IPSS $>18, \mathrm{Q}_{\max }<15 \mathrm{~mL} / \mathrm{s}$, acute urinary retention, failed trial of void without urinary catheter

- Exclusion criteria: documented or suspected prostate cancer, bladder calculus, neurogenic bladder, previous prostate surgery, renal impairment, associated hydronephrosis, urethral stricture

\section{Baseline characteristics}

No significant differences between arms reported

Mean age, years $(S D):(A)=66.6(6.8),(B)=66.5(7.2)$

Mean preoperative prostate volume, $\mathrm{mL}:(\mathrm{A})=56.5(17.9),(B)=54.8(19.2)$

Preoperative catheterisation status: $(A)=24(n=48),(B)=21(n=52)$

$\begin{array}{ll}\text { Interventions } & \text { Intervention A: bipolar TURP (Olympus TURIS System) } \\ & \text { - Intervention B: monopolar TURP (irrigation fluid = glycine 5\%) }\end{array}$

Outcomes

\section{Primary outcomes:}

IPSS (12 months): specific data not provided, in graphical format only

HRQoL (12 months): not reported

TUR syndrome: $(A)=0(n=48),(B)=2(n=52)$

\section{Secondary outcomes:}

Blood transfusion: $(A)=1(n=48),(B)=1(n=52)$

Urinary incontinence (12 months): not reported

Erectile dysfunction (IIEF-5) (12 months): not reported

Need for repeat TURP (i.e. re-TURP): not reported

\section{Other reported outcomes:}

$\mathrm{Q}_{\max }$

Clot retention

Urethral stricture

Bipolar versus monopolar transurethral resection of the prostate for lower urinary tract symptoms secondary to benign prostatic 
Ho 2007 (Continued)

\section{UTI}

Acute urinary retention

Mean resection time

Mean reduction in postoperative serum $\mathrm{Na}+$

Mean reduction in postoperative haemoglobin

\begin{tabular}{ll}
\hline Source of funding None reported \\
\hline Notes
\end{tabular}

\section{Risk of bias}

\begin{tabular}{lll}
\hline Bias & Authors' judgement & Support for judgement \\
\hline $\begin{array}{l}\text { Random sequence gener- } \\
\begin{array}{l}\text { ation (selection bias): All } \\
\text { outcomes }\end{array}\end{array}$ & Low risk & $\begin{array}{l}\text { Study states: "patients included in the study were computer randomized in a } \\
1: 1 \text { ratio into two groups" }\end{array}$ \\
\hline $\begin{array}{l}\text { Allocation concealment } \\
\text { (selection bias): All out- } \\
\text { comes }\end{array}$ & Unclear risk & Specific methods to ensure allocation concealment not clearly reported \\
\end{tabular}

Blinding of participants High risk Not reported but considered unlikely that operating surgeon(s) were blinded
and personnel (perfor-
mance bias): All outcomes

Blinding of outcome as- $\quad$ Unclear risk $\quad$ Not reported
sessment (detection bias):
Subjective outcomes
(IPSS, HRQoL, IIEF-5, TUR
syndrome, Urinary Inconti-
nence)

Blinding of outcome as- $\quad$ Low risk $\quad$ Not reported but objective outcomes unlikely to be affected
sessment: Objective out-

comes (Blood transfusion, Re-TURP)

\begin{tabular}{|c|c|c|}
\hline $\begin{array}{l}\text { Incomplete outcome da- } \\
\text { ta (attrition bias): Imme- } \\
\text { diate postoperative out- } \\
\text { comes (TUR syndrome, } \\
\text { Blood transfusion) }\end{array}$ & Low risk & $\begin{array}{l}\text { Study states: "all patients had at least one year follow-up"; all patients ( } n=48 \\
\text { for bipolar, } n=52 \text { for monopolar TURP) appear to have been included in the fi- } \\
\text { nal analyses for these outcomes }\end{array}$ \\
\hline $\begin{array}{l}\text { Incomplete outcome data } \\
\text { (attrition bias): Long-term } \\
\text { outcomes (IPSS/HRQoL/ } \\
\text { IIEF-5/urinary inconti- } \\
\text { nence at } 12 \text { months, and } \\
\text { re-TURP) }\end{array}$ & Unclear risk & $\begin{array}{l}\text { Study states: "all patients had at least one year follow-up"; however, data for } \\
\text { IPSS at } 12 \text { months are provided only in graphical format with no specific data } \\
\text { provided; therefore, full interpretation of data is not possible }\end{array}$ \\
\hline $\begin{array}{l}\text { Selective reporting (re- } \\
\text { porting bias): All outcomes }\end{array}$ & Unclear risk & $\mathrm{RCT}$ protocol not available to allow for full assessment \\
\hline
\end{tabular}


Huang 2012

\begin{tabular}{ll}
\hline Methods & Study type: single-centre, RCT $(1: 1)$ \\
& - Setting: China \\
\hline Participants & Total number enrolled: $136 ;(\mathrm{A})=71,(\mathrm{~B})=65$ \\
- & Inclusion criteria: symptomatic $\mathrm{BPH},>50$ years, medication failure, International Prostate Symptom \\
& Score (IPSS) $>16$, maximum flow rate $\left(\mathrm{Q}_{\max }\right)<15 \mathrm{~mL} / \mathrm{s}$, prostate volume of 30 to $80 \mathrm{~mL}$ estimated on \\
& transrectal ultrasound (TRUS) \\
- & Exclusion criteria: documented or suspected prostate cancer, neurogenic bladder, bladder calculus \\
& or tumour, previous prostate surgery, urethral stricture, parafunction of blood coagulability
\end{tabular}

\section{Baseline characteristics:}

No significant differences between arms reported.

Mean age, years (SD): (A) $65.08(4.19)(n=71),(B) 64.55(3.67)(n=65)(P=0.613)$

Mean preoperative prostate volume, $m L(S D):(A)=52.92(10.60),(B)=50.08(10.84)(P=0.101)$

Preoperative catheterisation state: not reported

\begin{tabular}{ll}
\hline Interventions & Intervention A: bipolar TURP (Gyrus), irrigation fluid $=0.9 \%$ saline \\
& - Intervention B: monopolar TURP (Storz), irrigation fluid = mannitol $5 \%$ solution
\end{tabular}

Outcomes

Primary outcomes:

IPSS (12 months): not reported

HRQoL (12 months): not reported

TUR syndrome: not reported

\section{Secondary outcomes:}

Blood transfusion: not reported

Urinary incontinence (12 months): not reported

Erectile dysfunction (IIEF-5) (12 months): not reported

Need for repeat TURP (i.e. re-TURP): not reported

\section{Other reported outcomes:}

Clot retention

Drop in sodium ( $\mathrm{mmol} / \mathrm{L})$

Drop in haemoglobin $(\mathrm{g} / \mathrm{dL})$

Duration of operation (minutes)

Operation duration

Capsular perforation

Postoperative bleeding

\begin{tabular}{ll}
\hline Source of funding None reported \\
\hline Notes
\end{tabular}


Huang 2012 (Continued)

Risk of bias

\begin{tabular}{|c|c|c|}
\hline Bias & Authors' judgement & Support for judgement \\
\hline $\begin{array}{l}\text { Random sequence gener- } \\
\text { ation (selection bias): All } \\
\text { outcomes }\end{array}$ & Low risk & Study states: "randomization was done by the opaque envelope method" \\
\hline $\begin{array}{l}\text { Allocation concealment } \\
\text { (selection bias): All out- } \\
\text { comes }\end{array}$ & Low risk & Study reports use of opaque envelopes to ensure allocation concealment \\
\hline $\begin{array}{l}\text { Blinding of participants } \\
\text { and personnel (perfor- } \\
\text { mance bias): All outcomes }\end{array}$ & High risk & Not reported but considered unlikely that operating surgeon(s) were blinded \\
\hline $\begin{array}{l}\text { Blinding of outcome as- } \\
\text { sessment (detection bias): } \\
\text { Subjective outcomes } \\
\text { (IPSS, HRQoL, IIEF-5, TUR } \\
\text { syndrome, Urinary Inconti- } \\
\text { nence) }\end{array}$ & Unclear risk & These outcomes were not reported by the trial \\
\hline $\begin{array}{l}\text { Blinding of outcome as- } \\
\text { sessment: Objective out- } \\
\text { comes (Blood transfusion, } \\
\text { Re-TURP) }\end{array}$ & Unclear risk & These outcomes were not reported by the trial \\
\hline
\end{tabular}

Incomplete outcome da- Unclear risk These outcomes were not reported by the trial
ta (attrition bias): Imme-
diate postoperative out-
comes (TUR syndrome,
Blood transfusion)

\begin{tabular}{l}
\hline Incomplete outcome data Unclear risk These outcomes were not reported by the trial \\
(attrition bias): Long-term \\
outcomes (IPSS/HRQoL/ \\
IIEF-5/urinary inconti- \\
nence at 12 months, and \\
re-TURP)
\end{tabular}

$\begin{array}{ll}\begin{array}{l}\text { Selective reporting (re- } \\ \text { porting bias): All outcomes }\end{array} & \text { Unclear risk }\end{array}$

porting bias): All outcomes

Iori 2008

\begin{tabular}{ll}
\hline Methods & Study type: single-centre randomised controlled trial $(1: 1)$ \\
& - Setting: Italy \\
\hline Participants & Total number enrolled: $53 ;(A)=27,(B)=26$ \\
& - Included: LUTS secondary to BPO \\
& Exclusion criteria: neurological illness, renal insufficiency, bladder stone, urethral stricture, taking \\
& finasteride
\end{tabular}

\section{Baseline characteristics}

Bipolar versus monopolar transurethral resection of the prostate for lower urinary tract symptoms secondary to benign prostatic 
Iori 2008 (Continued)

No significant differences between arms reported

Mean age, years (SD): $(A)=65(5),(B)=63(5)$

Mean prostate volume, $\mathrm{cm}^{3}(\mathrm{SD}):(\mathrm{A})=49(11),(\mathrm{B})=48(9)$

$\begin{array}{ll}\text { Interventions } & \text { Intervention A: bipolar TURP (Gyrus PlasmaKinetic); irrigation fluid }=0.9 \% \text { saline } \\ & \text { - Intervention B: monopolar TURP; irrigation fluid = mannitol }\end{array}$

\section{Outcomes}

\section{Primary outcomes:}

IPSS (12 months): mean IPSS at 12 months (SD): $(A)=7.0(1.7)(n=27),(B)=6.7(4)(n=26)$

HRQoL (12 months): $(A)=1(1)(n=27),(B)=1(1)(n=26)$

TUR syndrome: $(A)=0(n=27),(B)=0(n=26)$

\section{Secondary outcomes:}

Blood transfusion: $(A)=0(n=27),(B)=0(n=26)$

Urinary incontinence (12 months): not reported

Erectile dysfunction (IIEF-5) (12 months): not reported

Need for repeat TURP (i.e. re-TURP): not reported

\section{Other reported outcomes:}

Mean $\mathrm{Q}_{\max }(\mathrm{mL} / \mathrm{s})$

Clot retention

Acute urinary retention

Mean resection time (minutes)

Mean catheterisation time (hours)

Mean postoperative hospital stay (hours)

Mean reduction in $\mathrm{Hb}$ at 24 hours postop $(\mathrm{g} / \mathrm{dL}$ )

Source of funding None reported

\section{Notes}

\section{Risk of bias}

\begin{tabular}{lll}
\hline Bias & Authors' judgement & Support for judgement \\
\hline $\begin{array}{l}\text { Random sequence gener- } \\
\begin{array}{l}\text { ation (selection bias): All } \\
\text { outcomes }\end{array}\end{array}$ & Low risk & $\begin{array}{l}\text { Study states: "the patients were randomized 1:1, using envelopes, into two } \\
\text { groups" }\end{array}$ \\
\hline $\begin{array}{l}\text { Allocation concealment } \\
\text { (selection bias): All out- } \\
\text { comes }\end{array}$ & Unclear risk & $\begin{array}{l}\text { Study states: "the patients were randomized 1:1, using envelopes, into two } \\
\text { groups" }\end{array}$ \\
& $\begin{array}{l}\text { Unclear whether the envelopes were sealed, sequentially numbered, and } \\
\text { opaque }\end{array}$ \\
\hline
\end{tabular}

Bipolar versus monopolar transurethral resection of the prostate for lower urinary tract symptoms secondary to benign prostatic 
Iori 2008 (Continued)

Blinding of participants High risk Not reported but considered unlikely that operating surgeon(s) were blinded and personnel (performance bias): All outcomes

Blinding of outcome as-
sessment (detection bias):
Subjective outcomes
(IPSS, HRQoL, IIEF-5, TUR
syndrome, Urinary Inconti-
nence)

\section{Blinding of outcome as-} sessment: Objective outcomes (Blood transfusion, Re-TURP)

Incomplete outcome data (attrition bias): Immediate postoperative outcomes (TUR syndrome, Blood transfusion)
Unclear risk

This study does not explicitly report on attrition, exclusion of participants from analyses, or the presence of incomplete outcome data for these outcomes

\begin{tabular}{|c|c|c|}
\hline $\begin{array}{l}\text { Incomplete outcome data } \\
\text { (attrition bias): Long-term } \\
\text { outcomes (IPSS/HRQoL/ } \\
\text { IIEF-5/urinary inconti- } \\
\text { nence at } 12 \text { months, and } \\
\text { re-TURP) }\end{array}$ & Unclear risk & $\begin{array}{l}\text { This study does not explicitly report on attrition, exclusion of participants from } \\
\text { analyses, or the presence of incomplete outcome data for these outcomes } \\
\text { specifically }\end{array}$ \\
\hline
\end{tabular}

Selective reporting (reUnclear risk RCT protocol not available to allow for full assessment porting bias): All outcomes

\section{Kadyan 2014}

\begin{tabular}{ll}
\hline Methods & Study type: single-centre randomised controlled trial (1:1); only published abstract available for data \\
extraction \\
- Setting: India
\end{tabular}

Baseline characteristics: specific data not provided in abstract

Preoperative catheterisation, $\mathbf{n}:(A)=$ and $(B)=$ not reported

$\begin{array}{ll}\text { Interventions } & \text { Intervention A: bipolar TURP; specific technology used not reported } \\ \text { - Intervention B: monopolar TURP; irrigation fluid not reported }\end{array}$

\section{Outcomes}

\section{Primary outcomes:}

IPSS (12 months): not reported 
Kadyan 2014 (Continued)

HRQoL (12 months): not reported

TUR syndrome: not reported

Secondary outcomes:

Blood transfusion: not reported

Urinary incontinence (12 months): not reported

Erectile dysfunction (IIEF-5) (12 months): not reported

Need for repeat TURP (i.e. re-TURP): not reported

\section{Other reported outcomes:}

Resection duration

Serum sodium level change

IPSS change

$\mathrm{Q}_{\max }$ change

\section{Source of funding}

None reported

This is a conference abstract with limited information

\section{Risk of bias}

\begin{tabular}{lll}
\hline Bias & Authors' judgement & Support for judgement \\
\hline $\begin{array}{l}\text { Random sequence gener- } \\
\text { ation (selection bias): All } \\
\text { outcomes }\end{array}$ & Unclear risk & Not reported \\
\hline $\begin{array}{l}\text { Allocation concealment } \\
\text { (selection bias): All out- } \\
\text { comes }\end{array}$ & Unclear risk & Not reported \\
\hline
\end{tabular}

\begin{tabular}{|c|c|c|}
\hline $\begin{array}{l}\text { Blinding of participants } \\
\text { and personnel (perfor- } \\
\text { mance bias): All outcomes }\end{array}$ & High risk & Not reported but considered unlikely that operating surgeons were blinded \\
\hline $\begin{array}{l}\text { Blinding of outcome as- } \\
\text { sessment (detection bias): } \\
\text { Subjective outcomes } \\
\text { (IPSS, HRQoL, IIEF-5, TUR } \\
\text { syndrome, Urinary Inconti- } \\
\text { nence) }\end{array}$ & Unclear risk & Not reported \\
\hline
\end{tabular}

Blinding of outcome assessment: Objective outUnclear risk These outcomes were not reported by the trial comes (Blood transfusion, Re-TURP)

Incomplete outcome da- Unclear risk $\quad$ These outcomes were not reported by the trial
ta (attrition bias): Imme-
diate postoperative out-
comes (TUR syndrome,
Blood transfusion)


Kadyan 2014 (Continued)

Incomplete outcome data (attrition bias): Long-term

These outcomes were not reported by the trial outcomes (IPSS/HRQoL/ IIEF-5/urinary incontinence at 12 months, and re-TURP)

$\begin{aligned} & \text { Selective reporting (re- } \\ & \text { porting bias): All outcomes }\end{aligned}$
Unclear risk

\section{Kim 2006}

$\begin{array}{ll}\text { Methods } & \text { Study type: } \text { parallel RCT } \\ \text { - Setting: inpatient/single centre/South Korea } \\ \text { - Ethnicity: not reported } \\ \text { - Study duration: August } 2003 \text { to October } 2004\end{array}$

\section{Participants}

- Total participants enrolled: 50 (Intervention $A=25 /$ Intervention $B=25$ )

- Inclusion criteria: aged 50 or over with IPSS score higher than $8, \mathrm{Q}_{\max }$ lower than $15 \mathrm{~mL} / \mathrm{s}$, prostate volume 30 to $120 \mathrm{~mL}$ on the basis of the TRUS test

- Exclusion criteria: younger than 50 years of age, neurogenic bladder disorder, bladder cancer, prostate cancer, history of prostate surgery, medications taken that may have influenced functioning of the bladder, suspected to have a bladder abnormality and a disease in the lower part of the ureter without BPH in urodynamic study

Baseline characteristics: no significant differences between interventions in IPSS, $\mathrm{Q}_{\max }$, and prostate volume, but no report on differences in age

$$
\begin{aligned}
& \text { Mean age, years }(S D):(A)=68.1(8.9),(B)=70.6(7.5) \\
& \text { Mean prostate volume, } m L:(A)=53.2(14.9),(B)=51.7(19.1)
\end{aligned}
$$

\section{Primary outcomes:}

IPSS (12 months): not reported (only at 1 and 6 months)

HRQoL (12 months): not reported

TUR syndrome: $(A)=0(n=25),(B)=0(n=25)$

\section{Secondary outcomes:}

Blood transfusion: $(A)=0(n=25),(B)=2(n=25)$

Urinary incontinence (12 months): not reported explicitly at 12 months

Erectile dysfunction (IIEF-5) (12 months): not reported

Need for repeat TURP (i.e. re-TURP): not reported

\section{Other reported outcomes:}

Resection duration

Serum sodium level change 
Kim 2006 (Continued)

Haemoglobin level change

Catheterisation duration

Hospitalisation duration

IPSS change

Resection volume

$\mathrm{Q}_{\max }$ change

\begin{tabular}{ll}
\hline Source of funding None reported \\
\hline Notes
\end{tabular}

\section{Risk of bias}

\begin{tabular}{lll}
\hline Bias & Authors' judgement & Support for judgement \\
\hline $\begin{array}{l}\text { Random sequence gener- } \\
\text { ation (selection bias): All } \\
\text { outcomes }\end{array}$ & Unclear risk & Not reported \\
\hline $\begin{array}{l}\text { Allocation concealment } \\
\text { (selection bias): All out- } \\
\text { comes }\end{array}$ & Unclear risk & Not reported \\
\hline
\end{tabular}

Blinding of participants

High risk

Not reported but considered unlikely that operating surgeon(s) were blinded

and personnel (perfor-

mance bias): All outcomes

Blinding of outcome as-
sessment (detection bias):
Subjective outcomes
(IPSS, HRQoL, IIEF-5, TUR
syndrome, Urinary Inconti-
nence)

Blinding of outcome as-
sessment: Objective out-

Incomplete outcome data (attrition bias): Immediate postoperative outcomes (TUR syndrome, Blood transfusion)

\section{Unclear risk Not reported}
Incomplete outcome data (attrition bias): Long-term outcomes (IPSS/HRQoL/ IIEF-5/urinary inconti- nence at 12 months, and re-TURP) Unclear risk Unclear risk This study does not explicitly report on attrition, exclusion of participants from analyses, or the presence of incomplete outcome data for these outcomes

$\begin{aligned} & \text { Selective reporting (re- } \\ & \text { porting bias): All outcomes }\end{aligned}$
Unclear risk $\quad$ RCT protocol could not be identified to allow for full assessment

\footnotetext{
Bipolar versus monopolar transurethral resection of the prostate for lower urinary tract symptoms secondary to benign prostatic obstruction (Review)

Copyright $\odot 2019$ The Cochrane Collaboration. Published by John Wiley \& Sons, Ltd.
} This study does not explicitly report on attrition, exclusion of participants from analyses, or the presence of incomplete outcome data for these outcomes 


Methods $\quad$ Study type: single-centre randomised controlled trial (1:1)

- Setting: Japan

$\begin{array}{ll}\text { Participants } & \text { Total number enrolled: } 136 ;(A)=69,(B)=67 \\ \text { - Inclusion criteria: age }>50 \text { years, Eastern Cooperative Oncology Group performance status } \leq 2 ; \text { acute } \\ \text { urinary retention if catheter removal failed after therapy with alpha-blockers, chronic urinary reten- } \\ \text { tion unresponsive to medical therapies, IPSS } \geq 15 \\ \text { - Exclusion criteria: suspected prostate cancer, bladder calculus, previous prostate surgery, men tak- } \\ \text { ing 5-alpha reductase inhibitor preoperative medication }\end{array}$

\section{Baseline characteristics}

No significant differences between arms reported

Mean age, years $(S D):(A)=69.8(5.8),(B)=68.0(5.4)$

Mean preoperative prostate volume, $\mathrm{mL}(\mathrm{SD}):(\mathrm{A})=50.9(17.2),(\mathrm{B})=53.0(20.1)$

Preoperative indwelling catheter: $(A)=6,(B)=7$

Interventions $\quad$ - Intervention A: bipolar TURP; TURis (Olympus, Tokyo, Japan); irrigation fluid = $0.9 \%$ saline

- Intervention B: monopolar TURP; irrigation fluid = 4\% mannitol solution, $1 \%$ ethanol

\section{Outcomes}

\section{Primary outcomes:}

IPSS (12 months): $(A)=7.6(3.5)(n=52),(B)=8.3(2.3)(n=58)$

HRQoL (12 months): 12 months: $(A)=4.4(3.9)(n=52),(B)=4.1(5.4)(n=58)$

TUR syndrome: $(A)=0(n=63),(B)=0(n=61)$

\section{Secondary outcomes:}

Blood transfusion: $(A)=1(n=63),(B)=4(n=61)$

Urinary incontinence (12 months): not reported (data available only at 3 months)

Erectile dysfunction (IIEF-5) (12 months): not reported

Need for repeat TURP (i.e. re-TURP): not reported

\section{Other reported outcomes:}

IPSS at 24 and 36 months

HRQoL at 24 and 36 months

Mean $\mathrm{Q}_{\max }$

Clot retention

Urinary incontinence at 3 months

Urethral stricture and bladder neck contracture

UTI

Acute urinary retention

Mean reduction in postoperative $\mathrm{Na}(\mathrm{mEq} / \mathrm{L})$

Mean reduction in postoperative $\mathrm{Hb}(\mathrm{g} / \mathrm{dL})$ 
Komura 2015 (Continued)

Incidence of epididymitis

Mean duration of catheterisation time (hours)

Mean hospitalisation duration (days)

Mean duration of operation (minutes)

\begin{tabular}{ll}
\hline Source of funding & None reported \\
\hline Notes & $\begin{array}{l}\text { Protocol is available at https://upload.umin.ac.jp/cgi-open-bin/ctr/ctr.cgi?function=brows\&ac- } \\
\text { tion=brows\&type=summary\&recptno=R000012628\&language=E } \\
\text { "Multicentre randomised controlled trial comparing bipolar with monopolar transurethral resection of } \\
\text { the prostate" (UMIN000010801) }\end{array}$ \\
\hline
\end{tabular}

\section{Risk of bias}

\begin{tabular}{lll}
\hline Bias & Authors' judgement & Support for judgement \\
\hline $\begin{array}{l}\text { Random sequence gener- } \\
\text { ation (selection bias): All } \\
\text { outcomes }\end{array}$ & Low risk & $\begin{array}{l}\text { Study states: "randomisation was performed using a stratified permuted ran- } \\
\text { domisation algorithm (1:1)" }\end{array}$ \\
\hline $\begin{array}{l}\text { Allocation concealment } \\
\text { (selection bias): All out- } \\
\text { comes }\end{array}$ & Unclear risk & $\begin{array}{l}\text { Study states: "randomisation was performed using a stratified permuted ran- } \\
\text { domisation algorithm (1:1)" }\end{array}$ \\
$\begin{array}{l}\text { Any specific measures to ensure allocation concealment not reported explicit- } \\
\text { ly } \\
\text { Blinding of participants } \\
\text { mance bias): All outcomes }\end{array}$ & High risk & $\begin{array}{l}\text { "The nature of the intervention made blinding of the treatment providers im- } \\
\text { possible and thus the surgeon was not blinded; however, both the outcome } \\
\text { assessors and the patients were blinded with regard to the intervention type } \\
\text { (double-blind RCT)" }\end{array}$ \\
\hline
\end{tabular}

\begin{tabular}{|c|c|c|}
\hline $\begin{array}{l}\text { Blinding of outcome as- } \\
\text { sessment (detection bias): } \\
\text { Subjective outcomes } \\
\text { (IPSS, HRQoL, IIEF-5, TUR }\end{array}$ & Low risk & $\begin{array}{l}\text { "The nature of the intervention made blinding of the treatment providers im- } \\
\text { possible and thus the surgeon was not blinded; however, both the outcome } \\
\text { assessors and the patients were blinded with regard to the intervention type } \\
\text { (double-blind RCT)" }\end{array}$ \\
\hline
\end{tabular}

syndrome, Urinary Incontinence)

Blinding of outcome as- Low risk
sessment: Objective out-
comes (Blood transfusion,
Re-TURP)
Re-TURP)

\begin{abstract}
"The nature of the intervention made blinding of the treatment providers impossible and thus the surgeon was not blinded; however, both the outcome assessors and the patients were blinded with regard to the intervention type (double-blind RCT)"
\end{abstract}

Low risk

Study reports loss of follow-up at $n=1$ for MTURP and $n=0$ for BTURP for these perioperative outcomes

Low risk

Incomplete outcome da-

ta (attrition bias): Imme-

diate postoperative out-

comes (TUR syndrome,

Blood transfusion)

\footnotetext{
Incomplete outcome data (attrition bias): Long-term outcomes (IPSS/HRQoL/ IIEF-5/urinary incontinence at 12 months, and re-TURP)
}

Unclear risk All patients ( $n=58$ for MTURP and $n=52$ for BTURP), including those lost to follow-up ( $\mathrm{n}=9$ for MTURP, $\mathrm{n}=17$ for BTURP), were accounted for in the reported analyses. Considered unclear how loss to follow-up may have impacted observed differences in outcomes between arms 
Komura 2015 (Continued)

Selective reporting (reporting bias): All outcomes
Low risk

The study protocol is available. The report includes all expected outcomes, including those that were prespecified

Kong 2009

Methods - Study type: single-centre randomised controlled trial (1:1)

- Setting: Malaysia

$\begin{array}{ll}\text { Participants } & \text { Total number enrolled: } 102 ;(A)=51,(B)=51 \\ \text { - Inclusion criteria: moderate to severe LUTS that failed medical treatment, complications of BOO or } \\ \text { catheter dependency } \\ \text { - Exclusion criteria: American Society of Anesthesioligists Score > 2, pacemaker, suspected or known } \\ \text { prostate cancer, concurrent bladder stone, previous bladder neck surgery }\end{array}$

\section{Baseline characteristics:}

No significant differences between treatment arms reported

Mean age, years $(S D):(A)=68.44(7.33),(B)=68.53(6.69)$

Mean preoperative prostate volumes, $\mathrm{mL}:(\mathrm{A})=41.8(9.8),(B)=43.1(10.94)$

Interventions

- Intervention A: bipolar TURP; Gyrus Plasmakinetic Resection (PKRP); irrigation fluid = saline

- Intervention B: monopolar TURP; Pfizer Electrosurgical Instrument System; irrigation fluid = glycine

Outcomes

\section{Primary outcomes:}

IPSS (12 months): not reported

HRQoL (12 months): not reported

TUR syndrome: $(A)=0(n=51),(B)=0(n=51)$

\section{Secondary outcomes:}

Blood transfusion: $(A)=0(n=51),(B)=2(n=51)$

Urinary incontinence (12 months): not reported

Erectile dysfunction (IIEF-5) (12 months): not reported

Need for repeat TURP (i.e. re-TURP): not reported

\section{Other reported outcomes:}

IPSS at 1 month

HRQoL at 1 month

$\mathrm{Q}_{\max }$

Acute urinary retention

Mean reduction in haemoglobin $(\mathrm{g} / \mathrm{dL})$

Mean reduction in serum sodium ( $\mathrm{mmol} / \mathrm{l})$

Mean duration of catheterisation (hours)

Mean duration of hospital stay (days) 
Kong 2009 (Continued)

Duration of operation

\begin{tabular}{ll}
\hline Source of funding $\quad$ None reported \\
\hline Notes
\end{tabular}

\section{Risk of bias}

\begin{tabular}{lll}
\hline Bias & Authors' judgement & Support for judgement \\
\hline $\begin{array}{l}\text { Random sequence gener- } \\
\begin{array}{l}\text { ation (selection bias): All } \\
\text { outcomes }\end{array}\end{array}$ & Low risk & $\begin{array}{l}\text { Study states: "computerized random number generator was then used to se- } \\
\text { lect an envelope for each patient. A nurse not involved in this study then read } \\
\text { the content of the envelope and assigned the appropriate method of surgery" }\end{array}$ \\
\hline $\begin{array}{l}\text { Allocation concealment } \\
\text { (selection bias): All out- } \\
\text { comes }\end{array}$ & Low risk & $\begin{array}{l}\text { Study states: "allocation concealment was done via sequentially numbered, } \\
\text { opaque, sealed envelopes" }\end{array}$ \\
\hline
\end{tabular}

Blinding of participants High risk

Not reported but considered unlikely that operating surgeon(s) was blinded

and personnel (perfor-

mance bias): All outcomes

Blinding of outcome as-
sessment (detection bias):
Subjective outcomes
(IPSS, HRQoL, IIEF-5, TUR
syndrome, Urinary Inconti-
nence)

Blinding of outcome assessment: Objective outre-TURP)

$\begin{array}{ll}\begin{array}{l}\text { Selective reporting (re- } \\ \text { porting bias): All outcomes }\end{array} & \text { Unclear risk }\end{array}$

\section{Kumar 2013}

\begin{tabular}{ll}
\hline Methods & - Study type: single-centre randomised controlled trial $(1: 1: 1)$ \\
& - Setting: India
\end{tabular}

- Setting: India 
Kumar 2013 (Continued)

- Inclusion criteria: $L U T S$ secondary to BPE, age $\geq 50$, IPSS $>7$, prostate volume measured by transrectal ultrasound (TRUS): $>20$ and $<80 \mathrm{~mL}, \mathrm{Q}_{\max }<15 \mathrm{~mL} / \mathrm{s}$

- Exclusion criteria: history of prostate, bladder, or urethral surgery; spinal surgery or spinal trauma; neurological disease; postvoid residual urine (PVRU) $>300 \mathrm{~mL}$; indwelling Foley catheter where indication for catheterisation was chronic retention (PVRU > $300 \mathrm{~mL}$ ); diagnosis of carcinoma of the prostate; carcinoma of the bladder; urethral stricture; those receiving antiplatelet drugs for whom drugs could not be safely stopped perioperatively; not giving written informed consent

\section{Baseline characteristics:}

No significant differences between arms reported

Mean age, years (SD): $(A)=62.31(6.36),(B)=63.68(6.57)$

Mean preoperative prostate volume, $\mathrm{mL}(\mathrm{SD}):(\mathrm{A})=50.26(16.50),(\mathrm{B})=52.20(15.93)$
Interventions
- Intervention A: bipolar TURP; Gyrus ACMI Plasmakinetic System; irrigation fluid $=0.9 \%$ saline

- Intervention B: monopolar TURP, irrigation fluid = glycine

- Intervention C: third arm of RCT included Photoselective Vaporisation of the Prostate (PVP) with green light laser; no data were collected as not an intervention of interest
Outcomes

\section{Primary outcomes:}

IPSS (12 months): $(A)=6.94(1.22)(n=52),(B)=7.07(1.22)(n=57)$

HRQoL (12 months): $(A)=1.67(0.61)(n=52),(B)=1.59(0.65)(n=57)$

TUR syndrome: $(A)=0(n=57),(B)=1(1.66)(n=60)$

\section{Secondary outcomes:}

Blood transfusion: $(A)=3(n=57),(B)=7(n=60)$

Urinary incontinence (12 months): not reported

Erectile dysfunction (IIEF-5) (12 months): $(A)=16.30(2.59)(n=52),(B)=16.17(2.36)(n=57)$

Need for repeat TURP (i.e. re-TURP): data provided for "re-operation" but not specifically for re-TURP

Other reported outcomes:

IPSS at $1,3,6,>12$ months

HRQoL at 1, 3, 6, > 12 months

$\mathrm{Q}_{\max }$

IIEF-5 at $1,3,6,>12$ months

Clot retention

Urethral stricture and bladder neck contracture

UTI

Acute urinary retention

Mean duration of operation

Mean duration of catheterisation

Duration and volume of irrigation fluid used postoperatively

Haemoglobin level change 
Kumar 2013 (Continued)

Incidence of transient dysuria

Source of funding None reported

Notes

\section{Risk of bias}

\begin{tabular}{|c|c|c|}
\hline Bias & Authors' judgement & Support for judgement \\
\hline $\begin{array}{l}\text { Random sequence gener- } \\
\text { ation (selection bias): All } \\
\text { outcomes }\end{array}$ & Low risk & $\begin{array}{l}\text { Study states: "eligible patients were randomized into three groups using a } \\
\text { computer generated randomization table of equal numbers" }\end{array}$ \\
\hline $\begin{array}{l}\text { Allocation concealment } \\
\text { (selection bias): All out- } \\
\text { comes }\end{array}$ & Unclear risk & $\begin{array}{l}\text { Specific measures to ensure allocation concealment during randomisation } \\
\text { process not reported }\end{array}$ \\
\hline $\begin{array}{l}\text { Blinding of participants } \\
\text { and personnel (perfor- } \\
\text { mance bias): All outcomes }\end{array}$ & High risk & Not reported but considered unlikely that operating surgeon(s) were blinded \\
\hline $\begin{array}{l}\text { Blinding of outcome as- } \\
\text { sessment (detection bias): } \\
\text { Subjective outcomes } \\
\text { (IPSS, HRQoL, IIEF-5, TUR } \\
\text { syndrome, Urinary Inconti- } \\
\text { nence) }\end{array}$ & Unclear risk & Not reported \\
\hline
\end{tabular}

Blinding of outcome as- Low risk Not reported but objective outcomes unlikely to have been affected
sessment: Objective outcomes (Blood transfusion, Re-TURP)

\section{Incomplete outcome da- ta (attrition bias): Imme- diate postoperative out- comes (TUR syndrome, Blood transfusion)}

Low risk Study reports that all patients ( $n=60$ for MTURP, $n=57$ for BTURP) were included in analyses for these perioperative outcomes
Incomplete outcome data (attrition bias): Long-term outcomes (IPSS/HRQoL/ IIEF-5/urinary incontinence at 12 months, and re-TURP)
Unclear risk

Study reports loss to follow-up of $n=3$ for MTURP and $n=5$ for BTURP for these outcomes. Considered unclear how this loss to follow-up may have impacted observed differences in outcomes between arms

\section{Lin 2006}

\begin{tabular}{ll}
\hline Methods & - Study type: single-centre RCT (1:1) \\
& - Setting: Taiwan
\end{tabular}

- Setting: Taiwan
- Total number enrolled: $40 ;(A)=22,(B)=18$ 
Lin 2006 (Continued)

- Inclusion criteria: LUTS due to BPH

- Exclusion criteria: evidence of suspicion of prostate or bladder malignancy, bladder stones and/or bladder diverticulum, urethral stricture, IPSS $<15, \mathrm{Q}_{\max }>15$, neurogenic bladder disorder, previous surgical treatments for BPH

\section{Baseline characteristics:}

No significant differences between arms reported.

Mean age, years (SD): $(A)=69.0(n \circ S D)(n=22),(B)=69.0(n o S D)(n=24)(P=0.891)$

Mean preoperative prostate volume (grams) (SD): not reported.

Preoperative catheterisation state: not reported.

\begin{tabular}{ll}
\hline Interventions & Intervention A (bipolar): Vista CTR; irrigation fluid = saline \\
& - Intervention B (monopolar): Vista CTR; irrigation fluid = distilled water
\end{tabular}

\section{Outcomes}

\section{Primary outcomes:}

IPSS (12 months): values provided only for median (rather than mean) IPSS at 12 months: $(A)=15.5$ (no $\operatorname{SD})(n=22),(B)=18.5$ (no SD) $(n=18)$

HRQoL (12 months): not reported

TUR syndrome: not reported

\section{Secondary outcomes:}

Blood transfusion: not reported

Urinary incontinence (12 months): not reported

Erectile dysfunction (IIEF-5) (12 months): not reported

Need for repeat TURP (i.e. re-TURP): not reported

\section{Other reported outcomes:}

IPSS at 6 months

$\mathrm{Q}_{\max }$

Clot retention and evacuation

Bladder neck contracture

Resection time (minutes) (SD): $(A)=50.0$ (no SD) $(n=22),(B)=47.5$ (no SD) $(n=18)$

Change in serum sodium levels, $\mathrm{mEq} / \mathrm{L}(\mathrm{SD})$ : $(\mathrm{A})=-0.91$ (3.56), $(\mathrm{B})=-7.94$ (5.12)

Change in haemoglobin, $g / d L(S D):(A)=-0.62(0.59),(B)=-0.64(0.41)$

Source of funding None reported

Notes

\section{Risk of bias}


Lin 2006 (Continued)
Random sequence gener-
Low risk
Study states: "patients were randomized using opaque envelopes" ation (selection bias): All outcomes

\begin{tabular}{lll}
\hline $\begin{array}{l}\text { Allocation concealment } \\
\text { (selection bias): All out- }\end{array}$ & Low risk & Study reports use of "opaque envelopes" to ensure allocation concealment \\
comes & & \\
\hline $\begin{array}{l}\text { Blinding of participants } \\
\text { and personnel (perfor- } \\
\text { mance bias): All outcomes }\end{array}$ & High risk & Not reported but considered unlikely that operating surgeon(s) were blinded \\
\hline $\begin{array}{l}\text { Blinding of outcome as- } \\
\text { sessment (detection bias): }\end{array}$ & Unclear risk & Not reported \\
$\begin{array}{l}\text { Subjective outcomes } \\
\text { (IPSS, HRQoL, IlEF-5, TUR } \\
\text { syndrome, Urinary Inconti- } \\
\text { nence) }\end{array}$ & \\
\hline
\end{tabular}

Blinding of outcome as- Unclear risk These outcomes were not reported by the study
sessment: Objective out-
comes (Blood transfusion,
Re-TURP)

Incomplete outcome da- Unclear risk These outcomes were not reported by the study
ta (attrition bias): Imme-
diate postoperative out-
comes (TUR syndrome,
Blood transfusion)

\begin{tabular}{|c|c|c|}
\hline $\begin{array}{l}\text { Incomplete outcome data } \\
\text { (attrition bias): Long-term } \\
\text { outcomes (IPSS/HRQoL/ } \\
\text { IIEF-5/urinary inconti- } \\
\text { nence at } 12 \text { months, and } \\
\text { re-TURP) }\end{array}$ & Low risk & Study states: "none of the patients were lost to follow-up" \\
\hline $\begin{array}{l}\text { Selective reporting (re- } \\
\text { porting bias): All outcomes }\end{array}$ & Unclear risk & RCT protocol not available to allow for full assessment \\
\hline
\end{tabular}

Mamoulakis 2013

\begin{tabular}{ll}
\hline Methods & Study type: multi-centre RCT $(1: 1)$ \\
& - Settings: Netherlands, Greece, Italy, Germany \\
\hline Participants & Total number enrolled: $279 ;(A)=141,(B)=139$ \\
- Inclusion criteria: benign prostatic obstruction, $\mathrm{Q}_{\max }<15$, IPSS $>13$, voided volume $>125 \mathrm{~mL}$, in- \\
dwelling/intermittent catheterisation \\
- Exclusion criteria: suspected malignant disease of the lower urinary tract, including prostate can- \\
cer, impaired detrusor function (neurogenic bladder, postvoid residual urine volume $>400 \mathrm{~mL}$ ), active \\
UTI, 5-alpha reductase inhibitor or alpha blocker consumption within the last 3 months or 2 weeks \\
before surgery, cardiovascular disease necessitating anticoagulation continuation that might jeopar- \\
dise outcome, immunosuppression
\end{tabular}

\section{Baseline characteristics:}


No significant differences between arms reported

Mean age, years (SD): (A) $69.3(8.5)(n=135),(B) 68.4(8.2)(n=120)(P=0.525)$

Mean preoperative prostate volume, grams (SD): $(A)=63.8(29.4)(n=135),(B)=63.5(30.8)(n=120)(P=$ 0.939)

Preoperative catheterisation state: $(A)=47(n=135),(B)=47(n=120)$

Interventions

- Intervention A: bipolar TURP (Autocon II 400 ESU Karl Storz)

- Intervention B: monopolar TURP (Karl Storz), irrigation fluid = hypotonic solution as irrigation fluid (multi-centre): Centre 1 (Netherlands) sorbitol 5\%, Centre 2 (Germany) sorbitol-mannitol, Centre 3 (Greece) water for injection, Centre 4 (Italy) glycine

Outcomes

\section{Primary outcomes:}

IPSS (12 months) (SD): not catheterised preop: $(A)=7.7(4.0)(n=88),(B)=7.5(4.8)(n=73)^{\star}$; catheterised preop: $(A)=7.1(4.5)(n=47),(B)=5.5(4.8)(n=47)$

HRQoL (12 months) (SD): not catheterised preop: $(A)=1.1(1.0)(n=88),(B)=1.1(1.2)(n=73)^{*}$; catheterised preop $(A)=1.3(0.8)(n=47),(B)=0.9(1.1)(n=47)$

${ }^{\star}$ Non-catheterised patients were included in the meta-analyses

TUR syndrome: $(A)=0(n=141),(B)=1(n=138)$

\section{Secondary outcomes:}

Blood transfusion: $(A)=9(n=141),(B)=4(n=138)$

Urinary incontinence (12 months): not reported

Erectile dysfunction (IIEF-5) (12 months): data provided for IIEF-15 scores only

Need for repeat TURP (i.e. re-TURP): not reported

\section{Other reported outcomes:}

IPSS at 24 to 36 months

QoL at 24 to 36 months

$\mathrm{Q}_{\max }$

Clot retention

Urethral stricture/Bladder neck contracture

Acute urinary retention

Hospitalisation time

Sodium drop (mmol/L)

Haemoglobin drop (mmol/L)

Duration of operation (minutes)

Catheterisation time (days)

Capsular perforation rate

Hospitalisation duration 
Mamoulakis 2013 (Continued)

Notes
Protocol is available at http://www.trialregister.nl/trialreg/admin/rctview.asp?TC=703

"A prospective, randomized, double-blinded study to compare bipolar trans urethral resection of the prostate (bipolar TURP) versus monopolar trans urethral resection of the prostate (monopolar TURP) in terms of safety and efficacy" (NTR 703)

\section{Risk of bias}

\begin{tabular}{lll}
\hline Bias & Authors' judgement & Support for judgement \\
\hline $\begin{array}{l}\text { Random sequence gener- } \\
\begin{array}{l}\text { ation (selection bias): All } \\
\text { outcomes }\end{array}\end{array}$ & Low risk & $\begin{array}{l}\text { Study states: "randomization numbers were assigned using a strati- } \\
\text { fied permuted computer algorithm after completing eligibility screen- } \\
\text { ing" (Mamoulakis 2012) }\end{array}$ \\
\hline $\begin{array}{l}\text { Allocation concealment } \\
\text { (selection bias): All out- } \\
\text { comes }\end{array}$ & Low risk & $\begin{array}{l}\text { Study states: "randomization was performed within 24 h prior to treatment ap- } \\
\text { plication, which was done blindly among centres through the central electron- } \\
\text { ic system to minimize potential selection bias and guarantee allocation con- } \\
\text { cealment" }\end{array}$ \\
\hline
\end{tabular}

\begin{tabular}{|c|c|c|}
\hline $\begin{array}{l}\text { Blinding of participants } \\
\text { and personnel (perfor- } \\
\text { mance bias): All outcomes }\end{array}$ & High risk & $\begin{array}{l}\text { Study reports that surgeons were not blinded due to the nature of interven- } \\
\text { tions }\end{array}$ \\
\hline
\end{tabular}

\begin{tabular}{|c|c|c|}
\hline $\begin{array}{l}\text { Blinding of outcome as- } \\
\text { sessment (detection bias): } \\
\text { Subjective outcomes } \\
\text { (IPSS, HRQoL, IIEF-5, TUR } \\
\text { syndrome, Urinary Inconti- } \\
\text { nence) }\end{array}$ & Low risk & $\begin{array}{l}\text { Study states: "outcome assessors and patients were both blinded for the inter- } \\
\text { vention type (double-blind RCT)" }\end{array}$ \\
\hline
\end{tabular}

\begin{tabular}{|c|c|c|}
\hline $\begin{array}{l}\text { Blinding of outcome as- } \\
\text { sessment: Objective out- } \\
\text { comes (Blood transfusion, } \\
\text { Re-TURP) }\end{array}$ & Low risk & $\begin{array}{l}\text { Study states: "outcome assessors and patients were both blinded for the inter- } \\
\text { vention type (double-blind RCT)" }\end{array}$ \\
\hline $\begin{array}{l}\text { Incomplete outcome da- } \\
\text { ta (attrition bias): Imme- } \\
\text { diate postoperative out- } \\
\text { comes (TUR syndrome, } \\
\text { Blood transfusion) }\end{array}$ & Low risk & $\begin{array}{l}\text { Study states that all participants were included in analysis for these outcomes, } \\
\text { except } n=1 / 139 \text { in the MTURP arm was excluded because of incidental blad- } \\
\text { der cancer }\end{array}$ \\
\hline $\begin{array}{l}\text { Incomplete outcome data } \\
\text { (attrition bias): Long-term } \\
\text { outcomes (IPSS/HRQoL/ } \\
\text { IIEF-5/urinary inconti- } \\
\text { nence at } 12 \text { months, and } \\
\text { re-TURP) }\end{array}$ & Unclear risk & $\begin{array}{l}\text { At } 12 \text { months, differential loss to follow-up between arms; at } 12 \text { months, } n \\
=121 \text { analysed in MTURP arm ( } n=139 \text { received intervention) and } n=135 \\
\text { analysed in BTURP arm ( } n=141 \text { received intervention). The subsequent im- } \\
\text { pact of loss to follow-up on observed differences in outcomes between arms } \\
\text { was considered unclear }\end{array}$ \\
\hline $\begin{array}{l}\text { Selective reporting (re- } \\
\text { porting bias): All outcomes }\end{array}$ & Low risk & $\begin{array}{l}\text { The study protocol is available and all of the study's prespecified (primary and } \\
\text { secondary) outcomes that are of interest in the review have been reported in } \\
\text { the prespecified way }\end{array}$ \\
\hline
\end{tabular}

$\begin{array}{ll}\text { Methods } & \text { Study type: single-centre randomised controlled trial }(1: 1) \\ \text { - Setting: China }\end{array}$

Bipolar versus monopolar transurethral resection of the prostate for lower urinary tract symptoms secondary to benign prostatic 
Mei 2010 (Continued)

Participants
- Total participants enrolled: $146 ;(A)=73,(B)=73$

- Inclusion criteria: symptomatic BPH that required surgery owing to urinary retention or failed medical therapy

- Exclusion criteria: neurogenic bladder dysfunction, previous prostatic or urethral surgery, prostate cancer, bladder cancer, severe medical disease

\section{Baseline characteristics:}

No significant differences between arms reported

Mean age $(S D):(A)=72.1(4.4),(B)=71.6(5.1)$

Mean preoperative prostate volume, $\mathrm{mL}(\mathrm{SD}):(\mathrm{A})=55.5(6.3),(B)=53.6(5.2)$

Preoperative catheterisation state: not reported

- Intervention A: bipolar TURP (Gyrus Electrosurgical System)

- Intervention B: monopolar TURP (WOLF Electrosurgical System, irrigation fluid = 5\% mannitol)

Outcomes Primary outcomes:

IPSS (12 months): data available only at 3 and 6 months

HRQoL (12 months): data available only at 3 and 6 months

TUR syndrome: $(A)=0(n=73),(B)=2(n=73)$

\section{Secondary outcomes:}

Blood transfusion: $(A)=1(n=73),(B)=4(n=73)$

Urinary incontinence (12 months): reported only at 6 months

Erectile dysfunction (IIEF-5) (12 months): no specific data provided

Need for repeat TURP (i.e. re-TURP): not reported

\section{Other reported outcomes:}

Mean $\mathrm{Q}_{\max }$

Urethral stricture

Mean duration of operation (minutes)

Mean duration of catheterisation (days)

Mean change in postoperative serum sodium $(\mathrm{Na}+)$

Mean reduction in postoperative haemoglobin $(\mathrm{Hb})$

Source of funding None reported

Notes

\section{Risk of bias}

\begin{tabular}{lll}
\hline Bias & Authors' judgement & Support for judgement \\
\hline $\begin{array}{l}\text { Random sequence gener- } \\
\begin{array}{l}\text { ation (selection bias): All } \\
\text { outcomes }\end{array}\end{array}$ & Unclear risk & Not reported \\
\hline
\end{tabular}

Bipolar versus monopolar transurethral resection of the prostate for lower urinary tract symptoms secondary to benign prostatic 
Mei 2010 (Continued)

Allocation concealment Unclear risk Not reported
(selection bias): All out-

\begin{tabular}{lll}
\hline $\begin{array}{l}\text { Blinding of participants } \\
\text { and personnel (perfor- } \\
\text { mance bias): All outcomes }\end{array}$ & High risk & Not reported but considered unlikely that operating surgeon(s) were blinded \\
\hline Blinding of outcome as- & Unclear risk & Not reported \\
sessment (detection bias): & \\
Subjective outcomes & \\
(IPSS, HRQoL, IIEF-5, TUR & \\
syndrome, Urinary Inconti- & \\
nence) &
\end{tabular}

Blinding of outcome as- Low risk Not reported but objective outcomes unlikely to have been affected
sessment: Objective out-
comes (Blood transfusion,
Re-TURP)

\begin{tabular}{|c|c|c|}
\hline $\begin{array}{l}\text { Incomplete outcome da- } \\
\text { ta (attrition bias): Imme- } \\
\text { diate postoperative out- } \\
\text { comes (TUR syndrome, } \\
\text { Blood transfusion) }\end{array}$ & Low risk & $\begin{array}{l}\text { All included participants ( } n=73 \text { in monopolar and } n=73 \text { in bipolar arms) in- } \\
\text { cluded in analyses for these outcomes }\end{array}$ \\
\hline
\end{tabular}

Incomplete outcome data Unclear risk These outcomes were not reported
(attrition bias): Long-term
outcomes (IPSS/HRQoL/
IIEF-5/urinary inconti-
nence at 12 months, and
re-TURP)

$\begin{array}{lll}\text { Selective reporting (re- } & \text { Unclear risk } & \text { RCT protocol not available to allow for full assessment } \\ \text { porting bias): All outcomes }\end{array}$

Michielsen 2007

\begin{tabular}{|c|c|}
\hline Methods & $\begin{array}{l}\text { - Study type: single-centre RCT (1:1) } \\
\text { - Setting: Belgium }\end{array}$ \\
\hline \multirow{5}{*}{ Participants } & Baseline characteristics \\
\hline & No significant differences between arms reported \\
\hline & Mean age, years $(S D):(A)=72.5(9.2),(B)=72.4(9.0)$ \\
\hline & Mean preoperative prostate volume, $\mathrm{mL}(\mathrm{SD}):(\mathrm{A})=45.0(18.3),(\mathrm{B})=53.9(23.6)$ \\
\hline & Preoperative catheterisation state: not reported \\
\hline
\end{tabular}




$\begin{array}{ll}\text { Outcomes } & \text { Primary outcomes: } \\ \text { IPSS (12 months): not reported } \\ \text { HRQoL (12 months): not reported } \\ \text { TUR syndrome: }(A)=0 \text { ( } n=285),(B) \\ \text { Secondary outcomes: } \\ \text { Blood transfusion: }(A)=4 \text { ( } n=118), \\ \text { Urinary incontinence (12 months): } \\ \text { Erectile dysfunction (IIEF-5) (12 mont } \\ \text { Need for repeat TURP (i.e. re-TURP): } \\ \text { erative complication reported } \\ \text { Other reported outcomes: } \\ \text { Clot retention } \\ \text { Urethral stricture } \\ \text { Acute urinary retention } \\ \text { Drop in sodium level } \\ \text { Drop in haemoglobin } \\ \text { Duration of operation (minutes) } \\ \text { Duration of catheterisation (days) } \\ \text { Hospitalisation time (days) }\end{array}$

Source of funding None reported

Notes

\section{Risk of bias}

\begin{tabular}{lll}
\hline Bias & Authors' judgement & Support for judgement \\
\hline $\begin{array}{l}\text { Random sequence gener- } \\
\begin{array}{l}\text { ation (selection bias): All } \\
\text { outcomes }\end{array}\end{array}$ & Low risk & $\begin{array}{l}\text { "After initial cystoscopy and examination with the patient under anesthesia } \\
\text { the patient was randomized to monopolar TURP or bipolar TURIS by drawing a } \\
\text { closed envelope" (Michielsen 2007; Michielsen 2010; Michielsen 2010b) }\end{array}$ \\
\hline $\begin{array}{l}\text { Allocation concealment } \\
\text { (selection bias): All out- } \\
\text { comes }\end{array}$ & Unclear risk & $\begin{array}{l}\text { Not reported if envelopes were opaque, or if other measures were taken to en- } \\
\text { sure allocation concealment }\end{array}$ \\
\end{tabular}

\begin{tabular}{lll}
$\begin{array}{l}\text { Blinding of participants } \\
\text { and personnel (perfor- } \\
\text { mance bias): All outcomes }\end{array}$ & High risk & Study reported as "unblinded study" \\
\hline $\begin{array}{l}\text { Blinding of outcome as- } \\
\text { sessment (detection bias): }\end{array}$ & High risk & Study reported as "unblinded study" \\
$\begin{array}{l}\text { Subjective outcomes } \\
\text { (IPSS, HRQOL, IIEF-5, TUR }\end{array}$ & &
\end{tabular}


Michielsen 2007 (Continued) syndrome, Urinary Incontinence)

\begin{tabular}{|c|c|c|}
\hline $\begin{array}{l}\text { Blinding of outcome as- } \\
\text { sessment: Objective out- } \\
\text { comes (Blood transfusion, } \\
\text { Re-TURP) }\end{array}$ & Low risk & $\begin{array}{l}\text { Study reported as "unblinded study" but objective outcomes unlikely to have } \\
\text { been affected }\end{array}$ \\
\hline
\end{tabular}

$\begin{array}{lll}\text { Incomplete outcome da- } & \text { Unclear risk } & \begin{array}{l}\text { This study does not explicitly report on attrition, exclusion of participants from } \\ \text { analyses, or the presence of incomplete outcome data for these outcomes }\end{array}\end{array}$
diate postoperative outanalyses, or the presence of incomplete outcome data for these outcomes comes (TUR syndrome, Blood transfusion)

Incomplete outcome data
(attrition bias): Long-term
outcomes (IPSS/HRQoL/
IIEF-5/urinary inconti-
nence at 12 months, and
re-TURP)

Unclear risk These outcomes were not reported by this trial

\begin{tabular}{ll}
\hline $\begin{array}{l}\text { Selective reporting (re- } \\
\text { porting bias): All outcomes }\end{array}$ & Unclear risk
\end{tabular}

Méndez-Probst 2011

\begin{tabular}{ll}
\hline Methods & Study type: multi-centre, randomised controlled trial $(1: 1)$ \\
- Setting: 5 Canadian centres, Canada
\end{tabular}

\section{Participants}

- Total number enrolled: $43 ;(A)=22,(B)=21$

- Inclusion criteria: LUTS suggestive of BPH, peak urinary flow rates $<12 \mathrm{~mL} / \mathrm{s}$, American Urological Association (AUA) symptom scores $>12$, acute urinary retention

- Exclusion criteria: previous prostatic surgery (open or transurethral), urethral stricture, failure to discontinue alpha-adrenergic blocking agents for at least 14 days before surgery, failure to discontinue 5-alpha reductase inhibitor for at least 1 month before surgery, interest in future fertility, known neurogenic bladder dysfunction, untreated urinary tract infection, American Society of Anesthesiology (ASA) class > III, requiring anticoagulation, unwilling or unable to comply with the follow-up schedule

\section{Baseline characteristics:}

No significant differences between arms reported

Mean age years: $(A)=68(7),(B)=67(7)$

Mean preoperative prostate volume, grams (SD): $(A)=57.92(25.56),(B)=50.23(20.74)$

Preoperative catheterisation state: $(A)=6(n=22),(B)=6(n=21)$

- Intervention A: bipolar TURP (VISTA, ACMI), irrigation fluid = not explicitly stated. Assumed normal saline

- Intervention B: monopolar TURP (ERBE, Marietta, GA, or ValleyLab, Tyco Healthcare Group LP), irrigation fluid $=$ not explicitly stated

\section{Outcomes}

\section{Primary outcomes:}

IPSS (12 months): not reported

HRQoL (12 months): not reported 
Méndez-Probst 2011 (Continued)

$$
\text { TUR syndrome: }(A)=0(n=22),(B)=0(n=21)
$$

\section{Secondary outcomes:}

Blood transfusion: $(A)=0(n=22),(B)=0(n=21)$

Urinary incontinence (12 months): not reported explicitly at 12 months

Erectile dysfunction (IIEF-5) (12 months): not reported

Need for repeat TURP (i.e. re-TURP): not reported

\section{Other reported outcomes:}

AUA QoL not reported explicitly at 12 months

$\mathrm{Q}_{\max }(\mathrm{mL} / \mathrm{s})$

Urethral stricture

Bladder neck contracture

UTI

Acute urinary retention

Duration of operation (minutes)

Duration of bladder irrigation (minutes)

Duration of postop catheterisation (days)

Duration of hospital stay (days)

Haemoglobin change

Serum sodium change

Incidence of haematuria requiring intervention

Incidence of dysuria/overactive bladder symptoms

\section{Risk of bias}

\begin{tabular}{lll}
\hline Bias & Authors' judgement & Support for judgement \\
\hline $\begin{array}{l}\text { Random sequence gener- } \\
\text { ation (selection bias): All } \\
\text { outcomes }\end{array}$ & Unclear risk & Not reported \\
\hline $\begin{array}{l}\text { Allocation concealment } \\
\text { (selection bias): All out- } \\
\text { comes }\end{array}$ & Unclear risk & Not reported \\
\hline $\begin{array}{l}\text { Blinding of participants } \\
\text { and personnel (perfor- } \\
\text { mance bias): All outcomes }\end{array}$ & High risk & Not reported; considered unlikely that operating surgeon(s) were blinded \\
\hline
\end{tabular}


Méndez-Probst 2011 (Continued)
Blinding of outcome as-
Unclear risk
Not reported
sessment (detection bias)
Subjective outcomes
(IPSS, HRQOL, IIEF-5, TUR
syndrome, Urinary Inconti-
nence)

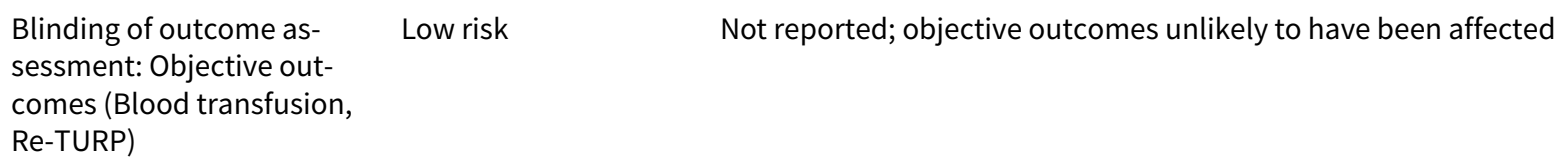

Blinding of outcome as- Low risk Not reported; objective outcomes unlikely to have been affected sessment: Objective outcomes (Blood transfusion, Re-TURP)

Incomplete outcome data (attrition bias): Immediate postoperative outcomes (TUR syndrome, Blood transfusion)
Unclear risk

This study does not explicitly report on attrition, exclusion of participants from analyses, or the presence of incomplete outcome data for these outcomes

Incomplete outcome data

Unclear risk

These outcomes were not reported by the trial (attrition bias): Long-term outcomes (IPSS/HRQoL/ IIEF-5/urinary incontinence at 12 months, and re-TURP)

$\begin{array}{ll}\begin{array}{l}\text { Selective reporting (re- } \\ \text { porting bias): All outcomes }\end{array} & \text { Unclear risk }\end{array}$

Nasution 2017

$\begin{array}{ll}\text { Methods } & \text { - Study type: multi-centre randomised controlled trial }(1: 1: 1) \\ \text { - Setting: } 3 \text { Indonesian centres }\end{array}$

- Total number enrolled: $220 ;(A)=80,(B)=76,(C)=64$
Participants $\quad$ Inclusion criteria: $\mathrm{BPH}$ and urinary retention planning for surgery
- Exclusion criteria: not reported
Baseline characteristics:
No significant differences between arms reported
Mean age, years: not reported
Mean preoperative prostate volume, grams (SD): 46.63 (12.33) (both arms)
Preoperative catheterisation state: not reported

$\begin{array}{ll}\text { Interventions } & \text { Intervention A: bipolar TURP, irrigation fluid = not explicitly stated. Assumed normal saline } \\ \text { - Intervention B: monopolar TURP, irrigation fluid = not explicitly stated } \\ \text { - Intervention C: Thulium Laser Vaporesection }\end{array}$

Outcomes

\section{Primary outcomes:}

IPSS (12 months): not reported

HRQoL (12 months): not reported

TUR syndrome: not reported

Bipolar versus monopolar transurethral resection of the prostate for lower urinary tract symptoms secondary to benign prostatic 
Nasution 2017 (Continued)

\section{Secondary outcomes:}

Blood transfusion: not reported

Urinary incontinence (12 months): not reported

Erectile dysfunction (IIEF-5) (12 months): not reported

Need for repeat TURP (i.e. re-TURP): not reported

Other reported outcomes:

Mean operation time

Catheterisation time

Hospital stay

Mean change in haemoglobin

Mean change in sodium level

Source of funding

Notes Only abstract proceedings available

\section{Risk of bias}

\begin{tabular}{lll}
\hline Bias & Authors' judgement & Support for judgement \\
\hline $\begin{array}{l}\text { Random sequence gener- } \\
\text { ation (selection bias): All } \\
\text { outcomes }\end{array}$ & Unclear risk & Not reported \\
\hline $\begin{array}{l}\text { Allocation concealment } \\
\text { (selection bias): All out- } \\
\text { comes }\end{array}$ & Unclear risk & Not reported \\
\hline
\end{tabular}

Blinding of participants

High risk

Not reported; considered unlikely that operating surgeon(s) were blinded and personnel (perfor-

mance bias): All outcomes

\begin{tabular}{|c|c|c|}
\hline $\begin{array}{l}\text { Blinding of outcome as- } \\
\text { sessment (detection bias): } \\
\text { Subjective outcomes } \\
\text { (IPSS, HRQoL, IIEF-5, TUR } \\
\text { syndrome, Urinary Inconti- } \\
\text { nence) }\end{array}$ & Unclear risk & Not reported \\
\hline $\begin{array}{l}\text { Blinding of outcome as- } \\
\text { sessment: Objective out- } \\
\text { comes (Blood transfusion, } \\
\text { Re-TURP) }\end{array}$ & Unclear risk & These outcomes were not reported \\
\hline $\begin{array}{l}\text { Incomplete outcome da- } \\
\text { ta (attrition bias): Imme- } \\
\text { diate postoperative out- } \\
\text { comes (TUR syndrome, } \\
\text { Blood transfusion) }\end{array}$ & Unclear risk & These outcomes were not reported \\
\hline
\end{tabular}

Bipolar versus monopolar transurethral resection of the prostate for lower urinary tract symptoms secondary to benign prostatic 
Nasution 2017 (Continued)

Incomplete outcome data (attrition bias): Long-term Unclear risk These outcomes were not reported outcomes (IPSS/HRQoL/ IIEF-5/urinary incontinence at 12 months, and re-TURP)

$\begin{aligned} & \text { Selective reporting (re- } \\ & \text { porting bias): All outcomes }\end{aligned}$
Unclear risk $\quad$ RCT protocol not available to allow for full assessment

\section{Nuhoğlu 2006}

\begin{tabular}{ll}
\hline Methods & - Study type: single-centre randomised controlled trial $(1: 1)$ \\
& - Setting: Turkey
\end{tabular}

Participants

- Total number enrolled: $57 ;(A)=27,(B)=30$

- Inclusion criteria: diagnosis of BPH, LUTS, I-PSS $>15, \mathrm{Q}_{\max }<10 \mathrm{~mL} / \mathrm{s}$

- Exclusion criteria: prostate/urethra surgery, suspicion of prostate cancer, neurogenic bladder

\section{Baseline characteristics:}

No significant differences between arms reported

Mean age, years (SD): $(A)=65.2(9.3)(B)=64.6(8.8)$

Mean preoperative prostate volume, grams (SD): $(A)=47(7.7),(B)=49(8.1)$

$\begin{array}{ll}\text { Interventions } & \text { Intervention A: bipolar (Gyrus), irrigation fluid = saline } \\ \text { - Intervention B: monopolar (Storz), irrigation fluid = glycine }\end{array}$

\section{Outcomes}

\section{Primary outcomes:}

IPSS (12 months): $(A)=5.4 \pm 3.7(n=24),(B)=5.2 . \pm 3.2(n=26)$

HRQoL (12 months): not reported

TUR syndrome: $(A)=0(n=27),(B)=0(n=30)$

\section{Secondary outcomes:}

Blood transfusion: $(A)=1(n=27),(B)=2(n=30)$

Urinary incontinence (12 months): not reported

Erectile dysfunction (IIEF-5) (12 months): not reported

Need for repeat TURP (i.e. re-TURP): $(A)=0(n=27),(B)=0(n=30)$

\section{Other reported outcomes:}

IPSS at 1 month

$\mathrm{Q}_{\max }(\mathrm{mL} / \mathrm{s})$

Acute urinary retention

Urethral stricture

Duration operation (minutes) 
Nuhoğlu 2006 (Continued)

Duration of catheter (hours)

Haemoglobin level change

Serum sodium level change

\begin{tabular}{ll}
\hline Source of funding $\quad$ None reported \\
\hline Notes
\end{tabular}

\section{Risk of bias}

\begin{tabular}{|c|c|c|}
\hline Bias & Authors' judgement & Support for judgement \\
\hline $\begin{array}{l}\text { Random sequence gener- } \\
\text { ation (selection bias): All } \\
\text { outcomes }\end{array}$ & Unclear risk & $\begin{array}{l}\text { Study states: "patients randomly divided into two groups" } \\
\text { No description of how randomisation was undertaken }\end{array}$ \\
\hline $\begin{array}{l}\text { Allocation concealment } \\
\text { (selection bias): All out- } \\
\text { comes }\end{array}$ & Unclear risk & $\begin{array}{l}\text { Study states: "patients randomly divided into two groups" } \\
\text { Unclear if steps undertaken to ensure allocation concealment }\end{array}$ \\
\hline $\begin{array}{l}\text { Blinding of participants } \\
\text { and personnel (perfor- } \\
\text { mance bias): All outcomes }\end{array}$ & High risk & Not reported; considered unlikely that operating surgeon(s) were blinded \\
\hline $\begin{array}{l}\text { Blinding of outcome as- } \\
\text { sessment (detection bias): } \\
\text { Subjective outcomes } \\
\text { (IPSS, HRQoL, IIEF-5, TUR } \\
\text { syndrome, Urinary Inconti- } \\
\text { nence) }\end{array}$ & Unclear risk & Not reported \\
\hline
\end{tabular}

\begin{tabular}{|c|c|c|}
\hline $\begin{array}{l}\text { Blinding of outcome as- } \\
\text { sessment: Objective out- } \\
\text { comes (Blood transfusion, } \\
\text { Re-TURP) }\end{array}$ & Low risk & Not reported but objective outcomes unlikely to have been affected \\
\hline $\begin{array}{l}\text { Incomplete outcome da- } \\
\text { ta (attrition bias): Imme- } \\
\text { diate postoperative out- } \\
\text { comes (TUR syndrome, } \\
\text { Blood transfusion) }\end{array}$ & Low risk & $\begin{array}{l}\text { Study states that all participants were included in all analyses up to 1-month } \\
\text { follow-up }\end{array}$ \\
\hline
\end{tabular}

\begin{tabular}{|c|c|c|}
\hline $\begin{array}{l}\text { Incomplete outcome data } \\
\text { (attrition bias): Long-term } \\
\text { outcomes (IPSS/HRQoL/ }\end{array}$ & Unclear risk & $\begin{array}{l}\text { Study reports loss to follow-up of } n=4 / 30 \text { for MTURP and } 3 / 27 \text { for BTURP with } \\
\text { specific reasons provided. Considered unclear how loss to follow-up may have } \\
\text { impacted observed differences between arms }\end{array}$ \\
\hline
\end{tabular}

IIEF-5/urinary inconti-

nence at 12 months, and re-TURP)

Selective reporting (re- $\quad$ Unclear risk
porting bias): All outcomes

Methods ․ Study type: single-centre randomised controlled trial (1:1)

Bipolar versus monopolar transurethral resection of the prostate for lower urinary tract symptoms secondary to benign prostatic 
Patankar 2006 (Continued)

\section{- Setting: India}

Participants Total participants enrolled: $512 ;(A)=261,(B)=251$

- Inclusion criteria: men older than 45 years, AUA score $\geq 18$, prostate volume 35 to $70 \mathrm{~mL}, \mathrm{Q}_{\max } \leq 10$ $\mathrm{mL} / \mathrm{s}$

- Exclusion criteria: previous prostate surgery or prostate cancer

\section{Baseline characteristics:}

No statistically significant differences between arms reported

Mean age, years (SD): $(A)=$ and $(B)=$; not clear which data refer to which intervention arm

Mean preoperative prostate volume, $\mathrm{mL}(\mathrm{SD}):(\mathrm{A})=51.3(12.44),(\mathrm{B})=52.26(10.71)$

Preoperative catheterisation status: not reported

\begin{tabular}{ll}
\hline Interventions & Intervention A: bipolar TURP (PK Superpulse) \\
& - Intervention B: monopolar TURP (irrigation fluid = glycine)
\end{tabular}

Outcomes

\section{Primary outcomes:}

IPSS (12 months): not reported

HRQoL (12 months): not reported

TUR syndrome: $(A)=0(n=52),(B)=2(n=51)$

\section{Secondary outcomes:}

Blood transfusion: $(A)=0(n=52),(B)=1(n=51)$

Urinary incontinence (12 months): not reported

Erectile dysfunction (IIEF-5) (12 months): not reported

Need for repeat TURP (i.e. re-TURP): not reported

\section{Other reported outcomes:}

UTI

Duration of operation

Cathterisation duration

Change in serum sodium level

Clot retention rate

Urethral stricture

\begin{tabular}{lll}
\hline Source of funding & None reported \\
\hline Notes & \\
\hline Risk of bias & Authors' judgement & Support for judgement \\
\hline Bias & Low risk & Study states: "randomization was done by the opaque envelope method" \\
\hline $\begin{array}{l}\text { Random sequence gener- } \\
\begin{array}{l}\text { ation (selection bias): All } \\
\text { outcomes }\end{array}\end{array}$ \\
\hline \hline
\end{tabular}

Bipolar versus monopolar transurethral resection of the prostate for lower urinary tract symptoms secondary to benign prostatic 
Patankar 2006 (Continued)

Allocation concealment (selection bias): All outStudy states: "opaque envelopes" were used for allocation concealment

\section{Blinding of participants} and personnel (performance bias): All outcomes

\section{High risk}

Not reported if operating surgeon(s) were blinded but considered unlikely; study reports that participants were blinded

"Participants were blinded regarding the treatment modality they were undergoing, as was the staff that did the outcome assessment and decided when to remove the catheter"
Blinding of outcome as- Low risk sessment (detection bias): Subjective outcomes (IPSS, HRQoL, IIEF-5, TUR syndrome, Urinary Incontinence)
Study states: "participants were blinded regarding the treatment modality
Blinding of outcome as- Low risk sessment: Objective outcomes (Blood transfusion, Re-TURP) decided when to remove the catheter"

\section{they were undergoing, as was the staff that did the outcome assessment and}

Incomplete outcome da- Low risk
ta (attrition bias): Imme-
diate postoperative out-
comes (TUR syndrome,
Blood transfusion)

Incomplete outcome da-

ta (attrition bias): Imme-

Blood transfusion)

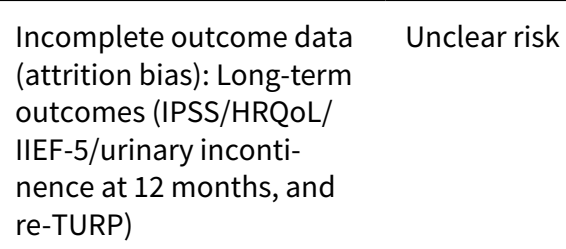

Study states: "participants were blinded regarding the treatment modality they were undergoing, as was the staff that did the outcome assessment and decided when to remove the catheter"
Selective reporting (re-
Unclear risk
RCT protocol not available to allow for full assessment

porting bias): All outcomes

Study states: $n=1 / 53$ patients were lost to follow-up in the BTURP arm, with no patients in the MTURP arm lost to follow-up

\section{Qian 2014}

Methods $\quad$ Study type: single-centre randomised controlled trial (1:1)

- Setting: China

Participants Total participants enrolled: $150 ;(A)=75,(B)=75$

- Inclusion criteria: symptomatic BPH that required surgery owing to urinary retention or failed medical therapy

- Exclusion criteria: neurogenic bladder dysfunction, previous prostatic or urethral surgery, prostate cancer, bladder cancer, severe medical disease

\section{Baseline characteristics:}

No significant differences between arms reported

Mean age, $\operatorname{years}(S D):(A)=61.1(10.9),(B)=60.4(11.3)$

Mean preoperative prostate volume, $\mathrm{mL}(\mathrm{SD}):(\mathrm{A})=59.1(8.2),(\mathrm{B})=59.5(8.6)$ 
Qian 2014 (Continued)

Preoperative catheterisation state: not reported

\begin{tabular}{ll}
\hline Interventions & Intervention A: bipolar TURP (technology not reported) \\
& - Intervention B: monopolar TURP (irrigation fluid not reported) \\
\hline
\end{tabular}

Outcomes

\section{Primary outcomes:}

IPSS (12 months): not reported explicitly at 12 months

HRQoL (12 months): not reported explicitly at 12 months

TUR syndrome: not reported

\section{Secondary outcomes:}

Blood transfusion: not reported

Urinary incontinence (12 months): not reported

Erectile dysfunction (IIEF-5) (12 months): reported only for 8-month follow-up

Need for repeat TURP (i.e. re-TURP): not reported

\section{Other reported outcomes:}

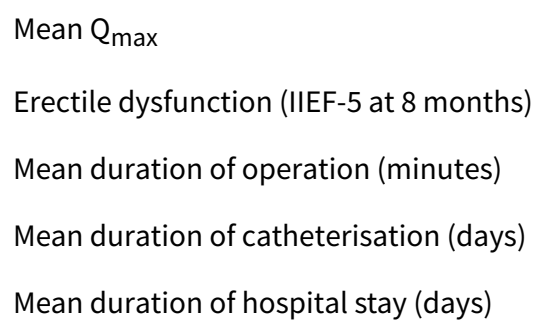

\section{Notes}

\section{Risk of bias}

\begin{tabular}{|c|c|c|}
\hline Bias & Authors' judgement & Support for judgement \\
\hline $\begin{array}{l}\text { Random sequence gener- } \\
\text { ation (selection bias): All } \\
\text { outcomes }\end{array}$ & Low risk & $\begin{array}{l}\text { Describes use of random number tables - no specific quotation available due } \\
\text { to Chinese translation }\end{array}$ \\
\hline $\begin{array}{l}\text { Allocation concealment } \\
\text { (selection bias): All out- } \\
\text { comes }\end{array}$ & Unclear risk & $\begin{array}{l}\text { Describes use of random number tables; unclear if additional measures were } \\
\text { used to ensure allocation concealment }\end{array}$ \\
\hline $\begin{array}{l}\text { Blinding of participants } \\
\text { and personnel (perfor- } \\
\text { mance bias): All outcomes }\end{array}$ & High risk & Not reported; considered unlikely that blinding surgeon(s) were blinded \\
\hline $\begin{array}{l}\text { Blinding of outcome as- } \\
\text { sessment (detection bias): } \\
\text { Subjective outcomes } \\
\text { (IPSS, HRQoL, IIEF-5, TUR } \\
\text { syndrome, Urinary Inconti- } \\
\text { nence) }\end{array}$ & Unclear risk & These outcomes were not reported \\
\hline
\end{tabular}


Qian 2014 (Continued)

\begin{tabular}{|c|c|c|}
\hline $\begin{array}{l}\text { Blinding of outcome as- } \\
\text { sessment: Objective out- } \\
\text { comes (Blood transfusion, } \\
\text { Re-TURP) }\end{array}$ & Unclear risk & These outcomes were not reported \\
\hline $\begin{array}{l}\text { Incomplete outcome da- } \\
\text { ta (attrition bias): Imme- } \\
\text { diate postoperative out- } \\
\text { comes (TUR syndrome, } \\
\text { Blood transfusion) }\end{array}$ & Unclear risk & These outcomes were not reported \\
\hline $\begin{array}{l}\text { Incomplete outcome data } \\
\text { (attrition bias): Long-term } \\
\text { outcomes (IPSS/HRQoL/ } \\
\text { IIEF-5/urinary inconti- } \\
\text { nence at } 12 \text { months, and } \\
\text { re-TURP) }\end{array}$ & Unclear risk & These outcomes were not reported \\
\hline
\end{tabular}

$\begin{array}{lll}\begin{array}{l}\text { Selective reporting (re- } \\ \text { porting bias): All outcomes }\end{array} & \text { Unclear risk } & \text { RCT protocol not available to allow for full assessment }\end{array}$

porting bias): All outcomes

Rojo 2018

$\begin{array}{ll}\text { Methods } & \text { Study type: single-centre randomised controlled trial (1:1) } \\ \text { - Setting: Spain }\end{array}$

Participants

- Total participants enrolled: $100 ;(A)=42,(B)=58$

- Inclusion criteria: refractory BPH (no response to oral treatment), acute urine retention, repetitive urinary tract infection

- Exclusion criteria: prostate cancer, previous pelvis surgery, previous pelvic radiotherapy, cognitive problems to follow study instructions

\section{Baseline characteristics:}

No significant differences between arms reported

Mean age, years $(S D):(A)=66.3(6.8),(B)=66.32(7.5)$

Mean preoperative prostate volume, $\mathrm{mL}(\mathrm{SD}):(\mathrm{A})=41.35$ (17.1), $(\mathrm{B})=37.02(16.7)$

Preoperative catheterisation state: not reported

$\begin{array}{ll}\text { Interventions } & \text { - Intervention A: bipolar TURP (technology not reported) } \\ & \text { - Intervention B: monopolar TURP (irrigation fluid }\end{array}$

- Intervention B: monopolar TURP (irrigation fluid = glycine)

Outcomes

\section{Primary outcomes:}

IPSS (12 months): not reported explicitly at 12 months

HRQoL (12 months): not reported

TUR syndrome: not reported

\section{Secondary outcomes:}

Blood transfusion: not reported

Urinary Incontinence (12 months): not reported 
Rojo 2018 (Continued)

Erectile dysfunction (IIEF-5) (12 months): not reported at 12 months

Need for repeat TURP (i.e. re-TURP): not reported

Other reported outcomes:

Retrograde ejaculation

\begin{tabular}{ll}
\hline Source of funding None reported & Notes
\end{tabular}

\section{Risk of bias}

\begin{tabular}{lll}
\hline Bias & Authors' judgement & Support for judgement \\
\hline $\begin{array}{ll}\text { Random sequence gener- } \\
\begin{array}{l}\text { ation (selection bias): All } \\
\text { outcomes }\end{array}\end{array}$ & Low risk & $\begin{array}{l}\text { In methods section, study authors state: "randomization under a cross se- } \\
\text { quence of numbers 1:1" }\end{array}$ \\
\end{tabular}

\begin{tabular}{|c|c|c|}
\hline $\begin{array}{l}\text { Allocation concealment } \\
\text { (selection bias): All out- } \\
\text { comes }\end{array}$ & Unclear risk & $\begin{array}{l}\text { Describes use of cross-section of numbers for randomisation; unclear if addi- } \\
\text { tional measures were used to ensure allocation concealment }\end{array}$ \\
\hline $\begin{array}{l}\text { Blinding of participants } \\
\text { and personnel (perfor- } \\
\text { mance bias): All outcomes }\end{array}$ & High risk & $\begin{array}{l}\text { Study reported blinding of participants; blinding of surgeons not reported but } \\
\text { considered unlikely that this was undertaken }\end{array}$ \\
\hline $\begin{array}{l}\text { Blinding of outcome as- } \\
\text { sessment (detection bias): } \\
\text { Subjective outcomes } \\
\text { (IPSS, HRQoL, IIEF-5, TUR } \\
\text { syndrome, Urinary Inconti- } \\
\text { nence) }\end{array}$ & Unclear risk & These outcomes were not reported \\
\hline $\begin{array}{l}\text { Blinding of outcome as- } \\
\text { sessment: Objective out- } \\
\text { comes (Blood transfusion, } \\
\text { Re-TURP) }\end{array}$ & Unclear risk & These outcomes were not reported \\
\hline $\begin{array}{l}\text { Incomplete outcome da- } \\
\text { ta (attrition bias): Imme- } \\
\text { diate postoperative out- } \\
\text { comes (TUR syndrome, } \\
\text { Blood transfusion) }\end{array}$ & Unclear risk & These outcomes were not reported \\
\hline $\begin{array}{l}\text { Incomplete outcome data } \\
\text { (attrition bias): Long-term } \\
\text { outcomes (IPSS/HRQoL/ } \\
\text { IIEF-5/urinary inconti- } \\
\text { nence at } 12 \text { months, and } \\
\text { re-TURP) }\end{array}$ & Unclear risk & These outcomes were not reported \\
\hline $\begin{array}{l}\text { Selective reporting (re- } \\
\text { porting bias): All outcomes }\end{array}$ & Unclear risk & $\begin{array}{l}\text { Study authors state that IIEF- } 5 \text { tool was used to measure erectile function out- } \\
\text { comes. However, specific data are not provided, but rather only use of the } \\
\text { phrase "erectile problems" when referring to data. Considered unclear how } \\
\text { this may have impacted overall findings }\end{array}$ \\
\hline
\end{tabular}


Rose 2007

\begin{tabular}{ll}
\hline Methods & Study type: single-centre randomised controlled trial $(1: 1)$ \\
- Setting: Germany
\end{tabular}

\section{Participants}

- Total participants enrolled: $72(A)=38,(B)=34$

- Inclusion criteria: not reported

\section{Baseline characteristics:}

No significant differences between arms reported

Mean age, years (SD): not reported specifically for BTURP and MTURP arms

Mean preoperative prostate volume, $\mathrm{mL}(\mathrm{SD})$ : not reported

Preoperative catheterisation state: not reported

\begin{tabular}{ll}
\hline Interventions & Intervention A: bipolar TURP (TURIS Olympus) \\
& - Intervention B: monopolar TURP (irrigation fluid = mannitol) \\
\hline
\end{tabular}

$\begin{array}{ll}\text { Outcomes } & \text { Primary outcomes: } \\ \text { IPSS (12 months): not repor } & \text { HRQoL (12 months): not repo } \\ \text { TUR syndrome: (A) }=0 \text { ( } \mathrm{n}= \\ \text { Secondary outcomes: } \\ \text { Blood transfusion: not rep } \\ \text { Urinary incontinence (12 } \\ \text { Erectile dysfunction (IIEF-5) } \\ \text { Need for repeat TURP (i.e. } \\ \text { Other reported outcomes: } \\ \text { Duration of operation } \\ \text { Catheterisation duration } \\ \text { Hospitalisation duration } \\ \text { Serum sodium level drop } \\ \text { Haemoglobin level drop }\end{array}$

Source of funding No clear source reported from translation

\section{Notes}

\section{Risk of bias}

\begin{tabular}{lll}
\hline Bias & Authors' judgement & Support for judgement \\
\hline $\begin{array}{l}\text { Random sequence gener- } \\
\text { ation (selection bias): All } \\
\text { outcomes }\end{array}$ & Unclear risk & $\begin{array}{l}\text { Specific method used for randomisation not completely clear: "the distribu- } \\
\text { tion in each surgical procedure took randomly place in two operating theaters, } \\
\text { in one of which a conventional resectoscope was installed, in the other a TURis } \\
\text { resectoscope was installed" }\end{array}$ \\
\hline
\end{tabular}


Rose 2007 (Continued)

Allocation concealment Unclear risk Specific method used for randomisation not completely clear: "the distribu(selection bias): All outtion in each surgical procedure took randomly place in two operating theaters, comes in one of which a conventional resectoscope was installed, in the other a TURis resectoscope was installed"

\section{Blinding of participants and personnel (perfor- mance bias): All outcomes \\ Blinding of outcome as- sessment (detection bias): \\ Subjective outcomes \\ (IPSS, HRQOL, IIEF-5, TUR \\ syndrome, Urinary Inconti- \\ nence)}

\section{High risk}

Not reported but considered unlikely that operating surgeon(s) were blinded

\section{Unclear risk Not reported}

\begin{tabular}{|c|c|c|}
\hline $\begin{array}{l}\text { Blinding of outcome as- } \\
\text { sessment: Objective out- } \\
\text { comes (Blood transfusion, } \\
\text { Re-TURP) }\end{array}$ & Unclear risk & These outcomes were not reported \\
\hline $\begin{array}{l}\text { Incomplete outcome da- } \\
\text { ta (attrition bias): Imme- } \\
\text { diate postoperative out- } \\
\text { comes (TUR syndrome, } \\
\text { Blood transfusion) }\end{array}$ & Low risk & $\begin{array}{l}\text { All participants ( } n=38 \text { for BTURP and } n=34 \text { for MTURP) were included in the } \\
\text { analyses for these outcomes }\end{array}$ \\
\hline $\begin{array}{l}\text { Incomplete outcome data } \\
\text { (attrition bias): Long-term } \\
\text { outcomes (IPSS/HRQoL/ } \\
\text { IIEF-5/urinary inconti- } \\
\text { nence at } 12 \text { months, and } \\
\text { re-TURP) }\end{array}$ & Unclear risk & These outcomes were not reported \\
\hline
\end{tabular}

Selective reporting (re- Unclear risk RCT protocol not available to allow for full assessment porting bias): All outcomes

Seckiner 2006

Methods $\quad$ Study type: single-centre RCT (1:1)

- Setting: Turkey

Participants Total number enrolled: $48,(A)=24,(B)=24$

- Inclusion criteria: IPSS $>8, \mathrm{Q}_{\max }<15 \mathrm{~mL} / \mathrm{s}$, prostate volume 30 to 70 g on transrectal ultrasonography

- Exclusion criteria: $<50$ years of age; those with a known neurogenic bladder, cancer of the prostate or bladder, history of prostate surgery, currently on medication known to affect voiding function

\section{Baseline characteristics:}

No significant differences between arms reported

Mean age, years (SD): $(A)=61.2(9.3)(n=24),(B)=63.9(10.9)(n=24)$

Mean preoperative prostate volume, grams (SD): $(A)=49.4(18.9)(n=24),(B)=41.4(14.5)(n=24)$

Preoperative catheterisation state: not reported 
Seckiner 2006 (Continued)

Interventions

\section{Outcomes}

- Intervention A: bipolar TURP (Gyrus), irrigation fluid = saline

- Intervention B: monopolar (Karl Storz), irrigation fluid = glycine

\section{Primary outcomes:}

IPSS (12 months) (SD): $(A)=8.7(4.1)(n=23),(B)=8.3(2.9)(n=21)$

HRQoL (12 months) (SD): $(A)=1.8(0.8)(n=23),(B)=2.0(0.8)(n=21)$

TUR syndrome: $(A)=0(n=24),(B)=0(n=24)$

\section{Secondary outcomes:}

Blood transfusion: not reported

Urinary incontinence (12 months): not reported

Erectile dysfunction (IIEF-5) (12 months): not reported

Need for repeat TURP (i.e. re-TURP): not reported

\section{Other reported outcomes:}

$\mathrm{Q}_{\max }(1,3,6,12$ months)

Urethral stricture rate

Mean duration of operation

Mean duration of catheterisation

Haemoglobin level change

Serum sodium level change

None reported

\section{Notes}

\section{Risk of bias}

\begin{tabular}{|c|c|c|}
\hline Bias & Authors' judgement & Support for judgement \\
\hline $\begin{array}{l}\text { Random sequence gener- } \\
\text { ation (selection bias): All } \\
\text { outcomes }\end{array}$ & Unclear risk & $\begin{array}{l}\text { Study states: "patients were randomized 1:1", but no information on method } \\
\text { of randomisation reported }\end{array}$ \\
\hline $\begin{array}{l}\text { Allocation concealment } \\
\text { (selection bias): All out- } \\
\text { comes }\end{array}$ & Unclear risk & Not reported \\
\hline $\begin{array}{l}\text { Blinding of participants } \\
\text { and personnel (perfor- } \\
\text { mance bias): All outcomes }\end{array}$ & High risk & Not reported but considered unlikely that operating surgeon(s) were blinded \\
\hline $\begin{array}{l}\text { Blinding of outcome as- } \\
\text { sessment (detection bias): } \\
\text { Subjective outcomes } \\
\text { (IPSS, HRQoL, IIEF-5, TUR } \\
\text { syndrome, Urinary Inconti- } \\
\text { nence) }\end{array}$ & Unclear risk & Not reported \\
\hline
\end{tabular}

Bipolar versus monopolar transurethral resection of the prostate for lower urinary tract symptoms secondary to benign prostatic 
Seckiner 2006 (Continued)

Blinding of outcome assessment: Objective outcomes (Blood transfusion, Re-TURP)
Low risk Not reported but objective outcomes unlikely to have been affected

\section{Incomplete outcome da- ta (attrition bias): Imme- diate postoperative out- comes (TUR syndrome, Blood transfusion)}

Low risk

Study reports inclusion of all participants $(n=24 / 24$ for MTURP and $n=24 / 24$ for BTURP) for analysis of these outcomes

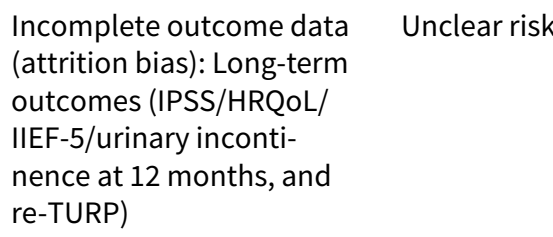

12-month data are not reported for 3 patients in MTURP arm and for 1 patient in BTURP arm. No reasons for missing data provided; considered unclear how missing data may have impacted observed differences between arms

Shaik 2017

$\begin{array}{ll}\text { Methods } & \text { - Study type: single-centre RCT (1:1) } \\ & \text { - Setting: India }\end{array}$

Participants

- Total number enrolled: $60 ;(A)=32(B)=28$

- Inclusion criteria: not reported

- Exclusion criteria: not reported

Baseline characteristics:

No significant differences between arms reported

Mean age, years (SD): not reported for individual arms, mean age for both arms: 72 years (3)

Mean preoperative prostate volume, $\mathrm{mL}(\mathrm{SD})$ : not reported for individual arms, mean volume for both arms: $71(5)$

Preoperative catheterisation state: not reported

Interventions _ Intervention A: bipolar TURP (specific technology not reported), irrigation fluid/specific technology not reported

- Intervention B: monopolar (specific technology not reported), irrigation fluid/specific technology not reported

\section{Primary outcomes:}

IPSS (12 months): no specific data reported, although study reports this outcome as recorded

HRQoL (12 months): not reported

TUR syndrome: not reported

\section{Secondary outcomes:}

Blood transfusion: not reported 
Shaik 2017 (Continued)

Urinary incontinence (12 months): not reported

Erectile dysfunction (IIEF-5) (12 months): not reported

Need for repeat TURP (i.e. re-TURP): not reported

\section{Other reported outcomes:}

Resection time

Postoperative catheterisation duration

Duration of hospital stay

$\mathrm{Q}_{\max }$

\begin{tabular}{ll}
\hline Source of funding $\quad$ None reported \\
\hline Notes
\end{tabular}

\section{Risk of bias}

\begin{tabular}{lll}
\hline Bias & Authors' judgement & Support for judgement \\
\hline $\begin{array}{l}\text { Random sequence gener- } \\
\text { ation (selection bias): All } \\
\text { outcomes }\end{array}$ & Unclear risk & Not reported \\
\hline $\begin{array}{l}\text { Allocation concealment } \\
\text { (selection bias): All out- } \\
\text { comes }\end{array}$ & Unclear risk & Not reported \\
\end{tabular}

Blinding of participants High risk Not reported but considered unlikely that operating surgeon(s) were blinded
and personnel (perfor-
mance bias): All outcomes

\begin{tabular}{|c|c|c|}
\hline $\begin{array}{l}\text { Blinding of outcome as- } \\
\text { sessment (detection bias): } \\
\text { Subjective outcomes } \\
\text { (IPSS, HRQoL, IIEF-5, TUR } \\
\text { syndrome, Urinary Inconti- } \\
\text { nence) }\end{array}$ & Unclear risk & These outcomes were not reported by the trial \\
\hline $\begin{array}{l}\text { Blinding of outcome as- } \\
\text { sessment: Objective out- } \\
\text { comes (Blood transfusion, } \\
\text { Re-TURP) }\end{array}$ & Unclear risk & These outcomes were not reported by the trial \\
\hline $\begin{array}{l}\text { Incomplete outcome da- } \\
\text { ta (attrition bias): Imme- } \\
\text { diate postoperative out- } \\
\text { comes (TUR syndrome, } \\
\text { Blood transfusion) }\end{array}$ & Unclear risk & These outcomes were not reported by the trial \\
\hline $\begin{array}{l}\text { Incomplete outcome data } \\
\text { (attrition bias): Long-term } \\
\text { outcomes (IPSS/HRQoL/ } \\
\text { IIEF-5/urinary inconti- } \\
\text { nence at } 12 \text { months, and } \\
\text { re-TURP) }\end{array}$ & Unclear risk & These outcomes were not reported by the trial \\
\hline
\end{tabular}


Shaik 2017 (Continued)

Selective reporting (reporting bias): All outcomes
Unclear risk $\quad$ RCT protocol not available to allow for full assessment of selective reporting. However, this study reports IPSS at 12 months as recorded but no specific data provided within published abstract

Singh 2005

Methods Study type: single-centre, RCT (1:1)

- Setting: India

Participants

- Total number enrolled: $60,(A)=30,(B)=30$

- Inclusion criteria: symptomatic benign prostatic hyperplasia (BPH) requiring surgical intervention, chronic retention with Schäfer obstruction grade 2

- Exclusion criteria: IPSS $<7$, Qmax $>12 \mathrm{~mL} / \mathrm{s}$, PCAR $<0.75$ on transrectal ultrasonography, neurological illness, renal insufficiency, bladder stone, urethral stricture, taking finasteride

\section{Baseline characteristics:}

Not reported whether baseline characteristics significantly different. No $P$ values

Mean age, years (SD): (A) 68.9 (7.6) $(n=30),(B) 67.9(9.8)(n=30)$. P not reported

Mean preoperative prostate volume: not reported

Preoperative catheterisation state: not reported

Interventions - Intervention A: bipolar TURP (ACMI Corp), irrigation fluid = saline with $1 \%$ ethanol

- Intervention B: monopolar TURP (Valley Laboratory), irrigation fluid = not stated

Outcomes

\section{Primary outcomes:}

IPSS (12 months): not reported

HRQoL (12 months): not reported

TUR syndrome: $(A)=0(n=30),(B)=0(n=30)$

\section{Secondary outcomes:}

Blood transfusion: $(A)=0(n=30),(B)=1(n=30)$

Urinary incontinence (12 months): reported only at 4 weeks

Erectile dysfunction (IIEF-5) (12 months): not reported

Need for repeat TURP (i.e. re-TURP): not reported

\section{Other reported outcomes:}

IPSS at 1, 3 months

HRQoL at 1, 3 months

$\mathrm{Q}_{\max }$ at 1,3 months

Urinary incontinence at 4 weeks

Urethral stricture

Bladder neck contracture

UTI

Bipolar versus monopolar transurethral resection of the prostate for lower urinary tract symptoms secondary to benign prostatic 
Singh 2005 (Continued)

Drop in postoperative serum sodium

Drop in postoperative haemoglobin

Duration of operation

Duration of catheterisation

Duration of bladder irrigation

\begin{tabular}{ll}
\hline Source of funding None reported & Notes \\
\hline Notes &
\end{tabular}

\section{Risk of bias}

\begin{tabular}{|c|c|c|}
\hline Bias & Authors' judgement & Support for judgement \\
\hline $\begin{array}{l}\text { Random sequence gener- } \\
\text { ation (selection bias): All } \\
\text { outcomes }\end{array}$ & Low risk & "Patients were randomized 1:1 using envelopes into two groups..." \\
\hline $\begin{array}{l}\text { Allocation concealment } \\
\text { (selection bias): All out- } \\
\text { comes }\end{array}$ & Unclear risk & $\begin{array}{l}\text { "Patients were randomized 1:1 using envelopes into two groups..." } \\
\text { Unclear whether the envelopes were sealed, sequentially numbered, and } \\
\text { opaque }\end{array}$ \\
\hline $\begin{array}{l}\text { Blinding of participants } \\
\text { and personnel (perfor- } \\
\text { mance bias): All outcomes }\end{array}$ & High risk & Not reported but considered unlikely that operating surgeon(s) were blinded \\
\hline $\begin{array}{l}\text { Blinding of outcome as- } \\
\text { sessment (detection bias): } \\
\text { Subjective outcomes } \\
\text { (IPSS, HRQoL, IIEF-5, TUR } \\
\text { syndrome, Urinary Inconti- } \\
\text { nence) }\end{array}$ & Unclear risk & Not reported \\
\hline
\end{tabular}

Blinding of outcome as- Low risk Not reported but objective outcomes unlikely to have been affected
sessment: Objective outcomes (Blood transfusion, Re-TURP)

Incomplete outcome data (attrition bias): Immediate postoperative outcomes (TUR syndrome, Blood transfusion)
Low risk Not reported but objective outcomes unlikely to have been affected

Unclear risk

This study does not explicitly report on attrition, exclusion of participants from analyses, or the presence of incomplete outcome data for these outcomes

\begin{abstract}
Incomplete outcome data (attrition bias): Long-term outcomes (IPSS/HRQoL/ IIEF-5/urinary incontinence at 12 months, and re-TURP)
\end{abstract}

Unclear risk These outcomes were not reported

$\begin{array}{ll}\begin{array}{l}\text { Selective reporting (re- } \\ \text { porting bias): All outcomes }\end{array} & \text { Unclear risk }\end{array}$




Methods - Study type: single-centre randomised controlled trial (1:1)

- Setting: India

Participants Total number enrolled: $60 ;(A)=30,(B)=30$

- Inclusion criteria: failed medical therapy, acute urinary retention with failed voiding trial, recurrent urinary tract infection and haematuria, documented or suspected prostate cancer, neurogenic bladder, previous prostate surgery, urethral stricture, bladder stones, renal impairment

- Exclusion criteria: documented or suspected prostate cancer, neurogenic bladder, previous prostate cancer, neurogenic bladder, previous prostate surgery, urethral stricture, associated bladder stones, renal impairment

\section{Baseline characteristics:}

Only limited data for baseline characteristics provided for comparison

Mean age $(S D):(A)=63.86(6.1),(B)=65.96(6.6)$

Mean preoperative prostate volume: not reported

Preoperative catheterisation status: not reported

- Intervention A: bipolar TURP (Gyrus PK Bipolar Resection System), irrigation fluid = normal saline

- Intervention B: monopolar TURP (Erbee); 1.5\%, irrigation fluid = glycine

Outcomes

\section{Primary outcomes:}

IPSS (12 months): $(A)=6.13(0.94),(B)=6.23(0.94)$

HRQoL (12 months): not reported

TUR syndrome: $(A)=0(n=30),(B)=0(n=30)$

\section{Secondary outcomes:}

Blood transfusion: $(A)=0(n=30),(B)=0(n=30)$

Urinary incontinence (12 months): not reported

Erectile dysfunction (IIEF-5) (12 months): not reported

Need for repeat TURP (i.e. re-TURP): $(A)=0(n=30),(B)=0(n=30)$

\section{Other reported outcomes:}

Mean IPSS at 1, 3, 6 months

Mean $\mathrm{Q}_{\max }$ at 1, 3, 6, 12 months

Clot retention

Urethral stricture

Bladder neck contracture

UTI

Mean duration of operation (minutes)

Mean decline in serum sodium (mEq/L)

Mean decline in haemoglobin ( $\mathrm{g} \%$ ) 
Singhania 2010 (Continued)

Postoperative incidence of epididymitis

\begin{tabular}{ll}
\hline Source of funding $\quad$ From the research society, BYL Nair Hospital \\
\hline Notes
\end{tabular}

\section{Risk of bias}

\begin{tabular}{|c|c|c|}
\hline Bias & Authors' judgement & Support for judgement \\
\hline $\begin{array}{l}\text { Random sequence gener- } \\
\text { ation (selection bias): All } \\
\text { outcomes }\end{array}$ & Low risk & $\begin{array}{l}\text { Study states: "they were divided into two groups using standard randomiza- } \\
\text { tion codes" }\end{array}$ \\
\hline $\begin{array}{l}\text { Allocation concealment } \\
\text { (selection bias): All out- } \\
\text { comes }\end{array}$ & Unclear risk & Any steps taken to ensure allocation concealment were not reported \\
\hline $\begin{array}{l}\text { Blinding of participants } \\
\text { and personnel (perfor- } \\
\text { mance bias): All outcomes }\end{array}$ & High risk & Not reported but considered unlikely that operating surgeon(s) were blinded \\
\hline
\end{tabular}

Blinding of outcome as- Low risk Not reported but objective outcomes unlikely to have been affected
sessment: Objective out-
comes (Blood transfusion,
Re-TURP)

\begin{tabular}{|c|c|c|}
\hline $\begin{array}{l}\text { Incomplete outcome da- } \\
\text { ta (attrition bias): Imme- } \\
\text { diate postoperative out- } \\
\text { comes (TUR syndrome, } \\
\text { Blood transfusion) }\end{array}$ & Unclear risk & $\begin{array}{l}\text { This study does not explicitly report on attrition, exclusion of participants from } \\
\text { analyses, or the presence of incomplete outcome data for these outcomes }\end{array}$ \\
\hline $\begin{array}{l}\text { Incomplete outcome data } \\
\text { (attrition bias): Long-term } \\
\text { outcomes (IPSS/HRQoL/ } \\
\text { IIEF-5/urinary inconti- } \\
\text { nence at } 12 \text { months, and } \\
\text { re-TURP) }\end{array}$ & Unclear risk & $\begin{array}{l}\text { This study does not explicitly report on attrition, exclusion of participants from } \\
\text { analyses, or the presence of incomplete outcome data for these outcomes }\end{array}$ \\
\hline $\begin{array}{l}\text { Selective reporting (re- } \\
\text { porting bias): All outcomes }\end{array}$ & Unclear risk & RCT protocol not available to allow for full assessment \\
\hline
\end{tabular}

\section{Stucki 2014}

\begin{tabular}{ll}
\hline Methods & Study type: single-centre randomised controlled trial (1:1) \\
& - Setting: Switzerland
\end{tabular}


- Included: presence of LUTS and relevant reduction in IPSS Qol and/or significant PVR $>100 \mathrm{~mL}$ refractory to medical therapy with alpha-blockers and/or 5 alpha-reductase inhibitors, BPH with acute urinary retention, failed TWOC

- Exclusion criteria: neurogenic bladder, prostate cancer, previous prostatic/urethral surgery, bleeding disorders

\section{Baseline characteristics:}

No significant differences between arms reported

Mean age, years (SD): $(A)=67$ (none), $(B)=66$ (none)

Median preoperative prostate volume $\left(\mathrm{cm}^{3}\right)(S D):(A)=34$ (none) $(n=67),(B)=35$ (none) $(n=66)$

Preoperative catheterisation state: not reported

Interventions

- Intervention A: bipolar TURP (Gyrus), irrigation fluid $=0.9 \%$ saline

- Intervention B: monopolar TURP (Karl Storz), irrigation fluid = sorbitol/mannitol

Outcomes

\section{Primary outcomes:}

IPSS (12 months): no numerical values reported

HRQoL (12 months): no numerical values reported

TUR syndrome: $(A)=0(n=70),(B)=1(n=67)$

\section{Secondary outcomes:}

Blood transfusion: $(A)=1(n=70),(B)=1(n=67)$

Urinary incontinence (12 months): not reported

Erectile dysfunction (IIEF-5) (12 months): not reported

Need for repeat TURP (i.e. re-TURP): not reported

\section{Other reported outcomes:}

Clot retention

Urethral stricture

Bladder neck stricture

Need for reoperation for procedures (other than re-TURP)

Duration of operation (median minutes)

Duration of catheterisation (median days)

Duration of hospital stay (median days)

Haemoglobin level change

Clot retention rate None reported

\section{Notes}

\section{Risk of bias}

Bias Authors' judgement Support for judgement

Bipolar versus monopolar transurethral resection of the prostate for lower urinary tract symptoms secondary to benign prostatic obstruction (Review)

Copyright (c) 2019 The Cochrane Collaboration. Published by John Wiley \& Sons, Ltd. 
Stucki 2014 (Continued)

Random sequence gener- Low risk Study states: "were computer randomized at a 1:1 ratio" ation (selection bias): All

outcomes

Allocation concealment $\quad$ Unclear risk $\quad$ Not reported
(selection bias): All out-
comes

\begin{tabular}{lll}
\hline $\begin{array}{l}\text { Blinding of participants } \\
\text { and personnel (perfor- } \\
\text { mance bias): All outcomes }\end{array}$ & High risk & Not reported but considered unlikely that operating surgeon(s) were blinded \\
\hline $\begin{array}{l}\text { Blinding of outcome as- } \\
\text { sessment (detection bias): }\end{array}$ & Unclear risk & Not reported \\
Subjective outcomes & \\
$\begin{array}{l}\text { (IPSS, HRQoL, IIEF-5, TUR } \\
\text { syndrome, Urinary Inconti- }\end{array}$ & \\
nence) & \\
\hline
\end{tabular}

Blinding of outcome as- Low risk Not reported but objective outcomes unlikely to have been affected sessment: Objective outcomes (Blood transfusion, Re-TURP)

\section{Incomplete outcome da- ta (attrition bias): Imme- diate postoperative out- comes (TUR syndrome, Blood transfusion)}

Unclear risk This study does not explicitly report on attrition, exclusion of participants from analyses, or the presence of incomplete outcome data for these outcomes

$\begin{array}{lll}\text { Incomplete outcome data } & \text { High risk } & \text { Study reports that } n=46 / 67 \text { and } n=43 / 70 \text { of participants in monopolar and } \\ \text { (attrition bias): Long-term } & & \text { bipolar arms, respectively, were included in 12-month IPSS follow-up analysis. } \\ \text { outcomes (IPSS/HRQoL/ } & \text { No reasons for incomplete data are reported. This was considered to represent } \\ \text { IIEF-5/urinary inconti- } & \text { significant loss to follow-up not accounted for in the analyses }\end{array}$

nence at 12 months, and re-TURP)

$\begin{aligned} & \text { Selective reporting (re- } \\ & \text { porting bias): All outcomes }\end{aligned}$
Unclear risk $\quad$ RCT protocol not available to allow for full assessment

\section{Symons 2002}

$\begin{array}{ll}\text { Methods } & \text { Study type: single-centre randomised controlled trial }(2: 1) \\ \text { - Setting: United Kingdom }\end{array}$

Participants

- Total number enrolled: $45 ;(A)=32,(B)=13$

- Inclusion criteria: clinical diagnosis of BPH with bladder outflow obstruction

- Exclusion criteria: not reported

\section{Baseline characteristics:}

No significant differences between arms reported

Mean age (SD): not reported

Mean preoperative prostate volume: not reported 
Symons 2002 (Continued)

Preoperative catheterisation status: not reported

\begin{tabular}{ll}
\hline Interventions & Intervention A: bipolar TURP; Gyrus Plasmakinetic Electrosurgical System, irrigation fluid = saline \\
- Intervention B: monopolar TURP, irrigation fluid $=1.5 \%$ glycine
\end{tabular}

\section{Outcomes}

\section{Primary outcomes:}

IPSS (12 months): not reported

HRQoL (12 months): not reported

TUR syndrome: not reported

\section{Secondary outcomes:}

Blood transfusion: not reported

Urinary incontinence (12 months): not reported

Erectile dysfunction (IIEF-5) (12 months): not reported

Need for repeat TURP (i.e. re-TURP): not reported

\begin{tabular}{ll}
\hline Source of funding & None reported \\
\hline Notes & This is a conference abstract with limited information \\
\hline
\end{tabular}

\section{Risk of bias}

\begin{tabular}{|c|c|c|}
\hline Bias & Authors' judgement & Support for judgement \\
\hline $\begin{array}{l}\text { Random sequence gener- } \\
\text { ation (selection bias): All } \\
\text { outcomes }\end{array}$ & Unclear risk & Not reported \\
\hline $\begin{array}{l}\text { Allocation concealment } \\
\text { (selection bias): All out- } \\
\text { comes }\end{array}$ & Unclear risk & Not reported \\
\hline $\begin{array}{l}\text { Blinding of participants } \\
\text { and personnel (perfor- } \\
\text { mance bias): All outcomes }\end{array}$ & High risk & Not reported but considered unlikely that operating surgeon(s) were blinded \\
\hline $\begin{array}{l}\text { Blinding of outcome as- } \\
\text { sessment (detection bias): } \\
\text { Subjective outcomes } \\
\text { (IPSS, HRQoL, IIEF-5, TUR } \\
\text { syndrome, Urinary Inconti- } \\
\text { nence) }\end{array}$ & Unclear risk & These outcomes were not reported \\
\hline $\begin{array}{l}\text { Blinding of outcome as- } \\
\text { sessment: Objective out- } \\
\text { comes (Blood transfusion, } \\
\text { Re-TURP) }\end{array}$ & Unclear risk & These outcomes were not reported \\
\hline $\begin{array}{l}\text { Incomplete outcome da- } \\
\text { ta (attrition bias): Imme- } \\
\text { diate postoperative out- } \\
\text { comes (TUR syndrome, } \\
\text { Blood transfusion) }\end{array}$ & Unclear risk & These outcomes were not reported \\
\hline
\end{tabular}

Bipolar versus monopolar transurethral resection of the prostate for lower urinary tract symptoms secondary to benign prostatic 
Symons 2002 (Continued)
Incomplete outcome data
Unclear risk
These outcomes were not reported; only abstract available with limited re- (attrition bias): Long-term ported data outcomes (IPSS/HRQoL/ IIEF-5/urinary incontinence at 12 months, and re-TURP)

$\begin{aligned} & \text { Selective reporting (re- } \\ & \text { porting bias): All outcomes }\end{aligned}$
Unclear risk

\section{Terrone 2006}

\begin{tabular}{ll}
\hline Methods & Study type: single-centre RCT; randomisation ratio not reported \\
- Setting: Italy
\end{tabular}

\section{Participants}

- Total number enrolled: 50; $(A)=$ not reported, $(B)=$ not reported

- Inclusion criteria: bothersome LUTS

- Exclusion criteria: not reported

\section{Baseline characteristics}

Study reports no significant differences between arms but specific data not available

Mean age (SD): not reported

Mean preoperative prostate volume: not reported

Preoperative catheterisation status: not reported

$\begin{array}{ll}\text { Interventions } & \text { Intervention A: bipolar TURP (Vista CTR Bipolar Resection System, ACMI) } \\ & \text { - Intervention B: monopolar TURP; specific irrigation fluid not reported }\end{array}$

\section{Outcomes}

\section{Primary outcomes:}

IPSS (12 months): unclear which values refer to specific arms of the trial

HRQoL (12 months): unclear which values refer to specific arms of the trial

TUR syndrome: not reported

\section{Secondary outcomes:}

Blood transfusion: not reported

Urinary incontinence (12 months): not reported

Erectile dysfunction (IIEF-5) (12 months): not reported

Need for repeat TURP (i.e. re-TURP): not reported

\section{Other reported outcomes:}

$\mathrm{Q}_{\max }$ : data provided only for range of improvement; not possible to determine which values refer to specific arms of the trial

Mean duration of catheterisation

Mean duration of procedure (minutes)

Mean postoperative haemoglobin (g/dL) 
Terrone 2006 (Continued)

Mean postoperative sodium (mmol/L)

\begin{tabular}{ll}
\hline Source of funding & None reported \\
\hline Notes & This is a conference abstract with limited information \\
\hline
\end{tabular}

\section{Risk of bias}

\begin{tabular}{|c|c|c|}
\hline Bias & Authors' judgement & Support for judgement \\
\hline $\begin{array}{l}\text { Random sequence gener- } \\
\text { ation (selection bias): All } \\
\text { outcomes }\end{array}$ & Unclear risk & Not reported \\
\hline $\begin{array}{l}\text { Allocation concealment } \\
\text { (selection bias): All out- } \\
\text { comes }\end{array}$ & Unclear risk & Not reported \\
\hline $\begin{array}{l}\text { Blinding of participants } \\
\text { and personnel (perfor- } \\
\text { mance bias): All outcomes }\end{array}$ & High risk & Not reported but considered unlikely that operating surgeon(s) were blinded \\
\hline $\begin{array}{l}\text { Blinding of outcome as- } \\
\text { sessment (detection bias): } \\
\text { Subjective outcomes } \\
\text { (IPSS, HRQoL, IIEF-5, TUR } \\
\text { syndrome, Urinary Inconti- } \\
\text { nence) }\end{array}$ & Unclear risk & Not reported \\
\hline
\end{tabular}

\begin{tabular}{|c|c|c|}
\hline $\begin{array}{l}\text { Blinding of outcome as- } \\
\text { sessment: Objective out- } \\
\text { comes (Blood transfusion, } \\
\text { Re-TURP) }\end{array}$ & Unclear risk & These outcomes were not reported \\
\hline $\begin{array}{l}\text { Incomplete outcome da- } \\
\text { ta (attrition bias): Imme- } \\
\text { diate postoperative out- } \\
\text { comes (TUR syndrome, } \\
\text { Blood transfusion) }\end{array}$ & Unclear risk & No evidence that these outcomes were recorded \\
\hline
\end{tabular}

Incomplete outcome data (attrition bias): Long-term outcomes (IPSS/HRQoL/ IIEF-5/urinary incontinence at 12 months, and re-TURP)
Unclear risk

It is unclear which data refer to which arms of the trial; therefore presented data cannot be fully interpreted to allow for full judgement

\section{Wang 2007}

$\begin{array}{ll}\text { Methods } & \text { - Study type: single-centre randomised controlled trial }(1: 1) \\ & - \text { Setting: China }\end{array}$

Participants

- Total participants enrolled: $164 ;(A)=82,(B)=82$ 
- Inclusion criteria: symptomatic BPH that required surgery owing to urinary retention or failed medical therapy

- Exclusion criteria: neurogenic bladder dysfunction, previous prostatic or urethral surgery, prostate cancer, bladder cancer, severe medical disease

\section{Baseline characteristics:}

No significant differences between arms reported

Mean age $(S D):(A)=70.0(4.2),(B)=70.5(4.6)$

Mean preoperative prostate volume, $\mathrm{mL}(\mathrm{SD})$ : $(\mathrm{A})=57.9(5.8),(\mathrm{B})=58.6$ (5.6)

Preoperative catheterisation state: not reported

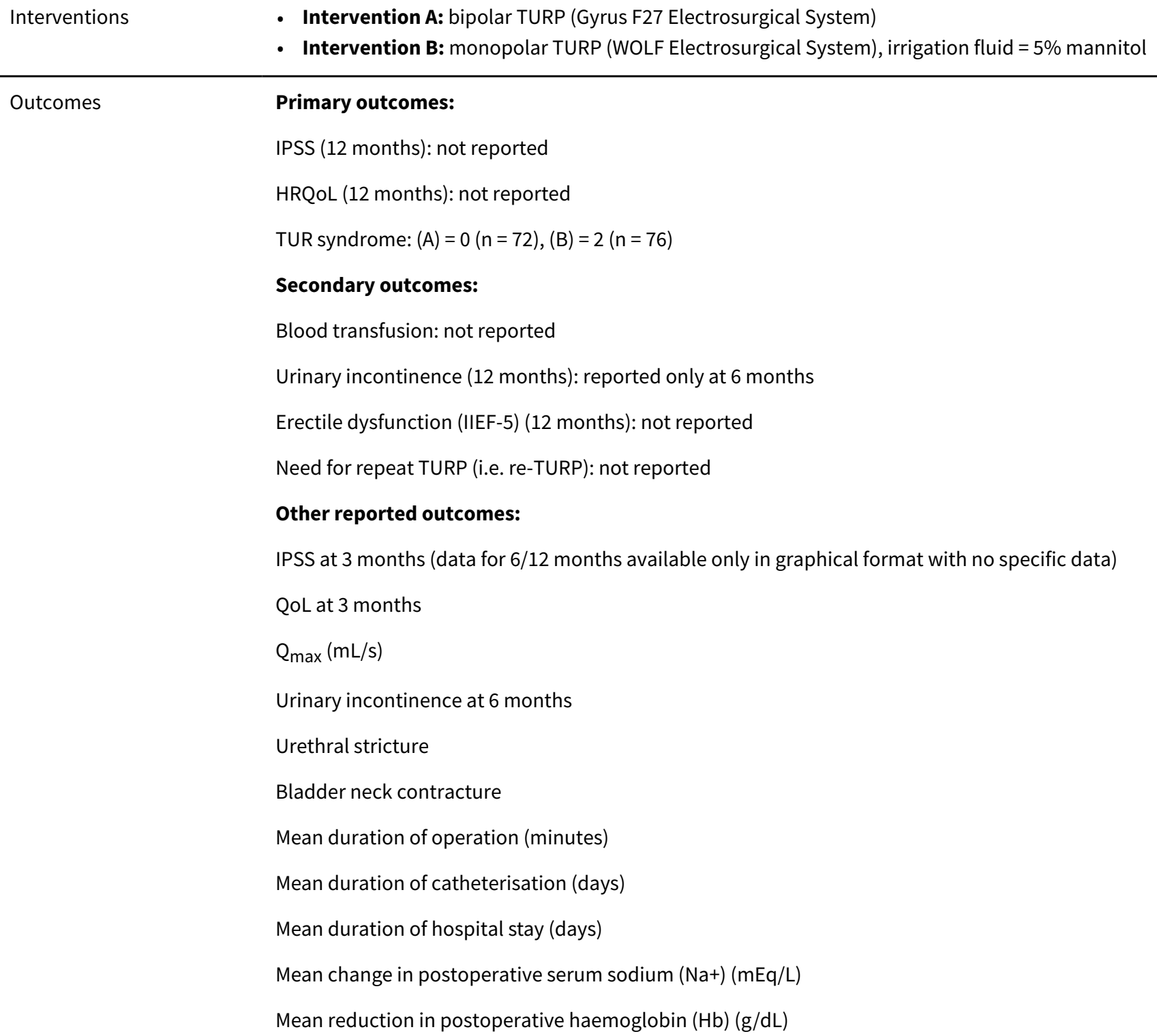

Outcomes

\section{Primary outcomes:}

IPSS (12 months): not reported

HRQoL (12 months): not reported

TUR syndrome: $(A)=0(n=72),(B)=2(n=76)$

\section{Secondary outcomes:}

Blood transfusion: not reported

Urinary incontinence (12 months): reported only at 6 months

Erectile dysfunction (IIEF-5) (12 months): not reported

Need for repeat TURP (i.e. re-TURP): not reported

\section{Other reported outcomes:}

IPSS at 3 months (data for $6 / 12$ months available only in graphical format with no specific data)

QoL at 3 months

$\mathrm{Q}_{\max }(\mathrm{mL} / \mathrm{s})$

Urinary incontinence at 6 months

Urethral stricture

Bladder neck contracture

Mean duration of operation (minutes)

Mean duration of catheterisation (days)

Mean duration of hospital stay (days)

Mean change in postoperative serum sodium $(\mathrm{Na}+)(\mathrm{mEq} / \mathrm{L})$

Mean reduction in postoperative haemoglobin $(\mathrm{Hb})(\mathrm{g} / \mathrm{dL})$

\section{Source of funding}

None reported

Notes 
Wang 2007 (Continued)

\section{Risk of bias}

\begin{tabular}{|c|c|c|}
\hline Bias & Authors' judgement & Support for judgement \\
\hline $\begin{array}{l}\text { Random sequence gener- } \\
\text { ation (selection bias): All } \\
\text { outcomes }\end{array}$ & Unclear risk & Not reported \\
\hline $\begin{array}{l}\text { Allocation concealment } \\
\text { (selection bias): All out- } \\
\text { comes }\end{array}$ & Unclear risk & Not reported \\
\hline $\begin{array}{l}\text { Blinding of participants } \\
\text { and personnel (perfor- } \\
\text { mance bias): All outcomes }\end{array}$ & High risk & Not reported but considered unlikely that operating surgeon(s) were blinded \\
\hline $\begin{array}{l}\text { Blinding of outcome as- } \\
\text { sessment (detection bias): } \\
\text { Subjective outcomes } \\
\text { (IPSS, HRQoL, IIEF-5, TUR } \\
\text { syndrome, Urinary Inconti- } \\
\text { nence) }\end{array}$ & Unclear risk & Not reported \\
\hline
\end{tabular}

Blinding of outcome as- Unclear risk These outcomes were not reported

sessment: Objective out-

comes (Blood transfusion, Re-TURP)

\section{Incomplete outcome da- ta (attrition bias): Imme- diate postoperative out- comes (TUR syndrome, Blood transfusion)}

\section{Incomplete outcome data (attrition bias): Long-term outcomes (IPSS/HRQoL/ IIEF-5/urinary inconti- nence at 12 months, and re-TURP)}

Low risk Study reports that all participants $(n=76$ in monopolar and $n=72$ in bipolar arms) were included in the analysis for these outcomes

$\begin{array}{lll}\begin{array}{l}\text { Selective reporting (re- } \\ \text { porting bias): All outcomes }\end{array} & \text { Unclear risk } & \text { RCT protocol not available to allow for full assessment }\end{array}$

Unclear risk These outcomes were not reported

porting bias): All outcomes

Wu 2005

$\begin{array}{ll}\text { Methods } & \text { Study type: single-centre randomised controlled trial (1:1) } \\ \text { - Setting: China }\end{array}$

Participants

- Total participants enrolled: $400 ;(A)=200,(B)=200$

- Inclusion criteria: symptomatic BPH that required surgery owing to urinary retention or failed medical therapy

- Exclusion criteria: prostate cancer

\section{Baseline characteristics:}


Wu 2005 (Continued)

No significant differences between arms reported

Mean age, years (range): $(A)=74.1(58$ to 91$),(B)=73.8(56$ to 90$)$

Mean preoperative prostate volume, grams (SD): $(A)=56.3(40.2),(B)=49.3(36.6)$

Preoperative catheterisation state: not reported

$\begin{array}{ll}\text { Interventions } & \text { Intervention A: bipolar TURP (Gyrus 27F Stoze Electrosurgical System) } \\ & \text { - Intervention B: monopolar TURP (WOLF Electrosurgical System, irrigation fluid }=5 \% \text { glucose) }\end{array}$

Outcomes Primary outcomes:

Mean IPSS (12 months): not reported (only 6 months)

Mean QoL (12 months): not reported (only 6 months)

TUR syndrome: $(A)=0(n=200),(B)=5(n=200)$

\section{Secondary outcomes:}

Blood transfusion: $(A)=0(n=200),(B)=18(n=200)$

Urinary incontinence (12 months): not reported

Erectile dysfunction (IIEF-5, 12 months): not reported explicitly at 12 months

Need for re-TURP: not reported

\section{Other reported outcomes:}

Mean duration of operation

Mean change in postoperative serum sodium

Mean change in postoperative haemoglobin

Source of funding None reported

Notes

\section{Risk of bias}

\begin{tabular}{lll}
\hline Bias & Authors' judgement & Support for judgement \\
\hline $\begin{array}{ll}\text { Random sequence gener- } \\
\text { ation (selection bias): All }\end{array}$ & Unclear risk & Not reported \\
outcomes &
\end{tabular}

Allocation concealment $\quad$ Unclear risk
$\begin{aligned} & \text { (selection bias): All out- } \\ & \text { comes }\end{aligned}$

Blinding of participants High risk Not reported but considered unlikely that operating surgeon(s) were blinded and personnel (performance bias): All outcomes

\begin{tabular}{|c|c|c|}
\hline $\begin{array}{l}\text { Blinding of outcome as- } \\
\text { sessment (detection bias): } \\
\text { Subjective outcomes } \\
\text { (IPSS, HRQoL, IIEF-5, TUR }\end{array}$ & Unclear risk & Not reported \\
\hline
\end{tabular}


Wu 2005 (Continued)

syndrome, Urinary Inconti-

nence)

Blinding of outcome as- Low risk Not reported but objective outcomes unlikely to have been affected
sessment: Objective out-
comes (Blood transfusion,
Re-TURP)

\begin{tabular}{|c|c|c|}
\hline $\begin{array}{l}\text { Incomplete outcome da- } \\
\text { ta (attrition bias): Imme- }\end{array}$ & Low risk & $\begin{array}{l}\text { Study reports that all participants ( } \mathrm{n}=200 \text { in both arms) were included in } \\
\text { analyses for these perioperative outcomes }\end{array}$ \\
\hline
\end{tabular}

diate postoperative outanalyses for these perioperative outcomes

comes (TUR syndrome,

Blood transfusion)

Incomplete outcome data
(attrition bias): Long-term
outcomes (IPSS/HRQoL/
IIEF-5/urinary inconti-
nence at 12 months, and
re-TURP)

Unclear risk These outcomes were not reported

$\begin{array}{lll}\begin{array}{l}\text { Selective reporting (re- } \\ \text { porting bias): All outcomes }\end{array} & \text { Unclear risk } & \text { RCT protocol not available to allow for full assessment }\end{array}$

Xie 2012

\begin{tabular}{ll}
\hline Methods & Study type: single-centre randomised controlled trial (1:1) \\
& - Setting: China
\end{tabular}

\section{Participants}

- Total number enrolled: $220 ;(A)=110,(B)=110$

- Inclusion criteria: BPO, maximal flow rate $\left(\mathrm{Q}_{\max }\right)<15 \mathrm{~mL} / \mathrm{s}$, $>45$ years of age, prostate volume on transrectal ultrasound $>20 \mathrm{~g}$, medication ( $5 a$-reductase inhibitors or $\alpha$-blockers) failure

- Exclusion criteria: renal impairment, neurovesical dysfunction, bladder calculus, prostate carcinoma, previous history of prostatic or urethral surgery, urethral stricture, hydronephrosis

\section{Baseline characteristics:}

No significant difference between arms reported

Mean age, years (SD): $(A)=69.95(11.54),(B)=64.91(10.92)$

Mean preoperative prostate volume, $\mathrm{mL}(\mathrm{SD}):(\mathrm{A})=65.86(17.32),(B)=67.00(18.93)$

Preoperative catheterisation state: not reported

\begin{tabular}{ll}
\hline Interventions & Intervention A: bipolar TURP (Gyrus), irrigation fluid = saline \\
& - Intervention B: monopolar (Olympus), irrigation fluid = glycine $1.5 \%$
\end{tabular}

\section{Outcomes Primary outcomes:}

IPSS (12 months): $(A)=6.50 \pm 2.03^{\star}(n=n r),(B)=6.79 \pm 2.59^{\star}(n=n r)$

HRQoL (12 months): $(A)=2.15 \pm 0.58^{\star}(n=n r),(B)=2.56 \pm 0.97^{\star}(n=n r)$

TUR syndrome: $(A)=0(n=110),(B)=2(n=110)$

\section{Secondary outcomes:}

Blood transfusion: $(A)=0(n=110),(B)=2(n=110)$ 
Xie 2012 (Continued)

Urinary incontinence (12 months): reported only at 6 months

Erectile dysfunction (IIEF-5) (12 months): not reported

Need for repeat TURP (i.e. re-TURP): $(A)=3(n=n r),(B)=3(n=n r)$

Other reported outcomes:

IPSS at 24, 36, 48, 60 months ( $n=$ unclear except for 60 months)

HRQoL at 24, 36, 48, 60 months

$\mathrm{Q}_{\max }$ at $12,24,36,48,60$ months

Clot retention

Urethral stricture

Bladder neck stenosis

UTI

Acute urinary retention

Mean drop in sodium (mmol/L)

Mean drop in haemoglobin $(\mathrm{g} / \mathrm{dL})$

Mean operative time (minutes)

Postoperative irrigation time (hours)

Mean catheterisation duration (days)

Mean hospital stay (days)

Source of funding None reported

Notes

\section{Risk of bias}

\section{Bias}

Authors' judgement Support for judgement

Random sequence generation (selection bias): All

Low risk

"Randomization was performed using the opaque envelope method" outcomes

\begin{tabular}{ll}
\hline $\begin{array}{l}\text { Allocation concealment } \\
\text { (selection bias): All out- } \\
\text { comes }\end{array}$ & Low risk \\
\hline
\end{tabular}

comes

High risk

and personnel (performance bias): All outcomes

Blinding of outcome assessment (detection bias):

Subjective outcomes

(IPSS, HRQoL, IIEF-5, TUR syndrome, Urinary Incontinence)

High risk
Study states: "neither the patient nor the surgeon was blinded to the type of the procedure performed"
Study reports that patients were not blinded to allocated arm

Study states: "one independent investigator, who was blinded to the type of surgery, performed the 1-, 6-, 12-, 24-, 36-, 48-, and 60-month follow-ups"

Study authors considered that IPSS, HRQoL, IIEF-5, and urinary incontinence are primarily patient-reported symptoms

Bipolar versus monopolar transurethral resection of the prostate for lower urinary tract symptoms secondary to benign prostatic 
Xie 2012 (Continued)

Blinding of outcome as- Low risk "One independent investigator, who was blinded to the type of surgery, persessment: Objective outcomes (Blood transfusion, Re-TURP) formed the 1-, 6-, 12-, 24-, 36-, 48-, and 60-month follow-ups"

\section{Incomplete outcome da- ta (attrition bias): Imme- diate postoperative out- comes (TUR syndrome, Blood transfusion)}

Low risk

Study reports that all participants ( $n=110$ in each arm) were included in analyses for these outcomes

\author{
Incomplete outcome data Low risk \\ (attrition bias): Long-term \\ outcomes (IPSS/HRQoL/ \\ IIEF-5/urinary inconti- \\ nence at 12 months, and \\ re-TURP)
}

Study does not specifically report on completeness of outcome data nor loss to follow-up at 1 year for these outcomes - only at 5 years

\begin{tabular}{|c|c|}
\hline Methods & $\begin{array}{l}\text { - Study type: single-centre randomised controlled trial (1:1) } \\
\text { - Setting: China }\end{array}$ \\
\hline Participants & $\begin{array}{l}\text { Total participants enrolled: } 130 ;(A)=65,(B)=65 \\
\text { - Inclusion criteria: not reported } \\
\text { - Exclusion criteria: not reported } \\
\text { Baseline characteristics: } \\
\text { Not clear if significant differences reported between arms } \\
\text { Mean age (SD): not reported } \\
\text { Mean preoperative prostate volume (mL) (SD): not reported } \\
\text { Preoperative catheterisation status: not reported }\end{array}$ \\
\hline Interventions & $\begin{array}{l}\text { - Intervention A: bipolar TURP (Plasmakinetic TURP, Gyrus device) } \\
\text { - Intervention B: monopolar TURP, irrigation fluid = not reported }\end{array}$ \\
\hline Outcomes & $\begin{array}{l}\text { Primary outcomes: } \\
\text { IPSS (12 months): not reported } \\
\text { HRQoL ( } 12 \text { months): not reported } \\
\text { TUR syndrome: }(A)=0(n=65),(B)=3(n=65) \\
\text { Secondary outcomes: } \\
\text { Blood transfusion: not reported } \\
\text { Urinary incontinence (12 months): not reported } \\
\text { Erectile dysfunction (IIEF-5) ( } 12 \text { months): not reported }\end{array}$ \\
\hline
\end{tabular}

Bipolar versus monopolar transurethral resection of the prostate for lower urinary tract symptoms secondary to benign prostatic 134 obstruction (Review)

Copyright $\odot 2019$ The Cochrane Collaboration. Published by John Wiley \& Sons, Ltd. 
Xin 2007 (Continued)

Need for repeat TURP (i.e. re-TURP): not reported

\section{Other reported outcomes:}

Mean decrease in postoperative serum sodium (mmol/L)

Mean decrease in postoperative $\mathrm{Hb}$ (gram/L)

\begin{tabular}{ll}
\hline Source of funding & None reported \\
\hline Notes & This is a conference abstract with limited information
\end{tabular}

\section{Risk of bias}

\begin{tabular}{|c|c|c|}
\hline Bias & Authors' judgement & Support for judgement \\
\hline $\begin{array}{l}\text { Random sequence gener- } \\
\text { ation (selection bias): All } \\
\text { outcomes }\end{array}$ & Unclear risk & Not reported \\
\hline $\begin{array}{l}\text { Allocation concealment } \\
\text { (selection bias): All out- } \\
\text { comes }\end{array}$ & Unclear risk & Not reported \\
\hline $\begin{array}{l}\text { Blinding of participants } \\
\text { and personnel (perfor- } \\
\text { mance bias): All outcomes }\end{array}$ & High risk & Not reported but considered unlikely that operating surgeon(s) were blinded \\
\hline $\begin{array}{l}\text { Blinding of outcome as- } \\
\text { sessment: Objective out- } \\
\text { comes (Blood transfusion, } \\
\text { Re-TURP) }\end{array}$ & Unclear risk & These outcomes were not reported \\
\hline $\begin{array}{l}\text { Incomplete outcome da- } \\
\text { ta (attrition bias): Imme- } \\
\text { diate postoperative out- } \\
\text { comes (TUR syndrome, } \\
\text { Blood transfusion) }\end{array}$ & Low risk & $\begin{array}{l}\text { This study does not explicitly report on attrition, exclusion of participants from } \\
\text { analyses, or the presence of incomplete outcome data for these outcomes }\end{array}$ \\
\hline $\begin{array}{l}\text { Incomplete outcome data } \\
\text { (attrition bias): Long-term } \\
\text { outcomes (IPSS/HRQoL/ } \\
\text { IIEF-5/urinary inconti- } \\
\text { nence at } 12 \text { months, and } \\
\text { re-TURP) }\end{array}$ & Unclear risk & These outcomes were not reported \\
\hline
\end{tabular}




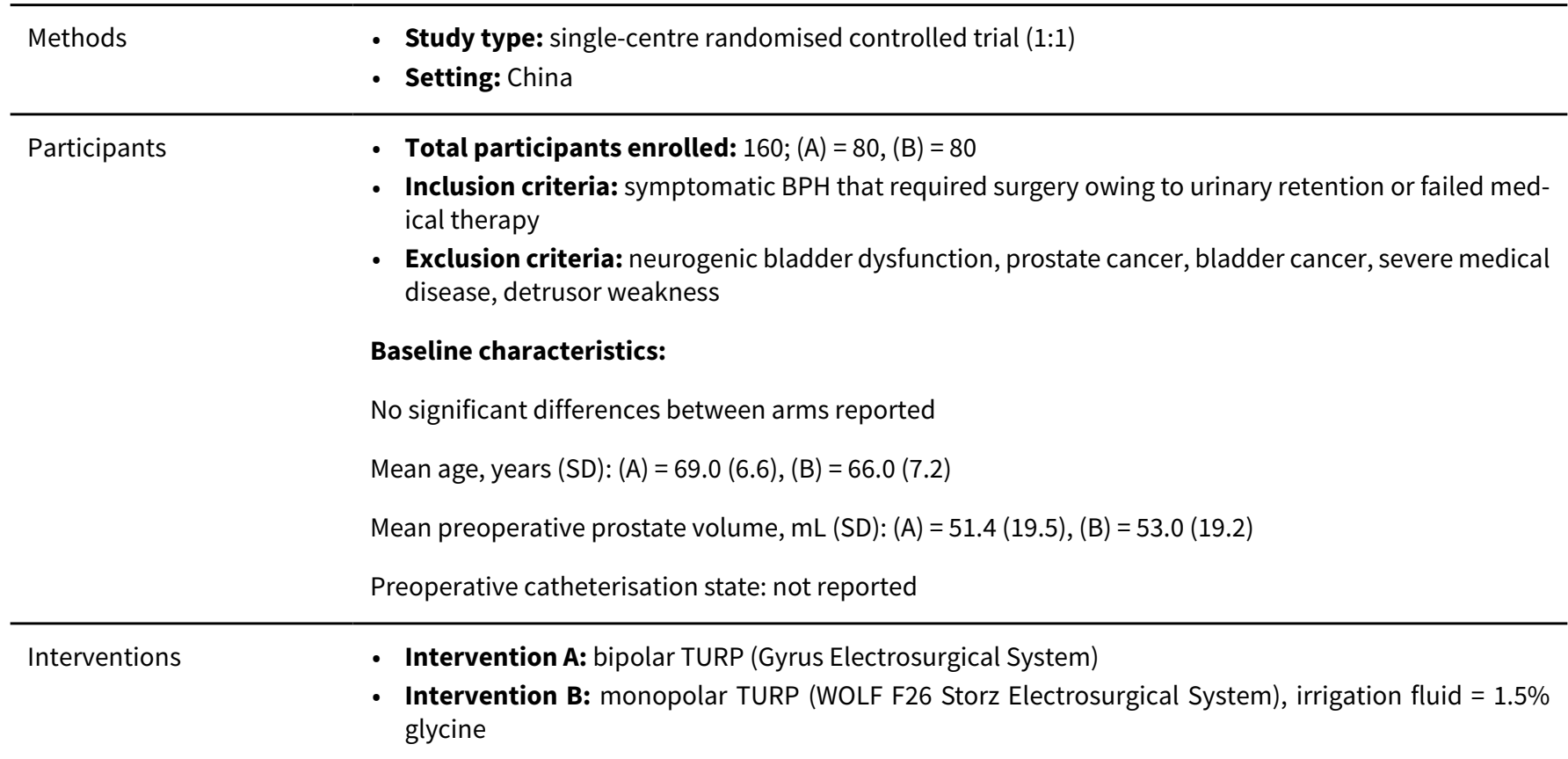

\section{Outcomes}

\section{Primary outcomes:}

IPSS (12 months): reported only at 6 months

HRQoL (12 months): reported only at 6 months

TUR syndrome: $(A)=0(n=76),(B)=5(n=77)$

\section{Secondary outcomes:}

Blood transfusion: $(A)=2(n=76),(B)=13(n=77)$

Urinary incontinence (12 months): reported only at 6 months

Erectile dysfunction (IIEF-5) (12 months): not reported

Need for repeat TURP (i.e. re-TURP): not reported

\section{Other reported outcomes:}

Mean $\mathrm{Q}_{\max }(\mathrm{mL} / \mathrm{s})$ (6 months)

Urethral stricture

Mean duration of catheterisation (days)

Mean duration of hospital stay (days)

Source of funding None reported

\section{Notes}

\section{Risk of bias}

Bias Authors' judgement Support for judgement


Xin 2009 (Continued)

Random sequence gener- Unclear risk Not reported
ation (selection bias): All
outcomes

Allocation concealment $\quad$ Unclear risk $\quad$ Not reported
(selection bias): All out-
comes

\begin{tabular}{lll}
\hline $\begin{array}{l}\text { Blinding of participants } \\
\text { and personnel (perfor- } \\
\text { mance bias): All outcomes }\end{array}$ & High risk & Not reported but considered unlikely that operating surgeon(s) were blinded \\
\hline $\begin{array}{l}\text { Blinding of outcome as- } \\
\text { sessment (detection bias): }\end{array}$ & Unclear risk & Not reported \\
Subjective outcomes & \\
(IPSS, HRQoL, IlEF-5, TUR & \\
syndrome, Urinary Inconti- \\
nence)
\end{tabular}

Blinding of outcome as- Low risk Not reported but objective outcomes unlikely to have been affected sessment: Objective outcomes (Blood transfusion, Re-TURP)

\begin{tabular}{|c|c|c|}
\hline $\begin{array}{l}\text { Incomplete outcome da- } \\
\text { ta (attrition bias): Imme- } \\
\text { diate postoperative out- } \\
\text { comes (TUR syndrome, } \\
\text { Blood transfusion) }\end{array}$ & Low risk & $\begin{array}{l}\text { Study reports that all participants ( } n=76 \text { in bipolar and } n=77 \text { in monopolar } \\
\text { arm) have been included in the analyses for these outcomes }\end{array}$ \\
\hline $\begin{array}{l}\text { Incomplete outcome data } \\
\text { (attrition bias): Long-term } \\
\text { outcomes (IPSS/HRQoL/ } \\
\text { IIEF-5/urinary inconti- } \\
\text { nence at } 12 \text { months, and } \\
\text { re-TURP) }\end{array}$ & Unclear risk & These outcomes were not reported \\
\hline
\end{tabular}

$\begin{array}{lll}\text { Selective reporting (re- } & \text { Unclear risk } & \text { RCT protocol not available to allow for full assessment } \\ \text { porting bias): All outcomes }\end{array}$

porting bias): All outcomes

Xue 2008

\begin{tabular}{ll}
\hline Methods & Study type: single-centre randomised controlled trial (1:1) \\
- Setting: China & - Total participants enrolled: $64 ;(A)=32,(B)=32$ \\
- Inclusion criteria: symptomatic BPH that required surgery owing to urinary retention or failed med- \\
ical therapy \\
- Exclusion criteria: neurogenic bladder dysfunction, prostate cancer \\
Baseline characteristics: \\
No significant differences between arms reported \\
Mean age, years (range): (A) = 69.5 (55 to 84), (B) $=68.2$ (53 to 84$)$ \\
Mean preoperative prostate volume, $\mathrm{mL}$ (range): (A) =54.4 (30 to 102$),(\mathrm{B})=53.6$ (36 to 92$)$
\end{tabular}

Bipolar versus monopolar transurethral resection of the prostate for lower urinary tract symptoms secondary to benign prostatic 
Xue 2008 (Continued)

Preoperative catheterisation state: 2 in group A were catheterised for retention

$\begin{array}{ll}\text { Interventions } & \text { - Intervention A: bipolar TURP (Gyrus Electrosurgical System) } \\ & \text { - Intervention B: monopolar TURP (WOLF Electrosurgical System), irrigation fluid }=1.5 \% \text { glycine }\end{array}$

Outcomes

Primary outcomes:

IPSS (12 months): not reported

HRQoL (12 months): not reported

TUR syndrome: $(A)=0(n=32),(B)=1(n=32)$

\section{Secondary outcomes:}

Blood transfusion: $(A)=0(n=32),(B)=3(n=32)$

Urinary incontinence (12 months): reported only at 6 months

Erectile dysfunction (IIEF-5) (12 months): not reported

Need for repeat TURP (i.e. re-TURP): not reported

\section{Other reported outcomes:}

IPSS: reported at 3 months, results for 6 and 12 months only reported in graphical format

QoL reported at 3 months only

Mean $\mathrm{Q}_{\max }(\mathrm{mL} / \mathrm{s})$

Mean duration of operation (minutes)

Mean duration of catheterisation (days)

Mean duration of hospital stay (days)

Mean change in postoperative serum sodium $(\mathrm{Na}+)(\mathrm{mEq} / \mathrm{L})$

Mean reduction in postoperative haemoglobin $(\mathrm{Hb})(\mathrm{g} / \mathrm{dL})$

Source of funding None reported

Notes

\section{Risk of bias}

\begin{tabular}{lll}
\hline Bias & Authors' judgement & Support for judgement \\
\hline $\begin{array}{l}\text { Random sequence gener- } \\
\text { ation (selection bias): All } \\
\text { outcomes }\end{array}$ & Unclear risk & Not reported \\
\hline $\begin{array}{l}\text { Allocation concealment } \\
\text { (selection bias): All out- } \\
\text { comes }\end{array}$ & Unclear risk & Not reported \\
\hline $\begin{array}{l}\text { Blinding of participants } \\
\text { and personnel (perfor- } \\
\text { mance bias): All outcomes }\end{array}$ & High risk & Not reported but considered unlikely that operating surgeon(s) were blinded \\
\hline $\begin{array}{l}\text { Blinding of outcome as- } \\
\text { sessment (detection bias): }\end{array}$ & Unclear risk & Not reported \\
\hline
\end{tabular}

Bipolar versus monopolar transurethral resection of the prostate for lower urinary tract symptoms secondary to benign prostatic 
Xue 2008 (Continued)

Subjective outcomes

(IPSS, HRQoL, IIEF-5, TUR

syndrome, Urinary Inconti-

nence)

\section{Blinding of outcome as-} sessment: Objective out-

\begin{tabular}{|c|c|c|}
\hline $\begin{array}{l}\text { Incomplete outcome da- } \\
\text { ta (attrition bias): Imme- } \\
\text { diate postoperative out- } \\
\text { comes (TUR syndrome, } \\
\text { Blood transfusion) }\end{array}$ & Low risk & $\begin{array}{l}\text { Study reports that all participants }(n=32 \text { in bipolar and } n=32 \text { in monopolar } \\
\text { arm) have been included in analyses for these outcomes }\end{array}$ \\
\hline
\end{tabular}

Incomplete outcome data Unclear risk These outcomes were not reported
(attrition bias): Long-term
outcomes (IPSS/HRQoL/
IIEF-5/urinary inconti-
nence at 12 months, and
re-TURP)

$\begin{aligned} & \text { Selective reporting (re- } \\ & \text { porting bias): All outcomes }\end{aligned}$
Unclear risk

\section{Yang 2004}

$\begin{array}{ll}\text { Methods } & \text { - Study type: single-centre randomised controlled trial }(1: 1) \\ & \text { - Setting: Taiwan }\end{array}$

- Setting: Taiwan

Participants Total number enrolled: $117 ;(A)=58,(B)=59$

- Inclusion criteria: confirmed bladder outlet obstruction caused by BPH and about to undergo surgical management (TURP); high PSA but with significant comorbid disease or old age not suitable or unwilling to undergo radical surgery

- Exclusion criteria: medical history suggesting little or no improvement in voiding symptoms after surgical management

\section{Baseline characteristics:}

No significant differences between arms reported

Mean age, years (SD): not reported

Mean preoperative prostate volume, $\mathrm{mL}(\mathrm{SD}):(A)=45.8(n=58),(B)=48.9(n=59)$

Preoperative catheterisation state: not reported

$\begin{array}{ll}\text { Interventions } & \text { Intervention A: bipolar TURP (Gyrus Plasmasect), irrigation fluid = normal saline } \\ \text { - Intervention B: monopolar TURP, irrigation fluid = distilled water }\end{array}$

\section{Outcomes}

\section{Primary outcomes:}

IPSS (12 months): not reported

HRQoL (12 months): not reported

TUR syndrome: $(A)=0(n=58),(B)=1(n=59)$ 
Yang 2004 (Continued)

\section{Secondary outcomes:}

Blood transfusion: $(A)=1(n=58),(B)=1(n=59)$

Urinary incontinence (12 months): not reported specifically at 12 months

Erectile dysfunction (IIEF-5) (12 months): not reported specifically at 12 months

Need for repeat TURP (i.e. re-TURP): not reported

Other reported outcomes:

IPSS at 3 months

QoL at 3 months

$\mathrm{Q}_{\max }(\mathrm{mL} / \mathrm{s})$

IIEF-5 at 3 months

Urethral stricture

Acute urinary retention

Mean drop in postoperative haemoglobin $(\mathrm{g} / \mathrm{dL})$

Mean drop in postoperative $\mathrm{Na}(\mathrm{mEq} / \mathrm{L})$

Frequency of retrograde ejaculation

Mean duration of operation (minutes)

Mean duration of irrigation (hours)

Mean duration of catheterisation (days)

Mean duration of hospital stay (days)

Source of funding None reported

Notes

\section{Risk of bias}

Bias Authors' judgement Support for judgement

Random sequence gener- Unclear risk Not reported
ation (selection bias): All outcomes

Allocation concealment $\quad$ Unclear risk Not reported
(selection bias): All out-
comes

\begin{tabular}{lll}
\hline $\begin{array}{l}\text { Blinding of participants } \\
\text { and personnel (perfor- } \\
\text { mance bias): All outcomes }\end{array}$ & High risk & Not reported \\
\hline $\begin{array}{l}\text { Blinding of outcome as- } \\
\text { sessment (detection bias): }\end{array}$ & Unclear risk & Not reported \\
$\begin{array}{l}\text { Subjective outcomes } \\
\text { (IPSS, HRQOL, IIEF-5, TUR }\end{array}$ & \\
\hline
\end{tabular}


Yang 2004 (Continued) syndrome, Urinary Incontinence)

Blinding of outcome as- Low risk Not reported but objective outcomes unlikely to have been affected
sessment: Objective out-
comes (Blood transfusion,
Re-TURP)

\begin{tabular}{|c|c|c|}
\hline $\begin{array}{l}\text { Incomplete outcome da- } \\
\text { ta (attrition bias): Imme- } \\
\text { diate postoperative out- } \\
\text { comes (TUR syndrome, } \\
\text { Blood transfusion) }\end{array}$ & Unclear risk & $\begin{array}{l}\text { This study does not explicitly report on attrition, exclusion of participants from } \\
\text { analyses, or the presence of incomplete outcome data for these outcomes }\end{array}$ \\
\hline
\end{tabular}

\begin{tabular}{|c|c|c|}
\hline $\begin{array}{l}\text { Incomplete outcome data } \\
\text { (attrition bias): Long-term } \\
\text { outcomes (IPSS/HRQoL/ } \\
\text { IIEF-5/urinary inconti- } \\
\text { nence at } 12 \text { months, and } \\
\text { re-TURP) }\end{array}$ & Unclear risk & These outcomes were not reported \\
\hline $\begin{array}{l}\text { Selective reporting (re- } \\
\text { porting bias): All outcomes }\end{array}$ & Unclear risk & $\mathrm{RCT}$ protocol could not be identified to allow for full assessment \\
\hline
\end{tabular}

Yousef 2010

\begin{tabular}{ll}
\hline Methods & Study type: single-centre, single-blinded RCT $(1: 1: 1)$ \\
& - Setting: Tanta, Egypt \\
\hline Participants & Total number enrolled: $360 ;(A)=120,(B)=120,(C)=120$ \\
- Inclusion criteria: symptomatic BPH & Exclusion criteria: bleeding disorders or existing coagulopathy, diabetes mellitus, metabolic acido- \\
& sis, apparent cardiac disease with ECG evidence of ischaemia, history of myocardial infarction/con- \\
& gestive cardiac failure, renal insufficiency, contraindication to spinal anaesthesia
\end{tabular}

\title{
Baseline characteristics:
}

No significant differences between arms reported

Mean age, years (SD): $(A)=62(6.5),(B)=60.7(5.1),(C)=60.9(4.9)$

Mean preoperative prostate volume, grams (SD): not reported

Preoperative catheterisation state: not reported

\begin{tabular}{ll}
\hline Interventions & Intervention A: bipolar TURP (Storez, Tottling, Germany), irrigation fluid = normal saline \\
& - Intervention B: monopolar TURP (Storez, Tottling, Germany), irrigation fluid = glycine $1.5 \%$ \\
& - Intervention C: monopolar TURP (Storez, Tottling, Germany), irrigation fluid $=$ glucose $5 \%$ \\
\hline
\end{tabular}

Outcomes

\author{
Primary outcomes: \\ IPSS (12 months): not reported \\ HRQoL (12 months): not reported \\ TUR syndrome: $(A)=0(n=120)(B)=17(n=240)$
}

\section{Secondary outcomes:}

Bipolar versus monopolar transurethral resection of the prostate for lower urinary tract symptoms secondary to benign prostatic obstruction (Review)

Copyright (c) 2019 The Cochrane Collaboration. Published by John Wiley \& Sons, Ltd. 
Yousef 2010 (Continued)

Blood transfusion: $(A)=0(n=120),(B)=4(n=240)$

Urinary incontinence (12 months): not reported

Erectile dysfunction (IIEF-5) (12 months): not reported

Need for repeat TURP (i.e. re-TURP): not reported

Other reported outcomes:

Clot retention

Acute urinary retention

Mean duration of operation

Mean duration of postoperative catheterisation

Mean duration of hospital stay

Serum sodium level change

Haemoglobin level change

\begin{tabular}{ll}
\hline Source of funding & None reported \\
\hline Notes & Protocol is available at http://www.pactr.org/ATMWeb/appmanager/atm/atmregistry?_nfp- \\
b=true\&_windowLabel=BasicSearchUpdateController_1\&BasicSearchUpdateController_1_ac- \\
tionOverride=\%2Fpageflows\%2Ftrial\%2FbasicSearchUpdate\%2FviewTrail\&BasicSearchUpdateCon- \\
troller_1id=179 \\
"A Randomized Comparison Between Three Types of Irrigating Fluids During Transurethral Resection in \\
Benign Prostatic Hyperplasia" (PACT Registry ID: ATMR2010010001793131)
\end{tabular}

\section{Risk of bias}

Bias Authors' judgement Support for judgement

Random sequence gener- Low risk
ation (selection bias): All outcomes

"Simple randomisation using a randomisation table created by a computer software program" (as stated in the protocol)

"Randomization was performed by computer-generated random allocations sequence by simple randomization" (Yousef 2010)

Allocation concealment Unclear risk Steps taken to ensure allocation concealment are not reported explicitly
(selection bias): All out-
comes

Blinding of participants High risk Not reported but considered unlikely that operating surgeon(s) were blinded and personnel (performance bias): All outcomes

\begin{tabular}{|c|c|c|}
\hline $\begin{array}{l}\text { Blinding of outcome as- } \\
\text { sessment (detection bias): } \\
\text { Subjective outcomes } \\
\text { (IPSS, HRQoL, IIEF-5, TUR } \\
\text { syndrome, Urinary Inconti- } \\
\text { nence) }\end{array}$ & Unclear risk & $\begin{array}{l}\text { Study states: "the medical and nursing stuff involved in patients care, monitor- } \\
\text { ing in the post-operative period and assessment of the complications and the } \\
\text { incidence and the severity of } \\
\text { TUR syndrome were completely blinded to the patient's group assignment } \\
\text { and the type irrigating fluid used" (Yousef 2010) } \\
\text { However, not reported whether patients were blinded to interventions }\end{array}$ \\
\hline
\end{tabular}

Blinding of outcome as- Low risk Not reported but objective outcomes unlikely to have been affected sessment: Objective out- 
Yousef 2010 (Continued)

comes (Blood transfusion, Re-TURP)

\begin{tabular}{|c|c|c|}
\hline $\begin{array}{l}\text { Incomplete outcome da- } \\
\text { ta (attrition bias): Imme- } \\
\text { diate postoperative out- } \\
\text { comes (TUR syndrome, } \\
\text { Blood transfusion) }\end{array}$ & Low risk & $\begin{array}{l}\text { Study reports that all participants ( } n=120 \text { in each trial arm) were included in } \\
\text { analyses for these outcomes }\end{array}$ \\
\hline $\begin{array}{l}\text { Incomplete outcome data } \\
\text { (attrition bias): Long-term } \\
\text { outcomes (IPSS/HRQoL/ } \\
\text { IIEF-5/urinary inconti- } \\
\text { nence at } 12 \text { months, and } \\
\text { re-TURP) }\end{array}$ & Unclear risk & These outcomes were not reported \\
\hline $\begin{array}{l}\text { Selective reporting (re- } \\
\text { porting bias): All outcomes }\end{array}$ & Unclear risk & RCT protocol not available to allow for full assessment \\
\hline
\end{tabular}

ASA: American Society of Anesthesiology.

AUA: American Urological Association.

AUASS: AUA Symptom Score.

BEP: benign enlargement of the prostate.

BOO: bladder outlet obstruction.

BPE: benign prostatic enlargement.

$\mathrm{BPH}$ : benign prostatic hyperplasia.

BTURP: bipolar transurethral resection of the prostate.

DRE: digital rectal examination.

HRQoL: health-related quality of life.

IIEF-5: International Index of Erectile Function.

IPSS: International Prostate Symptoms Score.

LUTS: lower urinary tract symptoms.

MTURP: monopolar transurethral resection of the prostate.

PMR: postmicturition residual.

PSA: prostate-specific antigen.

PVR: postvoid residual.

$\mathrm{Q}_{\max }$ : maximum urinary flow rate.

QoL: quality of life.

$\mathrm{RCT}$ : randomised controlled trial.

SD: standard deviation.

TRUS: transrectal ultrasound.

TUR: transurethral resection.

TURP: transurethral resection of the prostate.

UTI: urinary tract infection.

Characteristics of excluded studies [ordered by study ID]

\begin{tabular}{ll}
\hline Study & Reason for exclusion \\
\hline Demir 2015 & Quasi-randomisation process used \\
\hline El Saied Hafez 2013 & Quasi-randomisation process used \\
\hline Engeler 2010 & Not an RCT \\
\hline Fung 2005 & This study is an RCT that compares MTURP vs bipolar vaporesection instead of BTURP alone \\
\hline
\end{tabular}

Bipolar versus monopolar transurethral resection of the prostate for lower urinary tract symptoms secondary to benign prostatic 


\begin{tabular}{|c|c|}
\hline Study & Reason for exclusion \\
\hline Inzuna 2017 & Not an RCT \\
\hline Kwon 2011 & Not an RCT \\
\hline Liangyu 2006 & $\begin{array}{l}\text { No evidence of randomisation (article translated in English from Chinese language using Google } \\
\text { translator (https://translate.google.gr/) after appropriate conversion of pdf into word file (http:// } \\
\text { www.onlineocr.net) }\end{array}$ \\
\hline Lv 2012 & No evidence of randomisation \\
\hline Michielsen 2010b & No evidence of randomisation \\
\hline Michielsen 2011 & No evidence of randomisation \\
\hline Muslumanoglu 2012 & $\begin{array}{l}\text { This is an extension of Tefekli 2005. This study is an RCT that compares MTURP with a combination } \\
\text { of bipolar transurethral vaporisation and BTURP (hybrid technique) instead of BTURP alone (see } \\
\text { below) }\end{array}$ \\
\hline Neyer 2011 & Not an RCT \\
\hline Tefekli 2005 & $\begin{array}{l}\text { This study is an RCT that compares MTURP with a combination of bipolar transurethral vaporisa- } \\
\text { tion and BTURP (hybrid technique) instead of BTURP alone }\end{array}$ \\
\hline Treharne 2018 & Not an RCT \\
\hline Valdivia Uría 2005 & Not an RCT \\
\hline Vasudeva 2019 & Not an RCT \\
\hline Yoon 2006 & No evidence of randomisation \\
\hline Zhang 2013 & Not an RCT \\
\hline
\end{tabular}

BTURP: bipolar transurethral resection of the prostate.

MTURP: monopolar transurethral resection of the prostate.

RCT: randomised controlled trial.

\section{DATA AND ANALYSES}

\section{Comparison 1. BTURP versus MTURP}

\begin{tabular}{lllll}
\hline Outcome or subgroup title & $\begin{array}{l}\text { No. of } \\
\text { studies }\end{array}$ & $\begin{array}{l}\text { No. of } \\
\text { partici- } \\
\text { pants }\end{array}$ & Statistical method & Effect size \\
\hline $\begin{array}{l}1 \text { Urological symptoms (IPSS at 12 } \\
\text { months) }\end{array}$ & 16 & 2531 & $\begin{array}{l}\text { Mean Difference (IV, Random, 95\% } \\
\text { CI) }\end{array}$ & $-0.24[-0.39,-0.09]$ \\
\hline 2 Bother (HRQoL at 12 months) & 11 & 2004 & $\begin{array}{l}\text { Mean Difference (IV, Random, 95\% } \\
\text { CI) }\end{array}$ & $-0.12[-0.25,0.02]$ \\
\hline 3 TUR syndrome & 44 & 6745 & Risk Ratio (M-H, Random, 95\% Cl) & $0.17[0.09,0.30]$ \\
\hline
\end{tabular}




\begin{tabular}{llllll}
\hline Outcome or subgroup title & $\begin{array}{l}\text { No. of } \\
\text { studies }\end{array}$ & $\begin{array}{l}\text { No. of } \\
\text { partici- } \\
\text { pants }\end{array}$ & Statistical method & Effect size \\
\hline 4 Urinary incontinence at 12 months & 4 & 751 & Risk Ratio (M-H, Random, 95\% Cl) & $0.20[0.01,4.06]$ \\
\hline 5 Blood transfusion & 38 & 5727 & Risk Ratio (M-H, Random, 95\% Cl) & $0.42[0.30,0.59]$ \\
\hline 6 Re-TURP & 6 & 652 & Risk Ratio (M-H, Random, 95\% Cl) & $1.02[0.44,2.40]$ \\
\hline $\begin{array}{l}7 \text { Erectile function (IIEF-5 score at 12 } \\
\text { months) }\end{array}$ & 3 & 321 & $\begin{array}{l}\text { Mean Difference (IV, Random, 95\% } \\
\text { Cl) }\end{array}$ & $0.88[-0.56,2.32]$ \\
\hline
\end{tabular}

Analysis 1.1. Comparison 1 BTURP versus MTURP, Outcome 1 Urological symptoms (IPSS at 12 months).

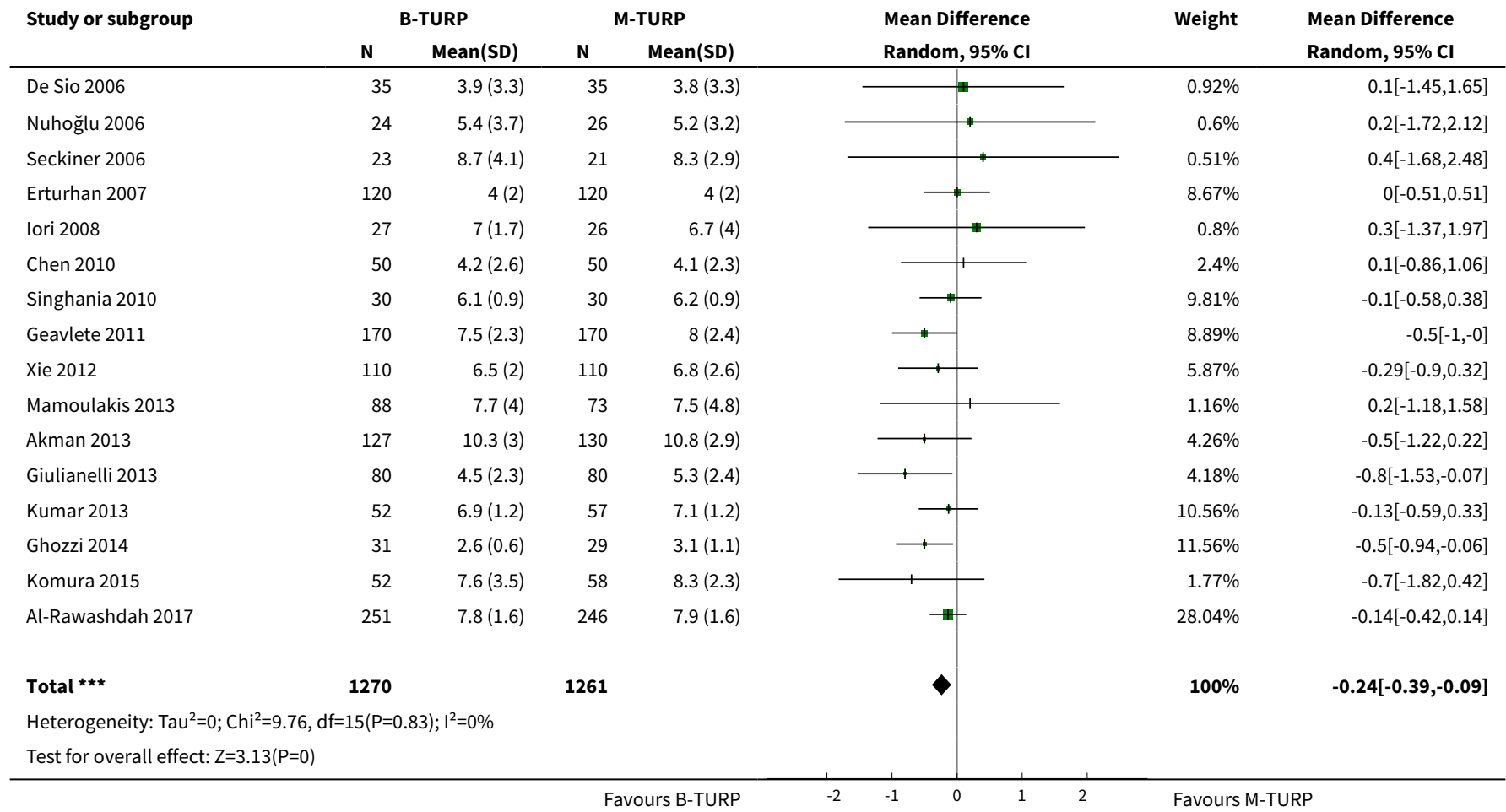

Analysis 1.2. Comparison 1 BTURP versus MTURP, Outcome 2 Bother (HRQoL at 12 months).

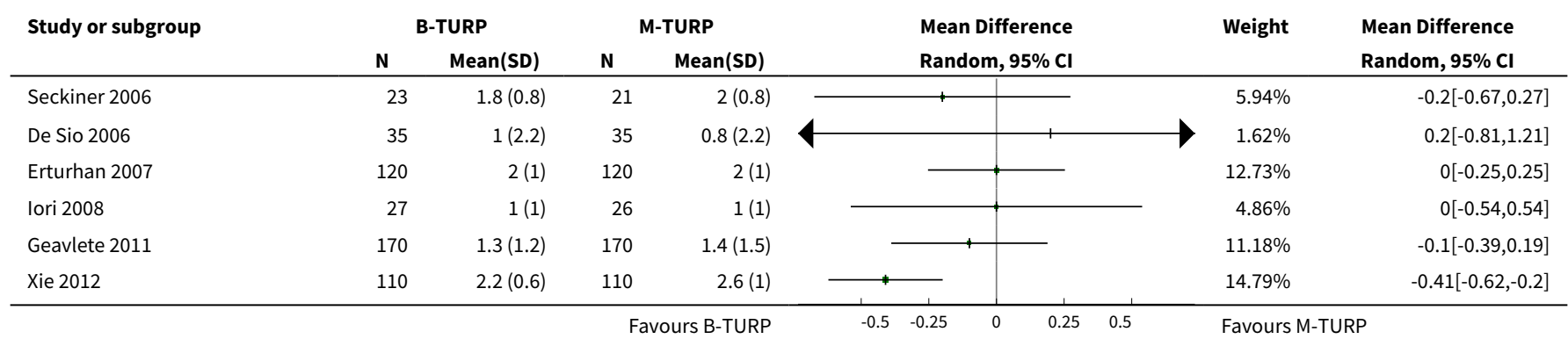




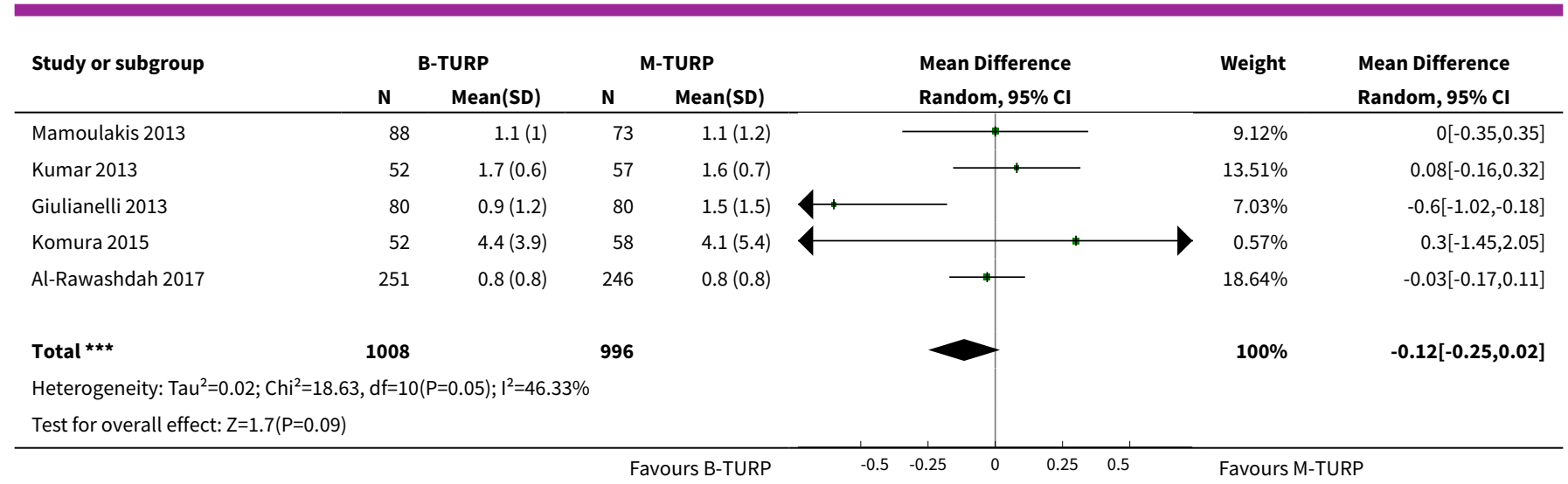

Analysis 1.3. Comparison 1 BTURP versus MTURP, Outcome 3 TUR syndrome.

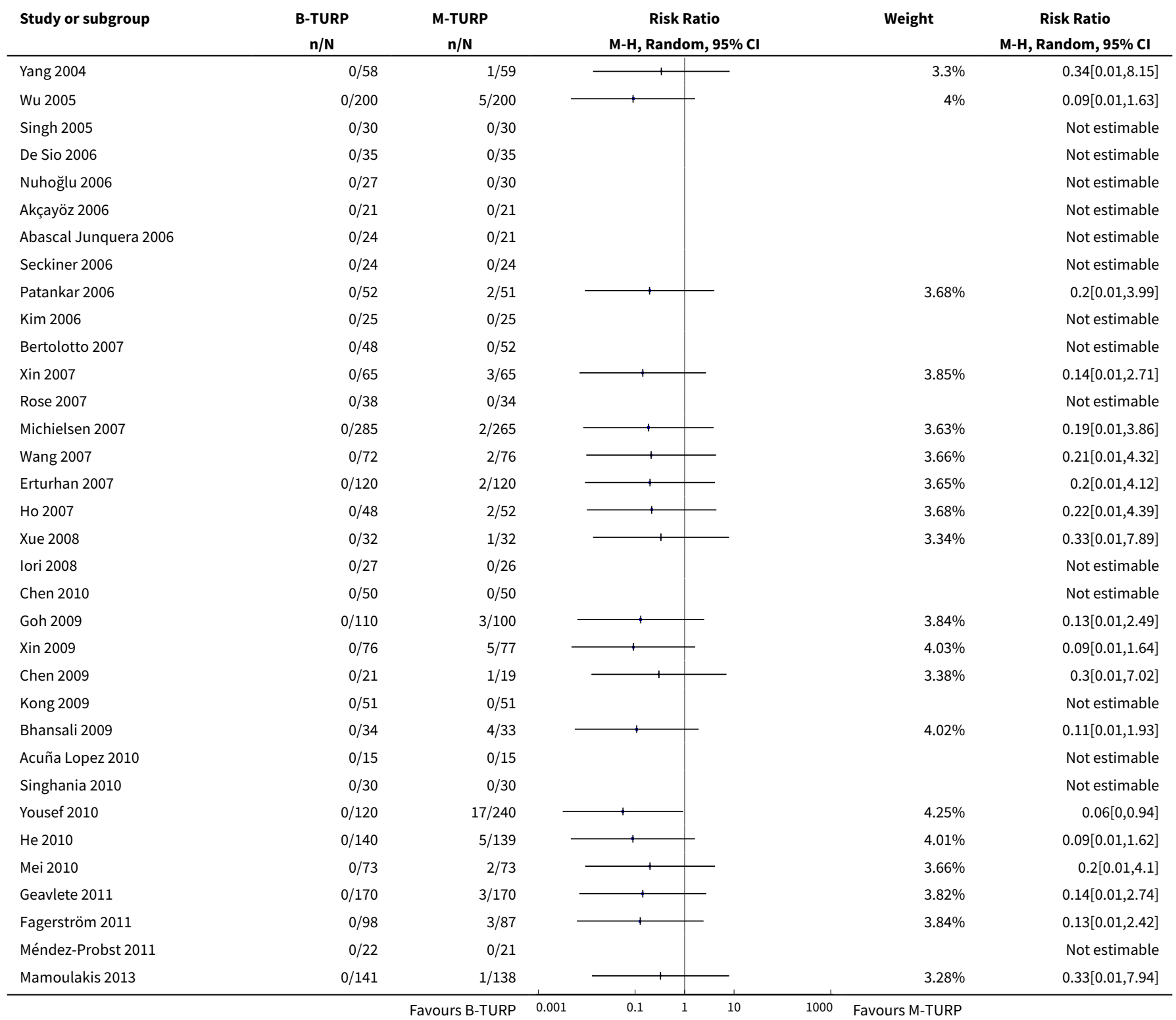




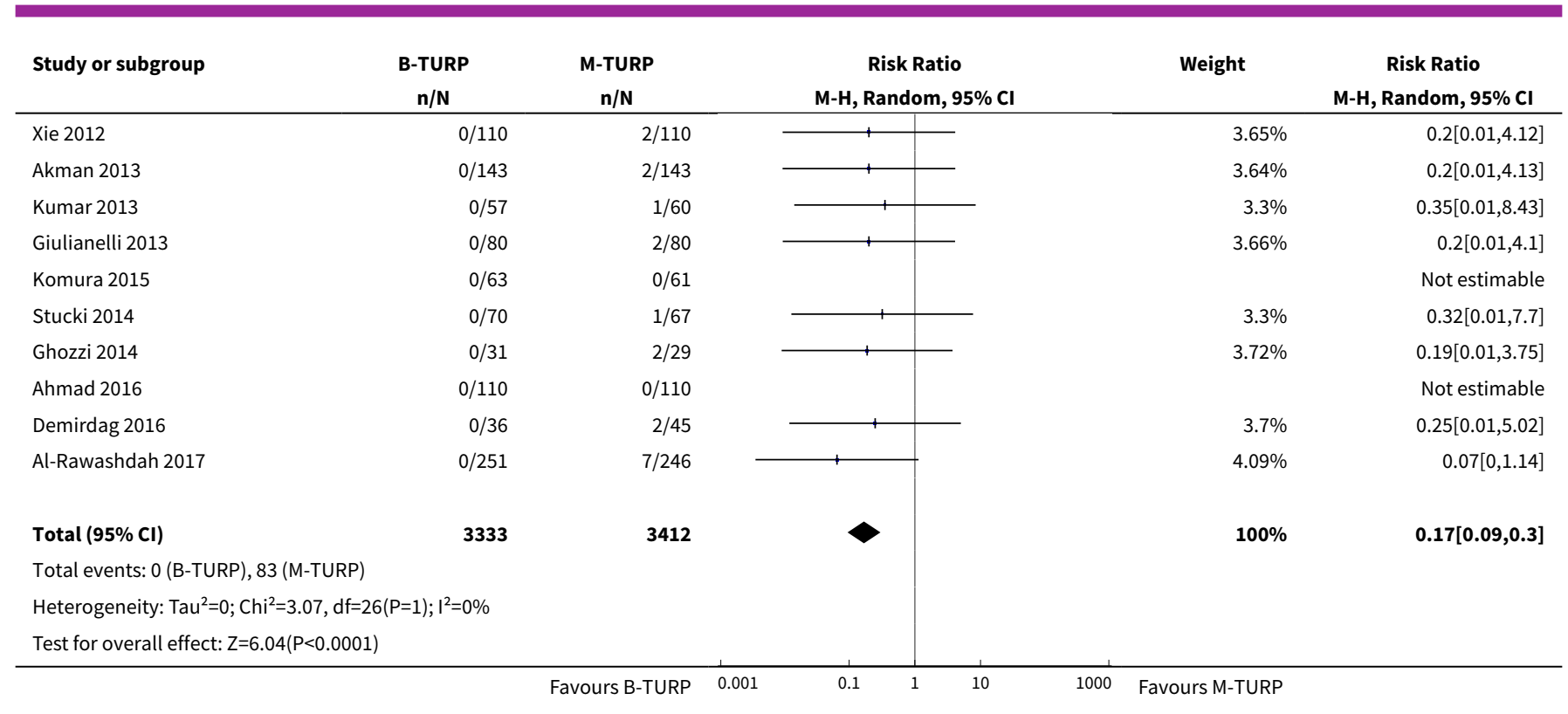

Analysis 1.4. Comparison 1 BTURP versus MTURP, Outcome 4 Urinary incontinence at 12 months.

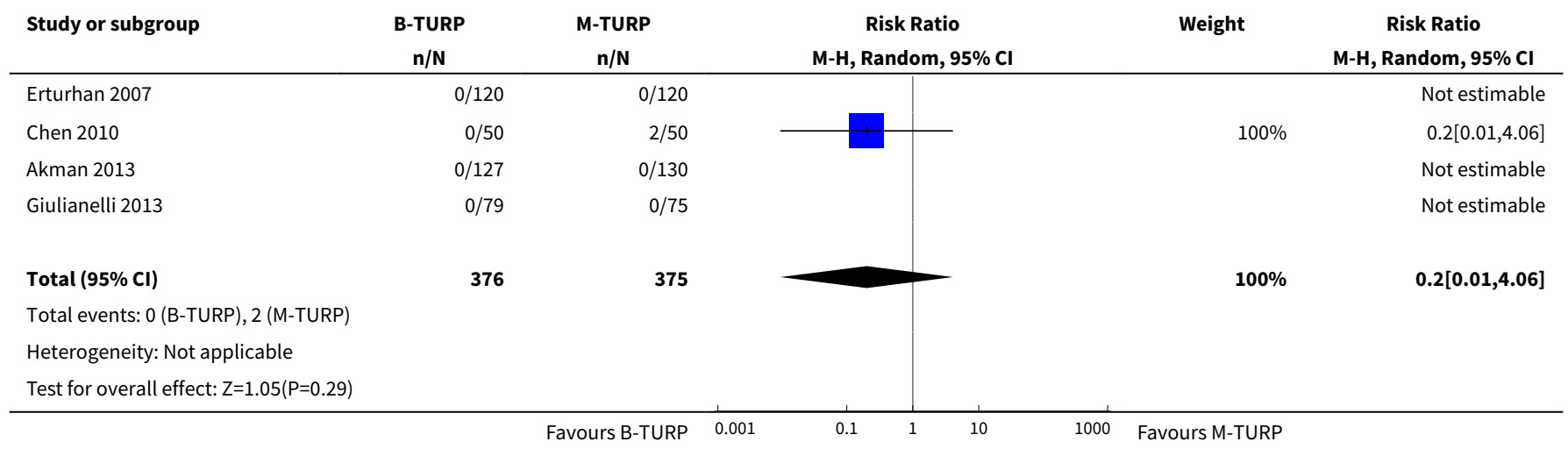

Analysis 1.5. Comparison 1 BTURP versus MTURP, Outcome 5 Blood transfusion.

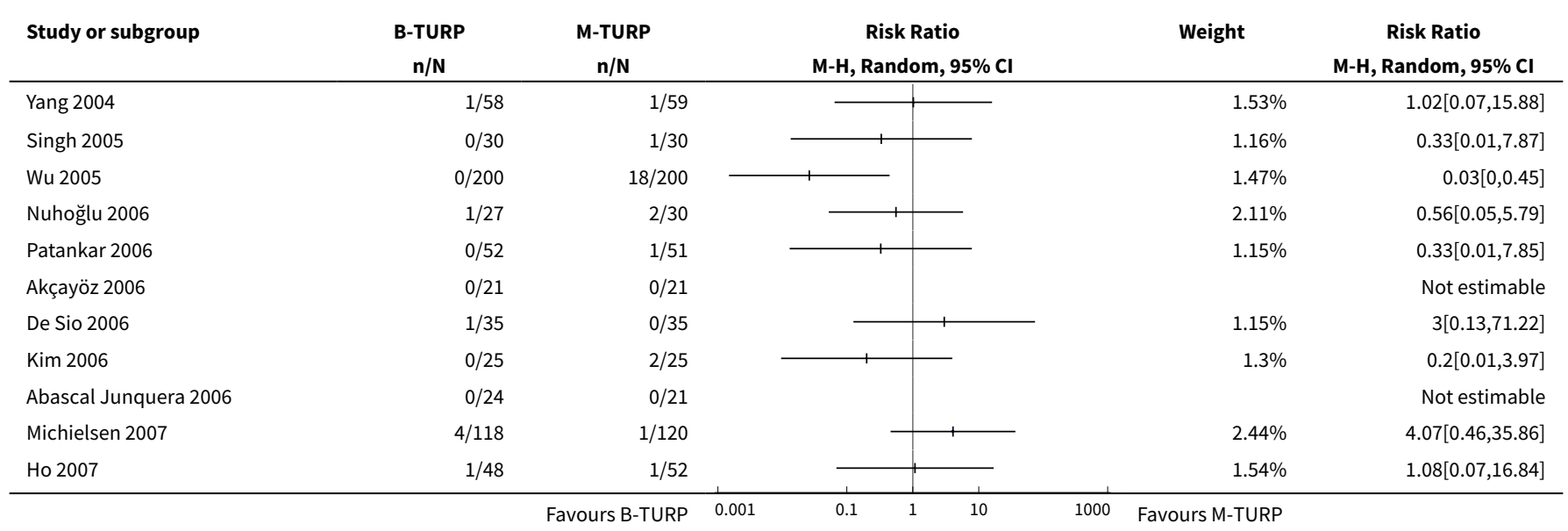




\begin{tabular}{|c|c|c|c|c|c|}
\hline Study or subgroup & $\begin{array}{c}\text { B-TURP } \\
n / N\end{array}$ & $\begin{array}{c}\text { M-TURP } \\
n / N\end{array}$ & $\begin{array}{c}\text { Risk Ratio } \\
\text { M-H, Random, 95\% Cl }\end{array}$ & Weight & $\begin{array}{c}\text { Risk Ratio } \\
\text { M-H, Random, } 95 \% \mathrm{Cl}\end{array}$ \\
\hline Erturhan 2007 & $1 / 120$ & $7 / 120$ & 1 & $2.68 \%$ & $0.14[0.02,1.14]$ \\
\hline Iori 2008 & $0 / 27$ & $0 / 26$ & & & Not estimable \\
\hline Xue 2008 & $0 / 32$ & $3 / 32$ & \begin{tabular}{l|l} 
& \\
\end{tabular} & $1.35 \%$ & $0.14[0.01,2.66]$ \\
\hline Bhansali 2009 & $2 / 34$ & $7 / 33$ & $\longrightarrow$ & $5.17 \%$ & $0.28[0.06,1.24]$ \\
\hline Chen 2010 & $1 / 50$ & $3 / 50$ & - & $2.33 \%$ & $0.33[0.04,3.1]$ \\
\hline Chen 2009 & $1 / 21$ & $3 / 19$ & \begin{tabular}{l|l}
1 & \\
\end{tabular} & $2.44 \%$ & $0.3[0.03,2.66]$ \\
\hline Kong 2009 & $0 / 51$ & $2 / 51$ & & $1.28 \%$ & $0.2[0.01,4.07]$ \\
\hline Xin 2009 & $2 / 76$ & $13 / 77$ & 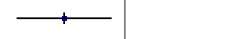 & $5.47 \%$ & $0.16[0.04,0.67]$ \\
\hline Singhania 2010 & $0 / 30$ & $0 / 30$ & & & Not estimable \\
\hline He 2010 & $1 / 142$ & $3 / 139$ & - & $2.29 \%$ & $0.33[0.03,3.1]$ \\
\hline Yousef 2010 & $0 / 120$ & $4 / 240$ & & $1.36 \%$ & $0.22[0.01,4.08]$ \\
\hline Acuña Lopez 2010 & $0 / 15$ & $0 / 15$ & & & Not estimable \\
\hline Mei 2010 & $1 / 73$ & $4 / 73$ & - & $2.47 \%$ & $0.25[0.03,2.18]$ \\
\hline Méndez-Probst 2011 & $0 / 22$ & $0 / 21$ & & & Not estimable \\
\hline Fagerström 2011 & $4 / 98$ & $10 / 87$ & - & $9.18 \%$ & $0.36[0.12,1.09]$ \\
\hline Geavlete 2011 & $3 / 170$ & $11 / 170$ & 4 & $7.31 \%$ & $0.27[0.08,0.96]$ \\
\hline Mamoulakis 2013 & $9 / 141$ & $4 / 138$ & & $8.69 \%$ & $2.2[0.69,6.98]$ \\
\hline Xie 2012 & $0 / 110$ & $2 / 110$ & & $1.27 \%$ & $0.2[0.01,4.12]$ \\
\hline Akman 2013 & $3 / 143$ & $8 / 143$ & $\longrightarrow$ & $6.78 \%$ & $0.38[0.1,1.38]$ \\
\hline Giulianelli 2013 & $0 / 80$ & $3 / 80$ & - & $1.33 \%$ & $0.14[0.01,2.72]$ \\
\hline Kumar 2013 & $3 / 57$ & $7 / 60$ & $\longrightarrow$ & $6.82 \%$ & $0.45[0.12,1.66]$ \\
\hline Komura 2015 & $1 / 63$ & $4 / 61$ & - & $2.48 \%$ & $0.24[0.03,2.1]$ \\
\hline Ghozzi 2014 & $1 / 31$ & $2 / 29$ & 1 & $2.1 \%$ & $0.47[0.04,4.89]$ \\
\hline Stucki 2014 & $1 / 70$ & $1 / 67$ & & $1.53 \%$ & $0.96[0.06,14.99]$ \\
\hline Demirdag 2016 & $4 / 36$ & $8 / 45$ & $\rightarrow-$ & $9.28 \%$ & $0.63[0.2,1.91]$ \\
\hline Ahmad 2016 & $1 / 110$ & $0 / 110$ & & $1.14 \%$ & $3[0.12,72.85]$ \\
\hline Al-Rawashdah 2017 & $0 / 251$ & $5 / 246$ & - & $1.39 \%$ & $0.09[0,1.6]$ \\
\hline Total $(95 \% \mathrm{Cl})$ & 2811 & 2916 & 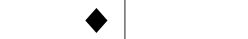 & $100 \%$ & $0.42[0.3,0.59]$ \\
\hline \multicolumn{6}{|c|}{ Total events: 47 (B-TURP), 141 (M-TURP) } \\
\hline \multicolumn{6}{|c|}{ Heterogeneity: $\mathrm{Tau}^{2}=0 ; \mathrm{Chi}^{2}=28.46, \mathrm{df}=31(\mathrm{P}=0.6) ; \mathrm{I}^{2}=0 \%$} \\
\hline \multicolumn{6}{|c|}{ Test for overall effect: $Z=5.02(P<0.0001)$} \\
\hline
\end{tabular}

Analysis 1.6. Comparison 1 BTURP versus MTURP, Outcome 6 Re-TURP.

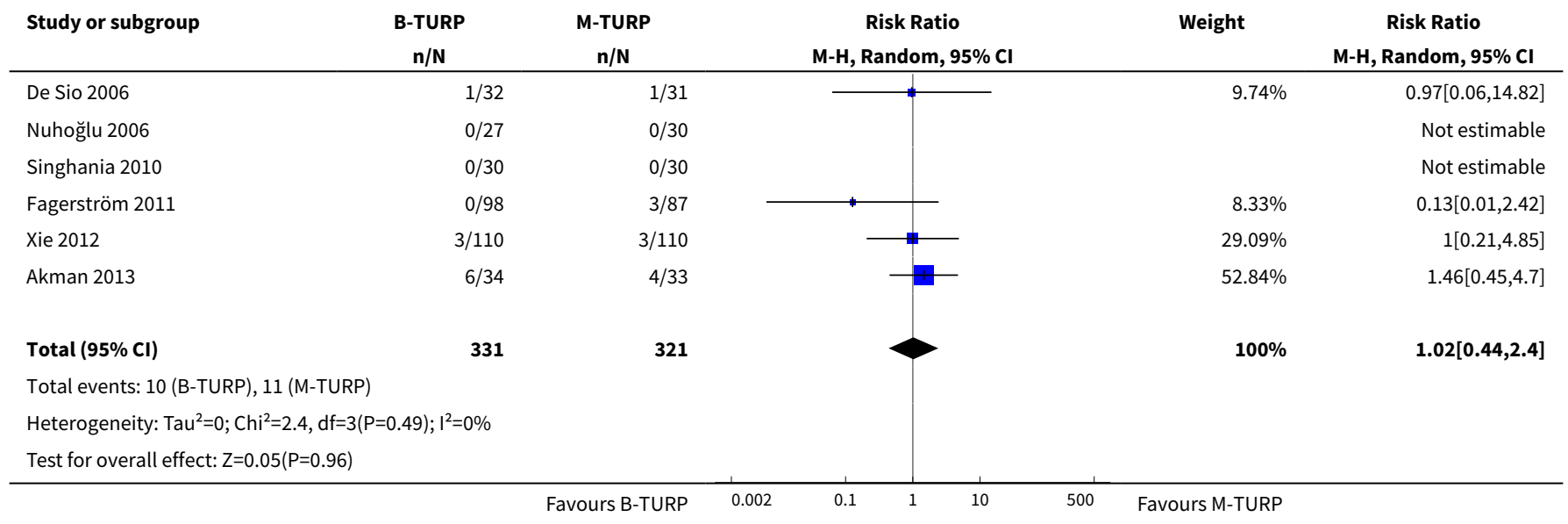


Analysis 1.7. Comparison 1 BTURP versus MTURP, Outcome 7 Erectile function (IIEF-5 score at 12 months).

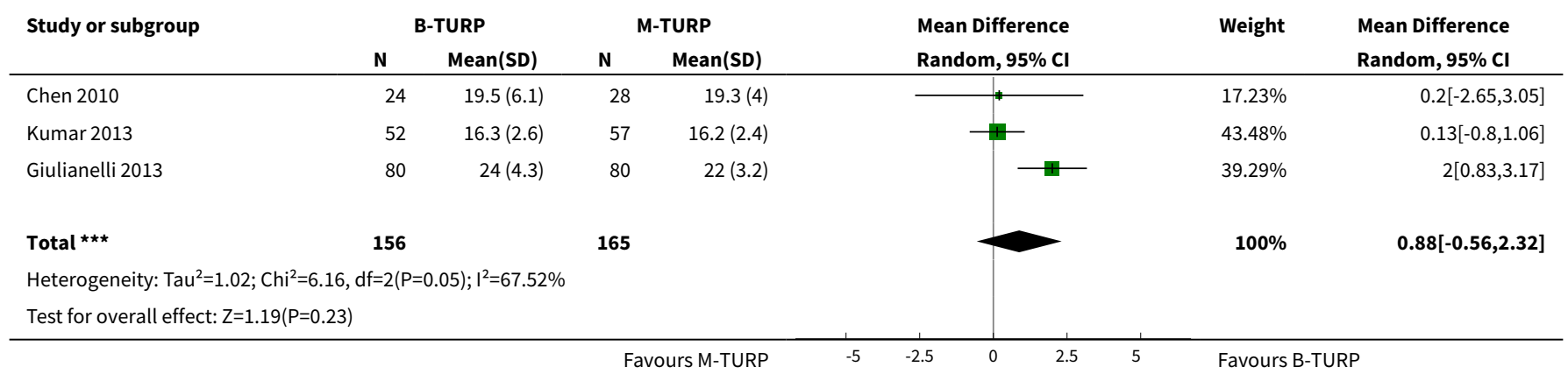

\section{ADDITIONAL TABLES}




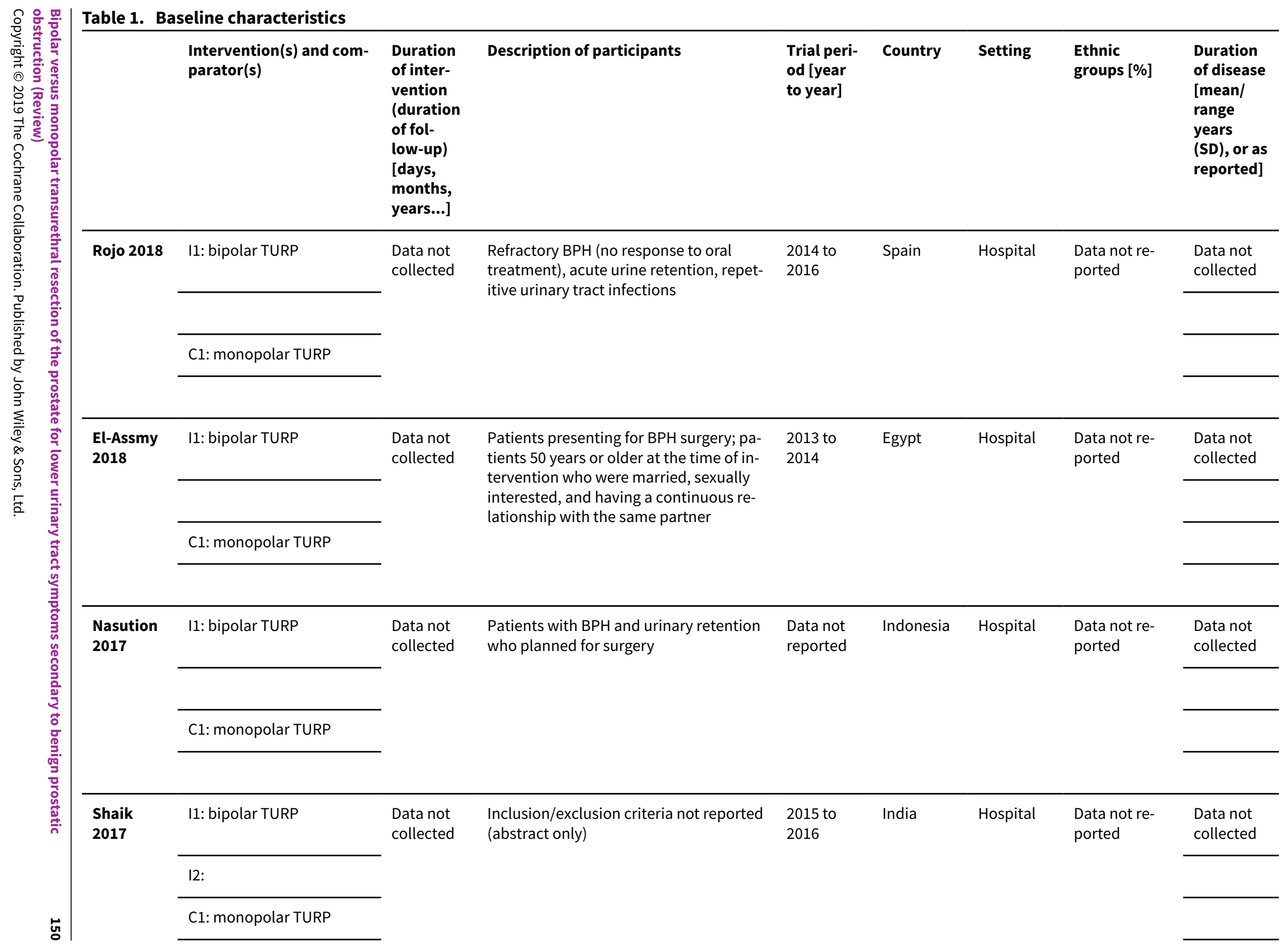




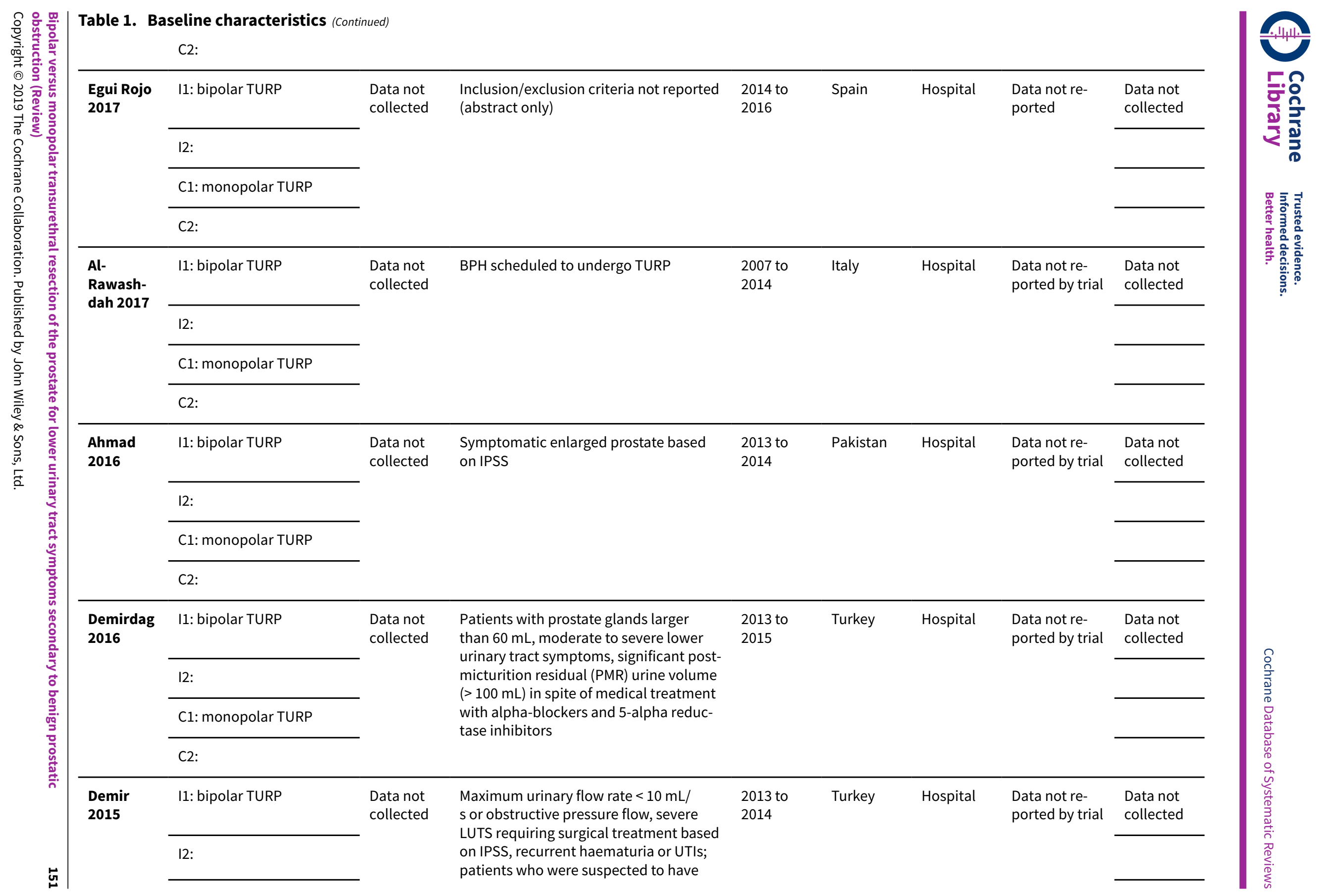




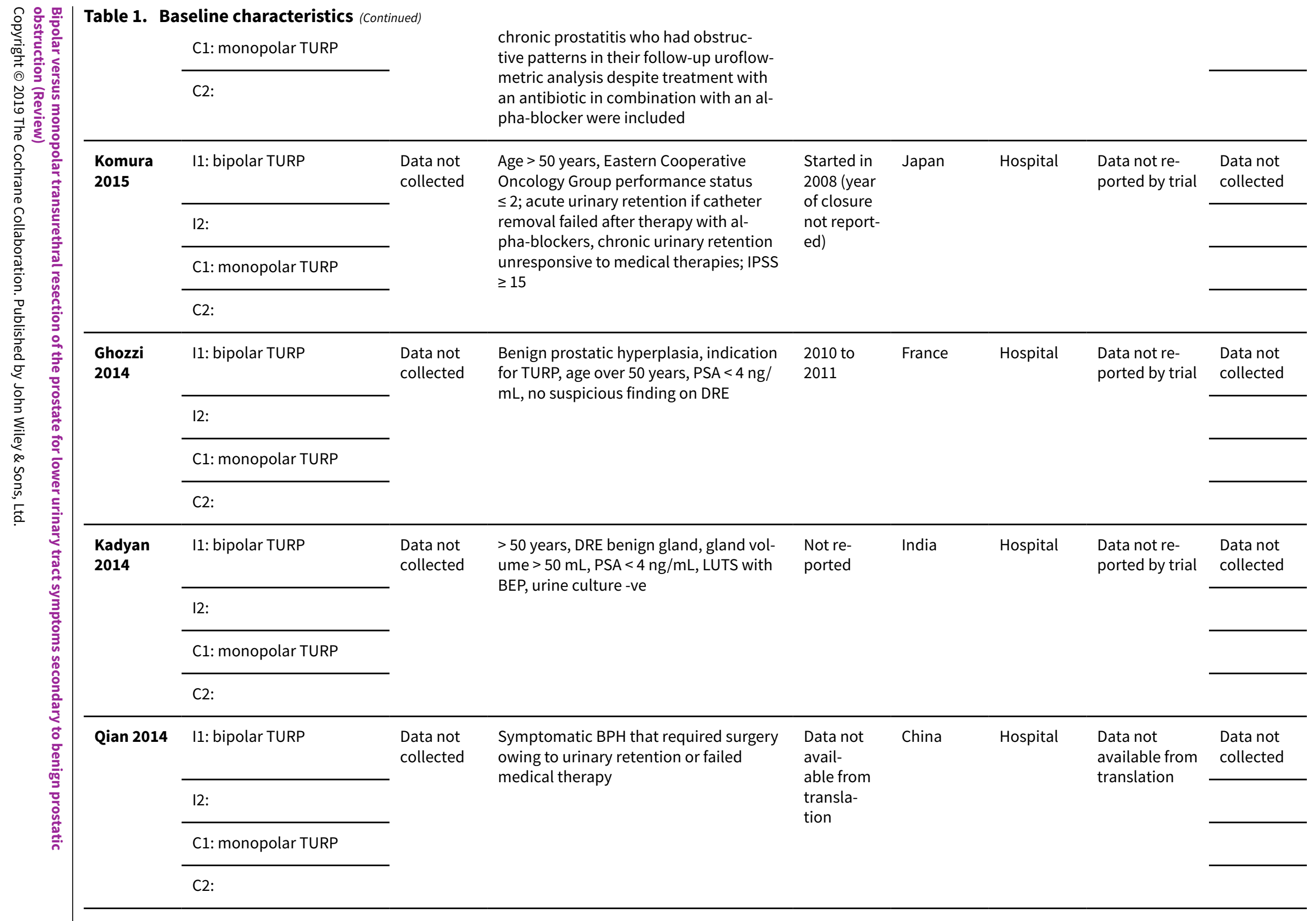




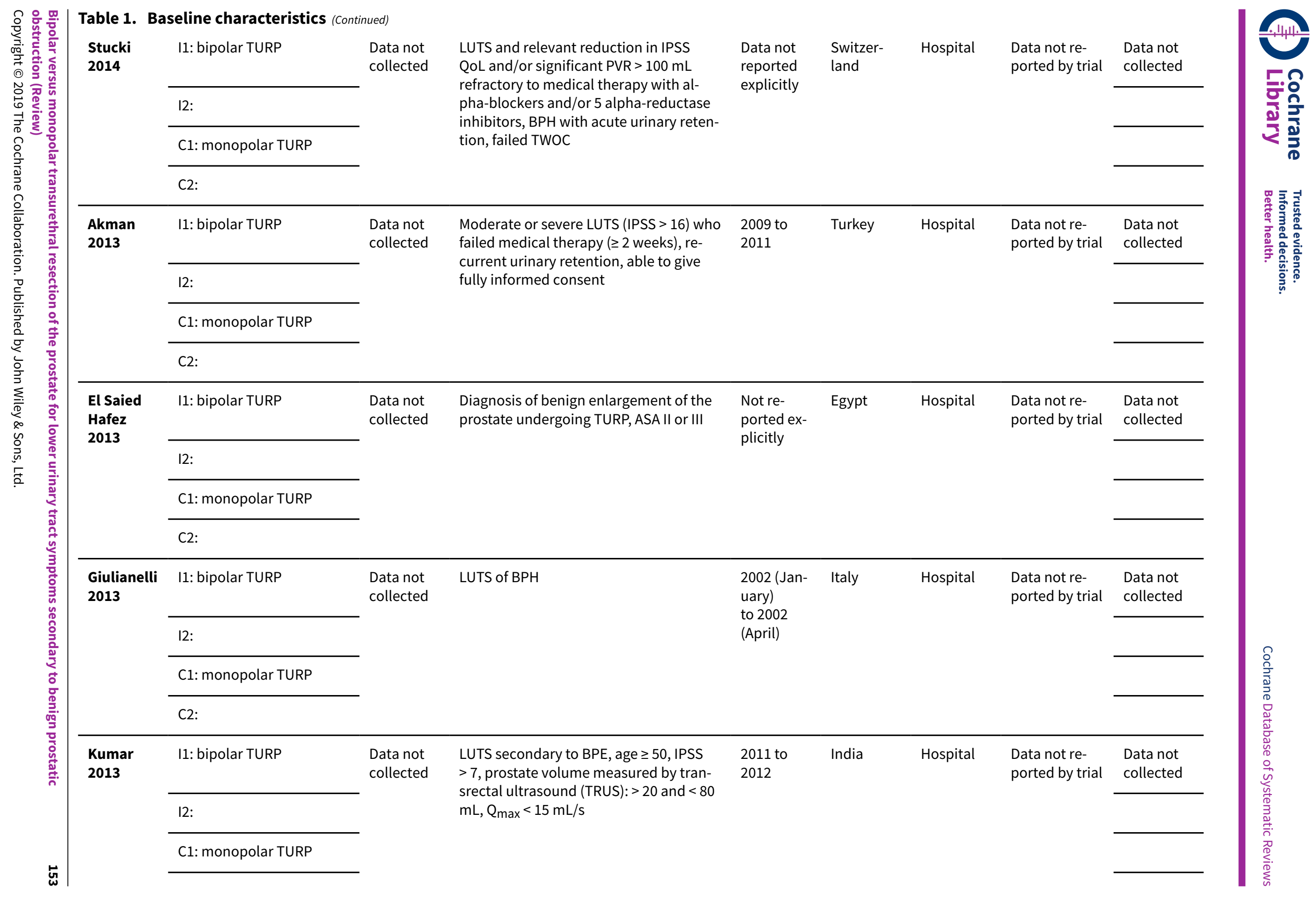




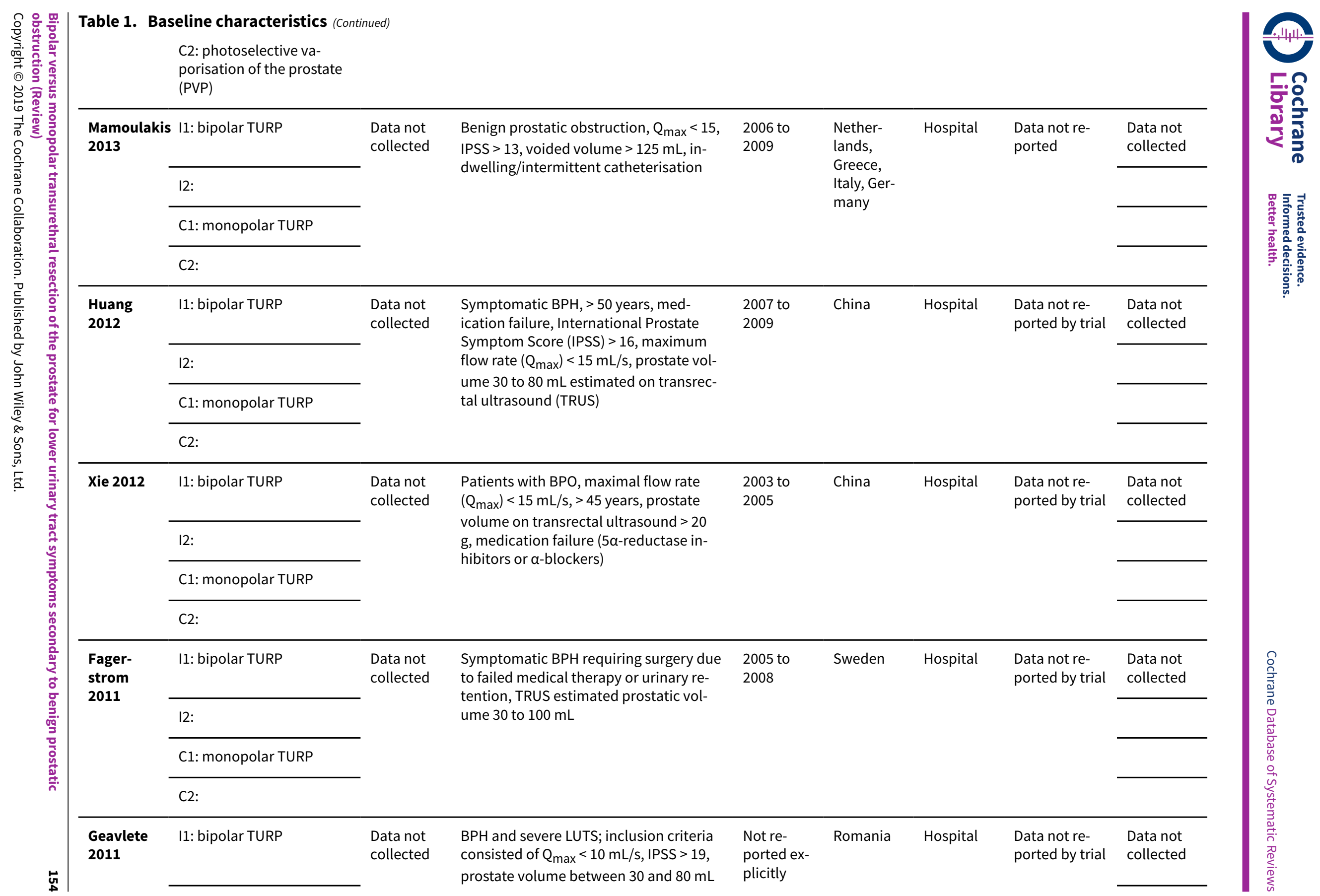




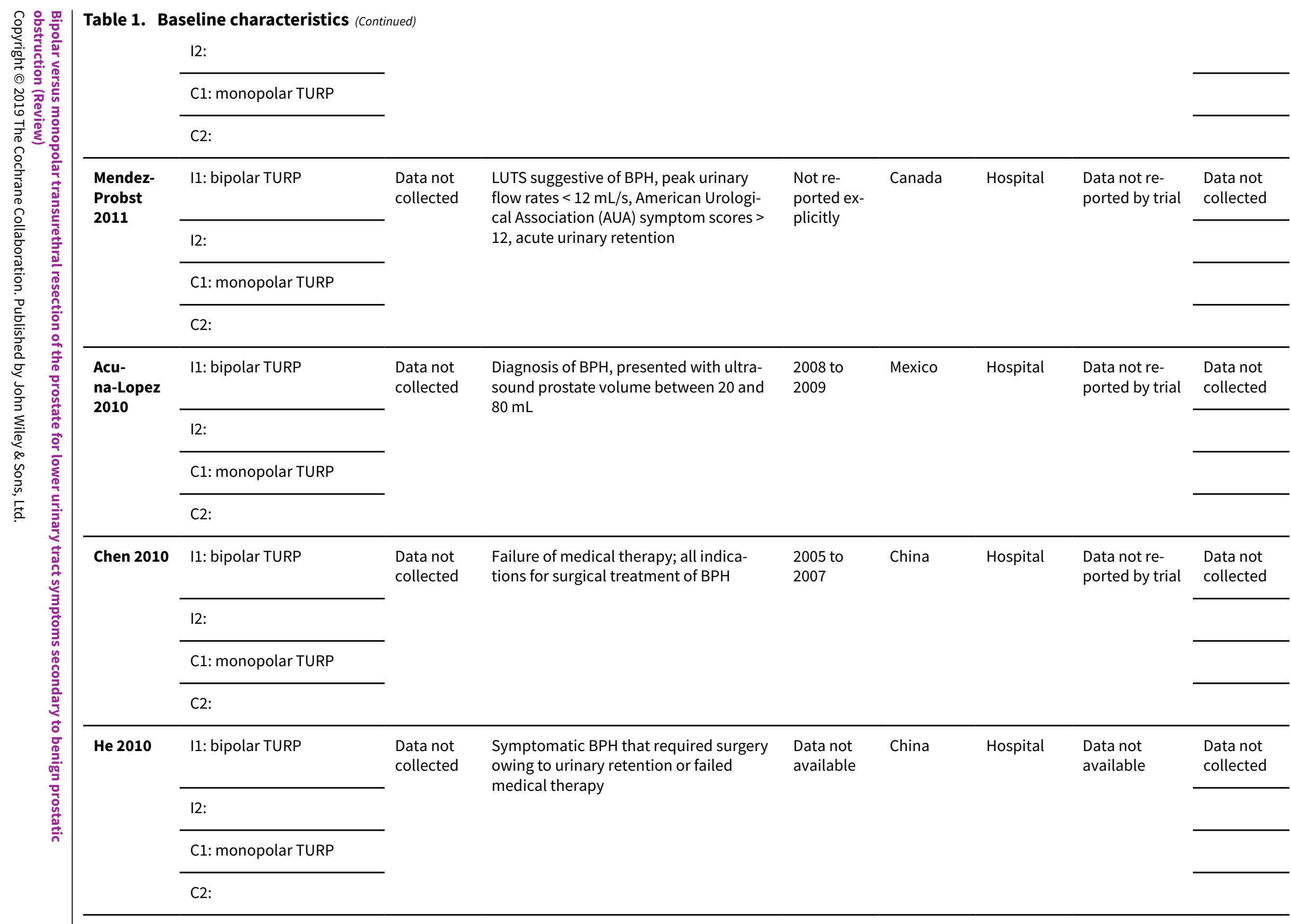




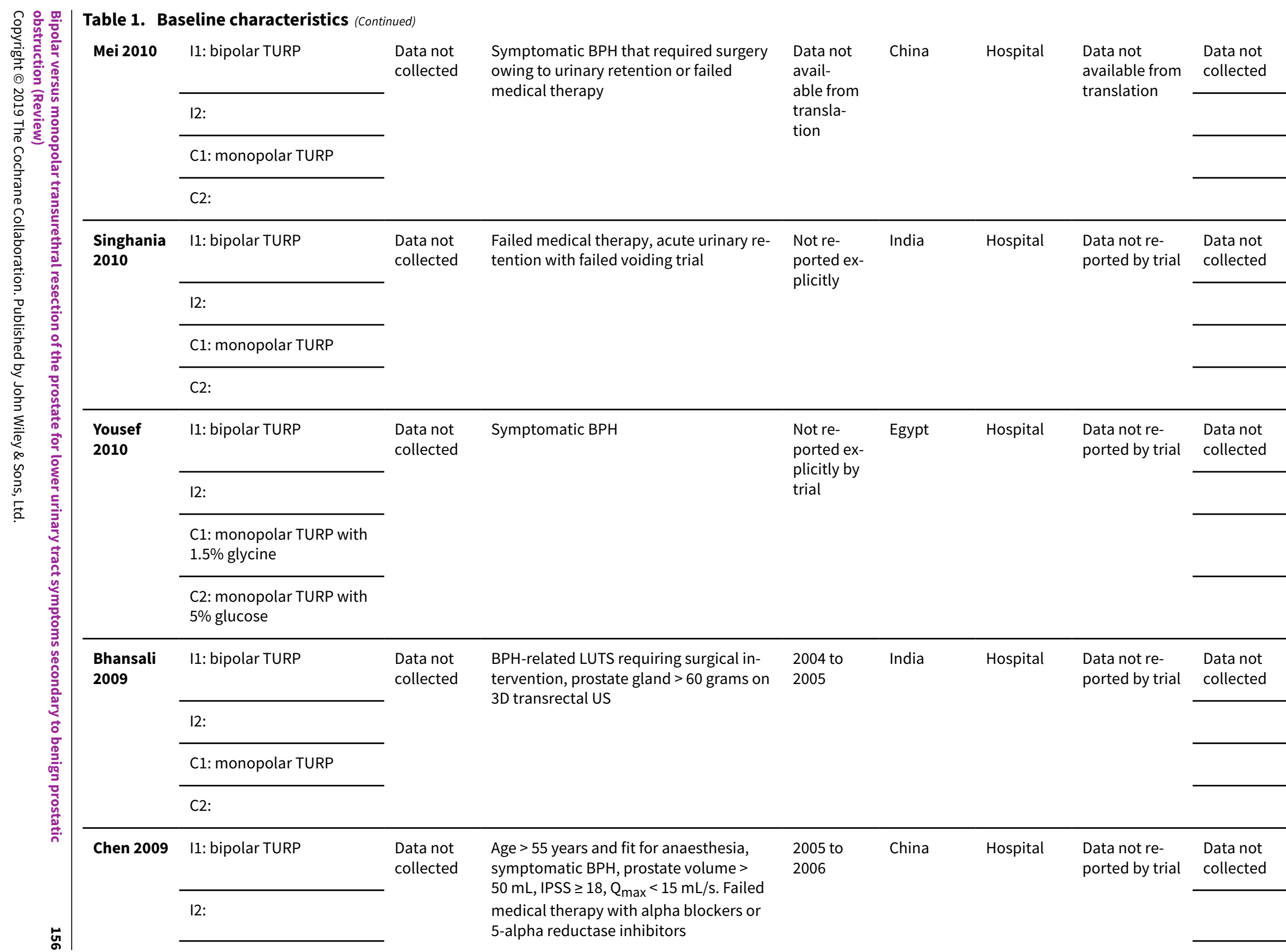




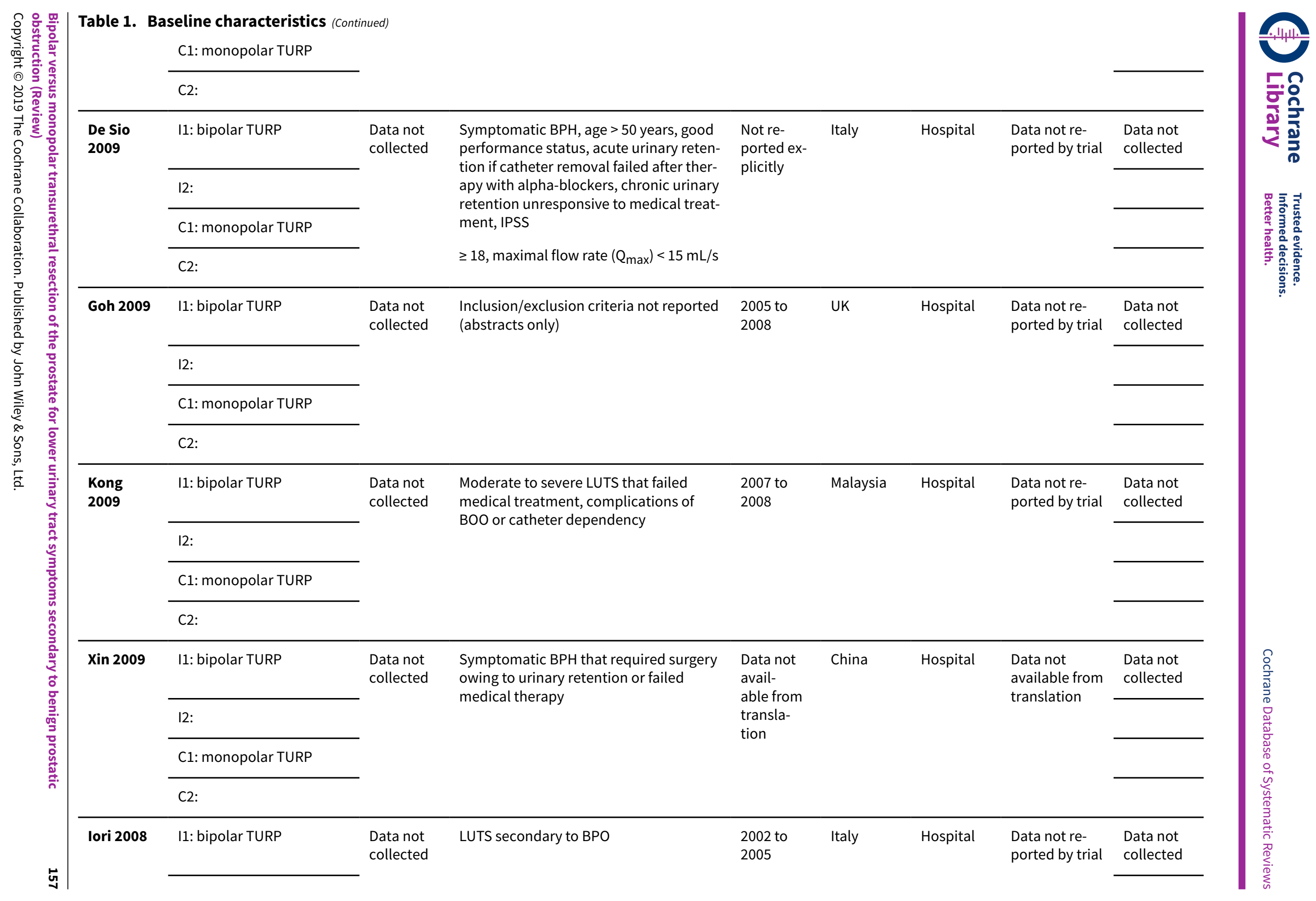




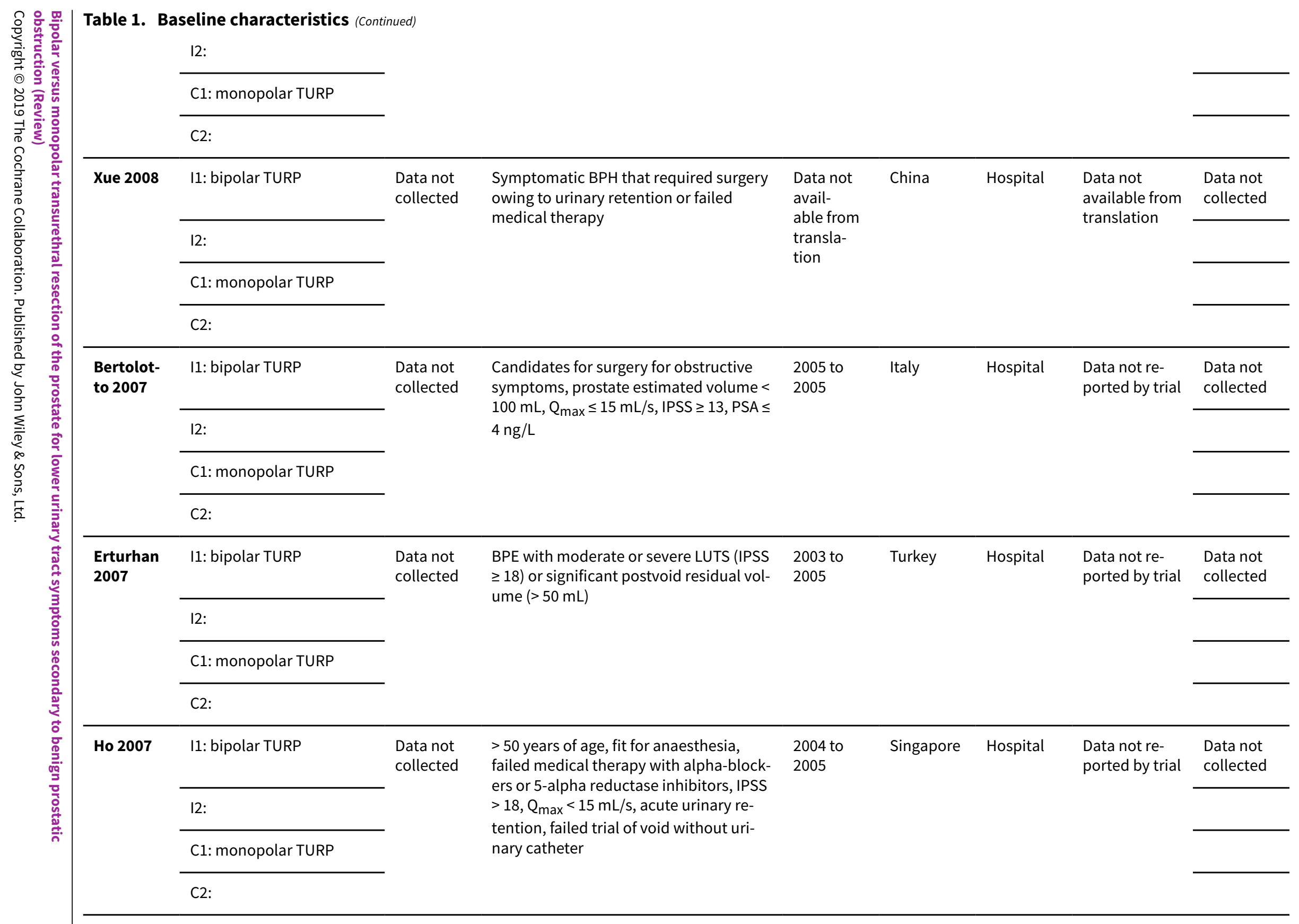




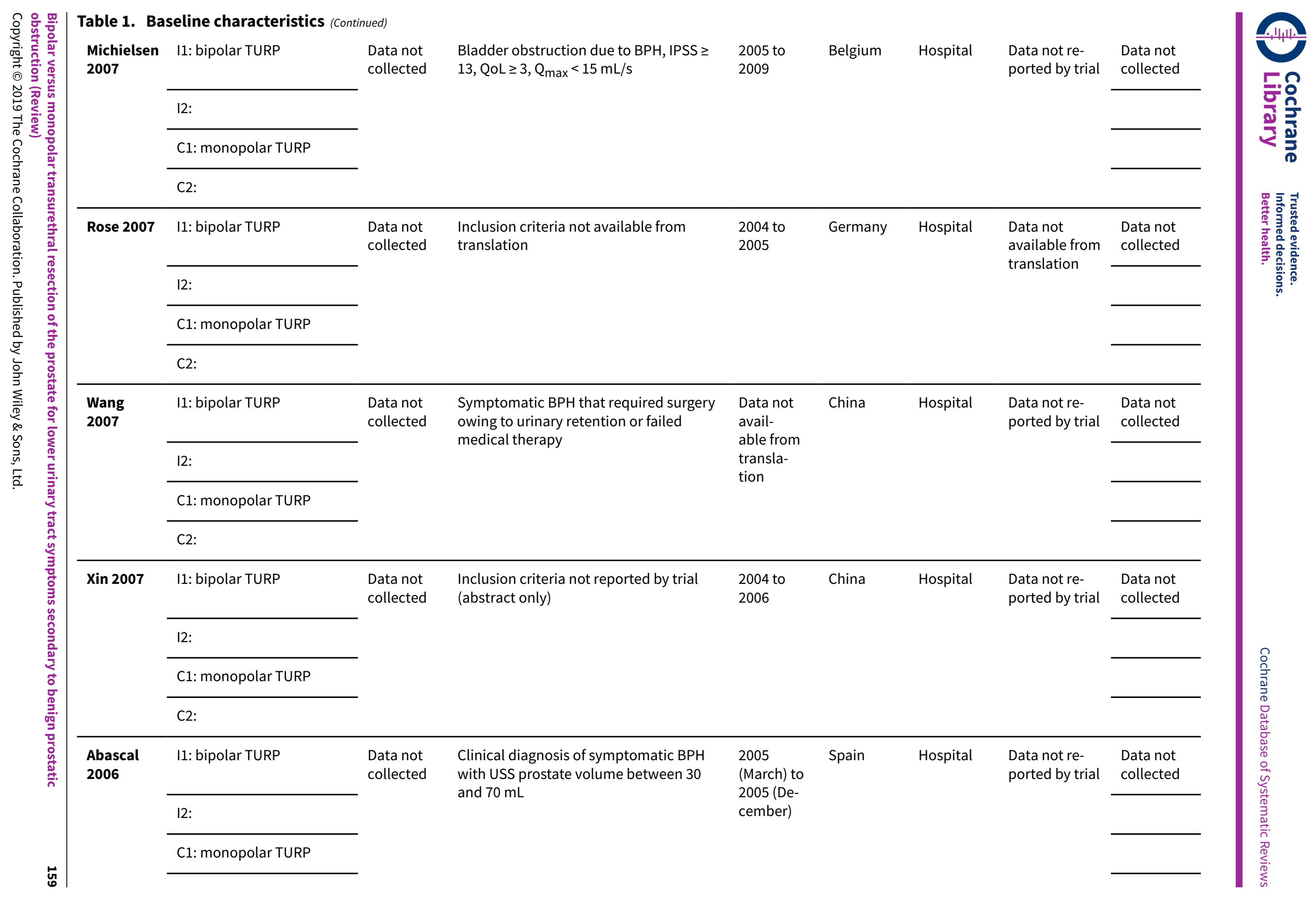




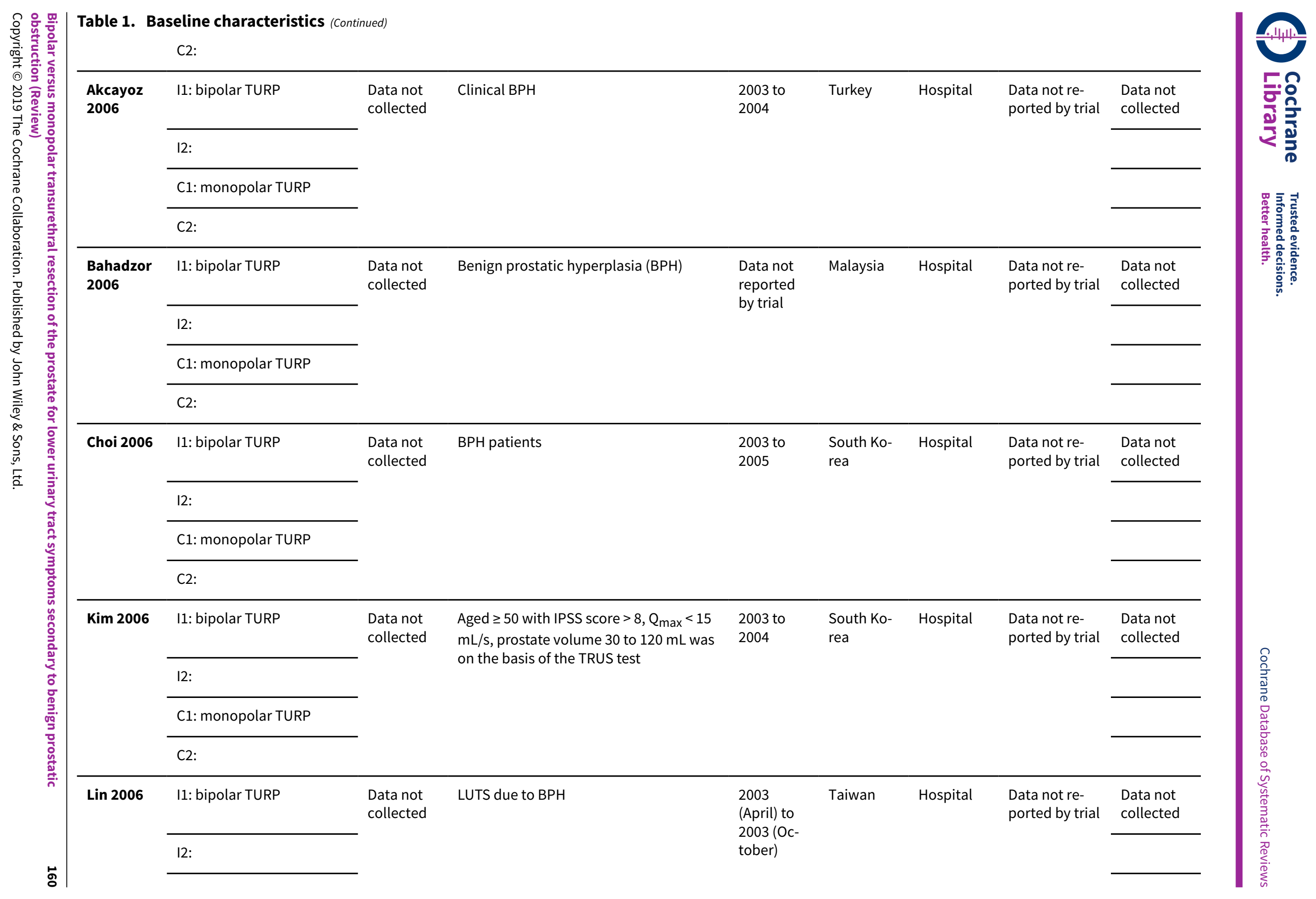




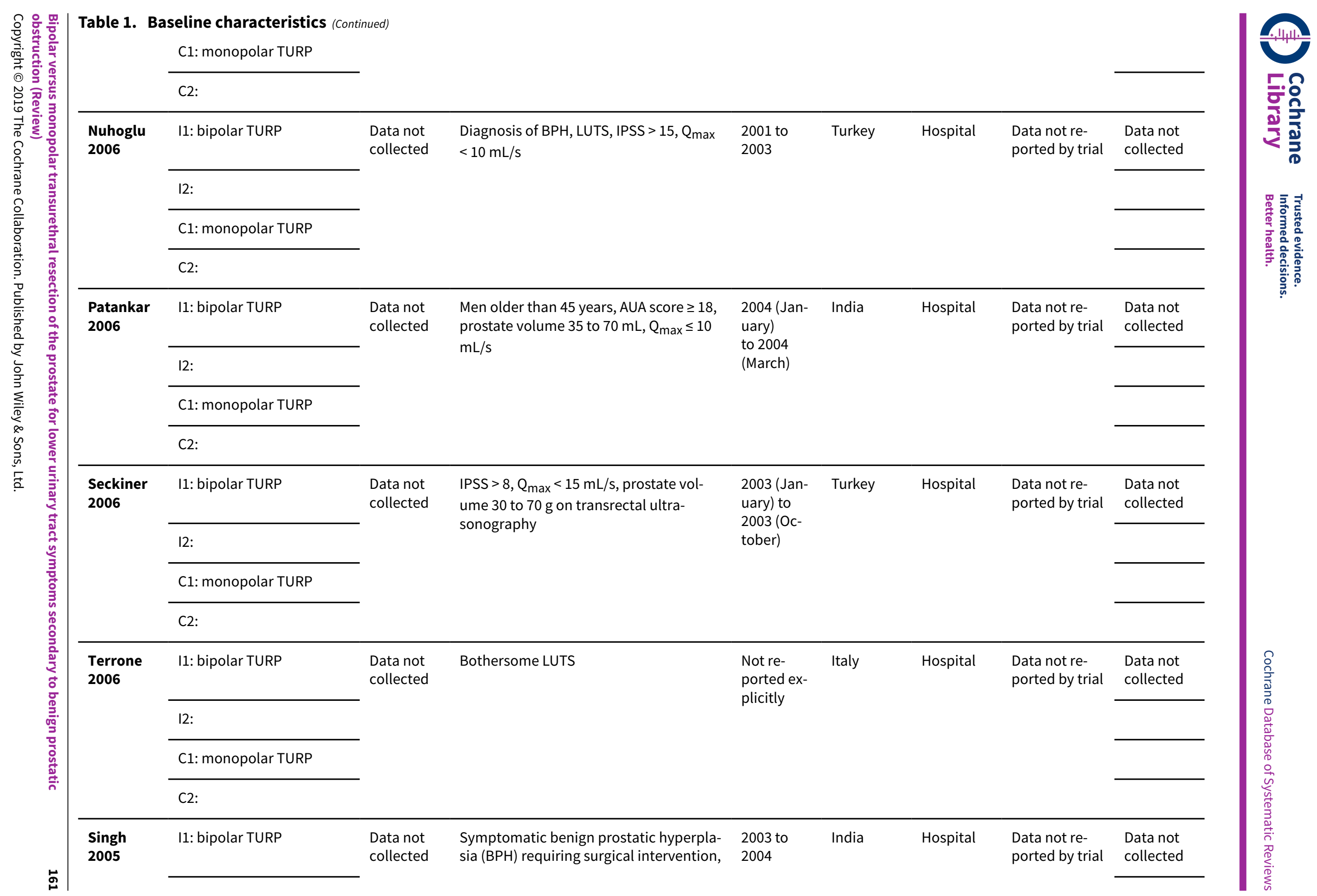




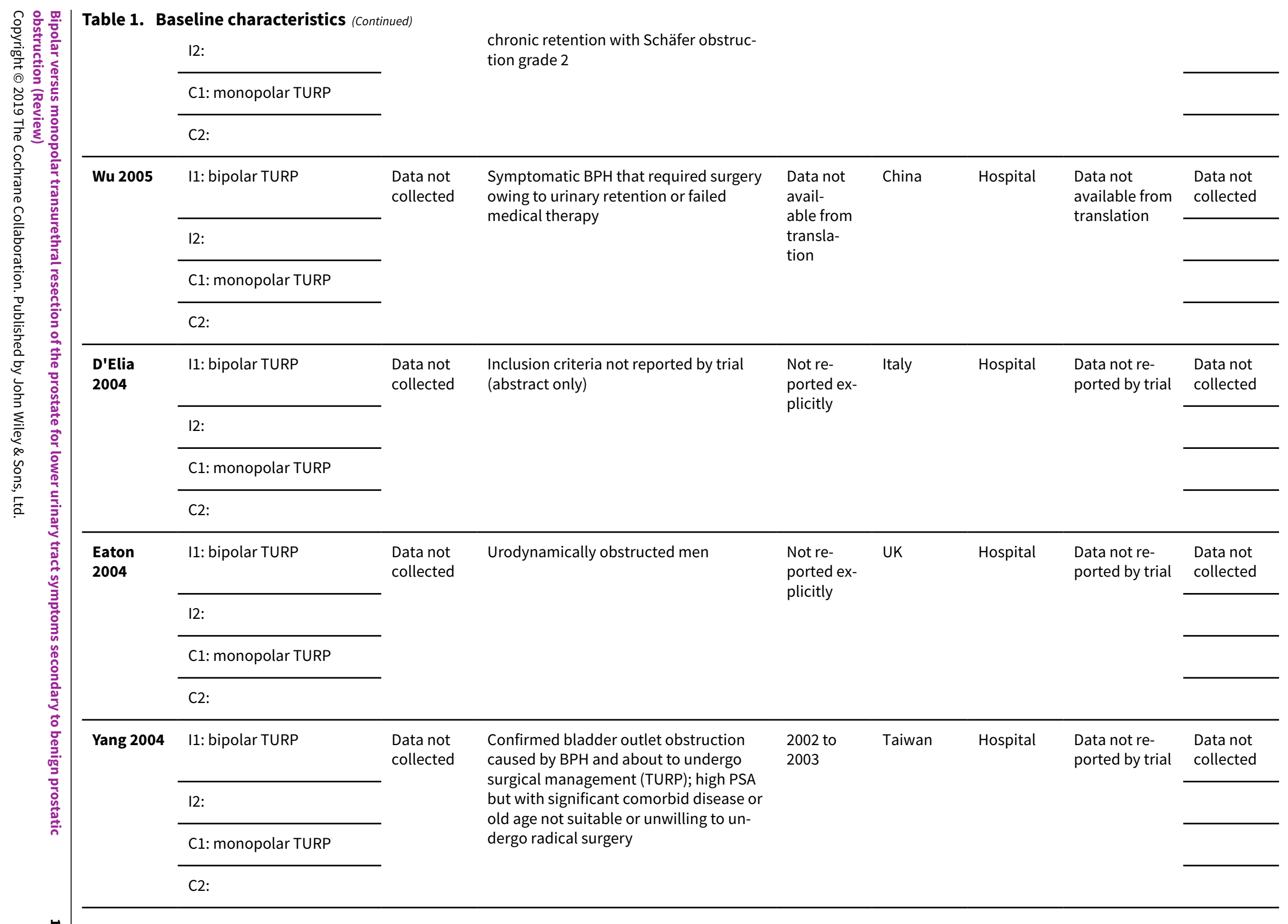




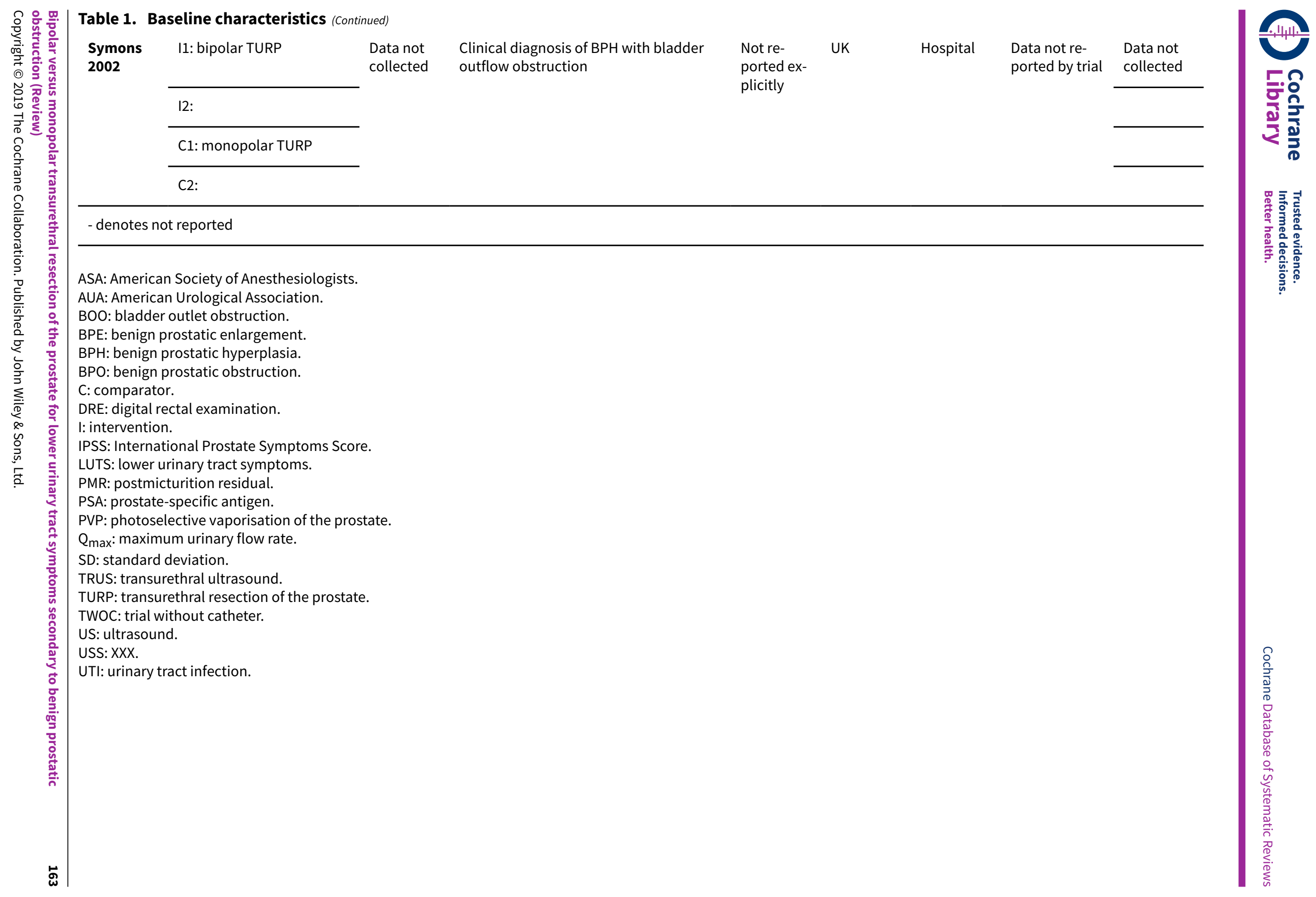


Table 2. Description of interventions

\begin{tabular}{|c|c|c|c|c|}
\hline & $\begin{array}{l}\text { Interven- } \\
\text { tion(s) [route, } \\
\text { frequency, to- } \\
\text { tal dose/d] }\end{array}$ & $\begin{array}{l}\text { Intervention(s) appro- } \\
\text { priate as applied in a } \\
\text { clinical practice settin- } \\
\text { ga }^{\text {[ }} \text { description] }\end{array}$ & $\begin{array}{l}\text { Comparator(s) } \\
\text { [route, frequency, } \\
\text { total dose/d] }\end{array}$ & $\begin{array}{l}\text { Comparator(s) appropriate as applied in a } \\
\text { clinical practice setting a [description] }\end{array}$ \\
\hline Rojo 2018 & $\begin{array}{l}\text { I1: bipolar } \\
\text { TURP }\end{array}$ & $\begin{array}{l}\text { Specific technology not } \\
\text { reported }\end{array}$ & $\begin{array}{l}\text { C1: monopolar } \\
\text { TURP }\end{array}$ & $\begin{array}{l}\text { Specific technology not reported, irrigation fluid } \\
=\text { glycine }\end{array}$ \\
\hline
\end{tabular}

\begin{tabular}{lllll}
\hline El-Assmy & I1: bipolar & TUR in Saline-TURis, & C1: monopolar & ValleyLab Force FX electrosurgical unit, irriga- \\
$\mathbf{2 0 1 8}$ & TURP & Olympus SurgMaster & TURP \\
& UES-40 Bipolar Genera- & & tion fluid = glycine \\
& tor & & \\
\hline
\end{tabular}

\begin{tabular}{|c|c|c|c|c|}
\hline $\begin{array}{l}\text { Nasution } \\
2017\end{array}$ & $\begin{array}{l}\text { I1: bipolar } \\
\text { TURP }\end{array}$ & $\begin{array}{l}\text { Specific technology not } \\
\text { reported }\end{array}$ & $\begin{array}{l}\text { C1: monopolar } \\
\text { TURP }\end{array}$ & Specific technology/irrigation fluid not reported \\
\hline
\end{tabular}

\begin{tabular}{|c|c|c|c|c|}
\hline $\begin{array}{l}\text { Shaik } \\
2017\end{array}$ & $\begin{array}{l}\text { I1: bipolar } \\
\text { TURP }\end{array}$ & $\begin{array}{l}\text { Specific technology not } \\
\text { reported }\end{array}$ & $\begin{array}{l}\text { C1: monopolar } \\
\text { TURP }\end{array}$ & Specific technology/irrigation fluid not reported \\
\hline
\end{tabular}

\begin{tabular}{|c|c|c|c|c|}
\hline $\begin{array}{l}\text { Egui Rojo } \\
2017\end{array}$ & $\begin{array}{l}\text { I1: bipolar } \\
\text { TURP }\end{array}$ & $\begin{array}{l}\text { Specific technology not } \\
\text { reported }\end{array}$ & $\begin{array}{l}\text { C1: monopolar } \\
\text { TURP }\end{array}$ & Specific technology/irrigation fluid not reported \\
\hline
\end{tabular}

\begin{tabular}{|c|c|c|c|c|}
\hline $\begin{array}{l}\text { Al- } \\
\text { Rawash- }\end{array}$ & $\begin{array}{l}\text { I1: bipolar } \\
\text { TURP }\end{array}$ & $\begin{array}{l}\text { Gyrus PK Super-Pulse } \\
\text { Olympus }\end{array}$ & $\begin{array}{l}\text { C1: monopolar } \\
\text { TURP }\end{array}$ & $\begin{array}{l}\text { Karl Storz and ERBE Generator, irrigation fluid = } \\
\text { sorbitol/mannitol irrigation fluid }\end{array}$ \\
\hline
\end{tabular}

\begin{tabular}{|c|c|c|c|c|}
\hline $\begin{array}{l}\text { Ahmad } \\
2016\end{array}$ & $\begin{array}{l}\text { I1: bipolar } \\
\text { TURP }\end{array}$ & $\begin{array}{l}\text { Specific technology not } \\
\text { reported }\end{array}$ & $\begin{array}{l}\text { C1: monopolar } \\
\text { TURP }\end{array}$ & $\begin{array}{l}\text { Specific technology not reported, irrigation fluid } \\
=\text { mannitol } 1.5 \%\end{array}$ \\
\hline
\end{tabular}

\begin{tabular}{lllll}
\hline $\begin{array}{l}\text { Demirdag } \\
\mathbf{2 0 1 6}\end{array}$ & $\begin{array}{l}\text { I1: bipolar } \\
\text { TURP }\end{array}$ & $\begin{array}{l}\text { Olympus Gyrus PK Su- } \\
\text { perPulse Generator }\end{array}$ & $\begin{array}{l}\text { C1: monopolar } \\
\text { TURP }\end{array}$ & $\begin{array}{l}\text { ValleyLab Force FX Electrocautery, irrigation flu- } \\
\text { id = glycine 5\% }\end{array}$ \\
\cline { 2 - 5 } & I2: & C2: & \\
\hline $\begin{array}{l}\text { Komura } \\
\mathbf{2 0 1 5}\end{array}$ & $\begin{array}{l}\text { I1: bipolar } \\
\text { TURP }\end{array}$ & Olympus TURis & $\begin{array}{l}\text { C1: monopolar } \\
\text { TURP }\end{array}$ & $\begin{array}{l}\text { Specific technology not reported, irrigation fluid } \\
\text { = mannitol } 4 \%\end{array}$ \\
\cline { 2 - 5 } & I2: & C2: & Olympus, irrigation fluid = 1.5\% glycine \\
\hline $\begin{array}{l}\text { Ghozzi } \\
\mathbf{2 0 1 4}\end{array}$ & I1: bipolar & Olympus TURis & C1: monopolar \\
& TURP & & TURP & \\
\cline { 2 - 5 } & I2: & & C2: & \\
\hline
\end{tabular}

Bipolar versus monopolar transurethral resection of the prostate for lower urinary tract symptoms secondary to benign prostatic 
Table 2. Description of interventions (Continued)

\begin{tabular}{|c|c|c|c|c|}
\hline \multirow[t]{2}{*}{$\begin{array}{l}\text { Kadyan } \\
2014\end{array}$} & $\begin{array}{l}\text { I1: bipolar } \\
\text { TURP }\end{array}$ & ERBE technology & $\begin{array}{l}\text { C1: monopolar } \\
\text { TURP }\end{array}$ & Technology/irrigation fluid not reported \\
\hline & 12: & & C2: & \\
\hline \multirow[t]{2}{*}{ Qian 2014} & $\begin{array}{l}\text { I1: bipolar } \\
\text { TURP }\end{array}$ & $\begin{array}{l}\text { Specific technology not } \\
\text { reported (study in Chi- } \\
\text { nese) }\end{array}$ & $\begin{array}{l}\text { C1: monopolar } \\
\text { TURP }\end{array}$ & Specific technology/irrigation fluid not reported \\
\hline & 12: & & C2: & \\
\hline \multirow[t]{2}{*}{$\begin{array}{l}\text { Stucki } \\
2014\end{array}$} & $\begin{array}{l}\text { I1: bipolar } \\
\text { TURP }\end{array}$ & Gyrus PK SuperPulse & $\begin{array}{l}\text { C1: monopolar } \\
\text { TURP }\end{array}$ & $\begin{array}{l}\text { Karl Storz, ERBE Generator, irrigation fluid = sor- } \\
\text { bitol/mannitol }\end{array}$ \\
\hline & 12: & & C2: & \\
\hline \multirow[t]{2}{*}{$\begin{array}{l}\text { Akman } \\
2013\end{array}$} & $\begin{array}{l}\text { I1: bipolar } \\
\text { TURP }\end{array}$ & $\begin{array}{l}\text { Olympus UES } 40 \text { Surg } \\
\text { MasterSystem }\end{array}$ & $\begin{array}{l}\text { C1: monopolar } \\
\text { TURP }\end{array}$ & $\begin{array}{l}\text { Gebruder Martine ME 411, irrigation fluid = } \\
\text { glycine }\end{array}$ \\
\hline & 12: & & C2: & \\
\hline \multirow{2}{*}{$\begin{array}{l}\text { El Saied } \\
\text { Hafez } \\
2013\end{array}$} & $\begin{array}{l}\text { I1: bipolar } \\
\text { TURP }\end{array}$ & Gyrus Plasmakinetic, PK & $\begin{array}{l}\text { I1: monopolar } \\
\text { TURP }\end{array}$ & $\begin{array}{l}\text { Erbee Resection System, irrigation fluid = 1.5\% } \\
\text { glycine }\end{array}$ \\
\hline & 12: & & & \\
\hline \multirow[t]{2}{*}{$\begin{array}{l}\text { Giulianel- } \\
\text { li } 2013\end{array}$} & $\begin{array}{l}\text { I1: bipolar } \\
\text { TURP }\end{array}$ & $\begin{array}{l}\text { Gyrus Plasmakinetic (PK- } \\
\text { TURP) }\end{array}$ & $\begin{array}{l}\text { C1: monopolar } \\
\text { TURP }\end{array}$ & Karl Storz, irrigation fluid = mannitol-sorbitol \\
\hline & 12: & & C2: & \\
\hline \multirow[t]{2}{*}{$\begin{array}{l}\text { Kumar } \\
2013\end{array}$} & $\begin{array}{l}\text { I1: bipolar } \\
\text { TURP }\end{array}$ & $\begin{array}{l}\text { Gyrus ACMI Plasmakinet- } \\
\text { ic System }\end{array}$ & $\begin{array}{l}\text { C1: monopolar } \\
\text { TURP }\end{array}$ & $\begin{array}{l}\text { Specific technology not reported; irrigation fluid } \\
=1.5 \% \text { glycine }\end{array}$ \\
\hline & 12: & & $\begin{array}{l}\text { C2: photoselective } \\
\text { vaporisation of the } \\
\text { prostate (PVP) }\end{array}$ & GreenLight Laser HPS \\
\hline \multirow[t]{2}{*}{$\begin{array}{l}\text { Mamoulakis } \\
2013\end{array}$} & $\begin{array}{l}\text { I1: bipolar } \\
\text { TURP }\end{array}$ & $\begin{array}{l}\text { Autocon II } 400 \text { ESU } \\
\text { Karl Storz }\end{array}$ & $\begin{array}{l}\text { C1: monopolar } \\
\text { TURP }\end{array}$ & $\begin{array}{l}\text { Karl Storz, irrigation fluid = sorbitol 5\%, sor- } \\
\text { bitol-mannitol, water for injection, glycine (mul- } \\
\text { ti-centre) }\end{array}$ \\
\hline & 12: & & C2: & \\
\hline \multirow[t]{2}{*}{$\begin{array}{l}\text { Huang } \\
2012\end{array}$} & $\begin{array}{l}\text { I1: bipolar } \\
\text { TURP }\end{array}$ & $\begin{array}{l}\text { PlasmaKinetic (Gyrus } \\
\text { ACMI) }\end{array}$ & $\begin{array}{l}\text { C1: monopolar } \\
\text { TURP }\end{array}$ & Karl Storz, irrigation fluid = mannitol 5\% \\
\hline & 12: & & C2: & \\
\hline \multirow[t]{2}{*}{ Xie 2012} & $\begin{array}{l}\text { I1: bipolar } \\
\text { TURP }\end{array}$ & Gyrus Plasmakinetic & $\begin{array}{l}\text { C1: monopolar } \\
\text { TURP }\end{array}$ & Olympus, irrigation fluid = glycine $1.5 \%$ \\
\hline & 12: & & C2: & \\
\hline $\begin{array}{l}\text { Fager- } \\
\text { strom } \\
2011\end{array}$ & $\begin{array}{l}\text { I1: bipolar } \\
\text { TURP }\end{array}$ & Olympus TURis & $\begin{array}{l}\text { C1: monopolar } \\
\text { TURP }\end{array}$ & $\begin{array}{l}\text { Karl Storz ERBE, irrigation fluid = mannitol } 3 \% \\
\text { and ethanol } 1 \%\end{array}$ \\
\hline
\end{tabular}

Bipolar versus monopolar transurethral resection of the prostate for lower urinary tract symptoms secondary to benign prostatic 
Table 2. Description of interventions (Continued)

12: $\quad$ C2:

\begin{tabular}{|c|c|c|c|c|}
\hline \multirow[t]{2}{*}{$\begin{array}{l}\text { Geavlete } \\
2011\end{array}$} & $\begin{array}{l}\text { I1: bipolar } \\
\text { TURP }\end{array}$ & $\begin{array}{l}\text { TURis Olympus SurgMas- } \\
\text { ter }\end{array}$ & $\begin{array}{l}\text { C1: monopolar } \\
\text { TURP }\end{array}$ & Storz, irrigation fluid = sterile water \\
\hline & 12: & & $\begin{array}{l}\text { C2: plasmakinetic } \\
\text { vaporisation of the } \\
\text { prostate }\end{array}$ & Olympus Vaporesection \\
\hline \multirow{2}{*}{$\begin{array}{l}\text { Acu- } \\
\text { na-Lopez } \\
2010\end{array}$} & $\begin{array}{l}\text { I1: bipolar } \\
\text { TURP }\end{array}$ & Gyrus ACMI & $\begin{array}{l}\text { C1: monopolar } \\
\text { TURP }\end{array}$ & $\begin{array}{l}\text { Specific technology not reported, irrigation fluid } \\
=\text { glycine solution }\end{array}$ \\
\hline & 12: & & $\mathrm{C} 2:$ & \\
\hline \multirow[t]{2}{*}{$\begin{array}{l}\text { Chen } \\
2010\end{array}$} & $\begin{array}{l}\text { I1: bipolar } \\
\text { TURP }\end{array}$ & $\begin{array}{l}\text { TURis Olympus SurgMas- } \\
\text { terSystem }\end{array}$ & $\begin{array}{l}\text { C1: monopolar } \\
\text { TURP }\end{array}$ & $\begin{array}{l}\text { Olympus, irrigation fluid = } 4 \% \text { mannitol, } 1 \% \\
\text { ethanol }\end{array}$ \\
\hline & 12: & & C2: & \\
\hline \multirow[t]{2}{*}{ He 2010} & $\begin{array}{l}\text { I1: bipolar } \\
\text { TURP }\end{array}$ & $\begin{array}{l}\text { Gyrus Electrosurgical } \\
\text { System }\end{array}$ & $\begin{array}{l}\text { C1: monopolar } \\
\text { TURP }\end{array}$ & $\begin{array}{l}\text { Storz Electrosurgical Generator, irrigation fluid = } \\
5 \% \text { mannitol }\end{array}$ \\
\hline & 12: & & C2: & \\
\hline \multirow[t]{2}{*}{ Mei 2010} & $\begin{array}{l}\text { I1: bipolar } \\
\text { TURP }\end{array}$ & $\begin{array}{l}\text { Gyrus Electrosurgical } \\
\text { System }\end{array}$ & $\begin{array}{l}\text { C1: monopolar } \\
\text { TURP }\end{array}$ & $\begin{array}{l}\text { WOLF Electrosurgical System, irrigation fluid = } \\
5 \% \text { mannitol }\end{array}$ \\
\hline & 12: & & C2: & \\
\hline \multirow[t]{2}{*}{$\begin{array}{l}\text { Singha- } \\
\text { nia } 2010\end{array}$} & $\begin{array}{l}\text { I1: bipolar } \\
\text { TURP }\end{array}$ & Gyrus PK System & $\begin{array}{l}\text { C1: monopolar } \\
\text { TURP }\end{array}$ & $\begin{array}{l}\text { Specific technology not specified, irrigation fluid } \\
=1.5 \% \text { glycine }\end{array}$ \\
\hline & 12: & & C2: & \\
\hline \multirow[t]{2}{*}{$\begin{array}{l}\text { Yousef } \\
2010\end{array}$} & $\begin{array}{l}\text { I1: bipolar } \\
\text { TURP }\end{array}$ & $\begin{array}{l}\text { "Storez" technology, un- } \\
\text { clear if this refers to Karl } \\
\text { Storz AUTOCON technol- } \\
\text { ogy }\end{array}$ & $\begin{array}{l}\text { C1: monopolar } \\
\text { TURP with } 1.5 \% \\
\text { glycine }\end{array}$ & Storez technology \\
\hline & 12: & & $\begin{array}{l}\text { C2: monopolar } \\
\text { TURP with 5\% glu- } \\
\text { cose }\end{array}$ & Storez technology \\
\hline \multirow[t]{2}{*}{$\begin{array}{l}\text { Bhansali } \\
2009\end{array}$} & $\begin{array}{l}\text { I1: bipolar } \\
\text { TURP }\end{array}$ & $\begin{array}{l}\text { Plasmakinetic Super- } \\
\text { pulse System - } 24 \text { Gyrus }\end{array}$ & $\begin{array}{l}\text { C1: monopolar } \\
\text { TURP }\end{array}$ & ValleyLab, irrigation fluid = glycine \\
\hline & 12: & & C2: & \\
\hline \multirow[t]{2}{*}{$\begin{array}{l}\text { Chen } \\
2009\end{array}$} & $\begin{array}{l}\text { I1: bipolar } \\
\text { TURP }\end{array}$ & TURIS, Olympus & $\begin{array}{l}\text { C1: monopolar } \\
\text { TURP }\end{array}$ & Olympus, irrigation fluid = mannitol $4 \%$ \\
\hline & 12: & & C2: & \\
\hline \multirow[t]{2}{*}{$\begin{array}{l}\text { De Sio } \\
2009\end{array}$} & $\begin{array}{l}\text { I1: bipolar } \\
\text { TURP }\end{array}$ & $\begin{array}{l}\text { Gyrus Plasmakinetic Sys- } \\
\text { tem }\end{array}$ & $\begin{array}{l}\text { C1: monopolar } \\
\text { TURP }\end{array}$ & $\begin{array}{l}\text { ValleyLab Force FX, specific irrigation fluid not } \\
\text { reported }\end{array}$ \\
\hline & 12: & & C2: & \\
\hline
\end{tabular}

Bipolar versus monopolar transurethral resection of the prostate for lower urinary tract symptoms secondary to benign prostatic 
Table 2. Description of interventions (Continued)

\begin{tabular}{|c|c|c|c|c|}
\hline \multirow[t]{2}{*}{ Goh 2009} & $\begin{array}{l}\text { I1: bipolar } \\
\text { TURP }\end{array}$ & $\begin{array}{l}\text { Olympus SurgMaster } \\
\text { TURis }\end{array}$ & $\begin{array}{l}\text { C1: monopolar } \\
\text { TURP }\end{array}$ & Olympus, irrigation fluid = glycine \\
\hline & 12: & & C2: & \\
\hline \multirow[t]{2}{*}{$\begin{array}{l}\text { Kong } \\
2009\end{array}$} & $\begin{array}{l}\text { I1: bipolar } \\
\text { TURP }\end{array}$ & $\begin{array}{l}\text { Gyrus Plasmakinetic Re- } \\
\text { section (PKRP) }\end{array}$ & $\begin{array}{l}\text { C1: monopolar } \\
\text { TURP }\end{array}$ & $\begin{array}{l}\text { Pfizer Electrosurgical Instrument System, irriga- } \\
\text { tion fluid = glycine }\end{array}$ \\
\hline & 12: & & C2: & \\
\hline \multirow{2}{*}{$\begin{array}{l}\text { Mendez- } \\
\text { Probst } \\
2009\end{array}$} & $\begin{array}{l}\text { I1: bipolar } \\
\text { TURP }\end{array}$ & VISTA, ACMI & $\begin{array}{l}\text { C1: monopolar } \\
\text { TURP }\end{array}$ & ERBE, irrigation fluid = not reported explicitly \\
\hline & 12: & & C2: & \\
\hline \multirow[t]{2}{*}{ Xin 2009} & $\begin{array}{l}\text { I1: bipolar } \\
\text { TURP }\end{array}$ & $\begin{array}{l}\text { Gyrus Electrosurgical } \\
\text { System (PKRP) }\end{array}$ & $\begin{array}{l}\text { C1: monopolar } \\
\text { TURP }\end{array}$ & $\begin{array}{l}\text { WOLF Storz Electrosurgical System, irrigation } \\
\text { fluid }=1.5 \% \text { glycine }\end{array}$ \\
\hline & 12: & & C2: & \\
\hline \multirow[t]{2}{*}{ Iori 2008} & $\begin{array}{l}\text { I1: bipolar } \\
\text { TURP }\end{array}$ & Gyrus PlasmaKinetic & $\begin{array}{l}\text { C1: monopolar } \\
\text { TURP }\end{array}$ & Storz Resectoscope, irrigation fluid = mannitol \\
\hline & 12: & & C2: & \\
\hline \multirow[t]{2}{*}{ Xue 2008} & $\begin{array}{l}\text { I1: bipolar } \\
\text { TURP }\end{array}$ & $\begin{array}{l}\text { Gyrus Electrosurgical } \\
\text { System (PKRP) }\end{array}$ & $\begin{array}{l}\text { C1: monopolar } \\
\text { TURP }\end{array}$ & $\begin{array}{l}\text { WOLF Electrosurgical System, irrigation fluid = } \\
1.5 \% \text { glycine }\end{array}$ \\
\hline & 12: & & C2: & \\
\hline \multirow[t]{2}{*}{$\begin{array}{l}\text { Bertolot- } \\
\text { to } 2007\end{array}$} & $\begin{array}{l}\text { I1: bipolar } \\
\text { TURP }\end{array}$ & $\begin{array}{l}\text { TURis Olympus Surgmas- } \\
\text { ter }\end{array}$ & $\begin{array}{l}\text { C1: monopolar } \\
\text { TURP }\end{array}$ & $\begin{array}{l}\text { Specific monopolar technology not reported, ir- } \\
\text { rigation fluid = glycine }\end{array}$ \\
\hline & 12: & & C2: & \\
\hline \multirow[t]{2}{*}{$\begin{array}{l}\text { Erturhan } \\
2007\end{array}$} & $\begin{array}{l}\text { I1: bipolar } \\
\text { TURP }\end{array}$ & $\begin{array}{l}\text { Gyrus Plasmakinetic Re- } \\
\text { section }\end{array}$ & $\begin{array}{l}\text { C1: monopolar } \\
\text { TURP }\end{array}$ & ValleyLab Force EX, irrigation fluid = glycine $5 \%$ \\
\hline & 12: & & C2: & \\
\hline \multirow[t]{2}{*}{ Ho 2007} & $\begin{array}{l}\text { I1: bipolar } \\
\text { TURP }\end{array}$ & $\begin{array}{l}\text { Olympus TURIS System } \\
\text { SurgMaster }\end{array}$ & $\begin{array}{l}\text { C1: monopolar } \\
\text { TURP }\end{array}$ & Olympus, irrigation fluid = glycine $5 \%$ \\
\hline & 12: & & C2: & \\
\hline \multirow[t]{2}{*}{$\begin{array}{l}\text { Michiel- } \\
\text { son } 2007\end{array}$} & $\begin{array}{l}\text { I1: bipolar } \\
\text { TURP }\end{array}$ & $\begin{array}{l}\text { Olympus SurgMaster } \\
\text { TURIS }\end{array}$ & $\begin{array}{l}\text { C1: monopolar } \\
\text { TURP }\end{array}$ & Olympus, irrigation fluid = glycine $1.5 \%$ \\
\hline & 12: & & C2: & \\
\hline \multirow[t]{2}{*}{$\begin{array}{l}\text { Rose } \\
2007\end{array}$} & $\begin{array}{l}\text { I1: bipolar } \\
\text { TURP }\end{array}$ & Olympus TURIS & $\begin{array}{l}\text { C1: monopolar } \\
\text { TURP }\end{array}$ & Olympus, irrigation fluid = mannitol \\
\hline & 12: & & C2: & \\
\hline $\begin{array}{l}\text { Wang } \\
2007\end{array}$ & $\begin{array}{l}\text { I1: bipolar } \\
\text { TURP }\end{array}$ & $\begin{array}{l}\text { Gyrus F27 Electrosurgical } \\
\text { System (PKRP) }\end{array}$ & $\begin{array}{l}\text { C1: monopolar } \\
\text { TURP }\end{array}$ & $\begin{array}{l}\text { WOLF Electrosurgical System, irrigation fluid = } \\
5 \% \text { mannitol }\end{array}$ \\
\hline
\end{tabular}

Bipolar versus monopolar transurethral resection of the prostate for lower urinary tract symptoms secondary to benign prostatic 
Table 2. Description of interventions (Continued)

12: $\quad \mathrm{C2}$ :

\begin{tabular}{lllll}
\hline Xin 2007 & $\begin{array}{l}\text { I1: bipolar } \\
\text { TURP }\end{array}$ & $\begin{array}{l}\text { Plasmakinetic TURP, } \\
\text { Gyrus device }\end{array}$ & $\begin{array}{l}\text { C1: monopolar } \\
\text { TURP }\end{array}$ & $\begin{array}{l}\text { Specific monopolar technology/irrigation fluid } \\
\text { not reported }\end{array}$ \\
\cline { 2 - 5 } & I2: & C2: & \\
\hline $\begin{array}{l}\text { Abascal } \\
\mathbf{2 0 0 6}\end{array}$ & $\begin{array}{l}\text { I1: bipolar } \\
\text { TURP }\end{array}$ & Olympus SurgMaster & $\begin{array}{l}\text { C1: } \text { monopolar } \\
\text { TURP }\end{array}$ & Storz, irrigation fluid = glycine \\
\cline { 2 - 5 } & I2: & C2: & \\
\hline
\end{tabular}

\begin{tabular}{|c|c|c|c|c|}
\hline \multirow[t]{2}{*}{$\begin{array}{l}\text { Akcayoz } \\
2006\end{array}$} & $\begin{array}{l}\text { I1: bipolar } \\
\text { TURP }\end{array}$ & $\begin{array}{l}\text { Gyrus Plasmakinetic } \\
\text { (PKRP) }\end{array}$ & $\begin{array}{l}\text { C1: monopolar } \\
\text { TURP }\end{array}$ & $\begin{array}{l}\text { Specific monopolar technology not reported, ir- } \\
\text { rigation fluid }=1.5 \% \text { glycine }\end{array}$ \\
\hline & 12: & & C2: & \\
\hline \multirow[t]{2}{*}{$\begin{array}{l}\text { Bahadzor } \\
2006\end{array}$} & $\begin{array}{l}\text { I1: bipolar } \\
\text { TURP }\end{array}$ & $\begin{array}{l}\text { Plasma Kinetic Resection } \\
\text { of Prostate (PKRP) }\end{array}$ & $\begin{array}{l}\text { C1: monopolar } \\
\text { TURP }\end{array}$ & $\begin{array}{l}\text { Specific monopolar technology/irrigation fluid } \\
\text { not reported }\end{array}$ \\
\hline & I2: & & C2: & \\
\hline Choi 2006 & $\begin{array}{l}\text { I1: bipolar } \\
\text { TURP }\end{array}$ & $\begin{array}{l}\text { PlasmaKinetic (PK) Tis- } \\
\text { sue Management System } \\
\text { (Gyrus) }\end{array}$ & $\begin{array}{l}\text { C1: monopolar } \\
\text { TURP }\end{array}$ & $\begin{array}{l}\text { Specific monopolar technology/irrigation fluid } \\
\text { not reported }\end{array}$ \\
\hline
\end{tabular}

12: $\quad$ C2:

\begin{tabular}{|c|c|c|c|c|}
\hline \multirow[t]{2}{*}{ Kim 2006} & $\begin{array}{l}\text { I1: bipolar } \\
\text { TURP }\end{array}$ & $\begin{array}{l}\text { Gyrus Plasma Kinetic Re- } \\
\text { sectoscope }\end{array}$ & $\begin{array}{l}\text { C1: monopolar } \\
\text { TURP }\end{array}$ & $\begin{array}{l}\text { Specific monopolar technology not available } \\
\text { from translation, irrigating fluid = Urion liquid }\end{array}$ \\
\hline & 12: & & C2: & \\
\hline
\end{tabular}

\begin{tabular}{|c|c|c|c|c|}
\hline Lin 2006 & $\begin{array}{l}\text { I1: bipolar } \\
\text { TURP }\end{array}$ & Vista CTR & $\begin{array}{l}\text { C1: monopolar } \\
\text { TURP }\end{array}$ & Vista CTR, irrigation fluid = distilled water \\
\hline & 12: & & C2: & \\
\hline \multirow[t]{2}{*}{$\begin{array}{l}\text { Nuhoglu } \\
2006\end{array}$} & $\begin{array}{l}\text { I1: bipolar } \\
\text { TURP }\end{array}$ & $\begin{array}{l}\text { Gyrus Plasmakinetic } \\
\text { (PKRP) }\end{array}$ & $\begin{array}{l}\text { C1: monopolar } \\
\text { TURP }\end{array}$ & Storz, irrigation fluid = glycine \\
\hline & 12: & & C2: & \\
\hline \multirow[t]{2}{*}{$\begin{array}{l}\text { Patankar } \\
2006\end{array}$} & $\begin{array}{l}\text { I1: bipolar } \\
\text { TURP }\end{array}$ & $\begin{array}{l}\text { Plasmakinetic Super- } \\
\text { pulse }\end{array}$ & $\begin{array}{l}\text { C1: monopolar } \\
\text { TURP }\end{array}$ & $\begin{array}{l}\text { Specific monopolar technology not reported, ir- } \\
\text { rigation fluid = glycine }\end{array}$ \\
\hline & 12: & & C2: & \\
\hline \multirow[t]{2}{*}{$\begin{array}{l}\text { Seckiner } \\
2006\end{array}$} & $\begin{array}{l}\text { I1: bipolar } \\
\text { TURP }\end{array}$ & $\begin{array}{l}\text { Gyrus Plasmakinetic Tis- } \\
\text { sue Management System }\end{array}$ & $\begin{array}{l}\text { C1: monopolar } \\
\text { TURP }\end{array}$ & Karl Storz, irrigation fluid = glycine \\
\hline & 12: & & C2: & \\
\hline \multirow[t]{2}{*}{$\begin{array}{l}\text { Terrone } \\
2006\end{array}$} & $\begin{array}{l}\text { I1: bipolar } \\
\text { TURP }\end{array}$ & $\begin{array}{l}\text { Vista CTR Bipolar Resec- } \\
\text { tion System, ACMI }\end{array}$ & $\begin{array}{l}\text { C1: monopolar } \\
\text { TURP }\end{array}$ & $\begin{array}{l}\text { Specific monopolar technology/irrigation fluid } \\
\text { not reported }\end{array}$ \\
\hline & 12: & & C2: & \\
\hline
\end{tabular}

Bipolar versus monopolar transurethral resection of the prostate for lower urinary tract symptoms secondary to benign prostatic 
Table 2. Description of interventions (Continued)

\begin{tabular}{|c|c|c|c|c|}
\hline \multirow[t]{2}{*}{$\begin{array}{l}\text { Singh } \\
2005\end{array}$} & $\begin{array}{l}\text { I1: bipolar } \\
\text { TURP }\end{array}$ & Vista CTR ACMI & $\begin{array}{l}\text { C1: monopolar } \\
\text { TURP }\end{array}$ & $\begin{array}{l}\text { Wolf Resectoscope, irrigation fluid = not report- } \\
\text { ed }\end{array}$ \\
\hline & 12: & & C2: & \\
\hline \multirow[t]{2}{*}{ Wu 2005} & $\begin{array}{l}\text { I1: bipolar } \\
\text { TURP }\end{array}$ & $\begin{array}{l}\text { Gyrus } 27 \text { F Stoze Electro- } \\
\text { surgical System }\end{array}$ & $\begin{array}{l}\text { C1: monopolar } \\
\text { TURP }\end{array}$ & $\begin{array}{l}\text { WOLF Electrosurgical System, irrigation fluid = } \\
5 \% \text { glucose }\end{array}$ \\
\hline & 12: & & C2: & \\
\hline \multirow[t]{2}{*}{$\begin{array}{l}\text { D'Elia } \\
2004\end{array}$} & $\begin{array}{l}\text { I1: bipolar } \\
\text { TURP }\end{array}$ & Gyrus technology & $\begin{array}{l}\text { C1: monopolar } \\
\text { TURP }\end{array}$ & $\begin{array}{l}\text { Specific monopolar technology/irrigation fluid } \\
\text { not reported }\end{array}$ \\
\hline & 12: & & C2: & \\
\hline \multirow[t]{2}{*}{$\begin{array}{l}\text { Eaton } \\
2004\end{array}$} & $\begin{array}{l}\text { I1: bipolar } \\
\text { TURP }\end{array}$ & $\begin{array}{l}\text { Use of both Plasmakinet- } \\
\text { ic Resection (PKRP) and } \\
\text { Karl Storz reported }\end{array}$ & $\begin{array}{l}\text { C1: monopolar } \\
\text { TURP }\end{array}$ & $\begin{array}{l}\text { Specific monopolar technology/irrigation fluid } \\
\text { not reported }\end{array}$ \\
\hline & 12: & & C2: & \\
\hline \multirow[t]{2}{*}{ Yang 2004} & $\begin{array}{l}\text { I1: bipolar } \\
\text { TURP }\end{array}$ & Gyrus Plasmasect & $\begin{array}{l}\text { C1: monopolar } \\
\text { TURP }\end{array}$ & $\begin{array}{l}\text { Specific monopolar technology not reported, ir- } \\
\text { rigation fluid = distilled water }\end{array}$ \\
\hline & 12: & & C2: & \\
\hline \multirow[t]{2}{*}{$\begin{array}{l}\text { Symons } \\
2002\end{array}$} & $\begin{array}{l}\text { I1: bipolar } \\
\text { TURP }\end{array}$ & $\begin{array}{l}\text { Gyrus Plasmakinetic } \\
\text { Electrosurgical System }\end{array}$ & $\begin{array}{l}\text { C1: monopolar } \\
\text { TURP }\end{array}$ & $\begin{array}{l}\text { Specific monopolar technology not reported, ir- } \\
\text { rigation fluid }=1.5 \% \text { glycine }\end{array}$ \\
\hline & 12: & & C2: & \\
\hline
\end{tabular}

\footnotetext{
- denotes not reported.

aThe term 'clinical practice setting' refers to the specification of the intervention/comparator as used in the course of a standard medical treatment (such as dose, dose escalation, dosing scheme, provision for contraindications, and other important features).

C: comparator; I: intervention; N/CPS: no specification of clinical practice setting possible.
}

CTR: controlled tissue resection.

PKRP: plasmakinetic resection.

PVP: photoselective vaporisation of the prostate.

TUR: transurethral resection.

TURP: transurethral resection of the prostate.

\section{A P PE N DICES}

\section{Appendix 1. The Cochrane Library search strategy}

(Ovid Cochrane Central Register of Controlled Trials, Cochrane Database of Systematic Reviews 2005 to Present>)

1 exp Prostatic Hyperplasia/

2 exp Urinary Bladder Neck Obstruction/

3 (benign and prostat* and (obstruction* or enlargement $\left.\left.{ }^{\star}\right)\right) . t w, k w$. 
4 (bladder adj5 (obstruction* or sclerosis or neck strangulation or obstructed voiding or stenosis or stenoses or scleroses or contracture or stricture or narrowing or fistula*)).tw,kw.

5 (BPH or BPO or BPE or BOO).tw.

6 (prostat* adj3 (adenoma* or hyperplas* or hypertroph*)).tw.

7 or/1-6

8 exp "Transurethral Resection of Prostate"/

9 ((transurethra* or trans-urethra*) and prostat* and (prostatectom ${ }^{\star}$ or resect* or electroresection* or ablation ${ }^{\star}$ or vaporesection $^{\star}$ or electrovaporization* or thermotherap*)).tw,kw.

10 (TUR or TURP or TURPs or Vlap or TUNA or TUVP).tw,kw.

11 or/8-10

127 and 11

13 (monopolar or bipolar or mono polar or bi polar or "Gyrus" or "TURIs" or "M-TURP" or "B-TURP").tw,kw.

14 (ablation* or coblation* or saline resectoscope or Tekno Tom or AUTOCON ).tw,kw.

1513 or 14

1612 and 15

\section{Appendix 2. MEDLINE search strategy}

(Ovid MEDLINE(R) In-Process \& Other Non-Indexed Citations and Ovid MEDLINE(R) $<1946$ to Present>)

1 exp Prostatic Hyperplasia/

2 exp Urinary Bladder Neck Obstruction/

3 (benign and prostat ${ }^{\star}$ and (obstruction* or enlargement $\left.\left.{ }^{\star}\right)\right) . t w, k w$.

4 (bladder adj5 (obstruction* or sclerosis or neck strangulation or obstructed voiding or stenosis or stenoses or scleroses or contracture or stricture or narrowing or fistula*)).tw,kw.

5 (BPH or BPO or BPE or BOO).tw.

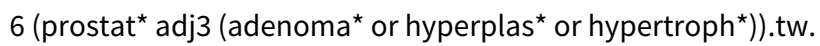

7 or/1-6

8 exp "Transurethral Resection of Prostate"/

9 ((transurethra* or trans-urethra*) and prostat* and (prostatectom* or resect* or electroresection* or ablation* or vaporesection ${ }^{\star}$ or electrovaporization* or thermotherap*)).tw,kw.

10 (TUR or TURP or TURPs or Vlap or TUNA or TUVP).tw,kw.

11 or/8-10

127 and 11

13 (monopolar or bipolar or mono polar or bi polar or "Gyrus" or "TURIs" or "M-TURP" or "B-TURP").tw,kw.

14 (ablation* or coblation* or saline resectoscope or Tekno Tom or AUTOCON ).tw,kw.

1513 or 14

1612 and 15

17 randomized controlled trial.pt.

18 controlled clinical trial.pt.

Bipolar versus monopolar transurethral resection of the prostate for lower urinary tract symptoms secondary to benign prostatic

Copyright (c) 2019 The Cochrane Collaboration. Published by John Wiley \& Sons, Ltd. 
19 random* ${ }^{\star} . a b$.

20 trial.ab.

21 groups.ab.

22 or/16-21

23 exp animals/ not humans.sh.

2422 not 23

2516 and 24

Note:

1. As suggested by the Cochrane handbook (http://handbook.cochrane.org/), we will use the RCT filter as suggested in "Box 6.4.c: Cochrane Highly Sensitive Search Strategy for identifying randomized trials in MEDLINE: sensitivity-maximizing version (2008 revision); Ovid format".

2. A minor revision is made: we use "random*" instead of "randomized.ab" or "randomly.ab." to capture other word variations such as "randomised, randomization".

3. We removed the lines "drug therapy.fs." and "placebo" because this review is not about drugs. Searching drug therapy trials will reduce the search specificity without increasing any sensitivity.

\section{Appendix 3. Embase search strategy}

(Database: Ovid Embase <1974 to present $>$

1 exp prostate hypertrophy/

2 exp bladder neck stenosis/

3 exp bladder obstruction/

4 exp prostate adenoma/

5 (benign and prostat* and (obstruction* or enlargement*)).tw,kw.

6 (bladder adj5 (obstruction* or sclerosis or neck strangulation or obstructed voiding or stenosis or stenoses or scleroses or contracture or stricture or narrowing or fistula*)).tw,kw.

7 (BPH or BPO or BPE or BOO).tw.

8 (prostat* adj3 (adenoma* or hyperplasia or hypertroph*)).tw.

9 or/1-8

10 exp transurethral resection/

11 ((transurethra* or trans-urethra*) and prostat* and (prostatectom* or resect* or electroresection* or ablation* or vaporesection* or electrovaporization* or thermotherap*)).tw,kw.

12 (TUR or TURP or TURPs or Vlap or TUNA or TUVP).tw.

13 or $/ 10-12$

149 and 13

15 (monopolar or bipolar or mono polar or bi polar or "Gyrus" or "TURIs" or "M-TURP" or "B-TURP").tw,kw.

16 (ablation* or coblation* or saline resectoscope or Tekno Tom or AUTOCON ).tw,kw.

1715 or 16

1814 and 17

19 random:.tw.

Bipolar versus monopolar transurethral resection of the prostate for lower urinary tract symptoms secondary to benign prostatic 
20 clinical trial:.mp.

21 exp health care quality/

22 double-blind:.tw.

23 or $/ 19-22$

24 exp animal/ not human.sh.

2523 not 24

2618 and 25

Note:

As suggested by the Cochrane Handbook for Systematic Reviews of Interventions (6.4.11.2 "Search filters for identifying randomized trials in EMBASE", http://handbook.cochrane.org/), we use the Wong 2006 method. "The search filter designed by Wong and colleagues for identifying what they define as "clinically sound treatment studies" in EMBASE may be used (Wong 2006) " (Wong SS, Wilczynski NL, Haynes RB. Developing optimal search strategies for detecting clinically sound treatment studies in EMBASE. Journal of the Medical Library Association 2006;94:41-47.) The Wong 2006 filter is also well known as Hedge, and is available online as: http://hiru.mcmaster.ca/hiru/ HIRU_Hedges_home.aspx

We combined the strings that are suggested under maximises sensitivity and maximises specificity in the filter for therapy. We removed the line "placebo:mp.", because this review is not about drugs and no placebo is possible.

\section{CONTRIBUTIONS OF AUTHORS}

Review and update of existing protocol: all review authors.

Electronic search: Y Yuan.

Abstract and full-text screening: C Alexander, M Scullion, C Chen.

Development of DE form: C Alexander, M Scullion.

Data extraction, risk of bias assessment: C Alexander, M Scullion, C Chen.

Input of data into Review Manager and meta-analysis: C Alexander, M Scullion.

GRADE certainty of evidence. C Alexander, M Scullion, M Omar.

Interpretation of data: all review authors.

Drafting the review: C Alexander and M Scullion; C. Mamoulakis and T Lam wrote the discussion section; all review authors made comments on various revisions.

\section{DECLARATIONS OF INTEREST}

Cameron Edwin Alexander: none known.

Malo MF Scullion: none known.

Muhammad Imran Omar: none known.

Yuhong Yuan: none known.

Charalampos Mamoulakis: none known.

James MO N'Dow: none known.

Changhao Chen: none known.

Thomas BL Lam: none known.

Bipolar versus monopolar transurethral resection of the prostate for lower urinary tract symptoms secondary to benign prostatic 


\section{SOURCES OF SUPPORT}

\section{Internal sources}

- none, Other.

\section{External sources}

- none, Other.

\section{DIFFERENCES BETWEEN PROTOCOL AND REVIEW}

- Review objective: altered to specifically focus on comparing clinical effectiveness between BTURP and MTURP. Comparing methods of TURP in terms of adverse effects or safety profile was removed as a primary objective because of associated limitations of RCTs in assessing this. However, a number of outcomes are recorded, which will be related to adverse effects

- Review outcomes: these have been re-arranged to include a smaller number of primary outcomes, most specifically related to the primary objective of clinical effectiveness, and a larger number of secondary outcomes. Those outcomes selected as primary and secondary outcomes and those to be used for GRADE certainty of evidence were included on the basis of re-assessment following discussion with clinical experts regarding those outcomes (i) of greatest clinical significance, and (ii) most related to answering the review objectives. Specifically, drop in sodium level, drop in haemoglobin level, meatal stenosis, retrograde ejaculation, operation time, duration of bladder irrigation, and catheterisation time were considered to be surrogate outcomes or of reduced clinical importance relative to other clinical outcomes

- Electronic search: updated to meet outlined Cochrane requirements. A more focused search for non-published trial data and ongoing trials was performed using ClinicalTrials.gov and WHO ICTRP

- Assessment of risk of bias was updated to meet those requirements outlined in the Cochrane Handbook for Systematic Reviews of Interventions, and the Cochrane RoB tool was primarily used to include blinding of participants and outcome assessors, which was not previously mentioned in the protocol

- Measure of treatment effect: updated according to guidance in the Cochrane Handbook for Systematic Reviews of Interventions and provided by the statistician. Number needed to treat for an additional beneficial outcome (NNTB) and number needed to treat for an additional harmful outcome (NNHB) were not included as they are not considered necessary in addition to other descriptive and statistical analyses

- Review authors: following publication of the protocol, the following authors were not involved in development of the review and as such did not remain as co-authors: Frank Sofras, Jean de la Rosette, and Dirk T Ubbink. The review was taken on by an updated team who had sufficient expertise in Cochrane Review methods. The following co-authors were involved since publication of the protocol: Cameron E Alexander, Malo MF Scullion, Yuhong Yuan, and Changhao Chen 